\title{
Safety and efficacy of intraocular lenses in cataract and refractive surgery
}

Citation for published version (APA):

Jonker, S. M. R. (2021). Safety and efficacy of intraocular lenses in cataract and refractive surgery.

[Doctoral Thesis, Maastricht University]. Maastricht University. https://doi.org/10.26481/dis.20211119sj

Document status and date:

Published: 01/01/2021

DOI:

10.26481/dis.20211119sj

Document Version:

Publisher's PDF, also known as Version of record

\section{Please check the document version of this publication:}

- A submitted manuscript is the version of the article upon submission and before peer-review. There can be important differences between the submitted version and the official published version of record.

People interested in the research are advised to contact the author for the final version of the publication, or visit the DOI to the publisher's website.

- The final author version and the galley proof are versions of the publication after peer review.

- The final published version features the final layout of the paper including the volume, issue and page numbers.

Link to publication

\footnotetext{
General rights rights.

- You may freely distribute the URL identifying the publication in the public portal. please follow below link for the End User Agreement:

www.umlib.nl/taverne-license

Take down policy

If you believe that this document breaches copyright please contact us at:

repository@maastrichtuniversity.nl

providing details and we will investigate your claim.
}

Copyright and moral rights for the publications made accessible in the public portal are retained by the authors and/or other copyright owners and it is a condition of accessing publications that users recognise and abide by the legal requirements associated with these

- Users may download and print one copy of any publication from the public portal for the purpose of private study or research.

- You may not further distribute the material or use it for any profit-making activity or commercial gain

If the publication is distributed under the terms of Article $25 \mathrm{fa}$ of the Dutch Copyright Act, indicated by the "Taverne" license above, 


\title{
SAFETY AND EFFICACY OF INTRAOCULAR LENSES IN CATARACT- AND REFRACTIVE SURGERY
}

\author{
Soraya M.R. Jonker
}


ISBN: 9789464192568

Printing: Gildeprint Enschede

Coverdesign and layout: (C) evelienjagtman.com

Medical illustrations: $\quad$ Rogier Trompert Medical Art

(C) 2021 Soraya M.R. Jonker, Maastricht

All rights reserved. No part of this thesis may be reproduced or transmitted in any form or by any means, electronic or mechanical, including photocopying, recording or any information storage or retrieval system, without permission in writing from the author, or, when appropriate, from the publishers of the publications. 


\title{
SAFETY AND EFFICACY OF INTRAOCULAR LENSES IN CATARACT- AND REFRACTIVE SURGERY
}

\author{
proefschrift \\ ter verkrijging van de graad van doctor aan de Universiteit van Maastricht, \\ op gezag van Rector Magnificus, prof. dr. Rianne M. Letschert \\ volgens het besluit van het College van Decanen,
} in het openbaar te verdedigen op vrijdag 19 november 2021 om 14:00 uur

door

Soraya Maria Regina Jonker

Geboren op 25 juni 1990 te 's-Hertogenbosch 


\section{Promotor}

Prof. dr. R.M.M.A. Nuijts

\section{Copromotoren}

Dr. N.J.C. Bauer

Dr. T.T.J.M. Berendschot

\section{Beoordelingscommissie}

Prof. dr. R.R.J.W. van der Hulst (voorzitter)

Prof. dr. R.J. van Oostenbrugge

Prof. dr. G.P.M. Luyten (Leids Universitair Medisch Centrum)

Prof. dr. O. Findl (Hanusch Hospital, Vienna) 
Opgedragen aan E.J.H. (opa Bert) Nissingh Die in dit promotietraject naast mijn opa ook mijn allergrootste fan is 



\section{TABLE OF CONTENTS}

Chapter 1 Introduction

Chapter 2 Phakic intraocular lens: Two-year results and comparison of endothelial cell loss to iris-fixated intraocular lenses

Chapter 3 Long-term endothelial cell loss in patients with Artisan Myopia and Artisan Toric phakic intraocular lenses: 5 and 10 year results

Chapter 4 Five-year endothelial cell loss after implantation with Artiflex Myopia and Artiflex Toric phakic intraocular lenses

Chapter 5 Long-term changes in visual outcomes and ocular morphometrics after myopic and toric phakic intraocular lens implantation: Five- and 10-year results

Chapter 6 Changes in visual outcomes and ocular morphometrics after foldable myopic and toric intraocular lens implantation: 5 year results.

Chapter 7 Risk factors for explantation of iris-fixated phakic intraocular lenses

Chapter 8 Bilateral implantation of $+2.5 \mathrm{D}$ multifocal intraocular lens and 189 contralateral implantation of $+2.5 \mathrm{D}$ and $+3.0 \mathrm{D}$ multifocal intraocular lenses: Clinical outcomes

Chapter 9 Comparison of a trifocal intraocular lens with a +3.0 D bifocal IOL: Results of a prospective randomized clinical trial

Chapter 10 Discussion

Chapter 11 Impact paragraph

Addendum Summary/Samenvatting

Dankwoord

Curriculum vitae

List of publications 







\section{CHAPTER 1}

\section{Introduction}

\section{Published in part as}

Phakic intraocular lenses: An overview.

Soraya MR Jonker, Tos TJM Berendschot, Isabelle EY Saelens,

Noël JC Bauer, Rudy MMA Nuijts

Indian J Ophthalmol. 2020 Dec;68(12):2779-96 


\section{PREFACE}

Refractive surgery is defined as the range of surgical interventions to make patients less dependent on their glasses or contact lenses. Three commonly used techniques can be identified: reshaping the anterior part of the eye (laser refractive surgery of the cornea), intraocular implantation of an artificial intraocular lens in addition to the natural lens (phakic lens), and replacing the natural lens by a new artificial lens (refractive lens exchange).

In a 2019 survey on common practice styles amongst Dutch eye surgeons, an estimated 5.000 refractive lens exchanges were performed that year (data on file, courtesy of Y. Henry), and 71 surgeons performed either laser refractive surgery or phakic lens implantation in the Netherlands. ${ }^{1}$ Contrary to laser refractive surgery, phakic lenses can be used in patients using high power spectacles or contact lenses, whereas refractive lens exchange can be used to make a patient less dependent on their reading glasses.

It is on the latter two techniques that we focus in this thesis, assessing their safety, efficacy, complication rate and target group. 


\section{REFRACTIVE ERRORS AND THE VISUAL SYSTEM}

Light is essential in visualization of any object: seeing an object clearly requires the adequate projection of light on the retina. In order to obtain this state, light directed towards the eye is refracted by the tear film, cornea and the crystalline lens to converge on the retina, thus providing a clear image (Figure 1).2,3

The way light is redirected in the eye is defined as its refractive state. Emmetropia is achieved if an image is focused exactly onto the retina when a perfectly balanced eye looks at a distant object (Figure 1). Refractive errors occur when light is focused in front of or behind the retina in an eye looking at a distant object, causing a blurred image. Myopia arises in a nearsighted eye looking at a distant object due to excessive convergence of incoming light, or by an excessively large distance (axial length) from cornea to the retina, focusing light in front of the retina (Figure 2). Hyperopia on the other hand arises in a farsighted eye caused by either insufficient convergence, or a short axial length, resulting in light focused behind the retina (Figure 2). 2,3 Cylindrical errors, resulting from astigmatism, are caused by differences in convergence at different angles, resulting in the projection of an irregular image on the retina (Figure 2). It can exist in an otherwise emmetropic eye, as well as in myopic or hyperopic eyes. Depending on the direction of the refractive difference, the astigmatic or cylindrical axis is defined as with the rule, against the rule, or oblique. With advancing age the direction of the cylindrical axis is known to change from with the rule to against the rule, a shift attributed to a changing corneal curvature over time. ${ }^{3}$

Refraction and refractive errors are expressed in Diopters (D), a reciprocal of the focal distance in meters (Diopter, $D=\frac{1}{\text { Focal distance, } F}$ ) and viceversa $\left(\right.$ Focal distance, $F=\frac{1}{\text { Diopter }, D}$ ). For example, a $4 \mathrm{D}$ lens has a $0.25 \mathrm{~m}$ focal distance, and a lens with a focal distance of $0.2 \mathrm{~m}$ has a refractive power of $5 \mathrm{D}$.

A positive convex lens converges light, and a negative concave lens diverges light (Figure 2). ${ }^{3}$ In the human eye, both the cornea and crystalline lens function as a positive lens, converging incoming light so that it is focused on the retina. The interface between air and cornea forms the main converging refractive surface of the eye, with a power of approximately $+40 \mathrm{D}$. The convergent refractive power of the crystalline lens is much less, contributing between $+15 \mathrm{D}$ and +20 D, but its ability to change refractive power (accommodation) is solely responsible for providing accurate focus at a large range of (reading) distances (Figure 3).3,4 Accommodation is caused by the changing curvature of the crystalline lens, thereby changing its refractive power. With advancing age the crystalline lens becomes sclerotic and loses flexibility, resulting in decreased accommodative capacity and requirement of reading glasses, defined as presbyopia. ${ }^{2-4}$ 
Refractive errors can be overcome using glasses or contact lenses, or by surgical intervention. Surgical correction can consist of laser refractive surgery (changing the corneal power through altering the corneal curvature by removing corneal tissue), phakic intraocular lens implantation (intraocular placement of an additional lens in front of the patients own crystalline lens), or cataract surgery (surgical removal of the crystalline lens and implantation of an intraocular lens) (Figure 4). ${ }^{3}$ Selecting the treatment best suited for the patient depends on patient wishes, patient characteristics, required correction and ocular anatomy and morphometry. This thesis focuses on the safety and efficacy of different intraocular lenses in cataract and refractive surgery, treatment of (high) myopia in adolescents and adults, and treatment of presbyopia in middle aged and elderly patients.

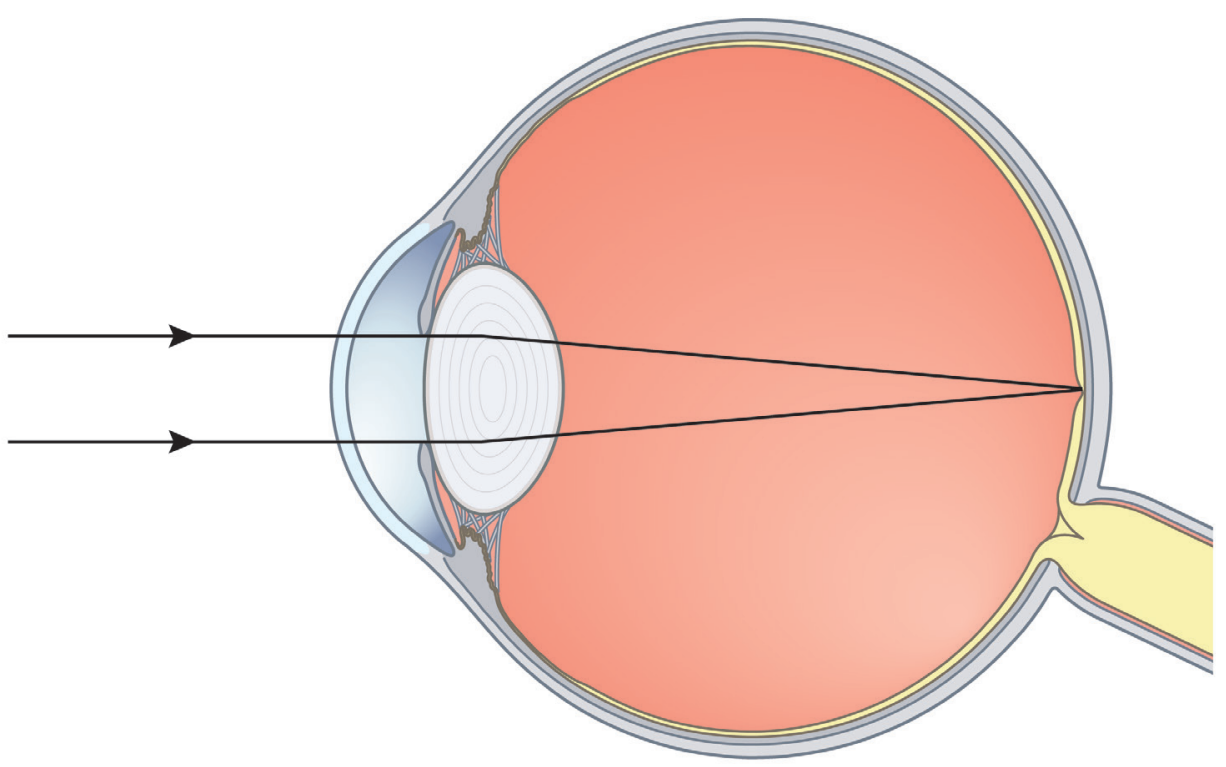

Figure 1. Light refraction and image projection in an emmetropic eye looking at a distant object. 

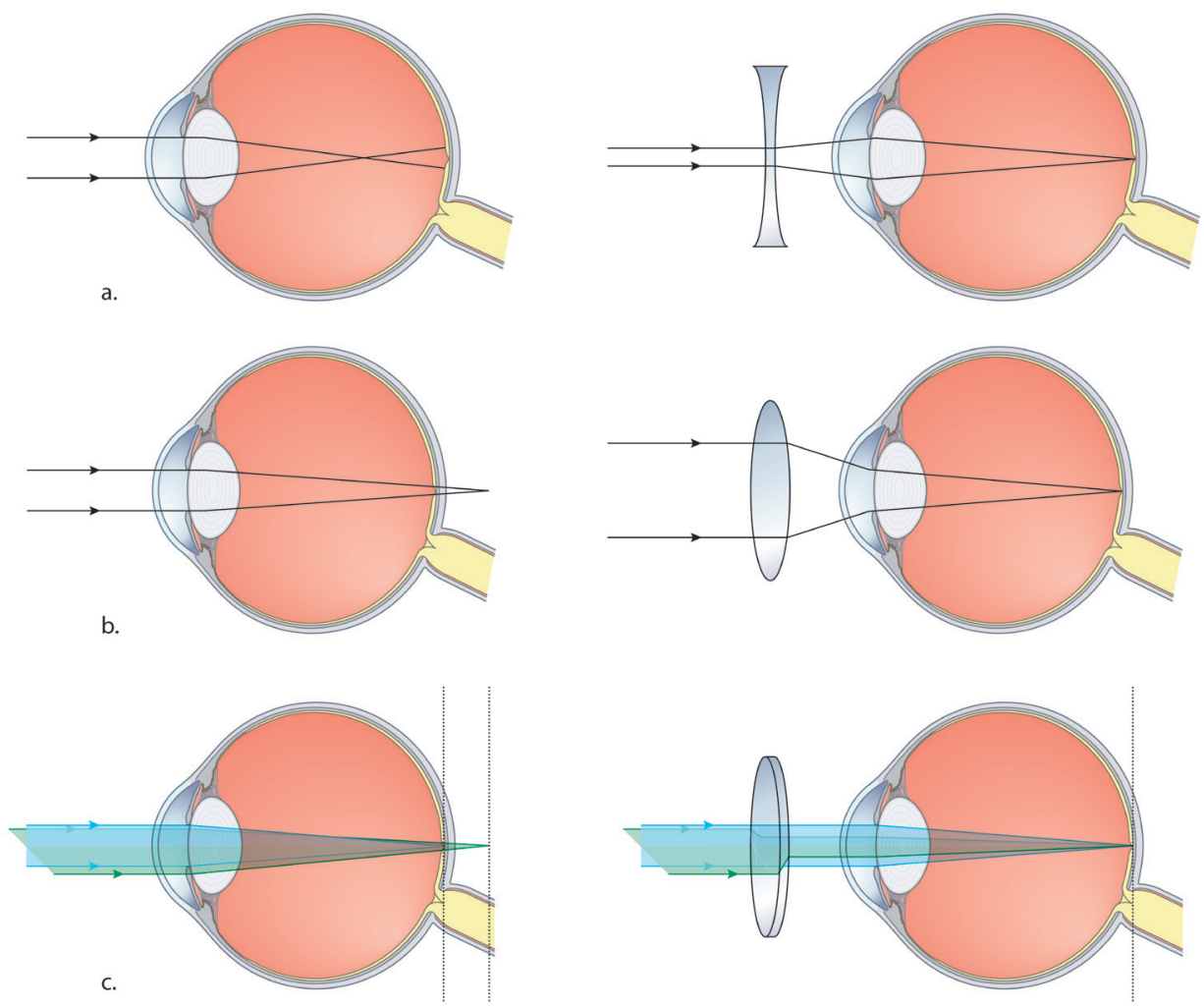

Figure 2. Correction of myopia using a concave lens that diverges light (a), correction of hyperopia using a convex lens that converges light (b), and correction of astigmatism (c). 


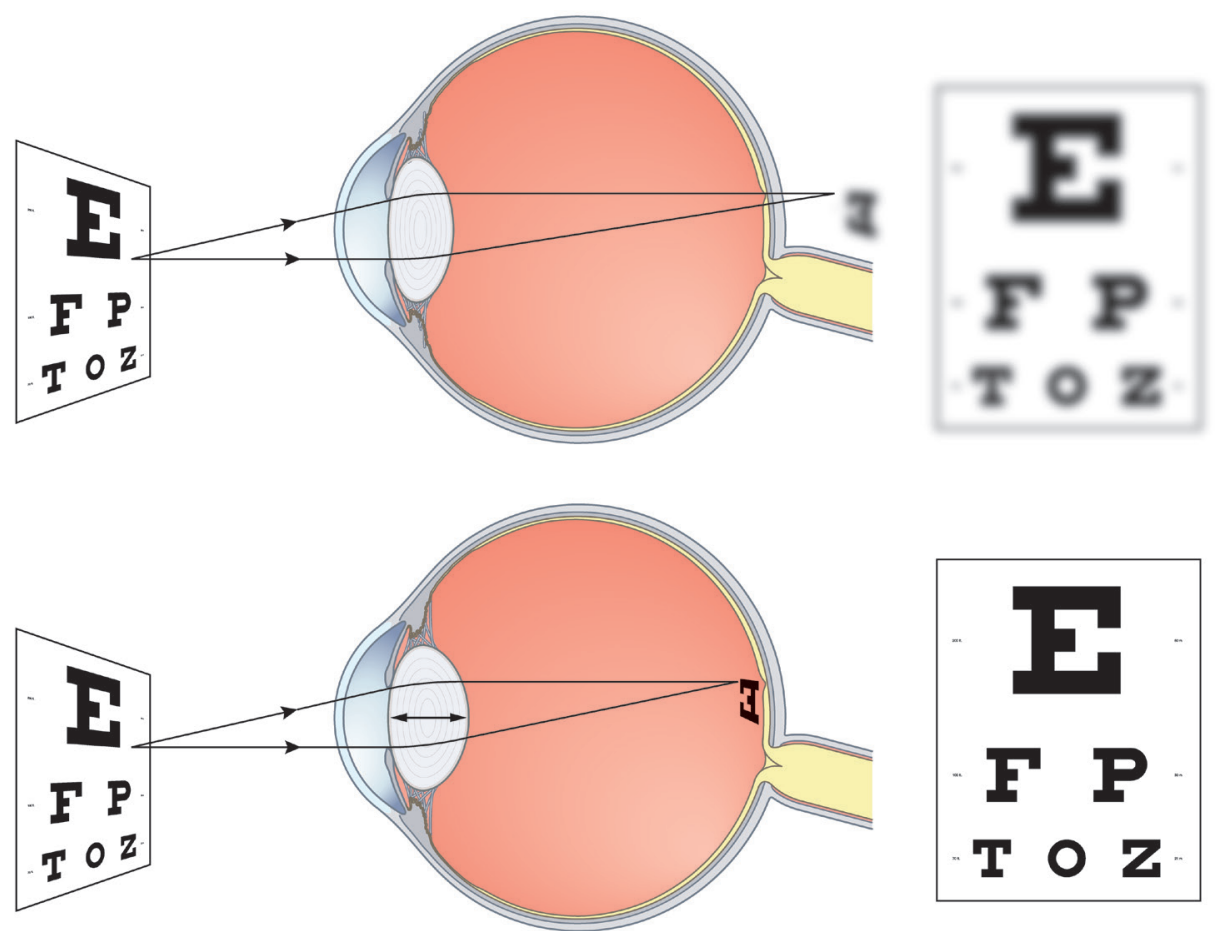

Figure 3. Accommodation: change of curvature of the crystalline lens in order to produce a clear projection on the retina. Unfocused image projected behind the retina (top) and projection of a focused image on the retina after accommodation (bottom). 
LASIK

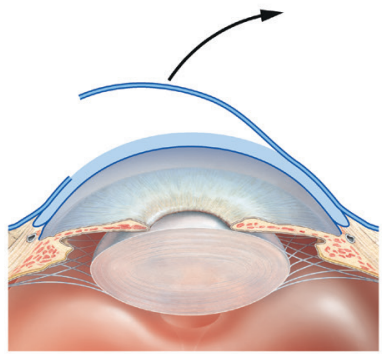

Lamellar keratotomy

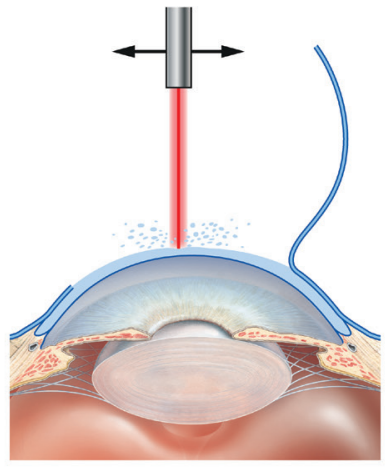

Excimer laser ablation

\section{phakic intraocular lens implantation}



refractive lens exchange
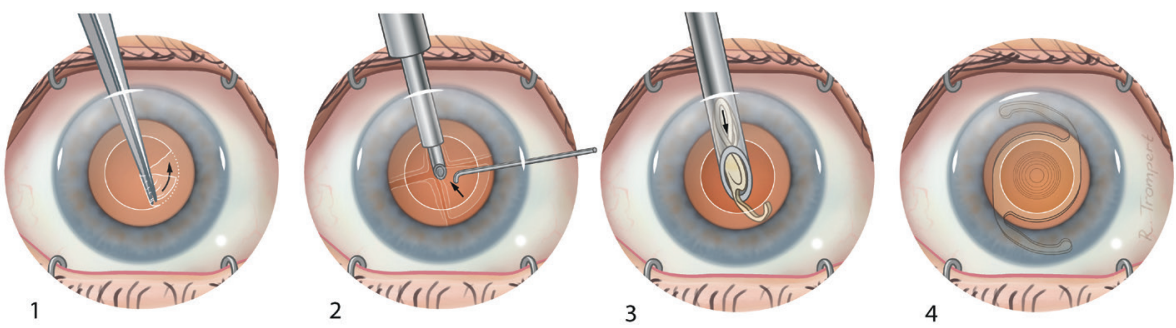

Figure 4. Surgical correction of refractive errors using laser refractive correction (top), phakic intraocular lens implantation (center), refractive lens exchange (bottom; 1) opening of the anterior lens capsule; 2) removal of the crystalline lens; 3) insertion of a - multifocal - intraocular lens; 4) final result). 


\section{CORRECTION OF (HIGH) MYOPIA}

Prevalence of high myopia has increased over the past years, resulting in a so-called epidemic of myopia that is especially prevalent in East and Southeast Asia (Figure 5).5,6 In these regions, myopia is seen in up to $90 \%$ of adolescents, a vast increase when compared to an incidence of maximum 30\% in adolescents 60 years ago..$^{5-7}$ Next to genetic factors, environmental factors are the main reason for this increased prevalence of myopia. This is mainly caused by intensive education resulting in children both spending more time indoor and doing near work., 5-8 If children and adolescents are required to perform near work, their eyes require constant accommodation to focus incoming light onto, rather than behind the retina. This combination of accommodation and lack of natural light falling on the retina causes the eye to grow, and the axial length to increase to create a situation where constant accommodation is no longer required during near work. However, this longer axial length also results in a distant image that is focused in front of the retina, introducing (high) myopia. Studies have shown that the onset, and progression of myopia can be reduced significantly by increasing the time a child spends in daylight. A vast amount of research focuses on stopping the myopic progression in the (very) young child in order to prevent increasing incidence of high myopia, defined as -5 to -6 D or higher., 6 Prevention of high myopia is important since it is associated with potentially blinding complications such as myopic macular degeneration, retinal detachment, staphyloma formation, or macular retinoschizis.,, ,8,10 Current treatments are based on using cycloplegic drops, orthokeratology (nighttime contact lenses) to temporarily change the shape of the cornea, or multifocal contact lenses., 8,11,12 Results seem promising in halting axial elongation, but long-term data and mechanisms have yet to be determined. 3, 8, 11,12 Furthermore, contact lens wear introduces a risk of corneal infection, which can result in corneal scarring requiring corneal transplantation. ${ }^{13,14}$

In a myopic patient non-surgical refractive correction can be obtained using contact lenses or glasses. It should be noted that refractive correction of high myopia will result in thicker contact lenses and glasses. Contact lenses in these patients are expensive, might cause problems with contact lens fitting and introduce the risk of contact lens related infections. ${ }^{13,}{ }^{14}$ Glasses are the best option to safeguard corneal health, but are aesthetically not preferred due to a misrepresentation of the contour of the face, and cause visual distortion in the peripheral visual field. 
Long-term treatment of stable myopia can be obtained by three different types of surgery: laser refractive surgery, phakic intraocular lens ( $\mathrm{PlOL}$ ) implantation, and lens surgery for refractive purposes (refractive lens exchange [RLE])(Figure 4). Both laser refractive surgery and refractive lens exchange are permanent, whereas refractive surgery using $\mathrm{plOL}$ implantation is a reversible procedure. ${ }^{15,16}$ For safety reasons, laser refractive surgery is performed in cases up to -8 D of myopia, depending on corneal thickness, thus excluding a large group of high myopes from treatment. ${ }^{16}$ The relative risk of developing a retinal detachment increases four times after cataract surgery, with patients under 50 years old and patients with a long axial length reported as especially at risk for developing a retinal detachment. ${ }^{17}$ Taking into account that cataract surgery also removes all accommodative capacity, refractive lens exchange is rarely performed in non-presbyopic patients. As a result, plOL implantation is regularly performed as a treatment for non-presbyopic high myopes. ${ }^{16,18,19}$

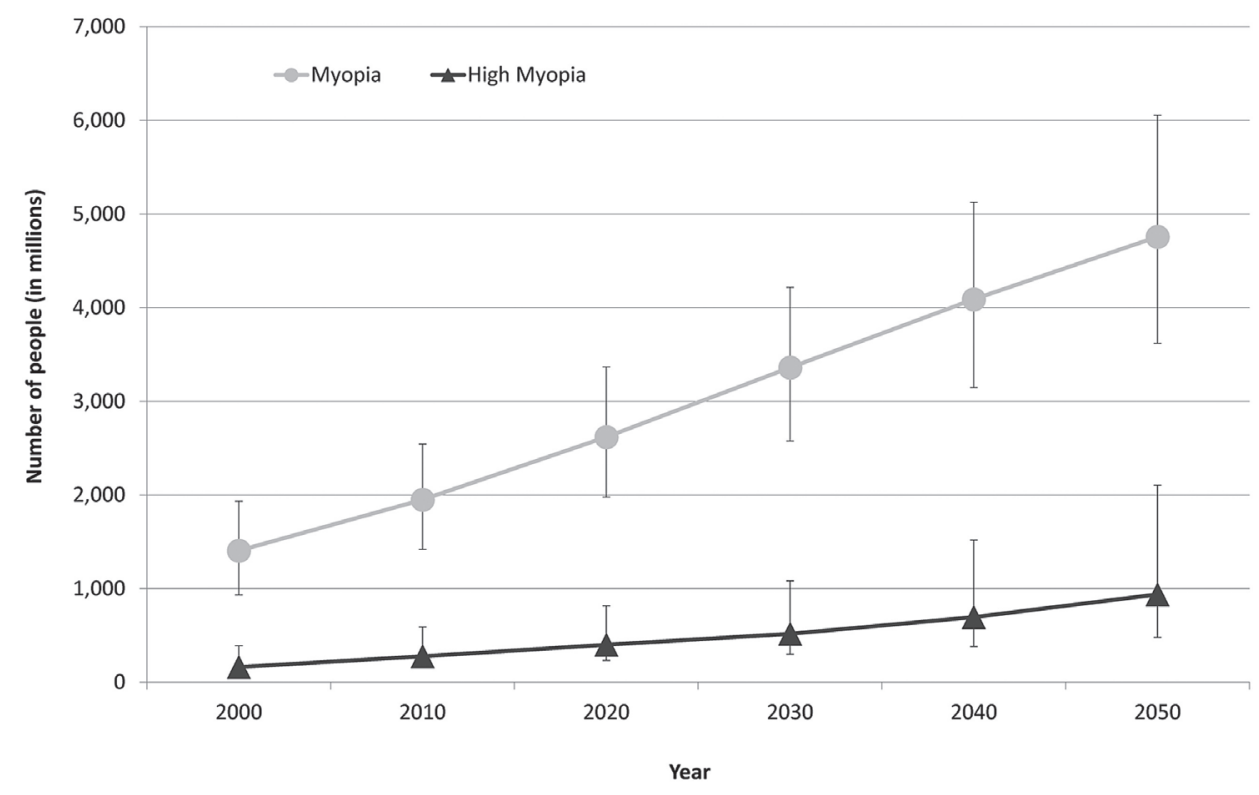

Figure 5. Graph showing the number of people estimated to have myopia and high myopia for each decade from 2000 through 2050. Error bars represent the 95\% confidence intervals. Image from Holden et al. ${ }^{6}$ 




Figure 6. Three different phakic intraocular lenses: angle supported (left), iris-fixated (center), posterior chamber (right) 


\section{HISTORY AND DEVELOPMENT OF PHAKIC INTRAOCULAR LENSES}

Phakic IOLs can be divided into: 1) anterior chamber angle supported plOLs that function with haptics positioned in the angle where the iris and cornea meet; 2) anterior chamber iris-fixated pIOLs that use small "lobster claws" to enclavate iris-tissue and position the pIOL in front of the pupil; and 3) posterior chamber plOLs that use plate haptics to support and position the lens in the posterior chamber (Figure 6). ${ }^{18,20}$

Implantation of plOLs for the correction of myopia started in 1953 when Strampelli implanted the first rigid angle-supported pIOL. Although refractive results were promising, the high rate of corneal complications, and excessive pressure on the iris root causing inflammation and pupil malformation, resulted in withdrawal of the plOL from the market. From the 1970's until the early 2010's multiple new angle-supported pIOLs were available, using different materials and different optic designs to try and cause less corneal complications and induce less pressure on the iris-root. Despite rendering good visual and refractive results, the complication rate of angle-supported pIOLs resulted in the withdrawal of all angle-supported pIOLs from the market

(Table 1a, Table 2a, Table 3a). ${ }^{18,19,21}$

First designed in 1953 by the Dutch ophthalmologist Cornelis Binkhorst, iris-fixated IOLs were originally created for implantation after crystalline lens removal. The Binkhorst IOL, using a paper-clip design to stabilize the lens, was associated with lens instability resulting in lens luxation, corneal complications and chronic inflammation causing retinal edema and problems with intraocular pressure. ${ }^{22}$ In 1978 the iris-fixated IOL design was updated by a second Dutch ophthalmologist, Jan Worst. He discovered that fixation of midperipheral iris tissue with small "lobster-claws" provided good stabilization of the IOL, without inducing the complications associated with chronic inflammation in the paper-clip design. Over time the Worst IOL was also implemented as a pIOL for the correction of refractive errors. Current iris-fixated plOLs are still largely based on the Worst lens, with different materials and designs for the correction of myopia, hyperopia and astigmatism, producing excellent visual and refractive results, and low rates of complications (Table $\mathbf{1 b}$, Table $\mathbf{2} \mathbf{b}$, Table $\mathbf{3 b}$ ). ${ }^{18,19,23}$

Posterior pIOLs were launched in the 1980's, driven by the complications associated with angle-supported pIOLs. By positioning the pIOL further back and away from the cornea, it was hypothesized that the risk of corneal complications would diminish. The specific downside of this design is its proximity to the crystalline lens, and zonular fibers. Early designs of posterior pIOLs frequently touched the anterior part of the crystalline lens causing a significant anterior subcapsular cataract, whereas friction between the $\mathrm{PIOL}$ and iris caused pigmentary dispersion and inflammation resulting in raised intraocular pressure. 
Table 1a. Overview of visual and refractive results after implantation with an anterior chamber angle supported phakic intraocular lens

\begin{tabular}{|c|c|c|c|c|}
\hline & \multirow[b]{2}{*}{ Nr. eyes [nr. pt] } & \multirow[b]{2}{*}{ Follow-up (mo) } & \multicolumn{2}{|c|}{ MRSE } \\
\hline & & & preop & postop \\
\hline \multicolumn{5}{|l|}{ AcrySof Cachet, Alcon } \\
\hline Kohnen, T., $2009^{25}$ & $190[190]$ & 24 & -10.38 & -0.23 \\
\hline Knorz. M.C., $2011^{26}$ & $360[N R]$ & 36 & -10.41 & -0.24 \\
\hline Mastropasqua, L., $2012^{27}$ & $36[N R]$ & 12 & NR & NR \\
\hline Yang, R.B., $2012^{28}$ & $25[13]$ & 12 & -12.08 & -0.23 \\
\hline Kermani, O., $2013^{29}$ & $50[28]$ & 3 & -9.71 & -0.35 \\
\hline Taneri, S., 2014 & $15[15]$ & 12 & -11.25 & -0.46 \\
\hline Gimbel, H.V., $2015^{31}$ & $51[N R]$ & 36 & -9.26 & -0.33 \\
\hline Kohnen, T., $2016^{21}$ & $415[360]$ & 60 & -10.41 & -0.34 \\
\hline Alio, J.L., $2017^{32}$ & $25[N R]$ & 60 & -12.27 & -0.59 \\
\hline Al-Qahtani, S., $2018^{33}$ & $36[21]$ & 36 & -10.5 & NR \\
\hline
\end{tabular}

Modern posterior pIOLs have evolved to use plate haptics to support them in the sulcus between the iris base and ciliary muscle, and apertures in the optic to facilitate aqueous humour flow, providing good visual and refractive results (Table 1c). They rely on correct sizing to prevent both iris chafing or pupillary block glaucoma caused by an oversized plate pushing the iris forward, and cataract formation caused by an undersized plate resulting in insufficient support and touch between the $\mathrm{pIOL}$ and crystalline lens (Table 3c). Although the altered aqueous humour flow in posterior plOLs with apertures reduces the rate of cataract formation after implantation, correct sizing remains the main determinant in the prevention of complications. Unfortunately there is no perfect way yet to measure the sulcus, introducing a higher risk of sizing problems.

One posterior pIOL type that was taken of the market did not require measurement of the sulcus. This lens relied on the natural flow of intraocular fluid to keep the $\mathrm{plOL}$ from touching the crystalline lens. However, its instability increased the rate of cataract formation, the rate of $\mathrm{plOL}$ luxation behind the crystalline lens in the vitreous, and made it unsuitable for the correction of astigmatism. ${ }^{18,19,24}$ 
$\%$ within target

UDVA

CDVA

Indices

+/- 0.5D +/-10D

$20 / 20$ (\%) $\quad 20 / 40$ (\%)

$20 / 20(\%)$

$20 / 40$ (\%)

Efficacy

Safety

72.7

95.7

57.8

99.4

85.7

100

1.04

1.25

78.9

91.3

46.2

97.1

80.8

100

0.92

1.21

$67 \quad 100$

100

NR

NR

0.81

NR

$84 \quad 100$

60

100

92

100

1.04

1.13

$84 \quad$ NR

69

NR

NR

NR

NR

NR

NR NR

NR

NR

NR

NR

NR

78.4

92.2

77.6

98

NR

NR

0.93

1.07

$70 \quad 89.8$

94.7

91.3

100

NR

NR

$48 \quad 76$

20

88

68

NR

0.81

1.14

NR

NR

NR

NR

41.7

NR

NR

NR 
Table 1b. Overview of visual and refractive results after implantation with an anterior chamber iris-fixated phakic intraocular lens

\begin{tabular}{|c|c|c|c|c|}
\hline & \multirow[b]{2}{*}{ Nr. eyes [nr. pt] } & \multirow[b]{2}{*}{ Follow-up (mo) } & \multicolumn{2}{|c|}{ MRSE } \\
\hline & & & preop & postop \\
\hline \multicolumn{5}{|c|}{ Artisan Myopia (Toric), Ophtec } \\
\hline Budo, C., $2000^{34}$ & $249[N R]$ & 36 & -12.95 & $N R$ \\
\hline Dick, H. B., $2003^{35}$ & $48[N R]$ & 6 & -8.90 & -0.5 \\
\hline Asano-Kato, N, $2005^{36}$ & $11[N R]$ & 24 & -12.8 & -0.71 \\
\hline Bartels, M., 2006 37 & $20[14]$ & 24 & -11.39 & -0.44 \\
\hline Coullet, J., 2006 38 & $31[31]$ & 12 & -10.3 & -1.01 \\
\hline Tahzib, N.G., 2006 39 & $120[60]$ & 12 & -12.09 & -0.60 \\
\hline Tehrani, M., $2006^{39}$ & $28[N R]$ & 36 & -9.84 & $N R$ \\
\hline Gierek-Ciaciura, S., $2007^{40}$ & $20[12]$ & 12 & -15.73 & $N R$ \\
\hline Moshirfar, M., $2007^{41}$ & $38[N R]$ & 24 & -12.20 & -0.5 \\
\hline Tahzib, N.G., $2007^{42}$ & $89[49]$ & 72 & -10.36 & -0.71 \\
\hline Tahzib, N.G., $2007^{42}$ & $89[49]$ & 120 & -10.36 & -0.70 \\
\hline Guell, J. L., $2008^{43}$ & $95[N R]$ & 12 & -19.8 & -0.71 \\
\hline Guell, J. L., $2008^{43}$ & $169[N R]$ & 12 & -11.27 & -0.49 \\
\hline Silva, R.A., $2008^{44}$ & $19[N R]$ & 60 & -12.30 & 0.97 \\
\hline Stulting, R.D., $2008^{45}$ & $386[232]$ & 36 & -12.3 & NR \\
\hline Tahzib, N.G., $2008^{46}$ & $22[13]$ & 12 & -9.90 & -0.21 \\
\hline Qasem, Q., 201047 & $151[84]$ & 12 & -11.2 & NR \\
\hline Hassaballa, M.A., $2011^{48}$ & $42[N R]$ & 12 & -12.89 & -0.86 \\
\hline Titiyal, J.S., $2012^{49}$ & $28[N R]$ & 60 & -14.23 & -0.63 \\
\hline Yuan, X., $2012^{50}$ & $84[43]$ & 60 & -14.17 & $N R$ \\
\hline \multicolumn{5}{|c|}{ Artisan Hyperopia (Toric), Ophtec } \\
\hline Dick, H. B., $2003^{35}$ & $22[N R]$ & 6 & 3.25 & -0.24 \\
\hline Tehrani, M., $2006^{51}$ & $12[N R]$ & 36 & 3.43 & NR \\
\hline Guell, J. L., $2008^{43}$ & $39[N R]$ & 12 & 4.92 & -0.81 \\
\hline Qasem, Q., 201047 & $14[7]$ & 12 & 7.1 & NR \\
\hline \multicolumn{5}{|c|}{ Artisan, Ophtec (Mixed Groups) } \\
\hline Guell, J. L., $2003^{52}$ & $27[16]$ & 12 & -11.78 & -0.58 \\
\hline Guell, J. L., $2008^{43}$ & $84[N R]$ & 12 & -6.82 & -0.77 \\
\hline Qasem, Q., $2010^{47}$ & $20[11]$ & 12 & -9.05 & NR \\
\hline \multicolumn{5}{|c|}{ Artiflex Myopia (Toric), Ophtec } \\
\hline Coullet, J., $2006^{38}$ & $31[31]$ & 12 & -9.5 & -0.58 \\
\hline Tahzib, N.G., $2008^{46}$ & $27[14]$ & 12 & -9.95 & -0.23 \\
\hline Dick, H. B., $2009^{53}$ & $290[191]$ & 24 & -7.33 & -0.15 \\
\hline
\end{tabular}


$\%$ within target

UDVA

CDVA

Indices

+/- 0.5D +/- 1.0D 20/20 (\%) 20/40 (\%) 20/20(\%) 20/40 (\%) Efficacy Safety

57.1

78.8

33.7

76.8

61.5

93.9

1.03

1.31

83.3

100

85.4

NR

NR

NR

NR

NR

NR NR

NR

NR

NR

NR

NR

NR

$70 \quad 95$

NR

NR

NR

NR

NR

NR

NR

58

52

NR

NR

0.60

1.13

62.4

81.5

25.8

68.3

NR

NR

NR

NR

NR 70

NR

58

NR

NR

1.04

1.12

65

95

80

NR

NR

1.71

NR

55

84

84

78.7

NR

NR

NR

NR

50.5

65.1

NR

50.6

96.6

0.83

1.10

43.8

68.8

82.0

52.8

93.3

0.80

1.10

NR NR

NR

NR

NR

NR

1.16

1.40

NR NR

NR

NR

NR

NR

0.95

1.17

$\begin{array}{ll}73.7 & 94.7\end{array}$

73.7

94.7

94.7

NR

NR

NR

NR NR

31.1

83.9

NR

NR

NR

NR

NR NR

NR

NR

77

NR

NR

NR

$41.7 \quad 64.9$

48.3

86.8

NR

NR

NR

NR

NR $\quad 56.52$

NR

NR NR

NR

0.95

1.02

NR NR

21.4

64.3

50

92.9

NR

NR

NR

39.3

100

65.5

100

NR

NR

50

100

95.5

NR

NR

NR

NR

NR

NR 7

NR

73

NR

NR

1.14

1.04

NR NR

NR

NR

NR

NR

0.79

0.98

57.1

35.7

92.9

NR

NR

NR

NR

$\begin{array}{llll}62.9 & 96.2 & N R & 63\end{array}$

63

NR

NR

NR

1.4

NR NR

NR

NR

NR

NR

0.96

1.26

55

90

80

NR

NR

NR

NR

$\begin{array}{cccccccc}\text { NR } & 83.9 & \text { NR } & 77 & \text { NR } & \text { NR } & 0.79 & 1.12 \\ \text { NR } & N R & \text { NR } & \text { NR } & 100 & \text { NR } & \text { NR } & \text { NR } \\ 75.2 & 94.3 & \text { NR } & 97.2 & \text { NR } & 100 & 1.00 & 1.09\end{array}$


Table 1b. Continued.

\begin{tabular}{|c|c|c|c|c|}
\hline & \multirow[b]{2}{*}{ Nr. eyes [nr. pt] } & \multirow[b]{2}{*}{ Follow-up (mo) } & \multicolumn{2}{|c|}{ MRSE } \\
\hline & & & preop & postop \\
\hline Doors, M., $2012^{54}$ & $115[73]$ & 6 & -7.53 & NR \\
\hline Munoz, G., $2012^{55}$ & $42[25]$ & 12 & NR & NR \\
\hline Ozerturk, Y., $2012^{56}$ & $50[N R]$ & 24 & -11.85 & -1.04 \\
\hline Ruckhofer, J., $2012^{57}$ & $42[24]$ & 6 & -7.52 & NR \\
\hline Ghoreishi, M., 202058 & $41[41]$ & 12 & -9.44 & -0.29 \\
\hline
\end{tabular}

Mo = months; MRSE = manifest refractive spherical equivalent; $D=$ Diopter; UDVA = uncorrected distance visual acuity; CDVA = corrected distance visual acuity; NR = not reported

Table 1c. Overview of visual and refractive results after implantation with a posterior chamber phakic intraocular lens.

\begin{tabular}{|c|c|c|c|c|}
\hline & \multirow[b]{2}{*}{ Nr. eyes [nr. pt] } & \multirow[b]{2}{*}{ Follow-up (mo) } & \multicolumn{2}{|c|}{ MRSE } \\
\hline & & & preop & postop \\
\hline \multicolumn{5}{|c|}{ PRL Myopia, CIBA Vision/Zeiss Meditec } \\
\hline Hoyos, J. E., $2002^{59}$ & $17[N R]$ & 12 & -18.46 & -0.22 \\
\hline Pallikaris, I. G., $2004^{60}$ & $34[19]$ & 17 & -14.70 & -0.61 \\
\hline Koivula, A., $2005^{61}$ & $14[N R]$ & 12 & -9.19 & -0.31 \\
\hline Donoso, R., $2006^{62}$ & $53[39]$ & 8 & -17.27 & -0.23 \\
\hline Jongsareejit, A., $2006^{63}$ & $50[31]$ & 12 & NR & -0.23 \\
\hline Verde, C. M., $2007^{64}$ & $90[N R]$ & 12 & -11.9 & 0.04 \\
\hline Portaliou, D. M., $2011^{65}$ & $34[N R]$ & 72 & -14.080 & -0.45 \\
\hline Perez-Cambrodi, R. J., $2011^{66}$ & $35[20]$ & 57 & -10.25 & -0.11 \\
\hline Torun, N., $2013^{67}$ & $53[29]$ & 86 & -12.14 & -0.32 \\
\hline \multicolumn{5}{|c|}{ PRL Hyperopia, CIBA Vision/Zeiss Meditec } \\
\hline Hoyos, J. E., $2002^{59}$ & $14[N R]$ & 12 & 7.77 & -0.38 \\
\hline Koivula, A., $2005^{61}$ & $6[N R]$ & 12 & 6.13 & -0.60 \\
\hline Gil-Cazorla, R., $2008^{68}$ & $16[9]$ & 12 & 5.65 & 0.07 \\
\hline Koivula, A., $2009^{69}$ & $40[25]]$ & 12 & 5.90 & -0.46 \\
\hline \multicolumn{5}{|c|}{ PRL, CIBA Vision/Zeiss Meditec (Mixed Groups) } \\
\hline Koivula, A., $2005^{61}$ & $20[N R]$ & 12 & NR & NR \\
\hline \multicolumn{5}{|l|}{ ICL V4(b Toric), STAAR Surgical } \\
\hline Kamiya, K., $2013^{70}$ & $50[28]$ & 36 & -9.47 & -0.22 \\
\hline Sari, E.S., $2013^{71}$ & $34[20]$ & 36 & NR & NR \\
\hline Alfonso, J.F., $2014^{72}$ & $35[20]$ & 12 & -7.03 & -0.18 \\
\hline Igarashi, A., $2014^{73}$ & $41[41]$ & 96 & -10.19 & -0.44 \\
\hline
\end{tabular}




\begin{tabular}{cccccccc}
\multicolumn{2}{c}{ \% within target } & \multicolumn{2}{c}{ UDVA } & \multicolumn{2}{c}{ CDVA } & \multicolumn{2}{c}{ Indices } \\
\hline +/- 0.5D & +/ 1.0D & $\mathbf{2 0 / 2 0}(\%)$ & $\mathbf{2 0 / 4 0}(\%)$ & $\mathbf{2 0 / 2 0}(\%)$ & $\mathbf{2 0 / 4 0}(\%)$ & Efficacy & Safety \\
\hline 81.4 & 99 & 65.7 & 99 & 83.3 & 100 & 1.04 & 1.13 \\
66.7 & 92.9 & 38.1 & 100 & 71.4 & 100 & 0.97 & 1.11 \\
NR & 88 & 24 & 84 & 18 & 82 & 0.79 & 1.12 \\
NR & NR & 90 & 100 & 90 & 100 & 1.07 & 1.14 \\
83 & 100 & NR & 100 & NR & NR & 1.08 & 1.20 \\
\hline
\end{tabular}

$\%$ within target

UDVA

CDVA

Indices

+/- 0.5D +/- 1.0D 20/20 (\%) $20 / 40$ (\%) $\quad 20 / 20(\%) \quad 20 / 40$ (\%) Efficacy Safety

$\begin{array}{llllllll}53 & 82 & N R & N R & N R & N R & N R & \text { NR }\end{array}$

44

79

NR

NR

NR

NR

NR

NR

$75 \quad 100$

NR

NR

NR

NR

NR

NR 71.2

NR

60

NR

88.2

1

1.4

NR

NR

82

54

84

NR

NR

68

80

NR

NR

NR

0.98

1.22

67.6

91.2

NR

NR

NR

NR

NR

94.28

97.14

97

NR

97

$1 . .16$

1.26

66.0

79.2

NR

NR

NR

0.9

1.21

$\begin{array}{cccccccc}50 & 79 & N R & N R & N R & N R & N R & \text { NR } \\ 67 & 100 & N R & N R & N R & N R & \text { NR } & \text { NR }\end{array}$

93.75

100

NR

NR

NR

NR

0.9

0.8

87.5

100

NR

NR

NR

NR

0.7

0.89

75

100

$50 \quad 90$

NR

NR

0.89

1.12

82

98

86

98

NR

NR

0.94

1.16

52.9

82.4

NR

NR

NR

NR

NR

NR

97.1

100

NR

NR

77

100

NR

1.08

68.3

85.4

73.2

87.8

NR

NR

0.83

1.13 
Table 1c. Continued.

\begin{tabular}{|c|c|c|c|c|}
\hline & \multirow[b]{2}{*}{ Nr. eyes [nr. pt] } & \multirow[b]{2}{*}{ Follow-up (mo) } & \multicolumn{2}{|c|}{ MRSE } \\
\hline & & & preop & postop \\
\hline Guber, I., 2016 & $90[N R]$ & 120 & -11.4 & NR \\
\hline Shimizu, K., $2016^{75}$ & $26[26]$ & 60 & -7.51 & -0.19 \\
\hline \multicolumn{5}{|c|}{ ICL V4c (Toric), STAAR Surgical } \\
\hline Shimizu, K., $2012^{76}$ & $20[20]$ & 6 & -7.36 & 0.01 \\
\hline Shimizu, K., $2016^{75}$ & $26[26]$ & 60 & -7.54 & -0.15 \\
\hline Kamiya, K., $2017^{77}$ & $57[57]$ & 12 & -4.29 & NR \\
\hline Kamiya, K., $2017^{78}$ & $294[294]$ & 12 & -10.31 & NR \\
\hline Pjano, M.A., $2017^{79}$ & $28[16]$ & 12 & -9.52 & -0.21 \\
\hline Kamiya, K., $2018^{80}$ & $365[201]$ & 12 & -8.66 & NR \\
\hline Miao, H., $2018^{81}$ & $67[38]$ & 3 & -12.44 & -0.30 \\
\hline Takahashi, M., $2018^{82}$ & $42[21]$ & 6 & -7.37 & -0.61 \\
\hline Alfonso, J. F., $2019^{83}$ & $141[83]$ & 60 & -9.20 & -0.44 \\
\hline Ghoreishi, M., $2019^{84}$ & $41[41]$ & 12 & -9.85 & -0.33 \\
\hline Jadidid, K., $2019^{85}$ & $14[14]$ & 36 & -8.15 & -1.02 \\
\hline Qin, Q., $2019^{86}$ & $30[15]$ & 3 & -13.87 & 0.05 \\
\hline Igarashi, A., $2019^{87}$ & $44[23]$ & 3 & -6.23 & NR \\
\hline Niu, L., $2019^{88}$ & $51[31]$ & 12 & -14.03 & -0.67 \\
\hline Nakamura, T., $2019^{89}$ & $65[N R]$ & 60 & -9.97 & NR \\
\hline Nakamura, T., $2019^{89}$ & $70[38]$ & 120 & -9.97 & NR \\
\hline Yu, Z., $2020^{90}$ & 38 [19] & 3 & -10.77 & -0.86 \\
\hline \multicolumn{5}{|c|}{ ICL, STAAR Surgical (Mixed Groups) } \\
\hline Hassaballa, M.A., $2011^{48}$ & $26[N R]$ & 12 & -12.44 & -0.63 \\
\hline Moya, Т., $2015^{91}$ & $110[N R]$ & 144 & -16.90 & -1.77 \\
\hline \multicolumn{5}{|c|}{ IPCL (Toric), CareGroup IOL } \\
\hline Vasavada, V., $2018^{92}$ & $30[16]$ & 36 & -16.50 & -0.89 \\
\hline Sachdev, G., $2019^{93}$ & $134[N R]$ & 12 & -10.31 & NR \\
\hline \multicolumn{5}{|l|}{ EYECRYL, Biotech } \\
\hline Yasa, D., $2018^{94}$ & $58[29]$ & 12 & -13.41 & -0.44 \\
\hline Yasa, D., $2020^{95}$ & $43[23]$ & 6 & -10.3 & -0.36 \\
\hline
\end{tabular}

Mo = months; MRSE = manifest refractive spherical equivalent; $D=$ Diopter; UDVA = uncorrected distance visual acuity; CDVA = corrected distance visual acuity; NR = not reported 


\begin{tabular}{|c|c|c|c|c|c|c|c|}
\hline \multicolumn{2}{|c|}{$\%$ within target } & \multicolumn{2}{|c|}{ UDVA } & \multicolumn{2}{|c|}{ CDVA } & \multicolumn{2}{|c|}{ Indices } \\
\hline$+/-0.5 \mathrm{D}$ & +/- 1.0D & $20 / 20(\%)$ & $20 / 40(\%)$ & $20 / 20(\%)$ & $20 / 40(\%)$ & Efficacy & Safety \\
\hline 48.6 & 65.7 & $N R$ & NR & NR & $N R$ & 0.76 & 1.25 \\
\hline 92 & 100 & 100 & 100 & NR & NR & NR & NR \\
\hline 100 & 100 & 100 & 100 & $N R$ & NR & 1.03 & 1.13 \\
\hline 88 & 96 & 85 & 100 & $N R$ & NR & NR & NR \\
\hline 93 & 98 & 91 & NR & $N R$ & NR & NR & NR \\
\hline 94 & 99 & 97 & $N R$ & $N R$ & NR & NR & NR \\
\hline NR & NR & 67.9 & 92.9 & NR & NR & 1.2 & 1.25 \\
\hline 90 & 98 & 94 & NR & NR & NR & NR & NR \\
\hline 72 & 95 & 94 & 100 & NR & NR & 1.14 & 1.33 \\
\hline 100 & 100 & 74 & 95 & NR & NR & NR & NR \\
\hline 67.4 & 90.1 & 45.4 & 88.7 & 86.5 & 98.6 & 0.87 & 1.09 \\
\hline 80 & 95 & NR & 97 & NR & NR & 1.24 & 1.40 \\
\hline NR & NR & $N R$ & $N R$ & NR & NR & 0.75 & 1.08 \\
\hline NR & NR & NR & $N R$ & NR & NR & 1.01 & 1.01 \\
\hline 93.2 & 100 & NR & NR & $N R$ & NR & 0.91 & 1.13 \\
\hline 69 & 92 & 69 & 100 & NR & NR & 1.14 & 1.33 \\
\hline 81.5 & 100 & NR & $N R$ & $N R$ & NR & 0.77 & 0.94 \\
\hline 71.4 & 87.1 & NR & 92.9 & NR & NR & 0.66 & 0.88 \\
\hline 87 & 97 & NR & NR & NR & NR & 1.15 & 1.37 \\
\hline NR & 53.84 & NR & NR & NR & NR & 0.95 & 1.18 \\
\hline NR & 34.3 & NR & NR & NR & NR & 0.65 & 1.22 \\
\hline 45 & 69 & 46 & NR & NR & NR & 1.02 & 0.64 \\
\hline 88 & 95.8 & 51 & 96 & NR & NR & NR & NR \\
\hline 62 & 93 & $N R$ & NR & NR & NR & 1.2 & 1.39 \\
\hline 70 & 91 & NR & $N R$ & 16 & 88 & 1.25 & 1.41 \\
\hline
\end{tabular}


Table 2a. Overview of studies reporting on endothelial cell health after anterior chamber angle supported phakic intraocular lens implantation.

\begin{tabular}{|c|c|c|c|c|c|c|}
\hline & \multirow[b]{2}{*}{ 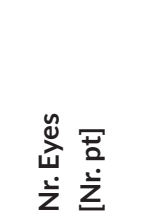 } & \multirow[b]{2}{*}{ 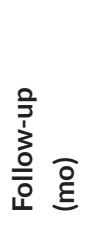 } & \multirow[b]{2}{*}{ 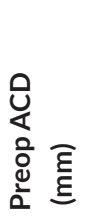 } & \multicolumn{2}{|c|}{$\mathrm{ECD}\left(\right.$ cells $\left./ \mathrm{mm}^{2}\right)$} & \multirow[b]{2}{*}{ 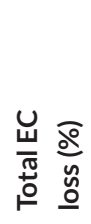 } \\
\hline & & & & $\frac{O}{0}$ & $\begin{array}{l}\circ \\
\stackrel{0}{0} \\
\text { ஸू } \\
0\end{array}$ & \\
\hline \multicolumn{7}{|l|}{ AcrySof Cachet, Alcon } \\
\hline Kohnen, T., $2009^{25}$ & $190[190]$ & 12 & NR & NR & NR & -4.8 \\
\hline Mastropasqua, L., $2012^{27}$ & $36[N R]$ & 12 & NR & NR & NR & $-4.0+$ \\
\hline Yang, R.B., $2012^{28}$ & $25[13]$ & 12 & NR & 2767 & 2764 & NR \\
\hline Kermani, O., $2013^{29}$ & $50[28]$ & 3 & NR & 2650 & 2500 & $\mathrm{NR}+$ \\
\hline Taneri, S., $2014^{30}$ & $15[15]$ & 12 & NR & 2676 & 2825 & $\mathrm{NR}+$ \\
\hline Gimbel, H.V., $2015^{31}$ & $51[N R]$ & 36 & $3.87^{*}$ & 2945 & 2768 & $-3.1 \dagger$ \\
\hline Kohnen, T., $2016^{21}$ & $415[326]$ & 60 & $3.73^{*}$ & NR & NR & -8.9 \\
\hline Alio, J.L., $2017^{32}$ & $25[N R]$ & 60 & NR & 2849 & 2513 & -13.7 \\
\hline Al-Qahtani, S., $2018^{33}$ & $36[21]$ & 6 & NR & 3017 & 2775 & $-7.2 \dagger$ \\
\hline \multicolumn{7}{|c|}{$\begin{array}{l}\text { Mo = months; } A C D=\text { anterior chamber depth; } E C D=\text { endothelial cell density; } E C=\text { endothelial cell; } N \\
=\text { not reported. }\end{array}$} \\
\hline
\end{tabular}

Table $\mathbf{2 b}$. Overview of studies reporting on endothelial cell health after anterior chamber iris-fixated phakic intraocular lens implantation.

\begin{tabular}{|c|c|c|c|c|c|c|}
\hline & \multirow[b]{2}{*}{ 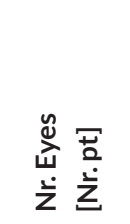 } & \multirow[b]{2}{*}{ 윽 } & \multirow{2}{*}{ 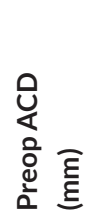 } & \multicolumn{2}{|c|}{ ECD (cells/mm²) } & \multirow[b]{2}{*}{ 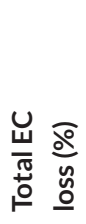 } \\
\hline & & & & $\begin{array}{l}\text { 음 } \\
\text { ํํㄴ }\end{array}$ & $\begin{array}{l}0 \\
\stackrel{0}{0} \\
\frac{\pi}{0} \\
0\end{array}$ & \\
\hline \multicolumn{7}{|l|}{ Artisan Myopia, Ophtec } \\
\hline Budo, C., $2000^{34}$ & $249[N R]$ & 36 & $3.38 \neq$ & 2876 & 2607 & NR† \\
\hline Pop, M., $2004^{96}$ & $293[N R]$ & 24 & NR & 2631 & 2577 & $-0.8+$ \\
\hline Asano-Kato, N., $2005^{36}$ & $11[N R]$ & 24 & NR & 2831 & 2750 & $N R+$ \\
\hline Coullet, J., $2006^{38}$ & $31[31]$ & 12 & NR & 2638 & 2473 & $-9.4 \dagger$ \\
\hline Benedetti, S., 200797 & $49[30]$ & 60 & NR & 2616 & 2379 & $-9+$ \\
\hline Gierek-Ciaciura, S, $2007^{40}$ & $20[12]$ & 12 & $3.39 \neq$ & 2651 & NR & $-6.8+$ \\
\hline Moshirfar, M., $2007^{41}$ & $38[N R]$ & 24 & NR & 2713 & 2534 & $-6.5+$ \\
\hline Tahzib, N.G., $2007^{42}$ & 89 [49] & 60 & $3.30 \neq$ & 2817 & 2734 & $-3.3 \dagger$ \\
\hline
\end{tabular}


Table 2b. Continued.

\begin{tabular}{|c|c|c|c|c|c|c|}
\hline & & & & ECD ( & $\left(\mathrm{mm}^{2}\right)$ & \\
\hline & 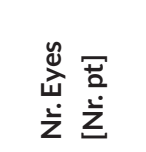 & 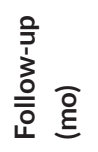 & 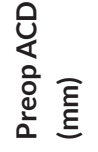 & $\frac{0}{0}$ & $\begin{array}{l}\frac{0}{0} \\
\frac{ث}{0} \\
0\end{array}$ & 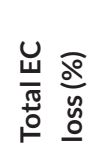 \\
\hline Tahzib, N.G., $2007^{42}$ & 89 [49] & 120 & $3.30 \neq$ & 2817 & 2800 & $-8.9 \dagger$ \\
\hline Guell, J. L., $2008^{43}$ & $89[N R]$ & 60 & NR & 2836 & 2514 & $-11.3 \dagger$ \\
\hline Guell, J. L., $2008^{43}$ & $165[N R]$ & 60 & NR & 2755 & 2454 & $-10.9+$ \\
\hline Silva, R.A., $2008^{44}$ & $19[N R]$ & 60 & $3.87^{*}$ & 2481 & 2156 & $-14.1 \dagger$ \\
\hline Stulting, R.D., $2008^{45}$ & $386[N R]$ & 36 & NR & NR & NR & $-4.8+$ \\
\hline Yamaguchi, T., $2008^{98}$ & $20[11]$ & 12 & $3.66^{*}$ & 3139 & 3023 & NR† \\
\hline Eldanasoury, A., $2019^{99}$ & $90[57]$ & 144 & $3.45^{*}$ & 2645 & 1751 & -26.7 \\
\hline Galvis, V., $2019^{100}$ & $67[45]$ & 114 & NR & NR & NR & -18.5 \\
\hline Shaaban, Y., 2020101 & $20[N R]$ & 36 & NR & 2707 & 2279 & $-15.7 \dagger$ \\
\hline Artisan Hyperopia (Tori & Ophtec & & & & & \\
\hline Guell, J. L., $2008^{43}$ & $34[N R]$ & 48 & NR & 2735 & 2560 & $-6.4 \dagger$ \\
\hline Galvis, V., $2019^{100}$ & $10[5]$ & 108 & NR & NR & NR & -10.5 \\
\hline Artisan Toric, Ophtec ( & d Groups) & & & & & \\
\hline Dick, H. B., $2003^{35}$ & $70[N R]$ & 6 & $3.47^{*}$ & 2983 & 2849 & $-4.5+$ \\
\hline Guell, J. L., $2003^{52}$ & $27[16]$ & 12 & NR & 2649 & 2726 & $2.9+$ \\
\hline Guell, J. L., $2008^{43}$ & $67[N R]$ & 36 & NR & 2632 & 2537 & $-3.6+$ \\
\hline Artiflex Myopia (Toric), & htec & & & & & \\
\hline Coullet, J., $2006^{38}$ & $31[31]$ & 12 & NR & 2654 & 2405 & $-9.0 \dagger$ \\
\hline Dick, H. B., $2009^{53}$ & $290[191]$ & 24 & $3.65^{*}$ & 2634 & 2605 & $-1.07 \dagger$ \\
\hline Doors, M., $2012^{54}$ & $115[73]$ & 6 & $3.65^{*}$ & 2805 & 2676 & $-4.3+$ \\
\hline Munoz, G., $2012^{55}$ & $42[25]$ & 12 & $3.51 \ddagger$ & 2801 & 2538 & NR† \\
\hline Ozerturk, Y., $2012^{56}$ & $50[N R]$ & 24 & $3.41 \neq$ & 3023 & 2797 & $-7.4 \dagger$ \\
\hline Ruckhofer, J., $2012^{57}$ & $42[24]$ & 6 & NR & 2646 & 2627 & $-0.7 \dagger$ \\
\hline Shaaban, Y., 2020101 & $20[N R]$ & 36 & NR & 2899 & 2173 & $-25.0 \dagger$ \\
\hline Ghoreishi, M., 202058 & $41[41]$ & 12 & NR & 2777 & 2721 & $N R \neq$ \\
\hline $\begin{array}{l}\text { Mo = months; } A C D=\text { ant } \\
=\text { not reported. } \\
\text { *as measured from the } c \\
\text { †measurement not repe } \\
\text { †measurement method }\end{array}$ & $\begin{array}{l}\text { chamber d } \\
\text { al epitheliun } \\
\text { e based on r } \\
\text { eported }\end{array}$ & $\begin{array}{l}\text { ound } 0 \\
\text { erials ar }\end{array}$ & $\begin{array}{l}\text { n consi } \\
\text { ethods }\end{array}$ & cornea & less & al cell; NR \\
\hline
\end{tabular}


Table 2c. Overview of studies reporting on endothelial cell health after posterior chamber phakic intraocular lens implantation.

\section{$\mathrm{ECD}$ (cells $/ \mathrm{mm}^{2}$ )}

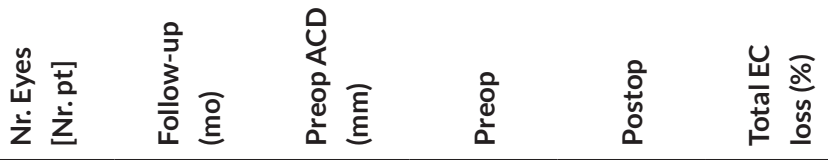

PRL Myopia, CIBA Vision/Zeiss Meditec

\begin{tabular}{lllllll}
\hline Koivula, A., 200561 & $14[N R]$ & 12 & NR & 2989 & 2771 & $-7.4+$ \\
Torun, N., 201367 & $53[29]$ & 86 & NR & 2581 & NR & -6.4 \\
\hline
\end{tabular}

PRL Hyperopia, CIBA Vision/Zeiss Meditec

\begin{tabular}{|c|c|c|c|c|c|c|}
\hline Koivula, A., $2005^{61}$ & $6[N R]$ & 12 & NR & 3198 & 3031 & $-6.2 \dagger$ \\
\hline Koivula, A., $2009^{69}$ & $40[25]$ & 12 & NR & NR & NR & $-3.8+$ \\
\hline \multicolumn{7}{|c|}{ PRL, CIBA Vision/Zeiss Meditec (Mixed Groups) } \\
\hline Koivula, A., $2005^{61}$ & $20[N R]$ & 12 & NR & NR & NR & $-7.1 \dagger$ \\
\hline \multicolumn{7}{|c|}{ ICL V4(b Toric), STAAR Surgical } \\
\hline Kamiya, K., $2013^{70}$ & $50[28]$ & 36 & $3.23^{*}$ & 2753 & 2682 & NR† \\
\hline Sari, E.S., $2013^{71}$ & $34[20]$ & 36 & $3.22^{*}$ & 3307 & 3102 & $-7.8+$ \\
\hline Alfonso, J.F., $2014^{72}$ & $35[20]$ & 12 & NR & 2755 & 2634 & NR† \\
\hline Igarashi, A., $2014^{73}$ & $41[41]$ & 96 & $3.24^{*}$ & 2819 & 2626 & $-6.2 \dagger$ \\
\hline Shimizu, K., $2016^{75}$ & $26[26]$ & 60 & $3.11 \neq$ & 2750 & 2711 & $-1.2 \dagger$ \\
\hline Goukon, H.. $2017^{102}$ & $25[25]$ & 24 & $3.16 \neq$ & 2829 & 2798 & $-1.1 \dagger$ \\
\hline \multicolumn{7}{|c|}{ ICL V4(c Toric), STAAR Surgical } \\
\hline Shimizu, K., $2012^{76}$ & $20[20]$ & 6 & $3.13^{*}$ & 2798 & 2720 & $-2.8+$ \\
\hline Shimizu, K., $2016^{75}$ & $26[26]$ & 60 & $3.13 \neq$ & 2803 & 2799 & $-0.5+$ \\
\hline Goukon, H., $2017^{102}$ & $34[34]$ & 24 & $3.14 \neq$ & 2816 & 2806 & $-0.3+$ \\
\hline Kamiya, K., $2017^{78}$ & $57[57]$ & 12 & $3.08^{*}$ & NR & NR & $-0.1 \dagger$ \\
\hline Kamiya, K., $2017^{78}$ & $294[294]$ & 12 & $3.14^{*}$ & NR & NR & $-0.1 \dagger$ \\
\hline Pjano, M.A., $2017^{79}$ & $28[16]$ & 12 & $3.48^{*}$ & 2656 & 2512 & $-5.5+$ \\
\hline Alfonso, J. F., $2019^{83}$ & $141[83]$ & 60 & 3.16 & 2657 & 2645 & $-0.4+$ \\
\hline Řeháková, T., $2019^{103}$ & $63[32]$ & 24 & NR & 3271 & 2803 & $-13.5 \dagger$ \\
\hline Choi, J., $2019^{104}$ & $71[N R]$ & 120 & NR & 2889 & 2749 & NR† \\
\hline Niu, L., $2019^{88}$ & $51[31]$ & 12 & 2.74 & 3235 & 2964 & $-8.4+$ \\
\hline Nakamura, T., $2019^{89}$ & $70[38]$ & 120 & 3.19 & 2739 & 2581 & $-5.3+$ \\
\hline Ghoreishi, M., 202058 & $41[41]$ & 12 & NR & 2723 & 2672 & $N R \neq$ \\
\hline \multicolumn{7}{|c|}{ IPCL (Toric), CareGroup IOL } \\
\hline Vasavada, V.,201892 & $30[16]$ & 36 & $3.28^{*}$ & 3036 & 2655 & $-9.7+$ \\
\hline Sachdev, G., $2019^{93}$ & $134[N R]$ & 12 & $3.21^{*}$ & 2755 & NR & $-2.0 \dagger$ \\
\hline Stodulka, P., 2020105 & $17[10]$ & 24 & 3.44 & 2552 & 2299 & -9.9 \\
\hline
\end{tabular}


Table 2c. Continued.

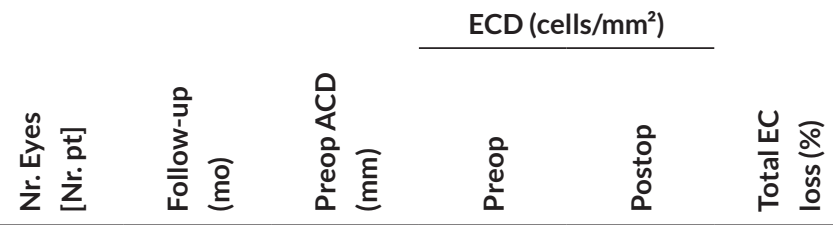

\section{EYECRYL, Biotech}

\begin{tabular}{lllllll}
\hline Yasa, D., 201894 & $58[29]$ & 12 & NR & 2713 & 2608 & $-3.9 \dagger$
\end{tabular}

\begin{tabular}{lllllll} 
Yasa, D., $2020^{95}$ & $43[23]$ & 6 & 3.23 & 2719 & 2779 & NRt \\
\hline
\end{tabular}

Mo = months; $A C D$ = anterior chamber depth; $E C D=$ endothelial cell density; $E C$ = endothelial cell; NR $=$ not reported.

*as measured from the corneal epithelium, around $0.5 \mathrm{~mm}$ consists of corneal thickness

†measurement not repeatable based on materials and methods section

łmeasurement method not reported 


\section{OUTCOMES AND COMPLICATIONS OF PHAKIC INTRAOCULAR LENSES}

Large numbers of studies have shown that all three types of plOLs render excellent results with regard to uncorrected visual acuity, distance corrected visual acuity, and residual refractive error (Table 1a-c). Other outcome measures reported after pIOL implantation are mainly related to the safety of the $\mathrm{pIOL}$ in the eye and report complications associated with the cornea, crystalline lens, or retina. ${ }^{19}$

The cornea is essential in refracting light - functioning as a positive lens - and its clarity is of vital importance to procure a clear image on the retina. Corneal clarity is maintained by the innermost cells of the cornea, called the endothelial cells. Endothelial cells function as an active pump that transports water from the corneal stroma, essential because excessive intracorneal water causes corneal edema and compromises its clarity. Although the number of endothelial cells decreases with advancing age, it remains sufficiently high to retain adequate pump function. 2, 15, 106, 107 Any intraocular surgery causes a surgery related, acute peak in endothelial cell loss that varies per person as well as per type of surgery. Additionally, the intraocular presence of a pIOL increases chronic endothelial cell loss. Therefore, endothelial cell density should be checked with regular intervals, both to monitor individual safety as well as safety of the specific pIOL in general. ${ }^{108}$ On a patient level these measurements are performed to prevent corneal transplantation due to endothelial cell loss and corneal decompensation. On a population level, regular measurements and standardized reporting can detect trends in order to remove high risk pIOLs from the market. Recent evidence have led to withdrawal of angle supported pIOLs because of increased levels of endothelial cell loss (Tables 2a-c). ${ }^{18,1}$ 19, 21, 108,109

Although high myopes are known to develop cataract at a younger age, plOLs may also lead to accelerated cataract formation, causing loss of accommodation and decreased visual acuity, requiring pIOL explantation combined with cataract surgery (Table 3a-c). ${ }^{15,19}$ Cataract formation after uneventful pIOL implantation is thought to be associated with inflammation in all plOL types, but patients with posterior chamber pIOLs are especially at risk for cataract formation due to the design of the pIOL (Table 3a-c). ${ }^{15,19,110}$ As highlighted previously, the position of the posterior $\mathrm{PIOL}$ in proximity to the crystalline lens, combined with known preoperative sizing difficulties, frequently induces contact between the $\mathrm{pIOL}$ and crystalline lens. As a result of this friction, these patients are at a high risk to develop anterior subcapsular cataract, which can require cataract surgery at a much younger age, whilst adhesions between the crystalline lens and its surrounding capsule increase the difficulty of the surgery. Fortunately, recent modifications with additional apertures in the optic have presumably changed the aqeous humour flow and resulted in a decreased rate of cataract formation (Table 3c). ${ }^{111}$ 
High myopia is associated with retinal complications because the retina is stretched out and becomes thinner, increasing the risk of developing weak spots in the retina. Ultimately these weak spots can result in complications such as myopic macular degeneration, retinal detachment, macular retinoschizis or choroidal neovascularization (Table 3a-c). ${ }^{9}$ Even though these complications can occur regardless of intraocular surgery, it is known that cataract surgery significantly increases the risk of developing a retinal detachment, especially when surgery is performed in younger patients. ${ }^{112,113}$ The causative mechanism might be that cataract surgery requires the removal of the crystalline lens, changing the dynamics of the posterior part of the eye, whereas in plOL implantation changes are only applied in the anterior segment of the eye, which is unlikely to result in a similar risk.

As reported in Tables $\mathbf{1 a - c}$, 2a-c, and $\mathbf{3 a - c}$ previous publications show large variations in the duration of follow-up, and reported outcome measures. This is especially true when reporting safety outcomes as endothelial cell loss, complications, and number and reason of phakic IOL explantations (Tables 2a-c, and $\mathbf{3 a - c}$ ).

This thesis provides a detailed overview of the major safety outcomes of recent and current applied phakic IOLs:

Chapter 2 describes the results after implantation with a recent angle-supported phakic IOL and compares it with iris-fixated phakic IOLs to assess its safety and efficacy.

The $\mathbf{3}^{\text {rd }}$ and $\mathbf{4}^{\text {th }}$ chapters focus on the long-term effects of four types of iris-fixated phakic IOLS on corneal health and describe the rate of endothelial cell loss after phakic IOL implantation.

Chapters $\mathbf{5}$ and $\mathbf{6}$ report the safety and efficacy profile of four types of iris-fixated phakic IOLs, describing visual and refractive outcome parameters, as well as complications occurring during the course of follow-up.

Finally, chapter 7 describes the rate of iris-fixated phakic IOL explantation, reasons for explantation, estimated time until explantation and risk-factors for explantation. 
Table 3a. Reported complications in eyes implanted with anterior chamber angle supported phakic intraocular lenses

\begin{tabular}{llllllll}
\hline & & & & \multicolumn{3}{c}{ Explants (\%) } \\
\cline { 5 - 7 } & $\begin{array}{c}\text { Nr. Eyes } \\
{[\text { Nr.pt }]}\end{array}$ & $\begin{array}{c}\text { Follow-up } \\
(\mathbf{m o})\end{array}$ & $\begin{array}{c}\text { Exchange } \\
(\%)\end{array}$ & Total & Cataract & EC loss \\
\hline AcrySof Cachet, Alcon & & & & & & & \\
\hline Kohnen, T., 200925 & $190[190]$ & 12 & 0.53 & 0.53 & NR & NR
\end{tabular}

\begin{tabular}{|c|c|c|c|c|c|c|}
\hline Knorz. M.C., $2011^{26}$ & $104[N R]$ & 36 & 0.56 & 1.39 & NR & NR \\
\hline Gimbel, H.V., $2015^{31}$ & $51[N R]$ & 36 & $N R$ & 1.68 & $N R$ & 1.68 \\
\hline Kohnen, T., 2016 21 & $415[326]$ & 60 & $N R$ & 6.33 & 1.27 & 2.53 \\
\hline
\end{tabular}

Alio, J.L., $2017^{32}$

$$
25[N R]
$$

60

$N R$

2

NR

1

$\mathrm{Mo}=$ months; $\mathrm{ACD}=$ anterior chamber depth; $\mathrm{ECD}=$ endothelial cell density; $\mathrm{EC}=$ endothelial cell; $\mathrm{NR}$

= not reported; $\mathrm{pIOL}=$ phakic intraocular lens; $I O P=$ intraocular pressure

Table 3b. Reported complications in eyes implanted with anterior chamber iris-fixated phakic intraocular lenses

\begin{tabular}{|c|c|c|c|c|c|c|}
\hline & \multirow[b]{2}{*}{$\begin{array}{c}\text { Nr. Eyes } \\
\text { [Nr.pt] }\end{array}$} & \multirow[b]{2}{*}{$\begin{array}{c}\text { Follow-up } \\
\text { (mo) }\end{array}$} & \multirow[b]{2}{*}{$\begin{array}{c}\text { Exchange } \\
(\%)\end{array}$} & \multicolumn{3}{|c|}{ Explants (\%) } \\
\hline & & & & Total & Cataract & ECloss \\
\hline \multicolumn{7}{|c|}{ Artisan Myopia (Toric), Ophtec } \\
\hline Budo, C., $2000^{34}$ & $249[N R]$ & 36 & NR & 2.8 & 1.2 & 0.4 \\
\hline Asano-Kato, N., $2005^{36}$ & $11[\mathrm{NR}]$ & 24 & NR & NR & NR & NR \\
\hline Bartels, M., $2006^{37}$ & $20[14]$ & 24 & NR & NR & NR & NR \\
\hline Benedetti, S., $2007^{97}$ & $49[30]$ & 60 & $N R$ & $N R$ & NR & $N R$ \\
\hline Moshirfar, M., $2007^{41}$ & $38[N R]$ & 24 & 1.18 & NR & NR & NR \\
\hline Tahzib, N.G., $2007^{42}$ & $89[49]$ & 120 & NR & 2.25 & 2.25 & NR \\
\hline
\end{tabular}




\section{Complication}

Retinal

Position Related

Other

NR

$32.6 \% \geq 15^{\circ}$ rotation, $1.05 \%$

NR

pIOL related synechiae. 0.53\%

explanted due to upside-down

implantation

$\begin{array}{ccc}\text { NR } & \text { NR } & \text { NR } \\ \text { NR } & \text { 1.68\% anterior synechiae } & N R \\ \text { NR } & 4.9 \% \text { anterior synechiae, } 0.39 \% & 4.1 \% \text { surgical intervention, } \\ & \text { upside down implantation } & 3.1 \% \text { cataract formation, } \\ & & 2.5 \% \text { raised IOP requiring } \\ & & \text { treatment }\end{array}$

NR

$1 \%$ iris-cyst development

$10 \%$ additional laser refractive

requiring explantation correction

\section{Complication}

Retinal

Position Related

Other

0.8\% retinal detachment

pupillary block

4.5\% pigment deposition on

NR

$\mathrm{plOL}$

$1.85 \%$ retinal detachment

NR

NR

$16.8 \%$ iris atrophy, $8.2 \%$

$1.85 \%$ cataract

pigment deposition on $\mathrm{plOL}$
2.4\% pupil deformation

NR
$2.4 \%$ age related cataract,

$1.6 \%$ hyphema, $0.8 \%$ persistent

corneal edema

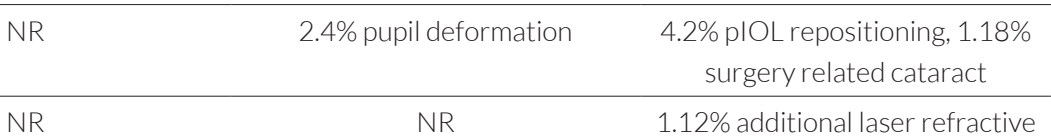

correction 
Table 3b. Continued.

\begin{tabular}{|c|c|c|c|c|c|c|}
\hline & \multirow[b]{2}{*}{$\begin{array}{l}\text { Nr. Eyes } \\
\text { [Nr.pt] }\end{array}$} & \multirow[b]{2}{*}{$\begin{array}{c}\text { Follow-up } \\
\text { (mo) }\end{array}$} & \multirow[b]{2}{*}{$\begin{array}{c}\text { Exchange } \\
(\%)\end{array}$} & \multicolumn{3}{|c|}{ Explants (\%) } \\
\hline & & & & Total & Cataract & EC loss \\
\hline Guell, J. L., $2008^{43}$ & $89[N R]$ & 60 & NR & 1.25 & 0.5 & 0.75 \\
\hline Guell, J. L., $2008^{43}$ & $165[N R]$ & 60 & NR & NR & NR & NR \\
\hline Silva, R.A., $2008^{44}$ & $19[\mathrm{NR}]$ & 60 & NR & 7.6 & 3.8 & NR \\
\hline Stulting, R.D., $2008^{45}$ & $386[232]$ & 36 & 1.02 & 1.1 & 0.25 & NR \\
\hline Qasem, Q., 201047 & $151[84]$ & 12 & NR & NR & NR & NR \\
\hline Titiyal, J.S., $2012^{49}$ & $28[N R]$ & 60 & NR & 1.17 & NR & 1.17 \\
\hline
\end{tabular}

\begin{tabular}{lcccccc}
\hline Moshirfar, M., 2014114 & $213[\mathrm{NR}]$ & 65 & NR & 2.76 & 2.3 & 0.92 \\
\hline Chebli, S., 2018115 & $113[60]$ & 65 & NR & NR & NR & 0.9 \\
\hline Eldanasoury, A., 201999 & $90[57]$ & 144 & NR & 33 & 7 & 27 \\
\hline Galvis, V., 2019100 & $67[45]$ & 114 & NR & 4.5 & 3 & 1.5
\end{tabular}

\begin{tabular}{llllllll}
\hline \multicolumn{1}{l}{ Artisan Hyperopia, Ophtec } & & & & & \\
\hline Guell, J. L., $2008^{43}$ & $28[N R]$ & 60 & 4.88 & NR & NR & NR \\
\hline Qasem, Q., $2010^{47}$ & $14[7]$ & 12 & NR & NR & NR & NR
\end{tabular}

\section{Artiflex Myopia (Toric), Ophtec}

\begin{tabular}{lllllll}
\hline Dick, H. B., 200953 & $290[191]$ & 24 & 0.34 & NR & NR & NR
\end{tabular}

\begin{tabular}{lllllll}
\hline Doors, M., 2012 & $115[73]$ & 6 & $N R$ & 1.74 & NR & NR
\end{tabular}

\begin{tabular}{lcccccc}
\hline Munoz, G., 201255 & $42[25]$ & 12 & NR & NR & NR & NR \\
\hline Ozerturk, Y., 201256 & $50[$ NR] & 24 & NR & NR & NR & NR \\
\hline Visser, N., 2012 & & & & & \\
\hline Galvis, V., 2019100 & $35[20]$ & 12 & NR & NR & NR & NR \\
\hline Ghoreishi, M., 2020 & $10[5]$ & 108 & NR & NR & NR & NR \\
\hline
\end{tabular}




\section{Complication}

Retinal

$0.25 \%$ macular hemorrhage,

$0.25 \%$ retinal detachment

NR
Position Related

NR

NR

\section{Other}

15.1\% additional laser refractive correction

$9,8 \%$ additional laser refractive correction

NR

3.8\% explanted due to glare/

$N R$

halo's

$0.51 \%$ retinal detachment

$2.54 \%$ refixations

NR

$2.16 \%$ myopic degeneration, $1.08 \%$ retinal detachment $4.32 \%$ refixation

17.9\% additional laser refractive

$1.17 \%$ retinal detachment,

$1.17 \%$ perifoveal subretinal

$57.41 \%$ refixation, $29.4 \%$ iris atrophy

hemorrhage, $1.17 \%$ peripheral

correction

retinal tear

\begin{tabular}{lcc} 
NR & NR & NR \\
NR & NR & NR \\
NR & NR & $11 \%$ corneal edema and DSAEK \\
\hline NR & $1.5 \%$ refixation after trauma & $29.9 \%$ over $25 \%$ total EC loss \\
\hline & & \\
\hline
\end{tabular}

$4.32 \%$ refixation

correction

$2.16 \%$ myopic degeneration,

28.6\% additional laser refractive

$1.08 \%$ retinal detachment correction

\begin{tabular}{|c|c|c|}
\hline NR & $\begin{array}{l}\text { 4.8\% pigment deposition on } \\
\text { plOL, 1.4\% giant cel deposition } \\
\text { on plOL, } 1.4 \% \text { repositioning }\end{array}$ & NR \\
\hline NR & $\begin{array}{c}\text { 14.8\% pigment deposition on } \\
\text { plOL, 12.2\% giant cel deposition } \\
\text { on plOL }\end{array}$ & 4.38\% posterior synechiae \\
\hline NR & $\begin{array}{c}\text { 16.7\% pigment deposition on } \\
\text { plOL, } 2.4 \% \text { repositioning }\end{array}$ & NR \\
\hline $\begin{array}{c}1.2 \% \text { choroidal } \\
\text { neovascularisation }\end{array}$ & $21.7 \%$ depositions on plOL & NR \\
\hline NR & $11.43 \%$ depositions on plOL & NR \\
\hline NR & NR & $20 \%$ over $25 \%$ total EC loss \\
\hline NR & $\begin{array}{l}\text { 2.44\% reposition due to } \\
\text { misalignment }\end{array}$ & NR \\
\hline
\end{tabular}


Table 3b. Continued.

\begin{tabular}{|c|c|c|c|c|c|c|}
\hline & \multirow[b]{2}{*}{$\begin{array}{l}\text { Nr. Eyes } \\
\text { [Nr.pt] }\end{array}$} & \multirow[b]{2}{*}{$\begin{array}{l}\text { Follow-up } \\
\text { (mo) }\end{array}$} & \multirow[b]{2}{*}{$\begin{array}{c}\text { Exchange } \\
(\%)\end{array}$} & \multicolumn{3}{|c|}{ Explants (\%) } \\
\hline & & & & Total & Cataract & EC loss \\
\hline \multicolumn{7}{|c|}{ Artisan/Artiflex (Toric), Ophtec (Mixed Groups) } \\
\hline Tehrani, M., $2006^{51}$ & $30[N R]$ & 36 & NR & NR & NR & NR \\
\hline Guell, J. L., $2008^{43}$ & $67[N R]$ & 36 & 1.19 & NR & NR & NR \\
\hline Saxena, R., $2008^{117}$ & $318[N R]$ & mean 35 & 1.57 & 1.26 & 1.26 & NR \\
\hline Qasem, Q., 201047 & $20[11]$ & 12 & NR & NR & NR & NR \\
\hline
\end{tabular}

Mo = months; $A C D$ = anterior chamber depth; $E C D=$ endothelial cell density; $E C$ = endothelial cell; NR = not reported; $\mathrm{pIOL}$ = phakic intraocular lens; $\mathrm{IOP}$ = intraocular pressure

Table 3c. Reported complications in eyes implanted with posterior chamber phakic intraocular lenses

\begin{tabular}{|c|c|c|c|c|c|c|}
\hline & \multirow[b]{2}{*}{$\begin{array}{l}\text { Nr. Eyes } \\
\text { [Nr.pt] }\end{array}$} & \multirow[b]{2}{*}{$\begin{array}{l}\text { Follow-up } \\
\text { (mo) }\end{array}$} & \multirow[b]{2}{*}{$\begin{array}{c}\text { Exchange } \\
(\%)\end{array}$} & \multicolumn{3}{|c|}{ Explants (\%) } \\
\hline & & & & Total & Cataract & EC loss \\
\hline \multicolumn{7}{|c|}{ PRL Myopia, CIBA Vision/Zeiss Meditec } \\
\hline Hoyos, J. E., $2002^{59}$ & $17[N R]$ & 12 & 18 & NR & NR & NR \\
\hline Pallikaris, I. G., $2004^{60}$ & $34[19]$ & 17 & NR & NR & NR & NR \\
\hline Donoso, R., $2006^{62}$ & $53[39]$ & 8 & NR & 3.8 & NR & NR \\
\hline Jongsareejit, A., $2006^{63}$ & $50[31]$ & 12 & NR & 2 & 2 & NR \\
\hline Portaliou, D. M., $2011^{65}$ & $34[N R]$ & 72 & NR & NR & NR & NR \\
\hline $\begin{array}{l}\text { Perez-Cambrodi, R. J., } \\
2011^{66}\end{array}$ & $35[20]$ & 57 & NR & NR & NR & NR \\
\hline Torun, N., $2013^{67}$ & $53[29]$ & 86 & NR & 9.3 & 7.5 & NR \\
\hline
\end{tabular}




\section{Complication}

Retinal

Position Related

\section{Other}

NR

$17.5 \%$ pigment deposition on

NR

$\mathrm{pIOL}$

NR

NR

5.95\% additional laser refractive

correction

0.31\% retinal detachment

0.31\% pupillary block

NR

$2.16 \%$ myopic degeneration,

$4.32 \%$ refixation

15\% additional laser refractive

$1.08 \%$ retinal detachment correction

\section{Complication}

Retinal

Position Related

Other

\begin{tabular}{|c|c|c|}
\hline NR & $6 \%$ cortical lens opacity & NR \\
\hline NR & $\begin{array}{l}2.9 \% \text { anterior opacification due } \\
\text { to lens touch }\end{array}$ & $\begin{array}{l}\text { 28.5\% glare and halo's, 8.8\% } \\
\text { damaged anterior capsule } \\
\text { during iridectomy creation, 5.9\% } \\
\text { glaucoma requiring surgery }\end{array}$ \\
\hline $1.9 \%$ retinal detachment & $\begin{array}{l}\text { 3.8\% lens subluxation through } \\
\text { zonules }\end{array}$ & NR \\
\hline $2 \%$ macular hemorrhage & $2 \%$ pupillary block glaucoma & NR \\
\hline NR & $\begin{array}{c}\text { 8.8\% damaged anterior capsule, } \\
\text { pigment dispersion, } 2.9 \% \text { lens } \\
\text { decentration }\end{array}$ & NR \\
\hline $2.86 \%$ retinal detachment & $\begin{array}{l}\text { 5.71\% lens decentration, } 2.86 \% \\
\text { cortical opcifications }\end{array}$ & NR \\
\hline $3.8 \%$ retinal detachment & $\begin{array}{l}\text { 11.3\% asymptomatic anterior } \\
\text { cataract, } 9.4 \% \text { slight lens } \\
\text { decentration, } 1.8 \% \text { lens } \\
\text { decentration requiring } \\
\text { explantation }\end{array}$ & NR \\
\hline
\end{tabular}


Table 3c. Continued.

\begin{tabular}{lcccccc}
\hline & $\begin{array}{c}\text { Nr. Eyes } \\
\text { [Nr. pt] }\end{array}$ & $\begin{array}{c}\text { Follow-up } \\
\text { (mo) }\end{array}$ & $\begin{array}{c}\text { Exchange } \\
\text { (\%) }\end{array}$ & Total & Cataract & EC loss \\
\hline PRL Hyperopia, CIBA Vision/Zeiss Meditec & & & & & \\
\hline Hoyos, J. E., 2002 & 14 [NR] & 12 & NR & NR & NR & NR \\
\hline Gil-Cazorla, R., 2008 & 16 [9] & 12 & NR & NR & NR & NR
\end{tabular}

\section{PRL, CIBA Vision/Zeiss Meditec (Mixed Groups)}

$\begin{array}{lllllll}\text { Koivula, A., } 2005^{61} & 20[N R] & 12 & \text { NR } & \text { NR } & \text { NR } & \text { NR }\end{array}$

\section{ICL V3/V4, STAAR Surgical}

\begin{tabular}{lllllll}
\hline Moya, T., $2015^{91}$ & $110[N R]$ & 144 & 1.38 & 11.8 & 7.6 & NR
\end{tabular}

\section{ICL V4(b Toric), STAAR Surgical}

\begin{tabular}{lllllll}
\hline Kamiya, K., $2013^{70}$ & $50[25]$ & 36 & NR & NR & NR & NR
\end{tabular}

\begin{tabular}{lcccccc}
\hline Sari, E.S., 201371 & $34[20]$ & 36 & NR & NR & NR & NR \\
\hline Igarashi, A., 2014 & & & & & \\
& $41[41]$ & 96 & NR & NR & 4.9 & NR \\
\hline Guber, I., $2016^{74}$ & $90[N R]$ & 120 & NR & NR & 18.3 & NR
\end{tabular}

$\begin{array}{lllllll}\text { Shimizu, K., } 2016^{75} & 26[26] & 60 & \text { NR } & \text { NR } & \text { NR } & \text { NR }\end{array}$

\section{ICL V4(c Toric), STAAR Surgical}

\begin{tabular}{lcccccc}
\hline Kamiya, K., 201778 & $294[294]$ & 12 & 0.7 & NR & NR & NR \\
\hline Kamiya, K., 201880 & $365[201]$ & 12 & 0.6 & NR & NR & NR \\
\hline Takahashi, M., 2018 202 & $42[21]$ & 6 & NR & NR & NR & NR
\end{tabular}




\section{Complication}

Retinal

Position Related

\section{Other}

NR

14\% pupillary block glaucoma,

$28 \%$ glare and halo's

7\% pigmentary dispersion

NR

NR

$50 \%$ additional laser refractive

correction to correct

astigmatism

NR

$10 \%$ pupillary block glaucoma

NR

$3.47 \%$ retinal detachment

$13.88 \%$ significant opacities,

NR

$0.69 \%$ subluxation needing

exchange, $0.69 \%$ incorrect sizing

needing exchange

\begin{tabular}{|c|c|c|}
\hline NR & $\begin{array}{c}12 \% \geq 10^{\circ} \text { rotation requiring } \\
\text { repositioning, } 8 \% \text { asymptomatic } \\
\text { anterior catatarct }\end{array}$ & NR \\
\hline NR & $\begin{array}{l}\text { 8.8\% repositioning, } 5.8 \% \\
\text { asymptomatic anterior catatarct }\end{array}$ & NR \\
\hline NR & $\begin{array}{l}\text { 9.8\% asymptomatic anterior } \\
\text { cataract }\end{array}$ & $\begin{array}{l}\text { 9.8\% asymptomatic nuclear } \\
\text { cataract }\end{array}$ \\
\hline $\begin{array}{l}1.5 \% \text { choroidal } \\
\text { neovascularisation, } 0.8 \% \\
\text { macular hole, } 0.8 \% \text { central } \\
\text { pigment atrophy }\end{array}$ & $\begin{array}{l}\text { 54.8\% lens opacities, } 12 \% \\
\text { increased IOP requiring } \\
\text { treatment }\end{array}$ & NR \\
\hline NR & $\begin{array}{l}\text { 3.1\% anterior cataract, } 3.1 \% \\
\quad \geq 30^{\circ} \text { rotation }\end{array}$ & $\begin{array}{l}\text { 3.1\% additional laser refractive } \\
\text { correction, }\end{array}$ \\
\hline NR & $0.3 \% \geq 30^{\circ}$ rotation, $0,3 \%$ iritis & $\begin{array}{l}0.3 \% \text { additional laser refractive } \\
\text { correction }\end{array}$ \\
\hline NR & $0.6 \% \geq 30^{\circ}$ rotation & NR \\
\hline NR & $\begin{array}{l}19 \% \text { glare and halo in the early } \\
\text { postoperative period }\end{array}$ & NR \\
\hline
\end{tabular}


Table 3c. Continued.

\begin{tabular}{lcccccc}
\hline & & & & \multicolumn{3}{c}{ Explants (\%) } \\
\cline { 5 - 7 } & $\begin{array}{c}\text { Nr. Eyes } \\
\text { [Nr.pt] }\end{array}$ & $\begin{array}{c}\text { Follow-up } \\
\text { (mo) }\end{array}$ & $\begin{array}{c}\text { Exchange } \\
\text { (\%) }\end{array}$ & Total & Cataract & EC loss \\
\hline Řeháková, T., 2019103 & $63[32]$ & 24 & NR & 3.1 & NR & NR \\
\hline Choi, J., 2019104 & $110[60]$ & 120 & 1.9 & 5.5 & 5.5 & NR
\end{tabular}

\begin{tabular}{llllllll}
\hline Niu, L., 201988 & $51[31]$ & 12 & $N R$ & NR & NR & NR \\
\hline Nakamura, T., $2019^{89}$ & $114[61]$ & 120 & NR & NR & 3.5 & NR
\end{tabular}

\section{IPCL (Toric), CareGroup IOL}

\begin{tabular}{lllllll}
\hline Vasavada, V., 201892 & $30[16]$ & 36 & NR & NR & NR & NR
\end{tabular}

\begin{tabular}{llllllll}
\hline Sachdev, G., $2019^{93}$ & $134[N R]$ & 12 & $N R$ & $N R$ & 0.7 & NR
\end{tabular}

$\mathrm{Mo}=$ months; $\mathrm{ACD}=$ anterior chamber depth; $\mathrm{ECD}=$ endothelial cell density; $\mathrm{EC}=$ endothelial cell; $\mathrm{NR}$

= not reported; $\mathrm{pIOL}=$ phakic intraocular lens; $\mathrm{IOP}=$ intraocular pressure 


\section{Complication}

Retinal

Position Related

\section{Other}

3.1\% explanted due to

$N R$

decentration and acute

glaucoma

$0.9 \%$ rhegmatogenous retinal

detachment

19.1\% lens opacities $(9.1 \%$

NR

anterior subcapsular

opacities), $1.8 \%$ exchange

due to acute glaucoma, $0.9 \%$

pigment dispersion requiring

trabeculectomy

NR $\quad 7.8 \%$ with a small vault due to

$N R$

incorrect haptic placement in

the sulcus

NR

$10.5 \%$ anterior subcapsular

NR

opacities

\section{NR}

3.3\% clinically significant vault

NR

reduction over 3 years, 3.3\%

anterior subcapsular cataract

with good VA untill 3y postop

NR

$2.9 \%$ anterior subcapsular

0.7\% hypopion/TASS

cataract, $0.7 \%$ pupillary block

glaucoma, $4.47 \% \geq 5^{\circ}$ rotation

requiring repositioning 


\section{CORRECTION OF PRESBYOPIA - MULTIFOCAL INTRAOCULAR LENSES}

Presbyopia occurs around the ages of 45-60 when the ageing crystalline lens loses its capacity to accommodate, and the majority of patients will require a reading addition to see clearly at near and/or intermediate distance. Non-surgical correction of presbyopia can be achieved by glasses or contact lenses to suit the majority of presbyopes. ${ }^{2}$ Options include separate glasses for near or multifocal contact lenses or glasses. Also, patients may use contact lenses to create monovision, applying distance correction in the dominant eye, and near correction in the nondominant eye. ${ }^{3}$

Surgical correction of presbyopia encompasses removal of the natural crystalline lens with implantation of a conventional IOL. ${ }^{15}$ Removal of the crystalline lens is regularly performed through a process called phacoemulsification, during which the crystalline lens is fragmentized and removed from its supporting capsular bag, and is replaced by a IOL. Multiple types of IOLS are currently available for implantation in the capsular bag, with variations based on haptic design, IOL material, IOL edge design and optic design. ${ }^{15,20}$ Optic designs can be classified in three main categories: monofocal, multifocal and enhanced depth of focus. ${ }^{3,20}$ All three optic types can also be combined with a "toric" component to correct an astigmatic error at the level of the cornea, to further increase spectacle independence. ${ }^{3,20,118,119}$

Monofocal IOLs focus incoming light on one point, creating spectacle independence for either distance or near vision. This will always require the use of glasses postoperatively. ${ }^{15,20}$

Modern trifocal and quadrifocal multifocal IOLs use a combination of refraction and diffraction to produce clear images at multiple working distances: far (around $4 \mathrm{~m}$ ), near (around $40 \mathrm{~cm}$, reading distance), and at the intermediate distance (around $70 \mathrm{~cm}$, computer distance)., 15, 120 Increased time spent on computer work at an intermediate distance has precluded the need for bifocal multifocal IOLs, designed solely for distance and near vision (Figure 7). ${ }^{121-123}$

The front surface of an IOL is usually convex and the material has a high refractive index, thus converging incoming light to focus on the retina. Unlike monofocal IOLs, the back surface of current multifocal IOLs consist of a series of concentric prism-shaped rings from the center of the IOL to the periphery (Figure 8). This arrangement of grouped circular prisms - with their bases pointing towards the center of the lens - causes diffraction of incoming light, bending it towards the base of each prism, and producing one or more additional focal points in front of the retina. ${ }^{3}$ As such, placing an object at the corresponding distance in front of the eye will result in one of these focal points falling onto the retina, and producing a clear image at the correct working distance (Table 4a-d). 
Decreased spectacle independence is the main benefit of multifocal IOLs, but the light distribution also produces unwanted side-effects. Strongly correlated to the light-dispersing design, these side-effects consist of glare, halo's, loss of contrast sensitivity (requiring additional light in a dimly lit room) and difficulty to cope with the fixed reading distances. ${ }^{120,124-126}$ Optimal functioning of a multifocal IOL also requires a stable tear film, clear optical media between the multifocal IOL and the retina, as well as a healthy retina and optic nerve. Studies have shown that corneal astigmatism of $1.0 \mathrm{D}$ or more significantly decreases the quality of the images at the different focal points. Patients with an expected postoperative corneal astigmatism of 1.0 D or more should be offered a toric (multifocal) IOL, rather than a regular (multifocal) IOL, to optimize visual quality. ${ }^{118,119}$

Extended depth of focus (EDOF) IOLs use a different diffractive pattern, creating a focal range that produces clear images from far to intermediate distance, with a distance dominant focal point (Table 4d). ${ }^{127-129}$ Although anticipated to generate less glare and halo's, less blurred images and a smaller decrease in contrast sensitivity than multifocal IOLs, EDOF lenses have shown to induce these side effects at rates similar to multifocal IOLs. ${ }^{130}$ Furthermore, multifocal IOLs render higher rates of spectacle independence for near vision when both eyes are implanted with a distance dominant multifocal IOL, when compared to EDOF IOLs. ${ }^{121,130,131}$

A third option to decrease spectacle dependence after cataract surgery is monovision, either with monofocal IOLs or with EDOF IOLs. ${ }^{127,132-136}$ The underlying principle of monovision is to facilitate optimal distance correction in the dominant eye, and either optimal near or optimal intermediate correction in the contralateral eye, at the cost of losing some stereopsis. ${ }^{20,133}$ Less commonly, extended depth of focus was produced with multifocal IOLs by combining two bifocal multifocal IOLs, both with an optimal distance correction but with variable near and intermediate correction, to create both a near and intermediate focal point (blended multifocal). ${ }^{134,136-139}$ Monovision with EDOF IOLs is slightly different and requires an EDOF IOL with a distance dominant main focus in the dominant eye, and a slightly intermediate distance focused EDOF $\mathrm{IOL}$ in the contralateral eye. This provides a focal range from far to intermediate distance for the dominant eye, whereas the non-dominant eye provides a focal range from intermediate to near distance. ${ }^{127,135}$

The following chapters describe two studies that were conducted just after the introduction of trifocal multifocal IOLs.

Chapter $\mathbf{8}$ compares visual and refractive outcomes after implantation of either the same bifocal multifocal IOL in both eyes, or a combination of two different bifocal multifocal IOLs to create more focal points and higher rates of spectacle independence (blended multifocal). 
Chapter 9 presents a randomized clinical trial, comparing patients after bilateral implantation with either a bifocal or trifocal multifocal IOL. Visual and refractive outcomes, spectacle independence and visual side effects of multifocal IOLs are reported and compared between groups. 


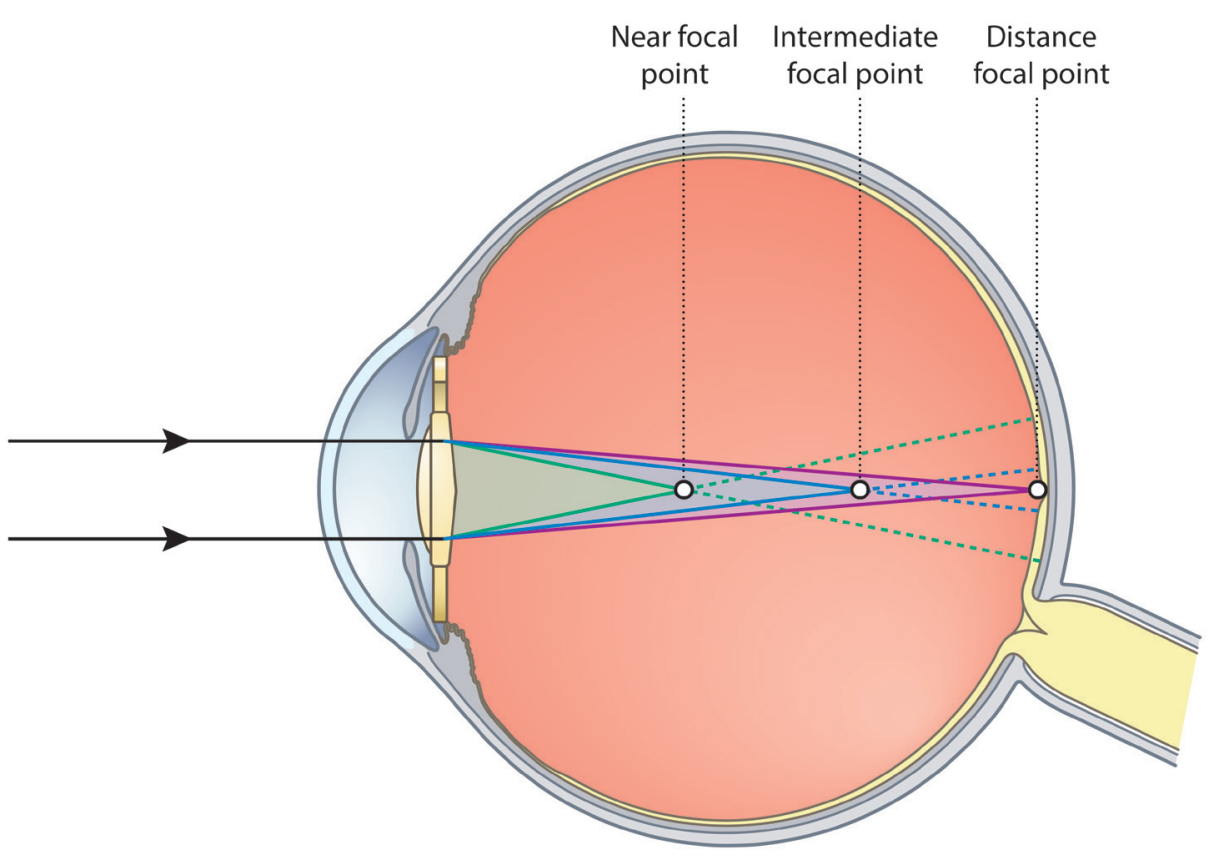

Figure 7. Refractive multifocal (trifocal) intraocular lens with three focal points.

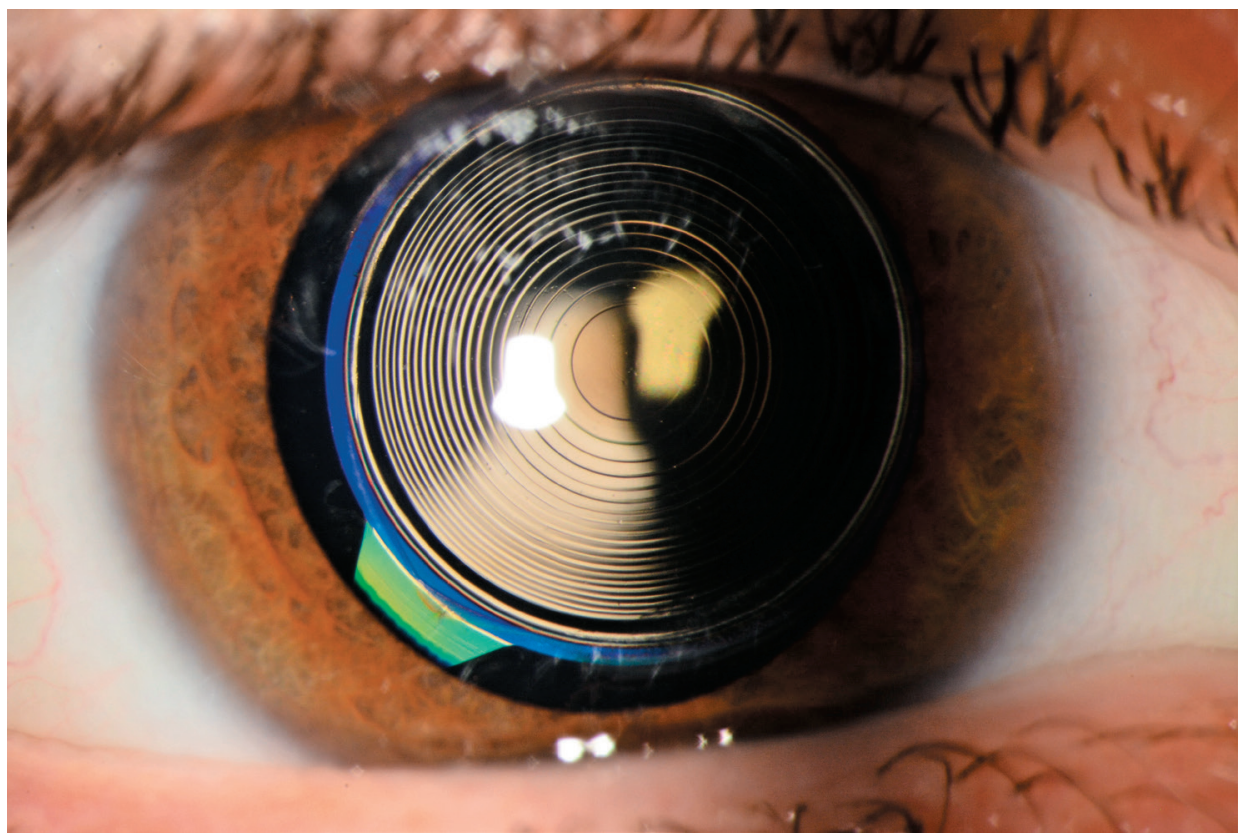

Figure 8. Concentric rings in a multifocal intraocular lens (courtesy of the University Eye Clinic Maastricht, MUMC+) 
Table 4a. Overview of recent papers reporting refractive and visual results after implantation with a FineVision Micro F/Pod F trifocal intraocular lens.



Mo = months; $M R S E$ = manifest refractive spherical equivalent; $D=$ Diopter; $C D V A=$ corrected distance visual acuity; UDVA = uncorrected distance visual acuity; UIVA = uncorrected intermediate visual acuity; UNVA = uncorrected near visual acuity; DCIVA = distance corrected intermediate visual acuity; DCNVA = distance corrected near visual acuity; NR = not reported 


$\begin{array}{llllll}\text { Postop } & \text { Postop } & \text { Postop } & \text { Postop } & \text { Postop } & \text { Postop } \\ \text { UDVA } & \text { UIVA } & \text { UNVA } & \text { CDVA } & \text { DCIVA } & \text { DCNVA }\end{array}$

\begin{tabular}{|c|c|c|c|c|c|c|c|c|c|c|c|}
\hline 离 & 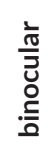 &  & 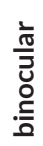 & $\begin{array}{l}\frac{\bar{\sigma}}{\bar{Z}} \\
\frac{0}{0} \\
\frac{0}{0}\end{array}$ & $\frac{\frac{1}{\pi}}{\frac{\pi}{d}}$ & 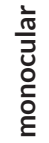 & 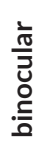 &  & 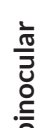 & $\begin{array}{l}\frac{1}{0} \\
\bar{Z} \\
\text { ㅇ } \\
0\end{array}$ & $\begin{array}{l}\frac{1}{\bar{t}} \\
\bar{U} \\
\circ \\
\text { 듬 }\end{array}$ \\
\hline
\end{tabular}

$\begin{array}{llllllllllll}0.08 & 0.02 & 0.08 & 0.05 & 0.01 & 0 & 0.03 & 0 & 0.08 & 0.05 & 0 & -0.01\end{array}$

$\begin{array}{llllllllllll}0.19 & N R & N R & N R & N R & N R & 0.08 & 0.06 & N R & N R & N R & N R\end{array}$

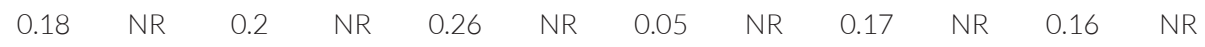

$\begin{array}{llllllllllll}0.06 & -0.04 & 0.05 & 0.1 & 0.11 & 0.02 & 0 & -0.07 & 0.06 & -0.13 & 0.09 & 0.02\end{array}$

$\begin{array}{lllllllllllll}0.01 & 0.01 & 0.08 & 0.06 & 0 & 0 & 0.01 & N R & 0.08 & N R & 0.01 & \text { NR }\end{array}$

$\begin{array}{llllllllllll}0.03 & 0.02 & 0.09 & 0.03 & 0.04 & 0.02 & -0.02 & -0.02 & 0.04 & 0.02 & 0.03 & 0.01\end{array}$

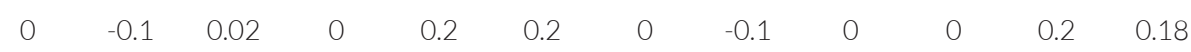

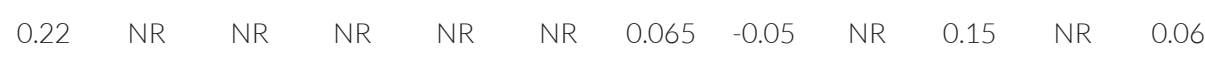

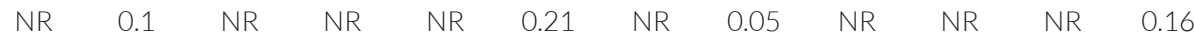

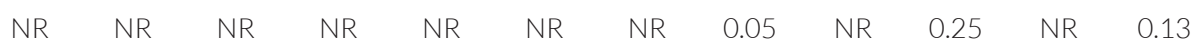

$\begin{array}{llllllllllll}N R & 0.02 & N R & 0.07 & N R & 0.01 & N R & N R & N R & N R & N R & N R\end{array}$

$\begin{array}{llllllllllll}N R & 0.01 & N R & 0.11 & N R & 0.06 & N R & N R & N R & N R & N R & N R\end{array}$

$\begin{array}{llllllllllll}N R & -0.04 & N R & N R & N R & N R & N R & -0.07 & N R & -0.04 & N R & -0.045\end{array}$

$\begin{array}{llllllllllll}0.06 & 0.01 & -0.01 & -0.05 & 0.08 & 0.05 & 0.03 & N R & N R & N R & N R & N R\end{array}$

$\begin{array}{llllllllllll}0.06 & N R & 0.04 & N R & 0.12 & N R & N R & N R & N R & N R & N R & N R\end{array}$

$\begin{array}{llllllllllll}0.19 & N R & 0.15 & N R & 0.17 & N R & 0.03 & N R & 0.19 & N R & 0.17 & N R\end{array}$

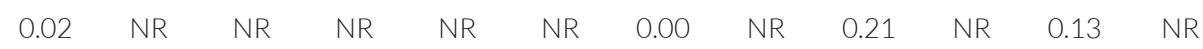

\begin{tabular}{llllllllllll}
0.19 & $N R$ & 0.15 & $N R$ & 0.17 & $N R$ & 0.03 & $N R$ & 0.19 & $N R$ & 0.17 & $N R$ \\
\hline
\end{tabular}

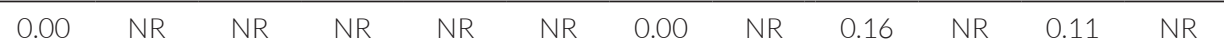

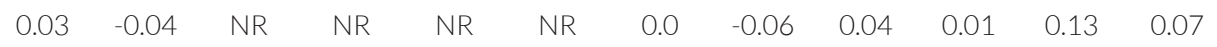

$\begin{array}{llllllllllll}0.04 & -0.01 & 0.09 & 0.04 & 0.04 & 0.02 & -0.01 & -0.02 & 0.05 & 0.02 & 0.03 & 0.00\end{array}$

\begin{tabular}{|c|c|c|c|c|c|c|c|c|c|}
\hline \multicolumn{2}{|l|}{0.0} & & & & & 0.02 & -0.01 & -0.02 & 0.0 \\
\hline
\end{tabular}

All visual acuity is displayed in logarithm of the minimal angle of resolution (logMAR) with 0.0 representing 20/20 vision, and higher numbers reporting a decrease in visual acuity 
Table 4b. Overview of recent papers reporting refractive and visual results after implantation with an AT Lisa Tri 839MP trifocal intraocular lens

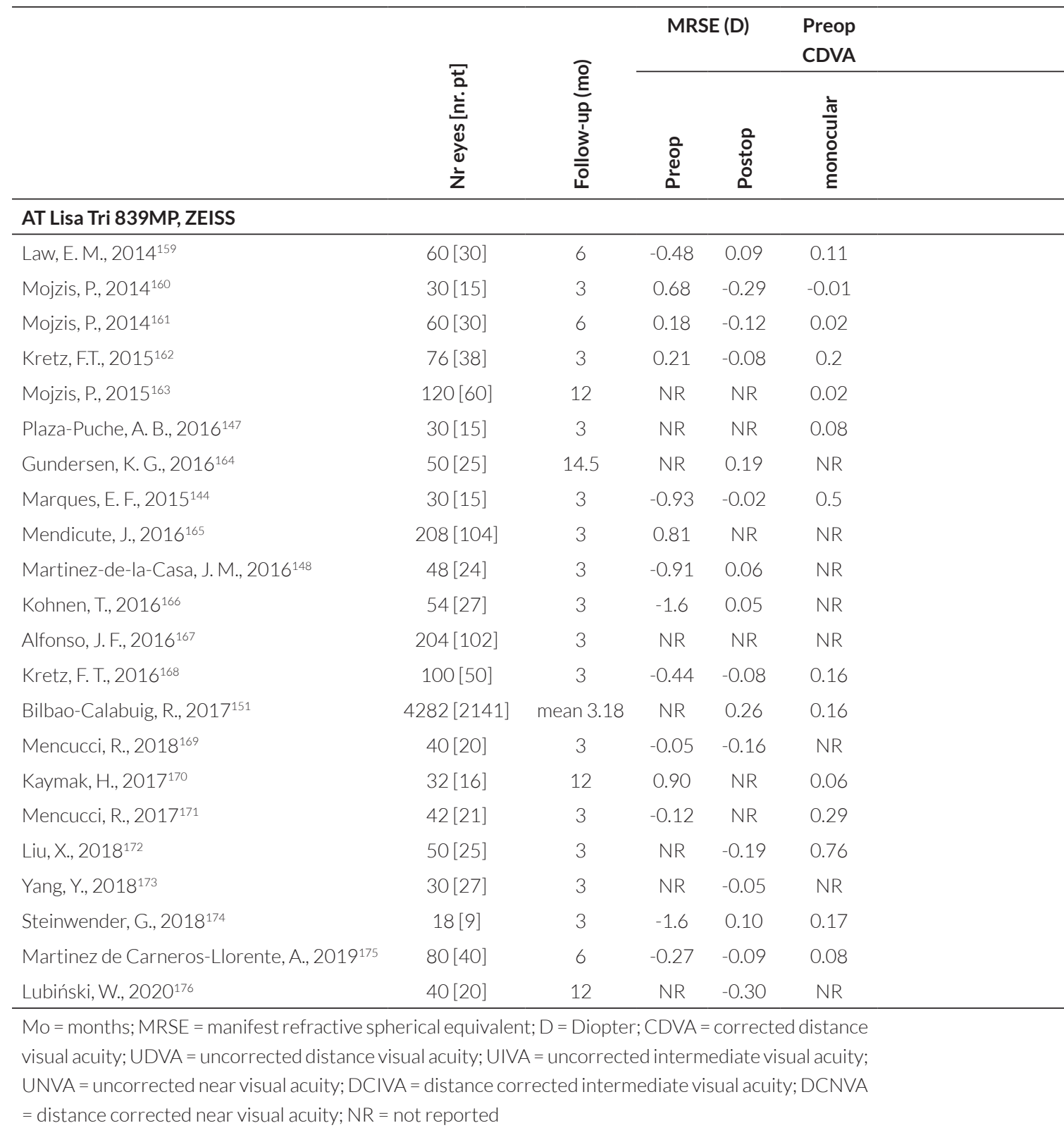




$\begin{array}{llllll}\text { Postop } & \text { Postop } & \text { Postop } & \text { Postop } & \text { Postop } & \text { Postop } \\ \text { UDVA } & \text { UIVA } & \text { UNVA } & \text { CDVA } & \text { DCIVA } & \text { DCNVA }\end{array}$

\begin{tabular}{|c|c|c|c|c|c|c|c|c|c|c|}
\hline $\begin{array}{l}\frac{1}{\bar{c}} \\
\text { 음 }\end{array}$ & 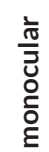 & 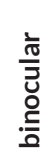 & 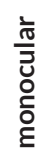 & 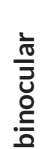 & 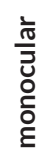 & $\begin{array}{l}\frac{1}{\bar{\sigma}} \\
\frac{\partial}{0} \\
. \frac{0}{0}\end{array}$ & 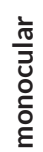 & 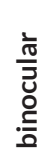 & 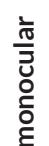 & 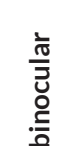 \\
\hline
\end{tabular}

$\begin{array}{llllllllllll}0.05 & N R & N R & N R & N R & 0.16 & -0.02 & -0.06 & N R & 0.16 & N R & N R\end{array}$

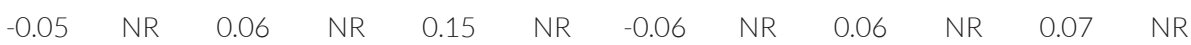

$\begin{array}{llllllllllll}0.03 & N R & 0.08 & N R & 0.2 & N R & 0.05 & N R & 0.08 & N R & 0.17 & N R\end{array}$

$\begin{array}{llllllllllll}0.1 & -0.05 & 0.15 & 0.05 & 0.1 & 0.05 & N R & N R & N R & N R & N R & N R\end{array}$

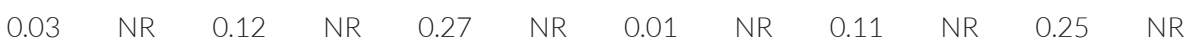

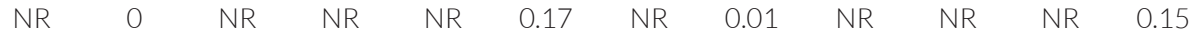

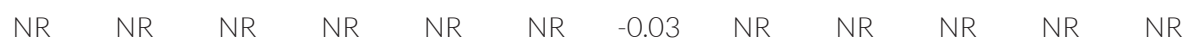

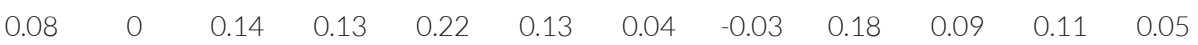

$\begin{array}{llllllllllll}N R & N R & N R & N R & N R & N R & N R & N R & N R & N R & N R & N R\end{array}$

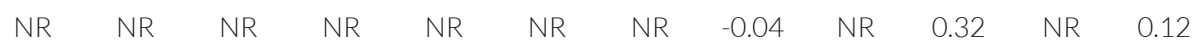

$\begin{array}{llllllllllll}0.01 & -0.06 & 0.06 & 0 & 0.09 & 0.04 & -0.04 & -0.1 & 0.04 & -0.01 & 0.06 & 0.02\end{array}$

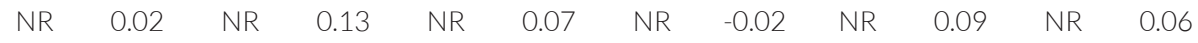

$\begin{array}{llllllllllll}0.06 & 0.04 & 0.09 & 0.04 & 0.06 & 0.01 & 0.04 & 0.04 & N R & N R & N R & N R\end{array}$

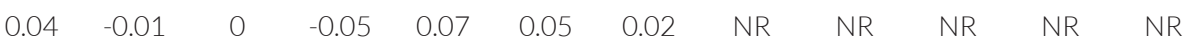

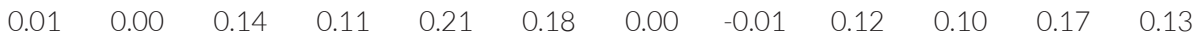

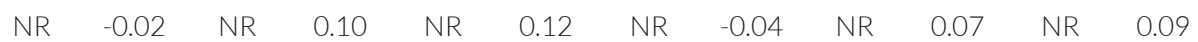

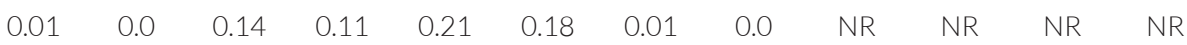

$\begin{array}{llllllllllll}0.02 & N R & 0.08 & N R & 0.11 & N R & -0.04 & N R & 0.06 & N R & 0.07 & N R\end{array}$

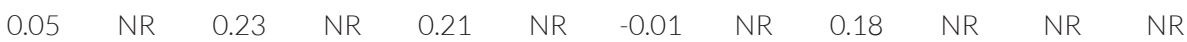

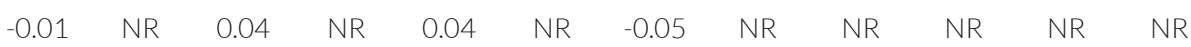



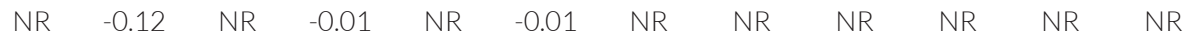

All visual acuity is displayed in logarithm of the minimal angle of resolution (logMAR) with 0.0 representing 20/20 vision, and higher numbers reporting a decrease in visual acuity 
Table 4c. Overview of recent papers reporting refractive and visual results after implantation with an AcrySof IQ PanOptix quadrifocal intraocular lens



Mo = months; $M R S E=$ manifest refractive spherical equivalent; $D=$ Diopter $;$ CDVA = corrected distance visual acuity; UDVA = uncorrected distance visual acuity; UIVA = uncorrected intermediate visual acuity; UNVA = uncorrected near visual acuity; DCIVA = distance corrected intermediate visual acuity; DCNVA

= distance corrected near visual acuity; NR = not reported 


$\begin{array}{llllll}\text { Postop } & \text { Postop } & \text { Postop } & \text { Postop } & \text { Postop } & \text { Postop } \\ \text { UDVA } & \text { UIVA } & \text { UNVA } & \text { CDVA } & \text { DCIVA } & \text { DCNVA }\end{array}$

\begin{tabular}{|c|c|c|c|c|c|c|c|c|c|c|c|}
\hline $\begin{array}{l}\frac{1}{\pi} \\
\frac{\bar{J}}{\partial} \\
\frac{0}{0}\end{array}$ & 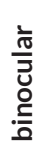 &  & $\begin{array}{l}\frac{1}{3} \\
\frac{1}{2} \\
\frac{0}{0}\end{array}$ & $\begin{array}{l}\frac{1}{J} \\
\frac{\pi}{J} \\
\text { ㅇ } \\
\text { ㅇ }\end{array}$ & $\begin{array}{l}\frac{1}{\bar{t}} \\
\frac{\mathrm{U}}{\mathrm{O}} \\
.\end{array}$ & 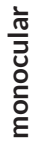 & 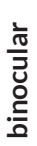 & 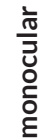 & 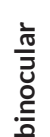 & 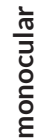 & 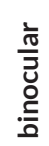 \\
\hline
\end{tabular}

\begin{tabular}{|c|c|c|c|c|c|c|c|c|c|c|c|}
\hline 0.01 & JR & .14 & NR & -0.03 & NR & 0.01 & NR & NR & NR & NR & NR \\
\hline NA & 0.03 & NA & 0.12 & NA & 0.02 & 政 & NR & NA & NR & JA & NR \\
\hline NR & -0.05 & TNR & NR & NR & NR & INR & -0.08 & NR & -0.09 & $\mathrm{NR}$ & -0.07 \\
\hline 0.01 & NR & 0.30 & NR & NR & NR & NR & NR & NR & NR & NR & NR \\
\hline .00 & NR & 0.23 & $N R$ & .02 & NR & -0.01 & NR & 0.13 & $A R$ & 0.01 & NR \\
\hline .04 & 0.0 & 0.06 & 0.02 & 0.06 & 0.01 & -0.05 & -0.07 & 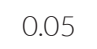 & 0.01 & 0.05 & 0.03 \\
\hline .07 & NR & 0.12 & INR & 0.16 & NR & 0.01 & NR & 0.12 & TNK & 0.13 & NR \\
\hline 0.01 & -0.02 & 0.11 & 0.07 & 0.17 & 0.15 & -0.01 & -0.03 & 0.10 & 0.06 & 0.104 & 0.12 \\
\hline$N R$ & 0.05 & NR & 0.11 & NR & 0.09 & NR & NR & $\mathrm{NF}$ & $N R$ & $\mathrm{NF}$ & NR \\
\hline 07 & $N$ & N & N & NR & N & $-c$ & $\mathrm{~N}$ & $\wedge$ & N & 0. & NR \\
\hline 0.10 & NR & 0.07 & NR & 0.05 & NR & 0.04 & NR & NR & NR & 0.02 & NR \\
\hline NR & 0.03 & $N R$ & 0.20 & NR & 0.23 & $N R$ & $N R$ & $N R$ & $N R$ & $N R$ & NR \\
\hline$N R$ & $N R$ & $N R$ & NR & NR & NR & -0.014 & -0.062 & 0.070 & -0.007 & 0.105 & 0.050 \\
\hline 22 & NR & -0.02 & $N R$ & 0.12 & NR & -0.08 & NR & 0.10 & $N R$ & 0.14 & NR \\
\hline 5 & -0.02 & 0.11 & 0.06 & 0.05 & 0.03 & -0.01 & -0.01 & 0.05 & 0.01 & 0.02 & 0.00 \\
\hline
\end{tabular}

All visual acuity is displayed in logarithm of the minimal angle of resolution (logMAR) with 0.0 representing 20/20 vision, and higher numbers reporting a decrease in visual acuity 
Table 4d. Overview of recent papers reporting refractive and visual results after implantation with a TECNIS Symfony extended depth of focus intraocular lens

\begin{tabular}{|c|c|c|c|c|c|}
\hline & \multirow[b]{2}{*}{ 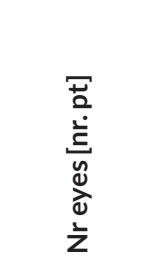 } & \multirow[b]{2}{*}{ 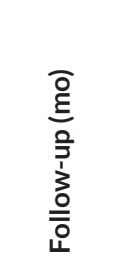 } & \multicolumn{2}{|c|}{ MRSE (D) } & $\begin{array}{l}\text { Preop } \\
\text { CDVA }\end{array}$ \\
\hline & & & $\begin{array}{l}\text { 웜 } \\
\text { 는 }\end{array}$ & 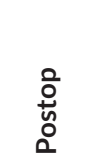 & 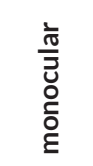 \\
\hline \multicolumn{6}{|c|}{ TECNIS Symfony, Johnson \& Johnson } \\
\hline Cochener, B., $2016^{127}$ & $224[112]^{\#}$ & mean 5 & -0.03 & -0.21 & NR \\
\hline Cochener, B., $2016^{127}$ & 598 [299] & mean 5 & 0.43 & -0.3 & NR \\
\hline Pedrotti, E., $2016^{185}$ & $50[25]$ & 3 & NR & -0.27 & NR \\
\hline Ruiz-Mesa, R., $2017^{149}$ & $40[20]$ & 12 & NR & -0.19 & 0.03 \\
\hline Monaco, G., $2017^{130}$ & $40[20]$ & 4 & NR & -0.23 & 0.40 \\
\hline Mencucci, R., $2018^{169}$ & $40[20]$ & 3 & -0.21 & -0.13 & NR \\
\hline Ganesh, S., $2018^{135}$ & $50[25]^{\#}$ & 6 & 0.92 & -0.22 & NR \\
\hline Pedrotti, E., $2018^{186}$ & $110[55]$ & 6 & 0.13 & -0.08 & 0.37 \\
\hline Pilger, D., $2018^{187}$ & $30[15]$ & 3 & NR & -1.03 & 0.43 \\
\hline Lubiński, W., 2020176 & $40[20]$ & 12 & NR & -0.45 & NR \\
\hline Paik, D. W., 2020 ${ }^{188}$ & $40[20]$ & 3 & -1.06 & NR & 0.35 \\
\hline Farvardin, M.,2020182 & $40[20]$ & mean 11 & NR & -0.29 & NR \\
\hline Pedrotti, E., 2020184 & $50[25]$ & 3 & -0.45 & -0.02 & NR \\
\hline Song, X., 2020189 & $47[34]$ & 3 & NR & -0.21 & NR \\
\hline
\end{tabular}

$\mathrm{Mo}=$ months; $\mathrm{MRSE}=$ manifest refractive spherical equivalent; $\mathrm{D}=$ Diopter; $C D V A=$ corrected distance visual acuity; UDVA = uncorrected distance visual acuity; UIVA = uncorrected intermediate visual acuity; UNVA = uncorrected near visual acuity; DCIVA = distance corrected intermediate visual acuity; DCNVA = distance corrected near visual acuity; NR = not reported 


$\begin{array}{llllll}\text { Postop } & \text { Postop } & \text { Postop } & \text { Postop } & \text { Postop } & \text { Postop } \\ \text { UDVA } & \text { UIVA } & \text { UNVA } & \text { CDVA } & \text { DCIVA } & \text { DCNVA }\end{array}$

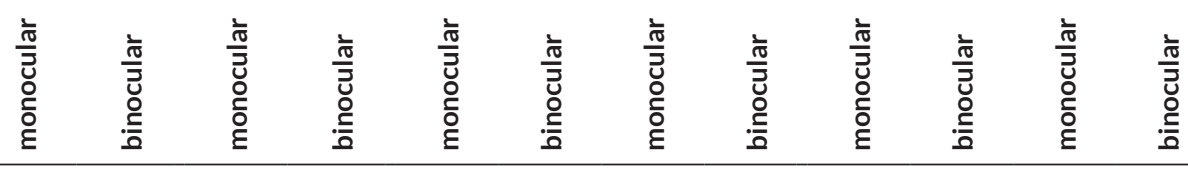

\begin{tabular}{|c|c|c|c|c|c|c|c|c|c|c|c|}
\hline NR & 0.04 & NR & 0.09 & NR & 0.17 & NR & -0.02 & $N R$ & NR & NR & NR \\
\hline NR & 0.03 & NR & 0.13 & NR & 0.21 & NR & -0.02 & NR & NR & NR & NR \\
\hline 08 & 0 & 0.24 & 0.1 & 0.27 & 0.18 & -0.04 & -0.08 & 0.19 & 0.1 & 0.33 & 0.21 \\
\hline $\mathrm{D}$ & 0.01 & NR & 0.09 & NR & 0.17 & NR & NR & NR & NR & NR & NR \\
\hline 03 & $N R$ & 0.27 & NR & 0.07 & NR & -0.01 & NR & 0.27 & NR & 0.07 & $N R$ \\
\hline 01 & -0.04 & -0.02 & 0.07 & 0.38 & 0.25 & -0.02 & -0.05 & 0.11 & 0.06 & 0.30 & 0.20 \\
\hline NR & -0.036 & NR & -0.044 & NR & 0.15 & NR & -0.11 & $N R$ & 0.012 & JR & 0.22 \\
\hline NR & -0.04 & NR & 0.05 & NR & 0.18 & NR & -0.08 & NR & 0.05 & NR & -0.04 \\
\hline .03 & -0.02 & -0.08 & -0.13 & 0.17 & 0.11 & 0.02 & -0.03 & 0.05 & -0.01 & 0.33 & 0.27 \\
\hline$N R$ & 0.08 & NR & 0.09 & NR & 0.21 & NR & NR & $N R$ & NR & NR & NR \\
\hline NR & -0.10 & $N R$ & 0.06 & NR & 0.14 & NR & -0.10 & $N R$ & NR & NR & $N R$ \\
\hline NR & 0.04 & NR & 0.23 & NR & 0.52 & NR & NR & $N R$ & NR & $N R$ & $N R$ \\
\hline مחم & NR & 0.10 & NR & 0.26 & $N R$ & -0.09 & NR & 0.07 & NR & 0.26 & $N R$ \\
\hline & NR & 0.14 & NR & 0.34 & NR & -0.01 & NR & 0.11 & NR & 0.37 & NR \\
\hline
\end{tabular}

All visual acuity is displayed in logarithm of the minimal angle of resolution (logMAR) with 0.0 representing 20/20 vision, and higher numbers reporting a decrease in visual acuity

\#(mini-)monovision 


\section{REFERENCES}

1. (NGRC) NGVRC. [Gecertificeerde Refractiechirurgen per Oktober 2020]. Nederlands Gezelschap voor Refractie Chirurgie (NGRC), 2020; v. 2021.

2. Remington LA. Clinical Anatomy and Physiology of the Visual System. St. Louis, Missouri, United States of America: Elsevier Butterworth Heinemann, 2012.

3. Azar DT, Azar NF, Brodie SE, et al. Clinical Optics. United States of America: American Academy of Ophthalmology, 2017.

4. Jick SL, Beardsley TL, Brasington CR, et al. Lens and Cataract. United States of America: American Academy of Ophthalmology, 2018.

5. WHO. The Impact of Myopia and High Myopia. World Health Organization Brien Holden Vision Institute, 2017.

6. Holden BA, Fricke TR, Wilson DA, et al. Global Prevalence of Myopia and High Myopia and Temporal Trends from 2000 through 2050. Ophthalmology 2016;123(5):1036-42.

7. Morgan IG, He M, Rose KA. EPIDEMIC OF PATHOLOGIC MYOPIA: What Can Laboratory Studies and Epidemiology Tell Us? Retina 2017;37(5):989-97.

8. Huang J, Wen D, Wang Q, et al. Efficacy Comparison of 16 Interventions for Myopia Control in Children: A Network Meta-analysis. Ophthalmology 2016;123(4):697-708.

9. Tideman JW, Snabel MC, Tedja MS, et al. Association of Axial Length With Risk of Uncorrectable Visual Impairment for Europeans With Myopia. JAMA Ophthalmol 2016;134(12):1355-63.

10. Tideman JW, Polling JR, Voortman T, et al. Low serum vitamin $D$ is associated with axial length and risk of myopia in young children. Eur J Epidemiol 2016;31(5):491-9.

11. Zhu Q, Liu Y, Tighe S, et al. Retardation of Myopia Progression by Multifocal Soft Contact Lenses. Int J Med Sci 2019;16(2):198-202.

12. Sun Y, Xu F, Zhang T, et al. Orthokeratology to control myopia progression: a meta-analysis. PLoS One 2015;10(4):e0124535.

13. Liu HY, Chu HS, Wang IJ, et al. Microbial Keratitis in Taiwan: A 20-Year update. Am J Ophthalmol 2019.

14. Kam KW, Yung W, Li GKH, et al. Infectious keratitis and orthokeratology lens use: a systematic review. Infection 2017;45(6):727-35.

15. Bowling B. Kanski's Clinical Ophthalmology. China: Elsevier, 2016.

16. Aalders-Deenstra V, Bartels M, Beerthuizen J, et al. Consensus Refractie Chirurgie. 3 ed: Nederlands Gezelschap voor Refractie Chirurgie (NGRC), 2013.

17. Bjerrum SS, Mikkelsen KL, La Cour M. Risk of pseudophakic retinal detachment in 202,226 patients using the fellow nonoperated eye as reference. Ophthalmology 2013;120(12):2573-9.

18. Guell JL, Morral M, Kook D, Kohnen T. Phakic intraocular lenses part 1: historical overview, current models, selection criteria, and surgical techniques. J Cataract Refract Surg 2010;36(11):1976-93.

19. Kohnen T, Kook D, Morral M, Guell JL. Phakic intraocular lenses: part 2: results and complications. J Cataract Refract Surg 2010;36(12):2168-94.

20. Bowes Hamill M, Berdy GJ, Davidson RS, et al. Refractive Surgery. United States of America: American Academy of Ophthalmology, 2017.

21. Kohnen T, Maxwell WA, Holland S. Correction of Moderate to High Myopia with a Foldable, Angle-Supported Phakic Intraocular Lens: Results from a 5-Year Open-Label Trial. Ophthalmology 2016;123(5):1027-35.

22. At the forefront of the $\mathrm{IOL}$ revolution. Cornelius D. Binkhorst, MD. J Cataract Refract Surg 1997;23(3):306-7. 
23. Alpar JJ. Professor Jan Gerben Frans Worst. J Cataract Refract Surg 2016;42(6):809.

24. Perez-Cambrodi RJ, Pinero DP, Ferrer-Blasco T, et al. The posterior chamber phakic refractive lens (PRL): a review. Eye (Lond) 2013;27(1):14-21.

25. Kohnen T, Knorz MC, Cochener B, et al. AcrySof phakic angle-supported intraocular lens for the correction of moderate-to-high myopia: one-year results of a multicenter European study. Ophthalmology 2009;116(7):1314-21, 21.e1-3.

26. Knorz MC, Lane SS, Holland SP. Angle-supported phakic intraocular lens for correction of moderate to high myopia: Three-year interim results in international multicenter studies. J Cataract Refract Surg 2011;37(3):469-80.

27. Mastropasqua L, Toto L, Vecchiarino L, et al. AcrySof cachet phakic intraocular lens in myopic patients: visual performance, wavefront error, and lens position. J Refract Surg 2012;28(4):267-74.

28. Yang RB, Zhao SZ. AcrySof phakic angle-supported intraocular lens for the correction of high to extremely high myopia: one-year follow-up results. Int J Ophthalmol 2012;5(3):360-5.

29. Kermani O, Oberheide U, Gerten G. Rotation stability of the cachet angle-supported phakic intraocular lens. J Refract Surg 2013;29(6):390-4.

30. Taneri S, Oehler S, Heinz C. Inflammatory response in the anterior chamber after implantation of an angle-supported lens in phakic myopic eyes. J Ophthalmol 2014;2014:923691.

31. Gimbel HV, Norton NR, Amritanand A. Angle-supported phakic intraocular lenses for the correction of myopia: Three-year follow-up. J Cataract Refract Surg 2015;41(10):2179-89.

32. Alio JL, Plaza-Puche AB, Cavas F, et al. An angle-supported foldable phakic intraocular lens for correction of myopia: A five-year follow-up. Arch Soc Esp Oftalmol 2017;92(1):4-11.

33. Al-Qahtani S, Al-Afraj K, Al-Jindan M, et al. Short and long-term outcomes of angle supported phakic intraocular lens implantation in high myopic eyes. Int J Ophthalmol 2018;11(5):888-90.

34. Budo C, Hessloehl JC, Izak M, et al. Multicenter study of the Artisan phakic intraocular lens. J Cataract Refract Surg 2000;26(8):1163-71.

35. Dick HB, Alio J, Bianchetti M, et al. Toric phakic intraocular lens: European multicenter study. Ophthalmology 2003;110(1):150-62.

36. Asano-Kato N, Toda I, Hori-Komai Y, et al. Experience with the Artisan phakic intraocular lens in Asian eyes. J Cataract Refract Surg 2005;31(5):910-5.

37. Bartels MC, Saxena R, van den Berg TJ, et al. The influence of incision-induced astigmatism and axial lens position on the correction of myopic astigmatism with the Artisan toric phakic intraocular lens. Ophthalmology 2006;113(7):1110-7.

38. Coullet J, Guell JL, Fournie P, et al. Iris-supported phakic lenses (rigid vs foldable version) for treating moderately high myopia: randomized paired eye comparison. Am J Ophthalmol 2006;142(6):909-16.

39. Tahzib NG, Bootsma SJ, Eggink FA, Nuijts RM. Functional outcome and patient satisfaction after Artisan phakic intraocular lens implantation for the correction of myopia. Am J Ophthalmol 2006;142(1):31-9.

40. Gierek-Ciaciura S, Gierek-Lapinska A, Ochalik K, Mrukwa-Kominek E. Correction of high myopia with different phakic anterior chamber intraocular lenses: ICARE angle-supported lens and Verisyse irisclaw lens. Graefes Arch Clin Exp Ophthalmol 2007;245(1):1-7.

41. Moshirfar M, Holz HA, Davis DK. Two-year follow-up of the Artisan/Verisyse iris-supported phakic intraocular lens for the correction of high myopia. J Cataract Refract Surg 2007;33(8):1392-7.

42. Tahzib NG, Nuijts RM, Wu WY, Budo CJ. Long-term study of Artisan phakic intraocular lens implantation for the correction of moderate to high myopia: ten-year follow-up results. Ophthalmology 2007;114(6):1133-42.

43. Guell JL, Morral M, Gris O, et al. Five-year follow-up of 399 phakic Artisan-Verisyse implantation for myopia, hyperopia, and/or astigmatism. Ophthalmology 2008;115(6):1002-12. 
44. Silva RA, Jain A, Manche EE. Prospective long-term evaluation of the efficacy, safety, and stability of the phakic intraocular lens for high myopia. Arch Ophthalmol 2008;126(6):775-81.

45. Stulting RD, John ME, Maloney RK, et al. Three-year results of Artisan/Verisyse phakic intraocular lens implantation. Results of the United States Food And Drug Administration clinical trial. Ophthalmology 2008;115(3):464-72.e1.

46. Tahzib NG, MacRae SM, Yoon G, et al. Higher-order aberrations after implantation of iris-fixated rigid or foldable phakic intraocular lenses. J Cataract Refract Surg 2008;34(11):1913-20.

47. Qasem Q, Kirwan C, O'Keefe M. 5-year prospective follow-up of Artisan phakic intraocular lenses for the correction of myopia, hyperopia and astigmatism. Ophthalmologica 2010;224(5):283-90.

48. Hassaballa MA, Macky TA. Phakic intraocular lenses outcomes and complications: Artisan vs Visian ICL. Eye (Lond) 2011;25(10):1365-70.

49. Titiyal JS, Sharma N, Mannan R, et al. Iris-fixated intraocular lens implantation to correct moderate to high myopia in Asian-Indian eyes: five-year results. J Cataract Refract Surg 2012;38(8):1446-52.

50. Yuan X, Ping HZ, Hong WC, et al. Five-year follow-up after anterior iris-fixated intraocular lens implantation in phakic eyes to correct high myopia. Eye (Lond) 2012;26(2):321-6.

51. Tehrani M, Dick HB. Iris-fixated toric phakic intraocular lens: Three-year follow-up. J Cataract Refract Surg 2006;32(8):1301-6.

52. Guell JL, Vazquez M, Malecaze F, et al. Artisan toric phakic intraocular lens for the correction of high astigmatism. Am J Ophthalmol 2003;136(3):442-7.

53. Dick HB, Budo C, Malecaze F, et al. Foldable Artiflex phakic intraocular lens for the correction of myopia: two-year follow-up results of a prospective European multicenter study. Ophthalmology 2009;116(4):671-7.

54. Doors M, Budo CJ, Christiaans BJ, et al. Artiflex Toric foldable phakic intraocular lens: short-term results of a prospective European multicenter study. Am J Ophthalmol 2012;154(4):730-9.e2.

55. Munoz G, Cardoner A, Albarran-Diego C, et al. Iris-fixated toric phakic intraocular lens for myopic astigmatism. J Cataract Refract Surg 2012;38(7):1166-75.

56. Ozerturk Y, Kubaloglu A, Sari ES, et al. Foldable iris-fixated phakic intraocular lens implantation for the correction of myopia: two years of follow-up. Indian J Ophthalmol 2012;60(1):23-8.

57. Ruckhofer J, Seyeddain O, Dexl AK, et al. Correction of myopic astigmatism with a foldable iris-claw toric phakic intraocular lens: short-term follow-up. J Cataract Refract Surg 2012;38(4):582-8.

58. Ghoreishi M, Kashfi A, Peyman M, Mohammadinia M. Comparison of Toric Implantable Collamer Lens and Toric Artiflex Phakic IOLs in terms of Visual Outcome, A paired Contralateral Eye Study. Am J Ophthalmol 2020.

59. Hoyos JE, Dementiev DD, Cigales M, et al. Phakic refractive lens experience in Spain. J Cataract Refract Surg 2002;28(11):1939-46.

60. Pallikaris IG, Kalyvianaki MI, Kymionis GD, Panagopoulou SI. Phakic refractive lens implantation in high myopic patients: one-year results. J Cataract Refract Surg 2004;30(6):1190-7.

61. Koivula A, Petrelius A, Zetterstrom C. Clinical outcomes of phakic refractive lens in myopic and hyperopic eyes: 1-year results. J Cataract Refract Surg 2005;31(6):1145-52.

62. Donoso R, Castillo P. Correction of high myopia with the PRL phakic intraocular lens. J Cataract Refract Surg 2006;32(8):1296-300.

63. Jongsareejit A. Clinical results with the medennium phakic refractive lens for the correction of high myopia. J Refract Surg 2006;22(9):890-7.

64. Verde CM, Teus MA, Arranz-Marquez E, Cazorla RG. Medennium posterior chamber phakic refractive lens to correct high myopia. J Refract Surg 2007;23(9):900-4. 
65. Portaliou DM, Kymionis GD, Panagopoulou SI, et al. Long-term results of phakic refractive lens implantation in eyes with high myopia. J Refract Surg 2011;27(11):787-91.

66. Perez-Cambrodi RJ, Pinero DP, Madrid-Costa D, et al. Medium-term visual, refractive, and intraocular stability after implantation of a posterior chamber phakic intraocular lens to correct moderate to high myopia. J Cataract Refract Surg 2011;37(10):1791-8.

67. Torun N, Bertelmann E, Klamann MK, et al. Posterior chamber phakic intraocular lens to correct myopia: long-term follow-up. J Cataract Refract Surg 2013;39(7):1023-8.

68. Gil-Cazorla R, Teus MA, Arranz-Marquez E, Marina-Verde C. Phakic refractive lens (Medennium) for correction of +4.00 to +6.00 diopters: 1 -year follow-up. J Refract Surg 2008;24(4):350-4.

69. Koivula A, Zetterstrom C. Phakic intraocular lens for the correction of hyperopia. J Cataract Refract Surg 2009;35(2):248-55.

70. Kamiya K, Shimizu K, Kobashi H, et al. Three-year follow-up of posterior chamber toric phakic intraocular lens implantation for moderate to high myopic astigmatism. PLoS One 2013;8(2):e56453.

71. Sari ES, Pinero DP, Kubaloglu A, et al. Toric implantable collamer lens for moderate to high myopic astigmatism: 3-year follow-up. Graefes Arch Clin Exp Ophthalmol 2013;251(5):1413-22.

72. Alfonso JF, Lisa C, Alfonso-Bartolozzi B, et al. Collagen copolymer toric phakic intraocular lens for myopic astigmatism: one-year follow-up. J Cataract Refract Surg 2014;40(7):1155-62.

73. Igarashi A, Shimizu K, Kamiya K. Eight-year follow-up of posterior chamber phakic intraocular lens implantation for moderate to high myopia. Am J Ophthalmol 2014;157(3):532-9.e1.

74. Guber I, Mouvet V, Bergin C, et al. Clinical Outcomes and Cataract Formation Rates in Eyes 10 Years After Posterior Phakic Lens Implantation for Myopia. JAMA Ophthalmol 2016.

75. Shimizu K, Kamiya K, Igarashi A, Kobashi H. Long-Term Comparison of Posterior Chamber Phakic Intraocular Lens With and Without a Central Hole (Hole ICL and Conventional ICL) Implantation for Moderate to High Myopia and Myopic Astigmatism: Consort-Compliant Article. Medicine (Baltimore) 2016;95(14):e3270.

76. Shimizu K, Kamiya K, Igarashi A, Shiratani T. Early clinical outcomes of implantation of posterior chamber phakic intraocular lens with a central hole (Hole ICL) for moderate to high myopia. Br J Ophthalmol 2012;96(3):409-12.

77. Kamiya K, Takahashi M, Takahashi N, et al. Monovision by Implantation of Posterior Chamber Phakic Intraocular Lens with a Central Hole (Hole ICL) for Early Presbyopia. Sci Rep 2017;7(1):11302.

78. Kamiya K, Shimizu K, Igarashi A, et al. Posterior chamber phakic intraocular lens implantation: comparative, multicentre study in 351 eyes with low-to-moderate or high myopia. Br J Ophthalmol 2017.

79. Pjano MA, Pidro A, Biscevic A, et al. Refractive Outcomes of Posterior Chamber Phakic Intraocular Lens Implantation for Correction of Myopia and Myopic Astigmatism. Med Arch 2017;71(2):93-6.

80. Kamiya K, Shimizu K, Igarashi A, et al. Posterior Chamber Phakic Intraocular Lens Implantation in Eyes with an Anterior Chamber Depth of Less Than 3 mm: A Multicenter Study. Sci Rep 2018;8(1):13322.

81. Miao H, Chen X, Tian M, et al. Refractive outcomes and optical quality after implantation of posterior chamber phakic implantable collamer lens with a central hole (ICL V4c). BMC Ophthalmol 2018;18(1):141.

82. Takahashi M, Kamiya K, Shoji N, et al. Intentional Undercorrection by Implantation of Posterior Chamber Phakic Intraocular Lens With A Central Hole (Hole ICL) For Early Presbyopia. Biomed Res Int 2018;2018:6158520.

83. Alfonso JF, Fernandez-Vega-Cueto L, Alfonso-Bartolozzi B, et al. Five-Year Follow-up of Correction of Myopia: Posterior Chamber Phakic Intraocular Lens With a Central Port Design. J Refract Surg 2019;35(3):169-76. 
84. Ghoreishi M, Abdi-Shahshahani M, Peyman A, Pourazizi M. A model for predicting sulcus-to-sulcus diameter in posterior chamber phakic intraocular lens candidates: correlation between ocular biometric parameters. Int Ophthalmol 2019;39(3):661-6.

85. Jadidi K, Mosavi SA, Nejat F, et al. Use of low-vault posterior chamber collagen copolymer phakic intraocular lenses for the correction of myopia: a 3-year follow-up. Graefes Arch Clin Exp Ophthalmol 2019;257(7):1555-60.

86. Qin Q, Wu Z, Bao L, et al. Evaluation of visual quality after EVO-ICL implantation for hypermyopia: An observational study. Medicine (Baltimore) 2019;98(44):e17677.

87. Igarashi A, Shimizu K, Kato S, Kamiya K. Predictability of the vault after posterior chamber phakic intraocular lens implantation using anterior segment optical coherence tomography. J Cataract Refract Surg 2019;45(8):1099-104.

88. Niu L, Miao H, Han T, et al. Visual outcomes of Visian ICL implantation for high myopia in patients with shallow anterior chamber depth. BMC Ophthalmol 2019;19(1):121.

89. Nakamura T, Isogai N, Kojima T, et al. Posterior Chamber Phakic Intraocular Lens Implantation for the Correction of Myopia and Myopic Astigmatism: A Retrospective 10-Year Follow-up Study. Am J Ophthalmol 2019;206:1-10.

90. Yu Z, Li J, Song H. Short-time evaluation on intraocular scattering after implantable collamer lens implantation for correcting high myopia. BMC Ophthalmol 2020;20(1):235.

91. Moya T, Javaloy J, Montes-Mico R, et al. Implantable Collamer Lens for Myopia: Assessment 12 Years After Implantation. J Refract Surg 2015;31(8):548-56.

92. Vasavada V, Srivastava S, Vasavada SA, et al. Safety and Efficacy of a New Phakic Posterior Chamber IOL for Correction of Myopia: 3 Years of Follow-up. J Refract Surg 2018;34(12):817-23.

93. Sachdev G, Ramamurthy D. Long-term safety of posterior chamber implantable phakic contact lens for the correction of myopia. Clin Ophthalmol 2019;13:137-42.

94. Yasa D, Urdem U, Agca A, et al. Early Results with a New Posterior Chamber Phakic Intraocular Lens in Patients with High Myopia. J Ophthalmol 2018;2018:1329874.

95. Yaşa D, Köse B, Ağca A. Rotational Stability of a New Posterior Chamber Toric Phakic Intraocular Lens. J Ophthalmol 2020;2020:1624632.

96. Pop M, Payette Y. Initial results of endothelial cell counts after Artisan lens for phakic eyes: an evaluation of the United States Food and Drug Administration Ophtec Study. Ophthalmology 2004;111(2):30917.

97. Benedetti S, Casamenti V, Benedetti M. Long-term endothelial changes in phakic eyes after Artisan intraocular lens implantation to correct myopia: five-year study. J Cataract Refract Surg 2007;33(5):784-90.

98. Yamaguchi T, Negishi K, Yuki K, et al. Alterations in the anterior chamber angle after implantation of iris-fixated phakic intraocular lenses. J Cataract Refract Surg 2008;34(8):1300-5.

99. Eldanasoury AM, Roozbahani M, Tolees S, Arana C. Long-Term Effect of Anterior Chamber Depth on Endothelial Cell Density in Patients With Iris-Fixated Phakic Intraocular Lenses. J Refract Surg 2019;35(8):493-500.

100. Galvis V, Villamil JF, Acuña MF, et al. Long-term endothelial cell loss with the iris-claw intraocular phakic lenses (Artisanß). Graefes Arch Clin Exp Ophthalmol 2019;257(12):2775-87.

101. Shaaban YM, Badran TAF. Three-Year Effect of Phakic Intraocular Lenses on the Corneal Endothelial Cell Density. Clin Ophthalmol 2020;14:149-55.

102. Goukon H, Kamiya K, Shimizu K, Igarashi A. Comparison of corneal endothelial cell density and morphology after posterior chamber phakic intraocular lens implantation with and without a central hole. Br J Ophthalmol 2017. 
103. Řeháková T, Veliká V, Rozsíval P, Jirásková N. Correction of Myopia and Myopic Astigmatism by Implantation of a Phakic Posterior Chamber Implantable Collamer Lens. Cesk Slov Oftalmol 2019;74(4):147-52.

104. Choi JH, Lim DH, Nam SW, et al. Ten-year clinical outcomes after implantation of a posterior chamber phakic intraocular lens for myopia. J Cataract Refract Surg 2019;45(11):1555-61.

105. Stodulka P, Slovak M, Sramka M, et al. Posterior chamber phakic intraocular lens for the correction of presbyopia in highly myopic patients. J Cataract Refract Surg 2020;46(1):40-4.

106. Weisenthal RW, Afshari NA, Bouchard CS, et al. External Disease and Cornea. United States of America: American Academy of Ophthalmology, 2016.

107. Bourne WM, Nelson LR, Hodge DO. Central corneal endothelial cell changes over a ten-year period. Invest Ophthalmol Vis Sci 1997;38(3):779-82.

108. MacRae S, Holladay JT, Hilmantel G, et al. Special Report: American Academy of Ophthalmology Task Force Recommendations for Specular Microscopy for Phakic Intraocular Lenses. Ophthalmology 2017;124(1):141-2.

109. Ostovic M, Hofmann C, Klaproth OK, Kohnen T. Corneal decompensation and angle-closure glaucoma after upside-down implantation of an angle-supported anterior chamber phakic intraocular lens. J Cataract Refract Surg 2013;39(5):806-9.

110. Perez-Santonja JJ, Iradier MT, Benitez del Castillo J M, et al. Chronic subclinical inflammation in phakic eyes with intraocular lenses to correct myopia. J Cataract Refract Surg 1996;22(2):183-7.

111. Packer M. The Implantable Collamer Lens with a central port: review of the literature. Clin Ophthalmol 2018;12:2427-38.

112. McCannel CA, Atebara NH, Kim SJ, et al. Retina and Vitreous. United States of America: American Academy of Ophthalmology, 2017.

113. Tuft SJ, Minassian D, Sullivan P. Risk factors for retinal detachment after cataract surgery: a casecontrol study. Ophthalmology 2006;113(4):650-6.

114. Moshirfar M, Imbornoni LM, Ostler EM, Muthappan V. Incidence rate and occurrence of visually significant cataract formation and corneal decompensation after implantation of Verisyse/Artisan phakic intraocular lens. Clin Ophthalmol 2014;8:711-6.

115. Chebli S, Rabilloud M, Burillon C, Kocaba V. Corneal Endothelial Tolerance After Iris-Fixated Phakic Intraocular Lens Implantation: A Model to Predict Endothelial Cell Survival. Cornea 2018;37(5):591-5.

116. Visser N, Berendschot TT, Bauer NJ, Nuijts RM. Vector analysis of corneal and refractive astigmatism changes following toric pseudophakic and toric phakic IOL implantation. Invest Ophthalmol Vis Sci 2012;53(4):1865-73.

117. Saxena R, Boekhoorn SS, Mulder PG, et al. Long-term follow-up of endothelial cell change after Artisan phakic intraocular lens implantation. Ophthalmology 2008;115(4):608-13.e1.

118. Hayashi K, Hayashi H, Nakao F, Hayashi F. Influence of astigmatism on multifocal and monofocal intraocular lenses. Am J Ophthalmol 2000;130(4):477-82.

119. Hayashi K, Manabe S, Yoshida M, Hayashi H. Effect of astigmatism on visual acuity in eyes with a diffractive multifocal intraocular lens. J Cataract Refract Surg 2010;36(8):1323-9.

120. de Vries NE, Nuijts RM. Multifocal intraocular lenses in cataract surgery: literature review of benefits and side effects. J Cataract Refract Surg 2013;39(2):268-78.

121. Cochener B, Boutillier G, Lamard M, Auberger-Zagnoli C. A Comparative Evaluation of a New Generation of Diffractive Trifocal and Extended Depth of Focus Intraocular Lenses. J Refract Surg 2018;34(8):507-14.

122. Cochener B, Vryghem J, Rozot P, et al. Clinical outcomes with a trifocal intraocular lens: a multicenter study. J Refract Surg 2014;30(11):762-8. 
123. Kohnen T, Herzog M, Hemkeppler E, et al. Visual performance of a quadrifocal (trifocal) intraocular lens following removal of the crystalline lens. Am J Ophthalmol 2017.

124. Cochener B. Prospective Clinical Comparison of Patient Outcomes Following Implantation of Trifocal or Bifocal Intraocular Lenses. J Refract Surg 2016;32(3):146-51.

125. Carson D, Xu Z, Alexander E, et al. Optical bench performance of 3 trifocal intraocular lenses. J Cataract Refract Surg 2016;42(9):1361-7.

126. Lee S, Choi M, Xu Z, et al. Optical bench performance of a novel trifocal intraocular lens compared with a multifocal intraocular lens. Clin Ophthalmol 2016;10:1031-8.

127. Cochener B. Clinical outcomes of a new extended range of vision intraocular lens: International Multicenter Concerto Study. J Cataract Refract Surg 2016;42(9):1268-75.

128. Pandit RT. Monocular Clinical Outcomes and Range of Near Vision following Cataract Surgery with Implantation of an Extended Depth of Focus Intraocular Lens. J Ophthalmol 2018;2018:8205824.

129. Power B, Murphy R, Leccisotti A, et al. Maximising Refractive Outcomes with an Extended Depth of Focus IOL. Open Ophthalmol J 2018;12:273-80.

130. Monaco G, Gari M, Di Censo F, et al. Visual performance after bilateral implantation of 2 new presbyopia-correcting intraocular lenses: Trifocal versus extended range of vision. J Cataract Refract Surg 2017;43(6):737-47.

131. Ruiz-Mesa R, Abengozar-Vela A, Ruiz-Santos M. A comparative study of the visual outcomes between a new trifocal and an extended depth of focus intraocular lens. Eur J Ophthalmol 2018;28(2):182-7.

132. Rodov L, Reitblat O, Levy A, et al. Visual Outcomes and Patient Satisfaction for Trifocal, Extended Depth of Focus and Monofocal Intraocular Lenses. J Refract Surg 2019;35(7):434-40.

133. Finkelman YM, Ng JQ, Barrett GD. Patient satisfaction and visual function after pseudophakic monovision. J Cataract Refract Surg 2009;35(6):998-1002.

134. Yang CM, Lim DH, Hwang S, et al. Prospective study of bilateral mix-and-match implantation of diffractive multifocal intraocular lenses in Koreans. BMC Ophthalmol 2018;18(1):73.

135. Ganesh S, Brar S, Pawar A, Relekar KJ. Visual and Refractive Outcomes following Bilateral Implantation of Extended Range of Vision Intraocular Lens with Micromonovision. J Ophthalmol 2018;2018:7321794.

136. Vilar C, Hida WT, de Medeiros AL, et al. Comparison between bilateral implantation of a trifocal intraocular lens and blended implantation of two bifocal intraocular lenses. Clin Ophthalmol 2017;11:1393-7.

137. Jacobi FK, Kammann J, Jacobi KW, et al. Bilateral implantation of asymmetrical diffractive multifocal intraocular lenses. Arch Ophthalmol 1999;117(1):17-23.

138. Mastropasqua R, Pedrotti E, Passilongo M, et al. Long-term visual function and patient satisfaction after bilateral implantation and combination of two similar multifocal IOLs. J Refract Surg 2015;31(5):30814.

139. Chang JSM, Liu SCT, Ng JCM, Ma PL. Monovision with a Bifocal Diffractive Multifocal Intraocular Lens in Presbyopic Patients: A Prospective, Observational Case Series. Am J Ophthalmol 2020;212:105-15.

140. Le Loir M, Cochener B. [Long-term results of posterior chamber phakic intraocular lens implantation for correction of high ametropia]. J Fr Ophtalmol 2012;35(6):402-11.

141. Sheppard AL, Shah S, Bhatt U, et al. Visual outcomes and subjective experience after bilateral implantation of a new diffractive trifocal intraocular lens. J Cataract Refract Surg 2013;39(3):343-9.

142. Alio JL, Montalban R, Pena-Garcia P, et al. Visual outcomes of a trifocal aspheric diffractive intraocular lens with microincision cataract surgery. J Refract Surg 2013;29(11):756-61.

143. Vryghem JC, Heireman S. Visual performance after the implantation of a new trifocal intraocular lens. Clin Ophthalmol 2013;7:1957-65. 
144. Marques EF, Ferreira TB. Comparison of visual outcomes of 2 diffractive trifocal intraocular lenses. J Cataract Refract Surg 2015;41(2):354-63.

145. Marques JP, Rosa AM, Quendera B, et al. Quantitative evaluation of visual function 12 months after bilateral implantation of a diffractive trifocal IOL. Eur J Ophthalmol 2015;25(6):516-24.

146. Carballo-Alvarez J, Vazquez-Molini JM, Sanz-Fernandez JC, et al. Visual outcomes after bilateral trifocal diffractive intraocular lens implantation. BMC Ophthalmol 2015;15:26.

147. Plaza-Puche AB, Alio JL. Analysis of defocus curves of different modern multifocal intraocular lenses. Eur J Ophthalmol 2016;26(5):412-7.

148. Martinez-de-la-Casa JM, Carballo-Alvarez J, Garcia-Bella J, et al. Photopic and mesopic performance of 2 different trifocal diffractive intraocular lenses. Eur J Ophthalmol 2016;27(1):26-30.

149. Ruiz-Mesa R, Abengozar-Vela A, Aramburu A, Ruiz-Santos M. Comparison of visual outcomes after bilateral implantation of extended range of vision and trifocal intraocular lenses. Eur J Ophthalmol 2017;27(4):460-5.

150. Gundersen KG, Potvin R. Trifocal intraocular lenses: a comparison of the visual performance and quality of vision provided by two different lens designs. Clin Ophthalmol 2017;11:1081-7.

151. Bilbao-Calabuig R, Llovet-Rausell A, Ortega-Usobiaga J, et al. Visual Outcomes Following Bilateral Implantation of Two Diffractive Trifocal Intraocular Lenses in 10084 Eyes. Am J Ophthalmol 2017;179:55-66.

152. Ferreira-Rios I, Zuniga-Posselt K, Serna-Ojeda JC, Chavez-Mondragon E. Objective and subjective results following implantation of the FineVision trifocal intraocular lens in Mexican patients. Int Ophthalmol 2018;38(6):2617-22.

153. Oliveira RF, Vargas V, Plaza-Puche AB, Alio JL. Long-term results of a diffractive trifocal intraocular lens: Visual, aberrometric and patient satisfaction results. Eur J Ophthalmol 2018:1120672118818019.

154. Poyales F, Garzon N, Pizarro D, et al. Stability and visual outcomes yielded by three intraocular trifocal lenses with same optical zone design but differing material or toricity. Eur J Ophthalmol 2018:1120672118795065.

155. Oliveira RF, Vargas V, Plaza-Puche AB, Alió JL. Long-term results of a diffractive trifocal intraocular lens: Visual, aberrometric and patient satisfaction results. Eur J Ophthalmol 2020;30(1):201-8.

156. Poyales F, Garzon N. Comparison of 3-month visual outcomes of a spherical and a toric trifocal intraocular lens. J Cataract Refract Surg 2019;45(2):135-45.

157. Ferreira TB, Ribeiro FJ. Prospective Comparison of Clinical Performance and Subjective Outcomes Between Two Diffractive Trifocal Intraocular Lenses in Bilateral Cataract Surgery. J Refract Surg 2019;35(7):418-25.

158. Ribeiro F, Ferreira TB. Comparison of clinical outcomes of 3 trifocal IOLs. J Cataract Refract Surg 2020;46(9):1247-52.

159. Law EM, Aggarwal RK, Kasaby H. Clinical outcomes with a new trifocal intraocular lens. Eur J Ophthalmol 2014;24(4):501-8.

160. Mojzis P, Kukuckova L, Majerova K, et al. Comparative analysis of the visual performance after cataract surgery with implantation of a bifocal or trifocal diffractive IOL. J Refract Surg 2014;30(10):666-72.

161. Mojzis P, Pena-Garcia P, Liehneova I, et al. Outcomes of a new diffractive trifocal intraocular lens. J Cataract Refract Surg 2014;40(1):60-9.

162. Kretz FT, Breyer D, Diakonis VF, et al. Clinical Outcomes after Binocular Implantation of a New Trifocal Diffractive Intraocular Lens. J Ophthalmol 2015;2015:962891.

163. Mojzis P, Majerova K, Hrckova L, Pinero DP. Implantation of a diffractive trifocal intraocular lens: oneyear follow-up. J Cataract Refract Surg 2015;41(8):1623-30. 
164. Gundersen KG, Potvin R. Comparison of visual outcomes and subjective visual quality after bilateral implantation of a diffractive trifocal intraocular lens and blended implantation of apodized diffractive bifocal intraocular lenses. Clin Ophthalmol 2016;10:805-11.

165. Mendicute J, Kapp A, Levy P, et al. Evaluation of visual outcomes and patient satisfaction after implantation of a diffractive trifocal intraocular lens. J Cataract Refract Surg 2016;42(2):203-10.

166. Kohnen T, Titke C, Bohm M. Trifocal Intraocular Lens Implantation to Treat Visual Demands in Various Distances Following Lens Removal. Am J Ophthalmol 2016;161:71-7.e1.

167. Alfonso JF, Fernandez-Vega Cueto L, Belda-Salmeron L, et al. Visual function after implantation of a diffractive aspheric trifocal intraocular lens. Eur J Ophthalmol 2016;26(5):405-11.

168. Kretz FT, Choi CY, Muller M, et al. Visual Outcomes, Patient Satisfaction and Spectacle Independence with a Trifocal Diffractive Intraocular Lens. Korean J Ophthalmol 2016;30(3):180-91.

169. Mencucci R, Favuzza E, Caporossi O, et al. Comparative analysis of visual outcomes, reading skills, contrast sensitivity, and patient satisfaction with two models of trifocal diffractive intraocular lenses and an extended range of vision intraocular lens. Graefes Arch Clin Exp Ophthalmol 2018;256(10):191322.

170. Kaymak H, Breyer D, Alio JL, Cochener B. Visual Performance With Bifocal and Trifocal Diffractive Intraocular Lenses: A Prospective Three-Armed Randomized Multicenter Clinical Trial. J Refract Surg 2017;33(10):655-62.

171. Mencucci R, Favuzza E, Caporossi O, Rizzo S. Visual performance, reading ability and patient satisfaction after implantation of a diffractive trifocal intraocular lens. Clin Ophthalmol 2017;11:1987-93.

172. Liu X, Xie L, Huang Y. Comparison of the Visual Performance After Implantation of Bifocal and Trifocal Intraocular Lenses Having an Identical Platform. J Refract Surg 2018;34(4):273-80.

173. Yang Y, Lv H, Wang Y, et al. Clinical outcomes following trifocal diffractive intraocular lens implantation for age-related cataract in China. Clin Ophthalmol 2018;12:1317-24.

174. Steinwender G, Schwarz L, Bohm M, et al. Visual results after implantation of a trifocal intraocular lens in high myopes. J Cataract Refract Surg 2018;44(6):680-5.

175. Martinez de Carneros-Llorente A, Martinez de Carneros A, Martinez de Carneros-Llorente P, JimenezAlfaro I. Comparison of visual quality and subjective outcomes among three trifocal intraocular lenses and one bifocal intraocular lens. J Cataract Refract Surg 2019.

176. Lubiński W, Podborączyńska-Jodko K, Kirkiewicz M, et al. Comparison of visual outcomes after implantation of AtLisa tri 839 MP and Symfony intraocular lenses. Int Ophthalmol 2020.

177. Garcia-Perez JL, Gros-Otero J, Sanchez-Ramos C, et al. Short term visual outcomes of a new trifocal intraocular lens. BMC Ophthalmol 2017;17(1):72.

178. Lawless M, Hodge C, Reich J, et al. Visual and refractive outcomes following implantation of a new trifocal intraocular lens. Eye Vis (Lond) 2017;4:10.

179. Alio JL, Plaza-Puche AB, Alio Del Barrio JL, et al. Clinical outcomes with a diffractive trifocal intraocular lens. Eur J Ophthalmol 2018;28(4):419-24.

180. Akman A, Asena L, Ozturk C, Gur Gungor S. Evaluation of quality of life after implantation of a new trifocal intraocular lens. J Cataract Refract Surg 2019;45(2):130-4.

181. Escaf LJ, Escaf LC, Polo S, et al. Standard Results and Contrast Sensitivity Reestablishment after Implantation of a Trifocal Intraocular Lens. Curr Eye Res 2020:1-6.

182. Farvardin M, Johari M, Attarzade A, et al. Comparison between bilateral implantation of a trifocal intraocular lens (Alcon Acrysof IQ $®$ PanOptix) and extended depth of focus lens (Tecnis $®$ Symfony $®$ ZXROO lens). Int Ophthalmol 2020.

183. Modi S, Lehmann R, Maxwell A, et al. Visual and Patient-Reported Outcomes of a Diffractive Trifocal Intraocular Lens Compared with Those of a Monofocal Intraocular Lens. Ophthalmology 2020. 
184. Pedrotti E, Carones F, Talli P, et al. Comparative analysis of objective and subjective outcomes of two different intraocular lenses: trifocal and extended range of vision. BMJ Open Ophthalmol 2020;5(1):e000497.

185. Pedrotti E, Bruni E, Bonacci E, et al. Comparative Analysis of the Clinical Outcomes With a Monofocal and an Extended Range of Vision Intraocular Lens. J Refract Surg 2016;32(7):436-42.

186. Pedrotti E, Carones F, Aiello F, et al. Comparative analysis of visual outcomes with 4 intraocular lenses: Monofocal, multifocal, and extended range of vision. J Cataract Refract Surg 2018;44(2):156-67.

187. Pilger D, Homburg D, Brockmann T, et al. Clinical outcome and higher order aberrations after bilateral implantation of an extended depth of focus intraocular lens. Eur J Ophthalmol 2018;28(4):425-32.

188. Paik DW, Park JS, Yang CM, et al. Comparing the visual outcome, visual quality, and satisfaction among three types of multi-focal intraocular lenses. Sci Rep 2020;10(1):14832.

189. Song X, Liu X, Wang W, et al. Visual outcome and optical quality after implantation of zonal refractive multifocal and extended-range-of-vision IOLs: a prospective comparison. J Cataract Refract Surg 2020;46(4):540-8. 


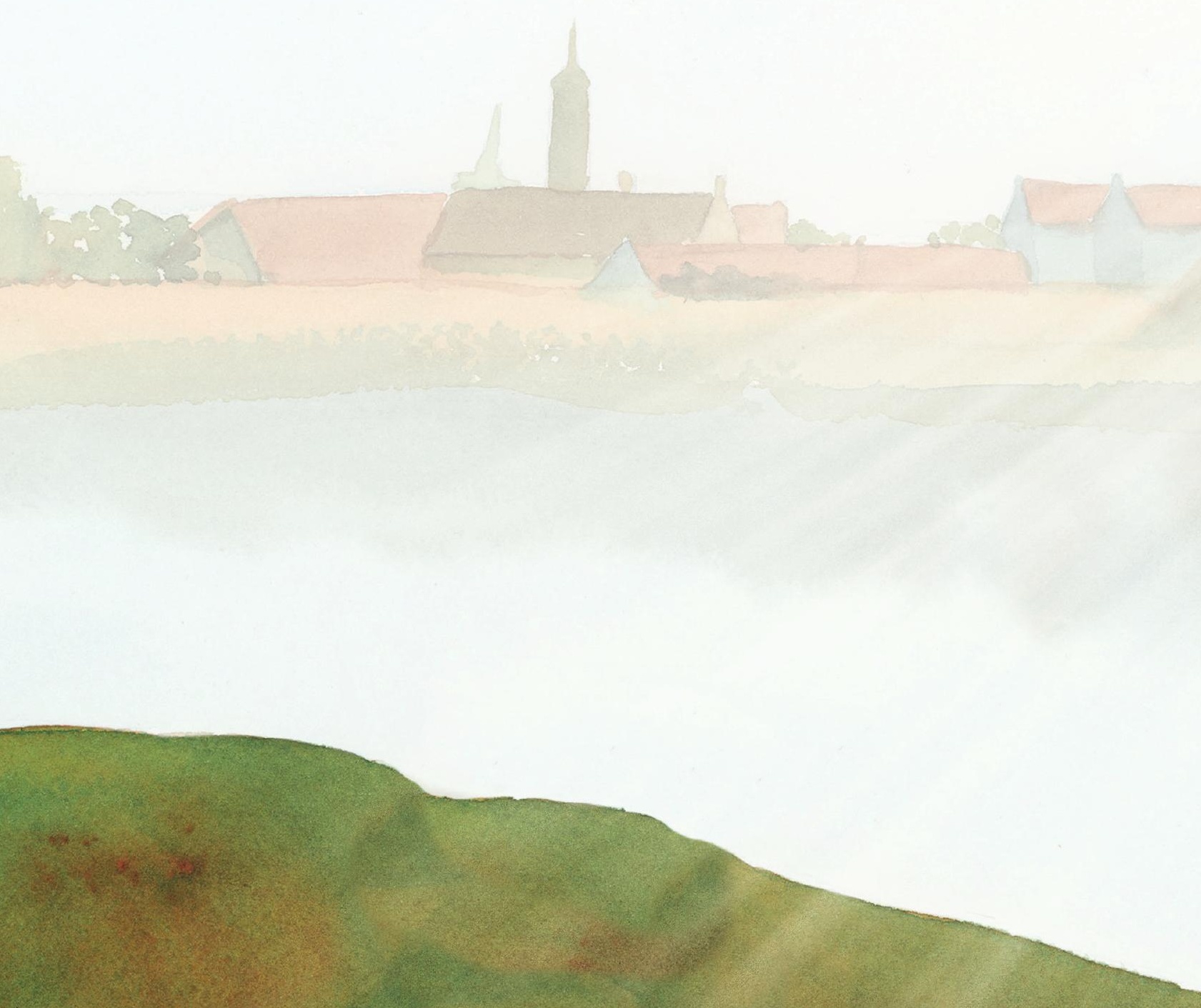




\section{CHAPTER 2}

\section{Phakic intraocular lens: \\ Two-year results and comparison of endothelial cell loss to iris-fixated intraocular lenses}

Andreas AS Aerts, Soraya MR Jonker, Laura HP Wielders,

Tos TJM Berendschot, Muriël Doors, John De Brabander, Rudy MMA Nuijts

J Cataract Refract Surg. 2015 Oct;41(10):2258-65 


\section{ABSTRACT}

Purpose: To evaluate the efficacy, safety, and stability of a foldable angle-supported Acrysof Cachet phakic intraocular lenses ( $\mathrm{plOL}$ ) to correct moderate to high myopia and compare endothelial cell loss to EC loss after iris-fixated Artisan and Artiflex pIOL implantation.

Setting: University Eye Clinic Maastricht, The Netherlands.

Design: Retrospective observational study.

Methods: Foldable angle-supported pIOL implantation for myopia ranging from -6.0 to -16.5 diopters (D) was done. Uncorrected (UDVA) and corrected (CDVA) distance visual acuity, spherical equivalent (SE), and adverse events were documented preoperatively and at 6 months and 1 and 2 years postoperatively. Endothelial cell loss after implantation of the foldable angle-supported pIOL and iris-fixated pIOLs was compared 6 months and 1 and 2 years postoperatively.

Results: There were 158 eyes. The UDVA was equal to or more than 20/25 in $95 \%$ of eyes at 1 and 2 years postoperatively. The mean SE was $-0.17 \mathrm{D} \pm 0.43$ (SD) 2 years postoperatively. One patient developed pupil ovalization, resulting in explantation of the plOL from both eyes. Acute endothelial cell loss in the foldable angle-supported pIOL group was $-3.2 \% \pm 0.7 \%$, significantly higher than after iris-fixated pIOL implantation. Chronic endothelial cell loss from 6 to 24 months after surgery was $-3.8 \% \pm 0.7 \%$. At the 2 -year follow-up, the chronic endothelial cell loss in the foldable angle-supported pIOL group was not significantly different than with iris-fixated plOLs $(P>.05)$.

Conclusions: The foldable angle-supported pIOL effectively corrected moderate to high myopia. However, acute surgical endothelial cell loss was significantly higher than with irisfixated pIOLs. 


\section{INTRODUCTION}

Laser refractive surgery has been the treatment of choice for most patients seeking spectacle independence. However, this technique is less desirable for patients with moderate to high myopia. Not only is the long-term accuracy of laser refractive surgery known to decline with higher levels of myopia, but secondary effects such as glare and halos are common downsides. ${ }^{1}$ To offer an alternative for patients with moderate to high myopia, phakic intra ocular lenses ( $\mathrm{plOLs)}$ were developed. Advantages of pIOL implantation over laser refractive surgery are a better uncorrected (UDVA) and corrected (CDVA) distance visual acuity, better contrast sensitivity, and a better quality of vision..$^{2,3}$

Anterior chamber pIOLs are available in angle-supported and iris-fixated models. Iris-claw pIOLs are a reversible, effective, stable and safe procedure. ${ }^{4,5}$ The initial (rigid) plOLs were angle-supported, but nowadays, iris-fixated plOLs (ie, Artisan or Artiflex plOL, both Ophtec BV) and posterior chamber sulcus fixated plOLs are the most widely used. The main complications of pIOLs are pupil ovalization, cataract formation and endothelial cell loss. ${ }^{1,6-9}$ Concerns have been raised especially about the potential risks of plOLs to cause damage to the corneal endothelium. ${ }^{7-11}$ Because iris-fixated plOLs have a challenging implantation technique that requires a skillful and experienced surgeon, manufacturers have designed various foldable angle-supported pIOLs. ${ }^{12,13}$ Recently, a new foldable angle-supported $\mathrm{pIOL}$, the Acrysof Cachet $\mathrm{pIOL}$ (Alcon laboratories, Inc), was introduced; it is made of a single-piece hydrophobic acrylate and has an optic disc of $6.0 \mathrm{~mm}$.

The purpose of the present study was to evaluate the efficacy, safety, and stability of the anglesupported Acrysof Cachet pIOL to correct moderate to high myopia and compare endothelial cell loss between this IOL and the rigid iris-fixated Artisan Myopia, Artisan Toric, and Artiflex (Ophtec BV) pIOLs. 


\section{PATIENTS AND METHODS}

\section{Patient population and study design}

This retrospective observational study consisted of patients with moderate to high myopia with surgical implantation of a foldable angle-supported pIOL between 2009 and 2013 at the Academic Center for Refractive Surgery, University Eye Clinic Maastricht, the Netherlands. Written informed consent was obtained from all patients. The study was conducted in accordance with the Declaration of Helsinki.

Inclusion criteria for performing plOL implantation were a stable refractive error during the previous 2 years; a central anterior chamber depth (ACD) of more than $2.8 \mathrm{~mm}$ (measured from the endothelium to the crystalline lens); a pupil diameter less than $6 \mathrm{~mm}$ in mesopic light conditions; endothelial cell density (ECD) count according to age with a minimum of 2000 cells/ $\mathrm{mm}^{2}$ for the highest age group; no corneal, pupil, or iris abnormalities; and no history of glaucoma or chronic or recurrent uveitis.

To compare endothelial cell loss with the angle-supported plOL with that of our routinely used iris-fixated pIOL, a control group was selected based on a consecutive series of $737 \mathrm{plOL}$ implantations at the Academic Center for Refractive Surgery from 1998 to 2013. All 737 eyes were operated by the same surgeon (R.N.), and all surgeries were performed in the same hospital.

\section{Preoperative examination}

Before surgery, subjective, objective, and cycloplegic refractions were determined. The UDVA and CDVA were measured using Snellen optotypes. Slitlamp microscopy, Goldmann applanation tonometry, and fundus examination were performed. Pupil sizes were measured in mesopic and scotopic conditions using a pupillometer (P2000, Procyon Instruments Ltd.). Axial length, white-to-white, and ACD measurement were calculated using partial coherence interferometry (IOLMaster, Carl Zeiss Meditec AG). Anterior chamber morphometrics were evaluated using anterior segment optical coherence tomography (AS-OCT) (Visante, Carl Zeiss Meditec AG). Central endothelial cell measurements were performed using a noncontact specular microscope (NonconRobo SP-8000, Konan Medical, Inc.). Three consecutive endothelial images of the central cornea were obtained and analyzed using the dot method, in which the centers of 50 or more contiguous cells are marked. The average of 3 measurements was used for the analysis. Postoperative examinations included subjective and objective UDVA and CDVA, slitlamp microscopy, Goldmann applanation tonometry, AS-OCT and central endothelial cell measurements. These exams were repeated 1 day, 1 week, 3 and 6 months and 1 and 2 years after surgery. Examinations performed at 6 months, 1 and 2 years were used for the data analysis. Comparisons between preoperative and postoperative data were made for all patients. 


\section{Angle-supported phakic intraocular lens}

The Cachet pIOL (Figure 1) is an angle-supported IOL made of a single-piece hydrophobic acrylate with an optic disc of $6.0 \mathrm{~mm}$; it is foldable and can be inserted through a small incision $(2.8 \mathrm{~mm})$. The overall length of the angle-supported $\mathrm{pIOL}$ varies from 12.5 to $14.0 \mathrm{~mm}$ and depends on the anterior chamber diameter of the eye. This study included 4 models of the Cachet pIOL: models L12500, L13000, L13500, and L14000, ranging in size from 12.5 to 14.0 $\mathrm{mm}$ with $0.5 \mathrm{~mm}$ steps. The power ranges from -6.0 to -16.5 diopters (D). The plOL consists of a 4-point haptic design connected with a bridge. The goal of the IOL design is to minimize compressive forces on the iridocorneal angle and to establish an ideal position of the $\mathrm{plOL}$ in the anterior chamber regarding the distance to the corneal endothelium and the lens. Due to this position of the angle-supported $\mathrm{pIOL}$, an iridectomy is unnecessary.

\section{Surgical technique of pIOL implantation}

Power calculation was performed using the formula originally derived by Van der Heijde ${ }^{14}$ and further refined by Holladay. ${ }^{15}$ Subsequently, pIOL power was determined to achieve the target refraction.

Prior to surgery the pupil was constricted using pilocarpine $2.0 \%$ to prevent possible contact between the pIOL and crystalline lens. Before surgery, sub-tenon anesthesia was used to anesthetize the eye. No eye required an iridotomy during or after surgery.

A corneal tunnel incision of $2.8 \mathrm{~mm}$ at 12 o'clock was created to access the anterior chamber. Acetylcholine chloride 1.0\% intraocular solution was used intraoperatively for pupil constriction. To inflate and maintain the chamber, sodium hyaluronate 1.0\% (Provisc) was injected into the chamber angle, away from the pupil. The pIOL was loaded into the Monarch III IOL Delivery System (Alcon Laboratories, Inc.) with its anterior optic surface facing upward and was then folded and slowly delivered with the cartridge positioned at midpupil to provide delivery in the area of maximum ACD. After unfolding of the leading haptics, delivery was continued when the leading haptics reached the distal angle and the cartridge was withdrawn to avoid increased compression in the distal angle. Trailing haptics were left just outside the incision and then tucked one at a time into the anterior chamber angle so that the $\mathrm{pIOL}$ was positioned with all 4 haptics in the anterior chamber. ${ }^{16,17}$ After plOL implantation, the cohesive ophthalmic viscosurgical device (OVD) was thoroughly removed from the anterior chamber by active irrigation/aspiration. Active removal included the use of a single-port system to simultaneously irrigate and aspirate the OVD. A 10-0 nylon closure suture was used. Acetazolamide $500 \mathrm{mg}$ at 30 minutes and 8 hours after the operation was given to control intraocular pressure (IOP).

The surgical technique for the Artisan Myopia, Artisan Toric, and Artiflex plOL implantation have been described. ${ }^{18,19}$ 
The postoperative eyedrop treatment consisted of tobramycin $0.3 \%$ and dexamethasone $0.1 \%$ (Tobradex) 4 times a day and ketorolac 0.5\% (Acular) 4 times a day for 4 weeks in a tapering regimen.

\section{Statistical analysis}

Statistical analysis was performed using SPSS for Windows software (version 21, International Business Machines Corp.). The primary study results were calculated descriptively. To determine central endothelial cell loss, a linear mixed model analysis was used with subject as grouping factor and $\mathrm{pIOL}$ and time and the interaction term of these 2 as covariates. The advantage of this model is that it allows use of all available data. If a datapoint is missing, it has no effect on other scores from that same eye. However, data from these patients will contribute to a more accurate estimate of the endothelial cell change over time (ie, the endothelial cell loss). A P values less than 0.05 was considered significant. Results are reported as specified in the standard format for reporting refractive surgical data. ${ }^{20}$

Table 1. Patient demographics

\begin{tabular}{lcccc}
\hline Demographic & $\begin{array}{c}\text { Acrysof } \\
\text { Cachet }\end{array}$ & $\begin{array}{c}\text { Artisan } \\
\text { Myopia }\end{array}$ & $\begin{array}{c}\text { Artisan } \\
\text { Toric }\end{array}$ & Artiflex \\
\hline Eyes $(\mathrm{n})$ & 158 & 371 & 111 & 257 \\
Male / female sex (n) & $62 / 96$ & $133 / 238$ & $54 / 57$ & $86 / 171$ \\
Mean age (y) & $39.0 \pm 10.6$ & $51.2 \pm 10.1$ & $44.5 \pm 11.6$ & $45.5 \pm 11.3$ \\
Mean anterior chamber depth (mm) & $3.64 \pm 0.35$ & $3.69 \pm 0.34$ & $3.48 \pm 0.33$ & $3.62 \pm 0.35$ \\
Mean endothelial cell count (cells/mm²) & $2817.0 \pm$ & $2664 \pm$ & $2689.2 \pm$ & $2741.9 \pm$ \\
& 25.2 & 362.6 & 366.5 & 293.1 \\
Mean spherical equivalent (D) & $-9.59 \pm 2.24$ & $-12.7 \pm 5.0$ & $-6.3 \pm 8.3$ & $-9.29 \pm 2.8$ \\
Mean best corrected visual acuity (Snellen) & $1.07 \pm 0.17$ & $0.8 \pm 0.25$ & $0.79 \pm 0.24$ & $1.0 \pm 0.18$ \\
\hline
\end{tabular}

Means \pm SD 


\section{RESULTS}

The study include 158 eyes of 81 patients. The mean age of the 49 women and 32 men at the time of pIOL implantation was 39.0 years \pm 10.6 (SD) (Table 1). The mean follow-up was $17.0 \pm$ 7.2 months (range 6 months to 2 years). The mean pIOL power was $-10.27 \pm 2.13 \mathrm{D}$.

\section{Safety}

Figure 2, $A$ and $B$ shows the change in CDVA in the angle-supported plOL group from preoperatively to 1 and 2 years after surgery. At 6 months $(n=158), 1$ year $(n=124)$ and 2 years ( $n=79$ ), 146 eyes (91\%), 114eyes (92\%), and 77 eyes (97\%), respectively, had no change in or gained lines of CDVA compared with preoperatively. After 2 years, no eye had lost 2 or more lines of CDVA. The safety index 1 and 2 years after implantation was 1.14 and 1.11, respectively.

\section{Efficacy}

Figure 3, $A$ and $B$, shows the UDVA in the angle-supported group 1 and 2 years after surgery. After 1 year, 92 (75\%) of 124 eyes had an UDVA of 20/20 or better, and after 2 years, 58 (73\%) of 79 eyes had an UDVA of 20/20 or better. At 6 months, 1 year, and 2 years, more than $90 \%$ of eyes (152/158, 118/124, and 75/79, respectively) had an UDVA of 20/25 or better. After 2 years, 67 (85\%) of 79 eyes had a CDVA of 20/20 or better. The 2-year efficacy index was 1.00.

\section{Predictability and stability}

Figure 4 shows the attempted versus achieved spherical equivalent (SE) refraction in every eye after 1 year of follow-up. The residual refractive error (SE) was within $\pm 0.5 \mathrm{D}$ and $\pm 1.0 \mathrm{D}$ of target in 113 eyes (91\%) and 122 eyes (98\%), respectively, after 1 year of follow-up.

After 2 years follow-up, the residual refractive error (SE) was within $\pm 0.5 \mathrm{D}$ of target in 72 eyes (91\%) and within $\pm 1.0 \mathrm{D}$ of target in 95 eyes (95\%). All patients who were more than 1.0 D offtarget were highly myopic and were satisfied with their visual outcome.

The mean SE was $-9.6 \pm 2.2 \mathrm{D}$ preoperatively and improved to $-0.18 \pm 0.29 \mathrm{D}$ and $-0.17 \pm 0.43$ $\mathrm{D}$ after 1 and 2 years, respectively (Figure 5). Figure 6 presents the results on the refractive accuracy outcomes after angle-supported pIOL implantation. The refractive astigmatism 1 year after surgery was within $\pm 0.25 \mathrm{D}$ in 80 eyes (65\%) and within $\pm 0.5 \mathrm{D}$ in 96 eyes (77\%) (Figure 7). Two years after surgery, these figures were 55 eyes (69\%) and 63 eyes (80\%), respectively $(n=79)$. 




Figure 1. Foldable angle-supported pIOL

A



Change in Corrected Distance Visual Acuity
B

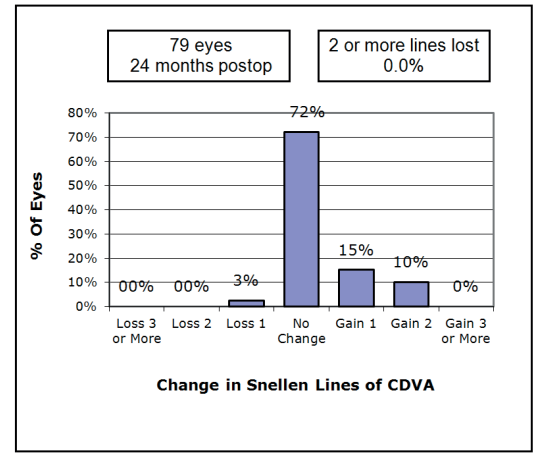

Change in Corrected Distance Visual Acuity

Figure 2. A: Snellen lines of CDVA gained or lost 1 year after angle-supported pIOL implantation. B: Snellen lines of CDVA gained or lost 2 years after angle-supported pIOL implantation (CDVA = corrected distance visual acuity).

A

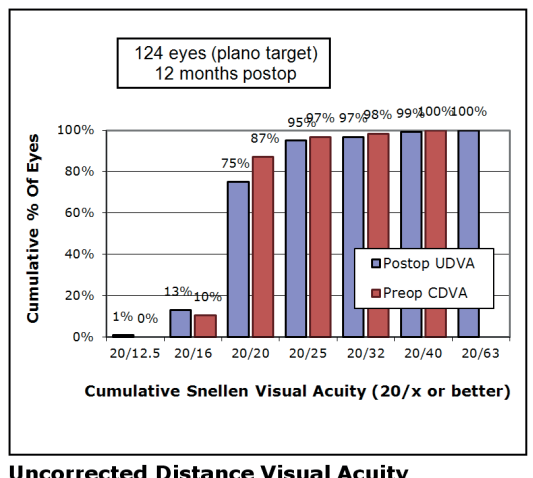

Uncorrected Distance Visual Acuity
B



Uncorrected Distance Visual Acuity

Figure 3. A: The UDVA 1 year after angle-supported pIOL implantation. B: The UDVA 2 years after anglesupported pIOL implantation (CDVA = corrected distance visual acuity; UDVA = uncorrected distance visual acuity). 


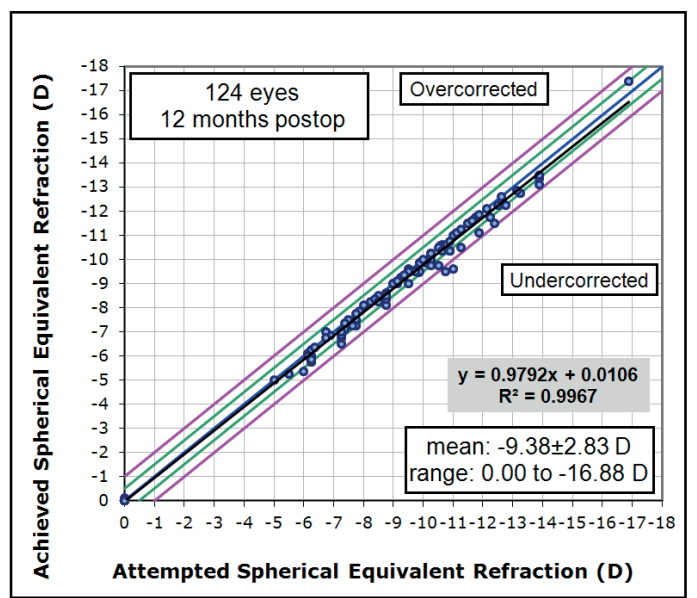

Spherical Equivalent Attempted vs Achieved

Figure 4. One-year predictability of angle-supported plOL, with 2 green lines demonstrating $0.5 \mathrm{D}$ and 2 outer pink lines demonstrating $1.0 \mathrm{D}$ of overcorrection or undercorrection.

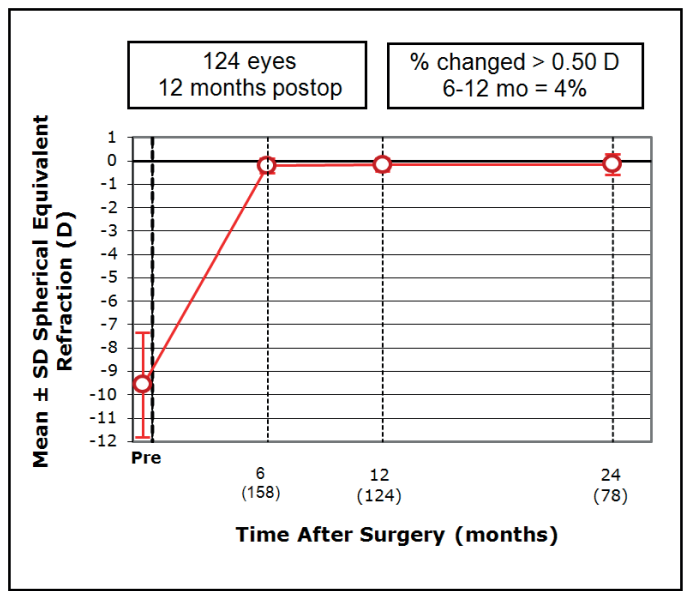

Stability of Spherical Equivalent Refraction

Figure 5. One-year stability of SE refraction after angle-supported pIOL implantation. 


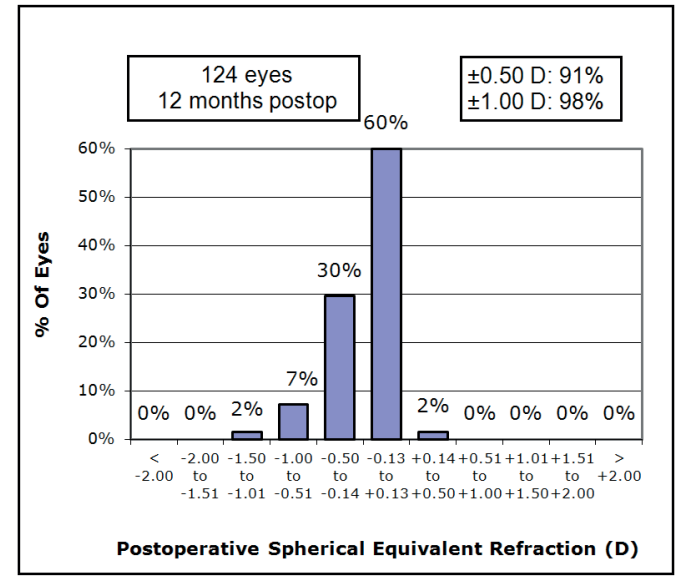

Spherical Equivalent Refractive Accuracy

Figure 6. Accuracy of SE refraction 1 year after angle-supported plOL implantation.



Refractive Astigmatism

Figure 7. Refractive astigmatism 1 year after angle-supported plOL implantation.

\section{Adverse events}

Table 2 shows the adverse events for all 158 eyes throughout the study. The most frequent complication was a presumed steroid-induced increase in IOP in the early postoperative period (7 to 10 days). All eyes responded well to topical treatment. There were no reports of retinal detachment, corneal edema, inflammation, or cystoid macular edema. 


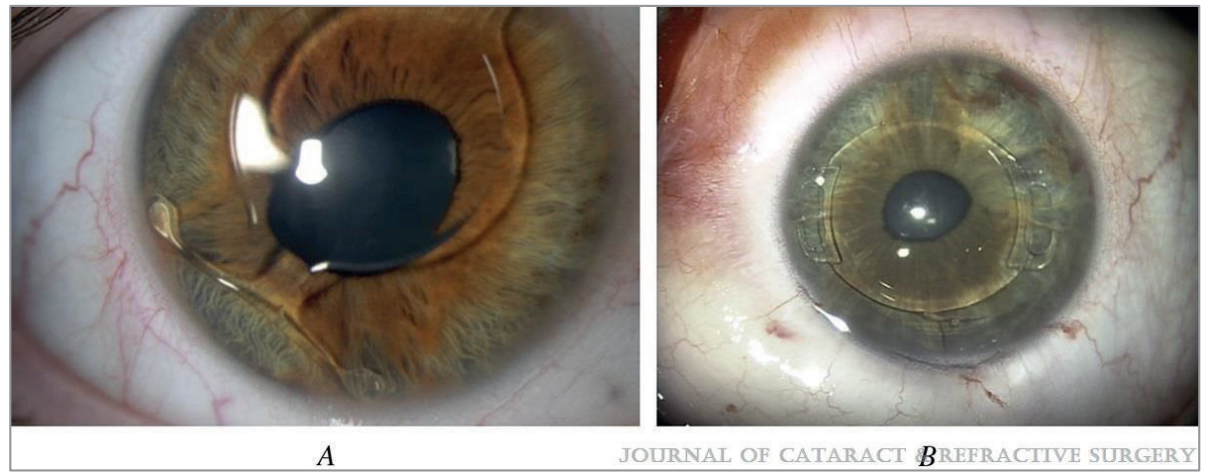

Figure 8. A: Slitlamp photograph of angle-supported pIOL with pupil ovalization. B: Slitlamp photograph after synechialysis and exchange for an Artiflex $\mathrm{PIOL}$ in an eye with previous pupil ovalization 3 years after Acrysof Cachet plOL implantation. Photograph was taken directly after surgery in the operating room.

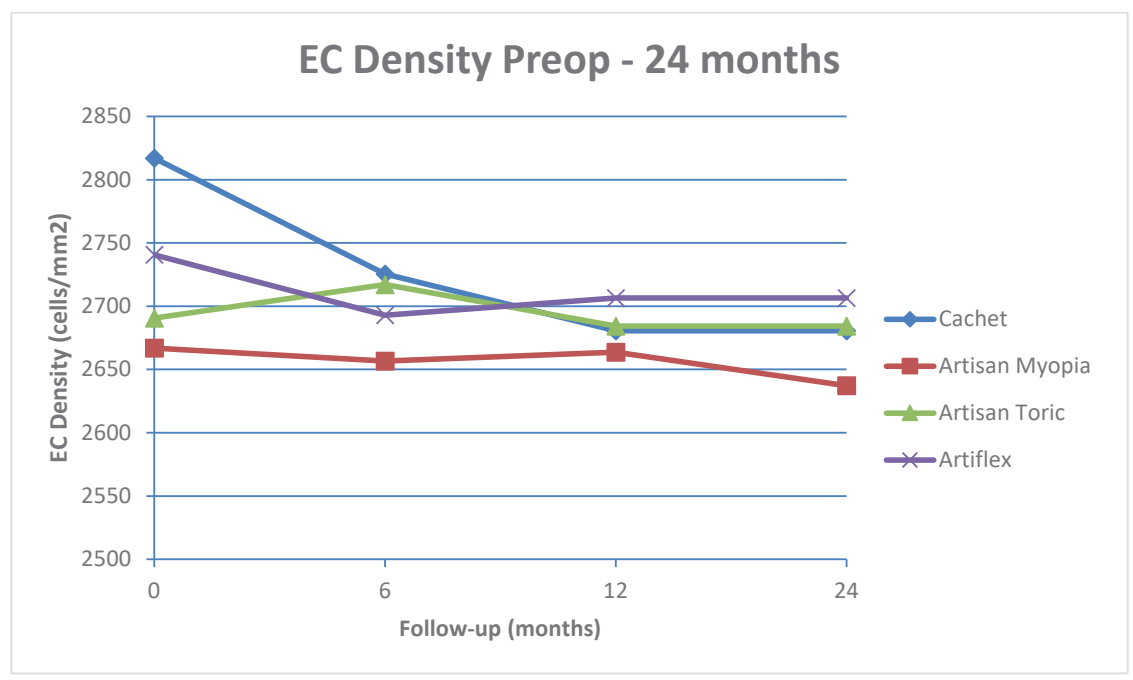

Figure 9. The ECD after implantation of plOLs.

\section{Additional procedures}

Four eyes of 3 patients had an additional refractive laser-assisted subepithelial keratectomy to treat residual ametropia. All 3 patients (4 eyes) were excluded from further analysis, including the assessment of predictability. In 2 eyes of 2 patients repositioning of the angle-supported pIOL was required. 
Dropout occurred in 3 eyes of 2 patients who had a pIOL exchange. In 1 patient ( 1 eye), the angle-supported pIOL was exchanged with a toric Artiflex due to a residual refractive error. In both eyes of another patient the angle-supported pIOL was exchanged with a spherical Artiflex due to pupil ovalization in both eyes. This patient had an angle-supported pIOL (L13000) implanted in both eyes. After 36 months, the right eye showed anterior synechiae formation with an irregular pupil, whereas the left eye also showed pupil ovalization but with minor synechiae formation. Neither eye had significant endothelial cell loss during follow-up. Six months and 2 months after pIOL exchange, UDVA was 20/20 in both eyes. Figure 8, $A$ and B, show the right eye before and after the $\mathrm{pIOL}$ exchange.

\section{Endothelial cell loss}

Data from 147 eyes in the angle-supported pIOL group were compared with the data for 3 irisfixated pIOLs: Artisan Myopia ( $n=337)$, Artisan Toric $(n=108)$, and Artiflex ( $n=255)$.

Acute endothelial cell loss

Acute endothelial cell loss, meaning endothelial cell loss from preoperatively to 6 months postoperatively, was $-3.2 \pm 0.7 \%$ for the angle-supported plOL. This was significantly higher when compared with the iris-fixated models: Artisan Myopia $(-0.4 \% \pm 0.9 \%, P=.001)$ and Artiflex $(-1.7 \% \pm 0.9 \%, P=.001)$. There was no significant difference in the Artisan Toric group $(+1.0 \% \pm$ $1.3 \%, P=.092)$. Figure 9 shows the significantly steeper decline in endothelial cells after anglesupported pIOL implantation versus the iris-fixated pIOLs.

\section{Chronic endothelial cell loss}

The angle-supported pIOL had a significant endothelial cell loss from 6 months to 2 years postoperatively of $-3.8 \% \pm 0.7 \%(P<.001, n=129)$ (Figure 9). There was no significant difference in chronic endothelial cell loss between the 4 plOL groups: Artisan Myopia $(-2.1 \% \pm 0.9 \%, n=$ 262), Artisan Toric $(-2.9 \% \pm 1.4 \%, n=59)$, and Artiflex $(-1.7 \% \pm 1.0 \%, n=177)$ (Figure 9). The mean change in central endothelial cell loss from preoperatively to 1 year postoperatively was $-6.9 \% \pm 0.5 \%$ in the angle-supported plOL group.

Table 2. Adverse events $(n=158)$

\begin{tabular}{lll}
\hline Adverse Event & $\mathbf{n}$ & \% \\
\hline Increased IOP requiring treatment & 9 & 5.7 \\
Surgical intervention & 8 & 5.1 \\
Pupil ovalization & 2 & 1.3 \\
CDVA loss $>0.2$ logMAR & 0 & 0 \\
\hline
\end{tabular}

CDVA = corrected distance visual acuity; $I O P=$ intraocular pressure 


\section{DISCUSSION}

Up to 2 years after implantation of the Acrysof Cachet pIOL, it demonstrated favorable results in terms of CDVA, UDVA, predictability, stability and safety. As in other reported studies, visual acuity was excellent, and no eye lost 2 or more lines of CDVA 1 and 2 years postoperatively. ${ }^{16,17,21}$ The safety index of 1.14 after 1 year and 1.11 after 2 years demonstrates the overall safety of this procedure. During our follow-up period, more than $90 \%$ of eyes had an UDVA of at least 20/25 or more.

In this population, there were no serious intraoperative complications. However, concerning postoperative complications, we had 1 patient who had a plOL exchange in both eyes due to pupil ovalization. The main postoperative complications seen in patients with angle-supported pIOLs are endothelial cell loss and pupil ovalization.9, 22 In the past, various angle-supported plOLs, both rigid and foldable, showed high endothelial cell loss and were eventually withdrawn from the market. ${ }^{11,23}$ Adequate position and stability of the pIOL play a crucial role in preventing endothelial cell loss. Kohnen and Klaproth demonstrated good stability of the Cachet pIOL in the anterior chamber, maintaining an adequate distance to the corneal endothelium and the crystalline lens. ${ }^{24}$ Pupil ovalization is a well-recognized problem after implantation of anglesupported pIOLs. It is hypothesized that ischemic or inflammatory changes of the iris occur due to excessive compression of the haptic on the iris root. This can lead to sectoral iris atrophy and pupil ovalization. ${ }^{22}$ Rigid haptics and an oversized plOL may lead to pupil ovalization. ${ }^{13,25}$ Recent studies concerning the Cachet pIOL do not report pupil ovalization. ${ }^{16,17}$

The present study reported an acute endothelial cell loss of $-3.2 \% \pm 0.7 \%$, which is comparable with other reports of $-3.31 \%$ and $-5.38 \%$ acute endothelial cell loss. ${ }^{16,21}$ The mean change in central ECD from preoperatively to 1 year postoperatively was $-6.9 \% \pm 0.5 \%$. Kohnen and Klaproth reported an endothelial cell loss of $-4.8 \%$, and Mastropasqua et al. reported $-4.1 \% 1$ year after implantation. ${ }^{24,26}$ Although the chronic endothelial cell loss from 6 months to 2 years postoperatively in the angle-supported pIOL group $(-3.8 \% \pm 0.7 \%, n=129)$ was higher than the loss in the other 3 iris-fixated pIOLs (Artisan Myopia: $-2.1 \% \pm 0.9 \%, n=262$; Artisan Toric : $-2.9 \%$ $\pm 1.4 \%, n=59$; Artiflex: $-1.7 \% \pm 1.0 \%, n=177$ ) (Figure 9), the difference was not significant. This may be explained by the smaller number of patients at the 2-year follow-up.

The Cachet plOL offers an advantage with its small incision size and easy implantation technique compared with the iris-fixated models. However, in our study, the angle-supported plOL has a significantly higher acute surgical endothelial cell loss than the 3 iris-fixated plOLs. The reason for this higher acute loss is presently unknown. Possibly, the flexible nature of the single-piece design of the single-piece design of the acrylic Cachet pIOL may unfold more slowly than silicone material and be in closer contact with the endothelium during implantation and/or 
OVD removal. Of course, this is a hypothesis that warrants reproducible findings from other surgeons and additional research. When excluding the surgical loss, there were no significant differences in endothelial cell loss between the iris-fixated pIOLs and the angle-supported pIOL. To our knowledge, there are no reported studies comparing endothelial cell loss after Cachet implantation to other pIOL models.

A limitation of our study is the number of eyes available for follow-up examinations. Of the 158 included eyes in the angle-supported pIOL group, only 124 and 79 eyes reached a follow-up of 1 year and 2 years, respectively.

In conclusion, the Acrys of Cachet pIOL effectively corrects moderate to high myopia, with good predictability and stability. Regarding safety, no eye lost 2 or more lines of CDVA at the 2-year follow-up. Acute surgical endothelial cell loss was larger with the Cachet pIOL than with the Artisan Myopia, Artisan Toric, and Artiflex iris-fixated plOLs. Longer follow-up is necessary to establish long-term safety of this angle-supported pIOL for the corneal endothelium.

\section{WHAT WAS KNOWN}

- Iris-fixated pIOLs have been used successfully to correct moderate to high myopia, with endothelial cell loss as a minor complication.

- $\quad$ Iris-fixated pIOLs have a challenging implantation technique.

\section{WHAT THIS PAPER ADDS}

- The new angle-supported pIOL effectively corrected moderate to high myopia with good predictability and stability.

- Acute endothelial cell loss after implantation of the new angle-supported pIOL appears to be higher than with iris-fixated pIOLs in this single-center study. 


\section{REFERENCES}

1. Tahzib NG, Nuijts RM, Wu WY, Budo CJ. Long-term study of Artisan phakic intraocular lens implantation for the correction of moderate to high myopia: ten-year follow-up results. Ophthalmology 2007;114(6):1133-42.

2. Malecaze FJ, Hulin H, Bierer P, et al. A randomized paired eye comparison of two techniques for treating moderately high myopia: LASIK and artisan phakic lens. Ophthalmology 2002;109(9):1622-30.

3. El Danasoury MA, El Maghraby A, Gamali TO. Comparison of iris-fixed Artisan lens implantation with excimer laser in situ keratomileusis in correcting myopia between -9.00 and -19.50 diopters: a randomized study. Ophthalmology 2002;109(5):955-64.

4. Guell JL, Morral M, Gris O, et al. Five-year follow-up of 399 phakic Artisan-Verisyse implantation for myopia, hyperopia, and/or astigmatism. Ophthalmology 2008;115(6):1002-12.

5. Qasem Q, Kirwan C, O'Keefe M. 5-year prospective follow-up of Artisan phakic intraocular lenses for the correction of myopia, hyperopia and astigmatism. Ophthalmologica 2010;224(5):283-90.

6. Yuan X, Ping HZ, Hong WC, et al. Five-year follow-up after anterior iris-fixated intraocular lens implantation in phakic eyes to correct high myopia. Eye (Lond) 2012;26(2):321-6.

7. Saxena R, Boekhoorn SS, Mulder PG, et al. Long-term follow-up of endothelial cell change after Artisan phakic intraocular lens implantation. Ophthalmology 2008;115(4):608-13.e1.

8. Benedetti S, Casamenti V, Benedetti M. Long-term endothelial changes in phakic eyes after Artisan intraocular lens implantation to correct myopia: five-year study. J Cataract Refract Surg 2007;33(5):784-90.

9. Alio JL, Abdelrahman AM, Javaloy J, et al. Angle-supported anterior chamber phakic intraocular lens explantation causes and outcome. Ophthalmology 2006;113(12):2213-20.

10. Kohnen T, Kook D, Morral M, Guell JL. Phakic intraocular lenses: part 2: results and complications. J Cataract Refract Surg 2010;36(12):2168-94.

11. Coullet J, Mahieu L, Malecaze F, et al. Severe endothelial cell loss following uneventful angle-supported phakic intraocular lens implantation for high myopia. J Cataract Refract Surg 2007;33(8):1477-81.

12. Guell JL, Morral M, Kook D, Kohnen T. Phakic intraocular lenses part 1: historical overview, current models, selection criteria, and surgical techniques. J Cataract Refract Surg 2010;36(11):1976-93.

13. Huang D, Schallhorn SC, Sugar A, et al. Phakic intraocular lens implantation for the correction of myopia: a report by the American Academy of Ophthalmology. Ophthalmology 2009;116(11):224458.

14. van der Heijde GL. Some optical aspects of implantation of an IOL in a myopic eye. Eur J Implant Refract Surg 1989;1:245-8.

15. Holladay JT. Standardizing constants for ultrasonic biometry, keratometry, and intraocular lens power calculations. J Cataract Refract Surg 1997;23(9):1356-70.

16. Knorz MC, Lane SS, Holland SP. Angle-supported phakic intraocular lens for correction of moderate to high myopia: Three-year interim results in international multicenter studies. J Cataract Refract Surg 2011;37(3):469-80.

17. Kohnen T, Knorz MC, Cochener B, et al. AcrySof phakic angle-supported intraocular lens for the correction of moderate-to-high myopia: one-year results of a multicenter European study. Ophthalmology 2009;116(7):1314-21, 21.e1-3.

18. Doors M, Cals DW, Berendschot TT, et al. Influence of anterior chamber morphometrics on endothelial cell changes after phakic intraocular lens implantation. J Cataract Refract Surg 2008;34(12):2110-8. 
19. Tahzib NG, Bootsma SJ, Eggink FA, Nuijts RM. Functional outcome and patient satisfaction after Artisan phakic intraocular lens implantation for the correction of myopia. Am J Ophthalmol 2006;142(1):31-9.

20. Dupps WJ, Jr., Kohnen T, Mamalis N, et al. Standardized graphs and terms for refractive surgery results. J Cataract Refract Surg 2011;37(1):1-3.

21. Lane SS, Waycaster C. Correction of high myopia with a phakic intraocular lens: interim analysis of clinical and patient-reported outcomes. J Cataract Refract Surg 2011;37(8):1426-33.

22. Javaloy J, Alio JL, Iradier MT, et al. Outcomes of ZB5M angle-supported anterior chamber phakic intraocular lenses at 12 years. J Refract Surg 2007;23(2):147-58.

23. Plainer S, Wenzl E, Saalabian AA, et al. Long-term follow-up with I-CARE phakic IOLs. Br J Ophthalmol 2011;95(5):710-4.

24. Kohnen T, Klaproth OK. Three-year stability of an angle-supported foldable hydrophobic acrylic phakic intraocular lens evaluated by Scheimpflug photography. J Cataract Refract Surg 2010;36(7):1120-6.

25. Alio JL, de la Hoz F, Perez-Santonja JJ, et al. Phakic anterior chamber lenses for the correction of myopia: a 7-year cumulative analysis of complications in 263 cases. Ophthalmology 1999;106(3):45866.

26. Mastropasqua L, Toto L, Vecchiarino L, et al. AcrySof cachet phakic intraocular lens in myopic patients: visual performance, wavefront error, and lens position. J Refract Surg 2012;28(4):267-74. 


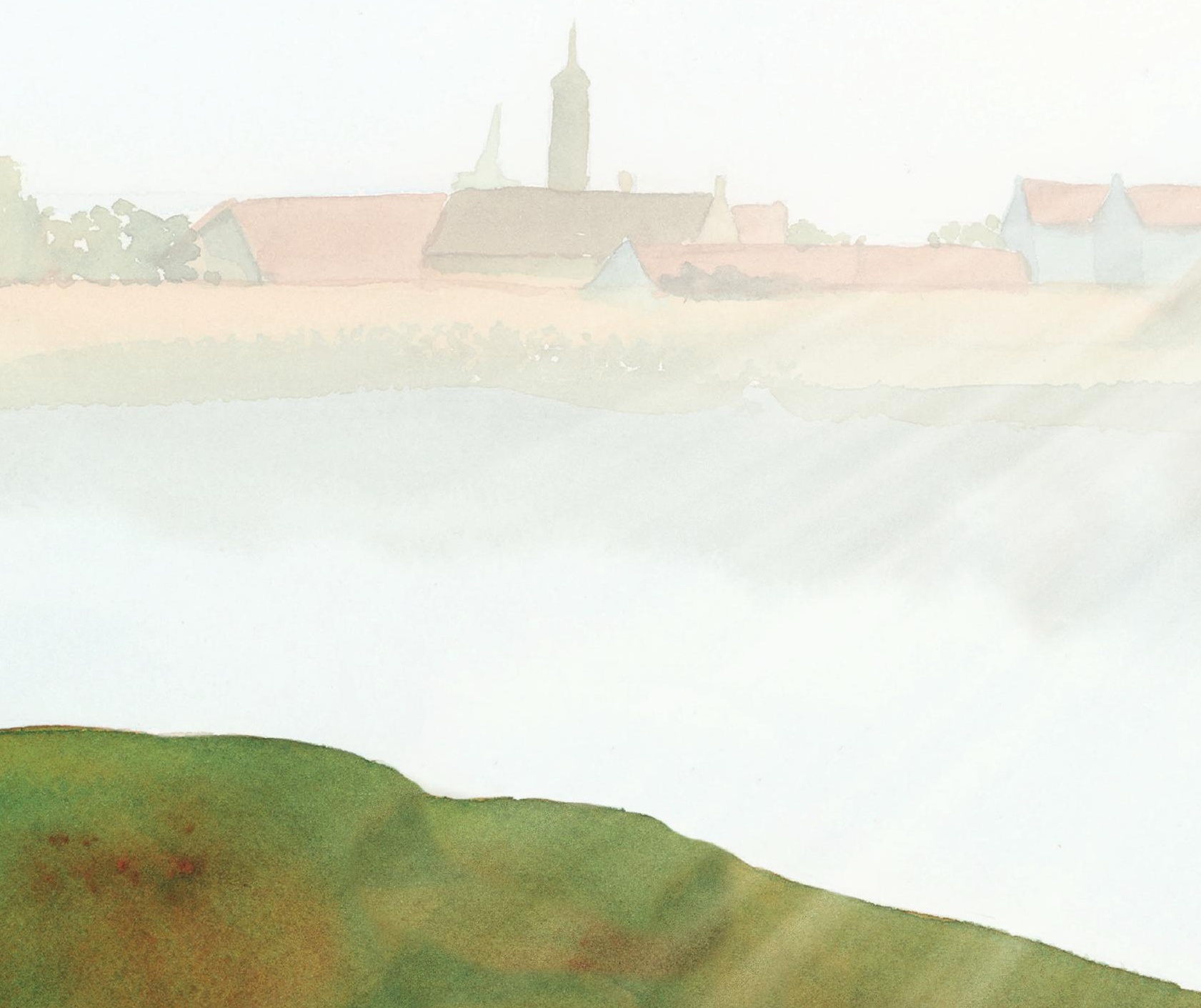




\section{CHAPTER 3}

Long-term endothelial cell loss in patients with Artisan Myopia and Artisan

Toric phakic intraocular lenses:

5 and 10 year results

Soraya MR Jonker, Tos TJM Berendschot, Annick E Ronden,

Isabelle EY Saelens, Noël JC Bauer, Rudy MMA Nuijts

Ophthalmology. 2018 Apr;125(4):486-494 


\section{ABSTRACT}

Purpose: To evaluate the long-term change in endothelial cell density (ECD) after the implantation of 2 types of rigid iris-fixated phakic intraocular lenses (pIOLs) for the treatment of myopia and astigmatism.

Design: Prospective, clinical cohort study.

Subjects: A total of 507 eyes of 289 patients receiving the Artisan Myopia or Artisan Toric (Ophtec B.V., Groningen, The Netherlands) iris-fixated plOL for the treatment of myopia or astigmatism at the University Eye Clinic Maastricht as of January 1998.

Methods: A total of 381 myopic and 126 toric plOLs were implanted. Five- and 10-year follow-ups were completed by 193 and 127 eyes implanted with the myopic pIOL and by 40 and 20 eyes implanted with the toric pIOL, respectively.

Main Outcome Measures: Chronic endothelial cell (EC) loss, percentage of eyes with a decrease of $\geq 25 \%$ in ECD, and percentage of eyes with an $E C D<1500$ cells $/ \mathrm{mm}^{2}$.

Results: Chronic EC loss was calculated from 6 months postoperatively to the end of followup and showed an annual ECD decline of 48 cells $/ \mathrm{mm}^{2}$ (standard error, 3.14) and 61 cells/ $\mathrm{mm}^{2}$ (standard error, 6.30) in the myopic $(P<0.001)$ and toric $(P<0.001)$ groups, respectively, resulting in a total EC loss of $16.6 \%$ and $21.5 \%$ from 6 months to 10 years postoperatively, respectively. Ten years after implantation, ECD had decreased by $\geq 25 \%$ in $7.9 \%$ and $6.3 \%$, whereas ECD was $<1500$ cells $/ \mathrm{mm}^{2}$ in $3.9 \%$ and $4.0 \%$ in the myopic and toric groups, respectively. Explantation of the pIOL occurred in $6.0 \%$ in the myopic group and $4.8 \%$ in the toric group. Risk factors for increased EC loss were a shallow anterior chamber depth $(A C D)(P \leq 0.005)$ and a smaller distance between central and peripheral plOL edge to the endothelium $(P \leq 0.005)$.

Conclusion: A significant linear chronic EC loss was reported after implantation with myopic or toric iris-fixated pIOLs. A smaller ACD and smaller distance between pIOL edge and endothelium were risk factors for EC loss. Modification of preoperative age-related ECD thresholds is indicated to maintain an ECD that warrants safe future combined pIOL explantation and cataract surgery. 


\section{INTRODUCTION}

Implantation of phakic intraocular lenses ( $\mathrm{plOL}$ ), whether angle supported, iris fixated, or positioned in the posterior chamber, is associated with an accelerated decrease in endothelial cell density (ECD). ${ }^{1-9}$ The magnitude of endothelial cell (EC) loss after pIOL implantation surpasses the physiological annual decrease of $0.6 \%$ as reported in 42 adults in a 1997 benchmark study. ${ }^{10}$ The importance of EC loss for assessing the safety of plOLs was emphasized in 2006 when the French Health Products and Safety Agency (I'Agence Française de Sécurité Sanitaire des Produits de Santé [AFSSAPS]) withdrew the foldable angle-supported Vivarte pIOL (Ioltech S.A., Perigny, France) from the market because of excessive EC loss. More recently, the American Academy of Ophthalmology (AAO) Task Force has formulated guidelines that define the percentage of eyes with a total EC loss equal to or more than 25\% after 3 years as an endpoint for clinical investigation of a new pIOL. In addition, the AFSSAPS guidelines describe an endothelial cell density (ECD) of less than 1500 cells/mm² as an explantation criterion.11, 12 However, so far none of the published studies have used these newly established EC loss criteria as outcome measures. In this study, we applied these criteria as outcome measures in our patient cohort of myopic and toric pIOLs that was followed over a 10-year period using the same specular microscope and ECD measurement protocols. 


\section{METHODS}

\section{Design}

From January 1998 to June 2016, 507 eyes of 289 patients received a myopic or toric irisfixated pIOL implant at the University Eye Clinic Maastricht, Maastricht University Medical Center, The Netherlands. Patients were prospectively evaluated preoperatively, and at 1 day, 1 week, and 1, 3, 6 and 12 months postoperatively in the first postoperative year. Regular follow-up continued with annual visits. The rigid myopic pIOL was implanted in 381 eyes of 209 patients, and 193 and 127 eyes completed the 5 and 10 year follow-up, respectively. The rigid toric pIOL was implanted in 126 eyes of 80 patients, with 40 and 20 eyes completing the 5- and 10-year follow-up, respectively.

The current study was performed in adherence to the tenets of the Declaration of Helsinki. The Maastricht University Medical Center Institutional Review Board stated that approval was not required for this study.

\section{Implantation criteria}

Before $\mathrm{pIOL}$ implantation, patients had to be aged $\geq 18$ years and have a stable refraction for at least 2 years. Anterior chamber depth (ACD) from the corneal endothelium to the anterior plane of the crystalline lens had to be at least $2.8 \mathrm{~mm}$ with a maximal clear lens rise (CLR) of $600 \mu \mathrm{m}^{1,13,14}$ Preoperative minimal ECD depended on age with $>2800$ cells $/ \mathrm{mm}^{2}$ required for patients aged 21 to 25 years, $>2650$ cells $/ \mathrm{mm}^{2}$ for patients aged 26 to 30 years, $>2400$ cells/ $\mathrm{mm}^{2}$ for patients aged 31 to 35 years, $>2200$ cells $/ \mathrm{mm}^{2}$ for patients aged 36 to 45 years, and >2000 cells $/ \mathrm{mm}^{2}$ in patients aged more than 45 years. ${ }^{1,15}$

This article does not contain data of patients treated with iris-fixated pIOLs in keratoconus or irregular astigmatism or patients treated with iris-fixated plOLs after corneal transplantation. Data from a subset of patients from the present study was reported in previous studies. ${ }^{16-19}$

\section{Phakic intraocular lenses and surgical technique}

The Artisan Myopia pIOL is a 1-piece, polymethyl methacrylate, rigid lens with a convex-concave optic and a total diameter of $8.5 \mathrm{~mm}$. The optic diameter is variable and depends on the required refractive correction: pIOLs from -1.0 to - 15.5 diopters (D) are available in a 6.0-mm optic diameter, whereas a 5.0-mm optic diameter is available for plOL powers from-1.0 to -23.5 D.

The Artisan Toric plOL is a 1-piece, polymethyl methacrylate, rigid lens with a convex-concave optic, a spherical power ranging from +14.0 to $-22.0 \mathrm{D}$, and a cylindrical power of up to $-7.5 \mathrm{D}$. The total diameter is $8.5 \mathrm{~mm}$ with an optic diameter of $5.0 \mathrm{~mm}$. Lens power calculations were performed by the manufacturer using the formula of van der Heijde et al. ${ }^{20}$ 
All surgeries were performed by the same surgeon (R.M.M.A.N.) at the University Eye Clinic Maastricht under general or local anesthesia. Previous reports by our group have described the surgical procedure and postoperative medication regimen. ${ }^{16-19}$

\section{Evaluation}

Preoperative examination consisted of subjective and cycloplegic refraction, Snellen uncorrected distance visual acuity (VA) and corrected distance VA measurements, and slit-lamp examination, including Goldmann applanation tonometry and fundoscopy. Additional measurements consisted of corneal topography (Orbscan [Bausch \& Lomb, Rochester, NY, USA], Pentacam HR [OCULUS Optikgeräte GmbH, Wetzlar, Germany], Sirius [Schwind eye-tech-solutions GmbH \& Co. KG, Kleinostheim, Germany]), biometry (A2500 [SonomedEscalon, New Hyde Park, NY, USA], IOLMaster [Carl Zeiss AG, Oberkochen, Germany]), anterior segment optical coherence tomography (OCT) (Visante [Carl Zeiss AG, Oberkochen, Germany]) and specular microscopy (NONCON ROBO PACHY SP9000 S/N PK1-1137 [KONAN MEDICAL Inc., Nishinomiya, Japan]). All preoperative measurements were performed 1 week after removal of soft contact lenses and 2 weeks after removal of rigid gas-permeable contact lenses.

From 2006 onward, OCT was used to perform preoperative pIOL simulation to measure the $A C D$, the vault between the $\mathrm{pIOL}$ and crystalline lens, the distance between the anterior $\mathrm{pIOL}$ and the endothelium, and clear lens rise as reported previously.1,13,14, 18,21,22 Annual postoperative follow-up visits consisted of subjective refraction, Snellen uncorrected distance VA and corrected distance VA measurements, slit-lamp examination, tonometry, corneal topography, anterior segment OCT, and specular microscopy.

In respect of the known variation between specular microscopes and the influence of this variation on the correct calculation of EC loss, all eyes continued their measurements with the same specular microscope. ${ }^{23-26}$ Per protocol, the mean ECD in each eye was calculated by determining the mean of 3 consecutive measurements of 50 central ECs using the manual center-to-center method. ${ }^{27}$

\section{Outcome measures}

The definitions of outcome measures were based on the recent guidelines of the AAO and AFSSAPS, describing the percentage of eyes reaching the AAO end point (i.e., EC loss $\geq 25 \%$ compared with the preoperative measurement) and AFSSAPS explantation criterion (i.e., ECD $<1500$ cells $/ \mathrm{mm}^{2}$ ). ${ }^{11,12}$ We calculated the mean ECD 5 and 10 years after pIOL implantation, as well as the annual EC loss. To adhere to the AAO-defined guidelines, we not only presented the percentage of eyes meeting the AAO-defined end point after 5 and 10 years but also added the percentage of eyes meeting this end point after 3 years. ${ }^{12}$ 


\section{Statistical analysis}

Statistical analysis was performed using SPSS for Windows (version 23, IBM, Armonk, NY, USA). All VA measurements were converted from Snellen VA to logarithm of the minimum angle of resolution (logMAR) VA prior to statistical analysis. Descriptive analyses were performed to compute mean and standard deviation ( \pm standard deviation) in primary outcome measures and preoperative characteristics. Longitudinal changes were analyzed using a linear mixed-model analysis with an eye identification number as a grouping variable and time as a covariate. The best fitted covariance structure was selected using the Bayesian information criterion. Similar to previous reports on $\mathrm{EC}$ loss, the effect of $\mathrm{plOL}$ implantation on the endothelium (i.e., acute EC loss) was assessed from preoperatively to 6 months postoperatively, whereas long-term changes (i.e., chronic EC loss) were assessed from 6 months postoperatively to the end of follow-up. Kaplan-Meier and multivariate Cox regression analyses were performed to assess survival from implantation to the occurrence of the AAO-defined end point (i.e., total EC loss $\geq 25 \%$ ) and the AFSSAPS-defined explantation criterion (i.e., ECD < 1500 cells $/ \mathrm{mm}^{2}$ ). P values were considered significant if the $P$ value was $<0.05$. 


\section{RESULTS}

From January 1998 to June 2016, 381 eyes of 209 patients were implanted with the myopic pIOL and 126 eyes of 80 patients were implanted with the toric pIOL. Mean follow-up was $94.9 \pm 56.5$ months in the myopic group and $50.4 \pm 46.8$ months in the toric group. Baseline characteristics of both groups are depicted in Table 1.

After extensive parental consultation, 4 eyes of 3 patients younger than 18 years were implanted with a myopic pIOL because of a -7.0 D anisometropia in 1 eye of 1 patient (age 14) with contact lens intolerance, because of contact lens intolerance in 2 eyes of 1 patient (age 15) with a -30.0 and -18.5 D preoperative refraction, and to prevent amblyopia in 1 eye of a 5-year old-12.0 D anisometropic and contact lens-intolerant patient. Between 1998 and 2006, there were no definitive thresholds formulated by the Netherlands Society for Refractive Surgery (Nederlands Gezelschap voor Refractie Chirurgie [NGRC]) with respect to preoperative ECD. ${ }^{15}$ As a result, myopic plOLs were implanted in 16 eyes of 12 patients, and toric pIOLs in 4 eyes of 4 patients with an ECD lower than 2000 cells $/ \mathrm{mm}^{2}$.

\section{Endothelial Cell Density}

The mean ECD preoperatively and at 6 months and 5 and 10 years postoperatively is reported in Table 2 and Figure 1. There was no significant acute EC loss from preoperatively to 6 months postoperatively in either the myopic group $(P=0.35)$ or toric group $(P=0.59)$.

With respect to chronic EC loss, we found a mean annual ECD decline of $48 \mathrm{cell} / \mathrm{s} / \mathrm{mm}^{2}$ (standard error, 3.14) per year in the myopic group $(P<0.001)$ and a mean annual ECD decline of $61 \mathrm{cells} / \mathrm{mm}^{2}$ (standard error, 6.30) per year in the toric group ( $P<0.001)$. By using these findings to compute the percentage of EC loss, from 6 months to 5 years postoperatively in the myopic and toric groups, these results equal a proportional EC loss of 7.9\% and 10.2\%, and from 6 months to 10 years postoperatively these results equal a proportional EC loss of $16.6 \%$ and $21.5 \%$, respectively. When correcting for a physiological EC loss of $0.6 \%$ per year,, 10 the plOL-related total chronic EC loss from 6 months to 5 years is $5.2 \%$ and $7.5 \%$, and $10.9 \%$ and $15.8 \%$ from 6 months to 10 years in the myopic and toric groups respectively. When performing a direct subgroup analysis, comparing ECD preoperatively and 5 and 10 years postoperatively, we found a total EC loss of $4.1 \%$ and $11.5 \%$ in the myopic and $11.9 \%$ and $18.5 \%$ in the toric group, respectively.

The AAO-defined end point of an EC loss $\geq 25 \% 3$ years after implantation was reached in $1.6 \%$ of eyes in the myopic and in $0.8 \%$ of eyes in the toric group. For 5 and 10 years after implantation, these proportions were $1.8 \%$ and $7.9 \%$, and $3.2 \%$ and $6.3 \%$ in the myopic and toric groups, respectively. The percentage of eyes that reached the AFSSAPS-defined explantation criterion of ECD $<1500$ cells $/ \mathrm{mm}^{2}$ after 5 and 10 years was $0.8 \%$ and $3.9 \%$ in the myopic group and $3.2 \%$ and $4.0 \%$ in the toric group, respectively. 
Median survival time (i.e., time until 50\% of eyes will reach the AAO-defined endpoint or AFSSAPS-defined explantation criterion) was 180 months in the myopic group and could not be calculated in the toric group because there were too few eyes reaching the defined endpoint or explantation criterion (Figure 2).

In 23 eyes of 16 patients (6.0\%) in the myopic group and 6 eyes of 5 patients (4.8\%) in the toric group, EC loss or corneal decompensation resulted in explantation of the plOL after $11.9 \pm 2.7$ and $7.4 \pm 2.6$ years, respectively (Table 3 ). Only 1 myopic pIOL (0.3\%) was explanted because of EC loss within 5 years, and 4 eyes of 4 patients (1.0\%) required pIOL explantation due to EC loss within 10 years of pIOL implantation. Likewise, only 1 toric pIOL (0.8\%) was explanted due to EC loss within 5 years and in 4 eyes of 4 patients (3.2\%) within 10 years. Unfortunately, because of the small number of eyes requiring $\mathrm{pIOL}$ explantation because of $\mathrm{EC}$ loss, a median survival time (i.e., time until 50\% of eyes requires explantation) could not be calculated (Figure 3).

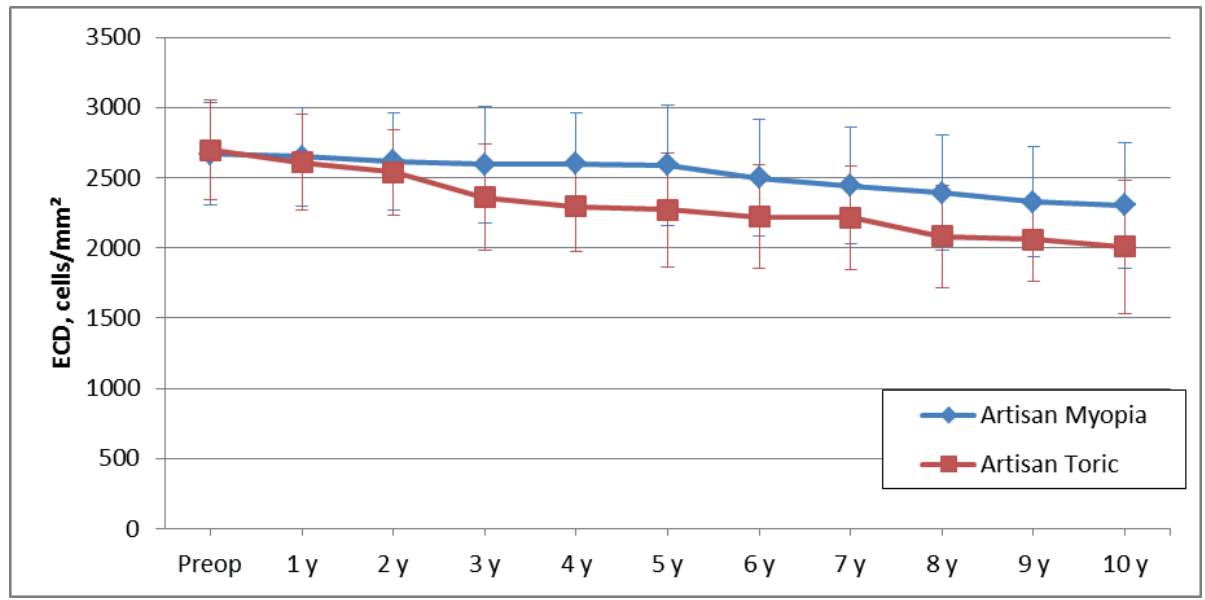

Figure 1. Mean endothelial cell density (ECD) from preoperatively to 10 years postoperatively in eyes implanted with rigid iris-fixated myopic $(n=381)$ and toric $(n=126)$ phakic intraocular lenses $($ mean \pm standard deviation). $\mathrm{n}=$ number of eyes; $\mathrm{y}=$ years. 


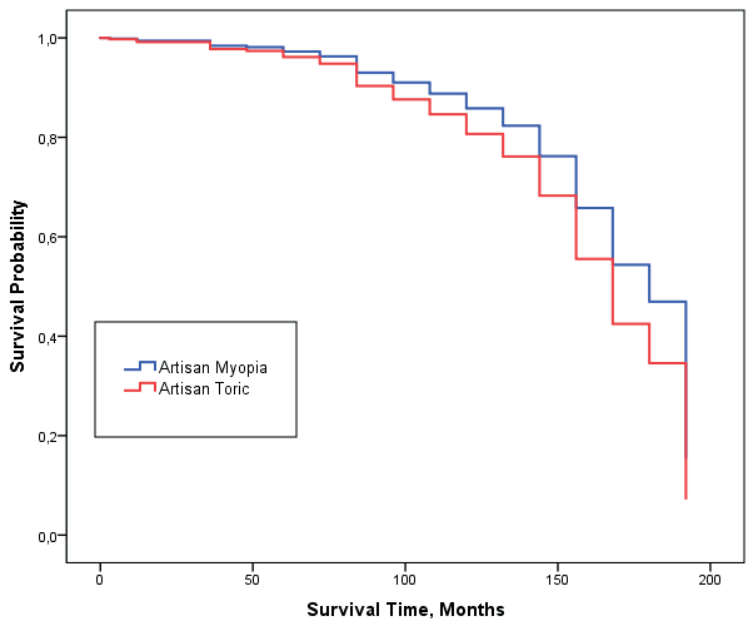

Figure 2. Survival curve for reaching the American Academy of Ophthalmology (AAO) end point (i.e. 25\% decrease in endothelial cell density [ECD]) or French Health Products and Safety Agency (AFSSAPS) explantation criterion (i.e., ECD $<1500$ cells $/ \mathrm{mm}^{2}$ ) in eyes implanted with rigid iris-fixated myopic $(\mathrm{n}=$ 381) and toric ( $n=126$ ) phakic intraocular lenses. $n=$ number of eyes.

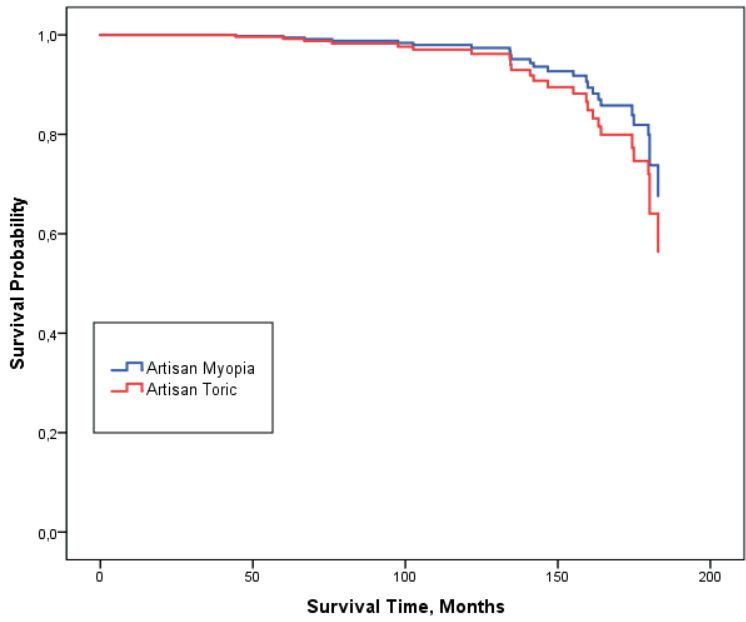

Figure 3. Survival curve for reaching endothelial cell (EC) loss-related phakic intraocular lens explantation in eyes implanted with rigid iris-fixated myopic $(n=381)$ and toric $(n=126)$ phakic intraocular lenses. $n$ = number of eyes. 


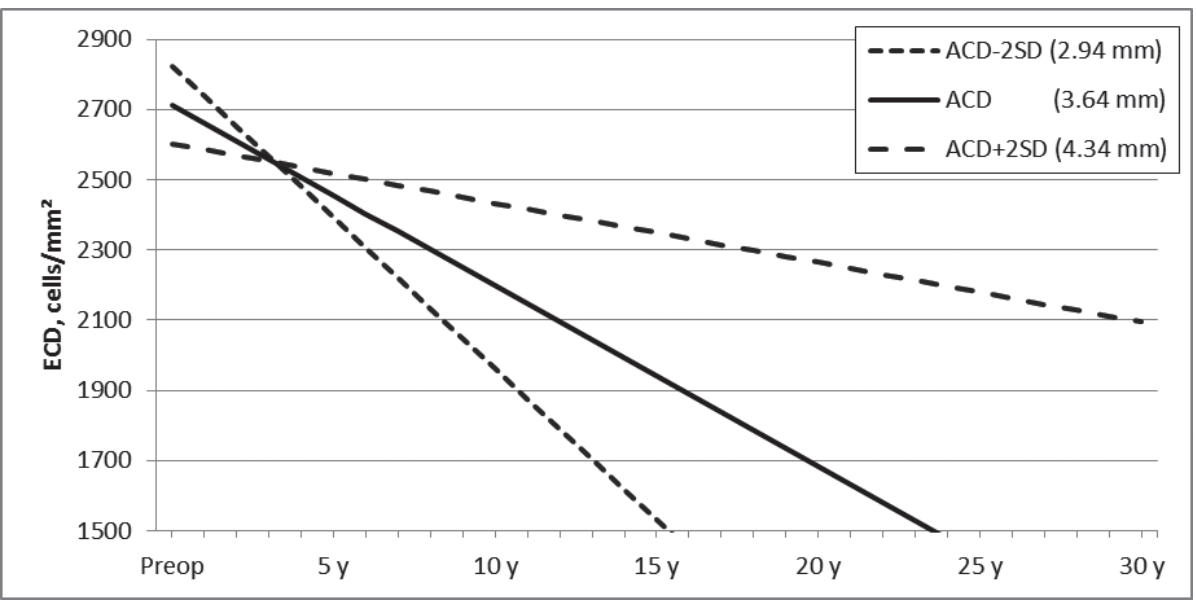

Figure 4. Differences in linear decrease in endothelial cell (ECD) with changing preoperative anterior chamber depths (ACDs) in eyes implanted with rigid iris-fixated myopic $(n=381)$ and toric $(n=126)$ phakic intraocular lenses. $\mathrm{n}$ = number of eyes; SD = standard deviation; $y=$ years.

\section{Risk Factors}

Additional analyses were performed to evaluate which eyes were at risk for an increased EC loss. Univariate risk factors for increased EC loss in a linear mixed-model were smaller preoperative ACD $(P<0.001)$, smaller distance from the central plOL edge to the endothelium $(P=0.008)$ and peripheral plOL-edge to the endothelium $(P=0.013)$, younger preoperative age $(P<0.001)$, and higher preoperative ECD ( $P=0.008)$. Based on the anatomy of the anterior chamber, the position of the pIOL induces a strong correlation between ACD and central or peripheral pIOL edge to the endothelium distance. Therefore, 3 different multivariate linear-mixed models were fitted to the data including either the ACD, central or peripheral pIOL edge to the endothelium distance, and the above mentioned univariate risk factors. This resulted in 3 final simplified models: 1 model describing a lower preoperative age $(P=0.001)$ and smaller preoperative ACD $(P<0.001)$ as risk factors and 2 models reporting only smaller central $(P=0.002)$ and peripheral $(P=0.003) \mathrm{plOL}$ edge to the endothelium as significant risk factors. The effects of changing age and $A C D$, and central or peripheral pIOL edge to the endothelium distance on EC loss are depicted in Tables 4 and 5 and Figure 4.

To assess which risk factors influenced survival, multivariate Cox regression analyses were performed. The effect of a risk factor on survival was expressed as a hazard ratio (HR), with an $H R>1$ or $<1$ indicating an increased or decreased probability of a shorter survival, respectively. All risk factors identified in the univariate linear mixed-model analyses were added to 3 different multivariate Cox regression models composed around either the ACD, central or peripheral $\mathrm{pIOL}$ edge to the endothelium distance. After excluding insignificant risk factors, smaller ACD (HR, 5.69; 95\% Confidence Interval [CI], 2.71-11.96; $P<0.001$ ), smaller central plOL edge to 
the endothelium distance ( $\mathrm{HR}, 5.35 ; 95 \% \mathrm{Cl}, 2.50-11.46 ; \mathrm{P}<0.001)$, and smaller peripheral plOL edge to the endothelium distance ( $H R, 5.94 ; 95 \% \mathrm{Cl}, 2.31-15.26 ; P<0.001)$ were identified as risk factors for reaching the AAO end point (i.e., $\geq 25 \%$ total EC loss) or AFSSAPS explantation criterion (i.e., ECD $<1500$ cells $/ \mathrm{mm}^{2}$ ). Similar results are reported with regard to survival until explantation, reporting smaller ACD (HR, 18.07; 95\% CI, 4.22-77.37; $P<0.001)$, smaller central $\mathrm{pIOL}$ edge to the endothelium distance (HR, 22.93; 95\% CI 3.52-149.29; $P=0.003$ ), and smaller peripheral pIOL edge to the endothelium distance ( $H R, 24.44 ; 95 \% \mathrm{Cl}, 2.85-209.87 ; P=0.004)$ as significant risk factors.

Table 1. Patient and phakic intraocular lens characteristics at baseline (mean \pm standard deviation [sd]).

\begin{tabular}{lcc}
\hline & Artisan Myopia & Artisan Toric \\
\hline Age, y & $41.2 \pm 10.7$ (range 5.3 to 62.3) & $38.8 \pm 11.4$ (range 18.5 to 68.2) \\
Ratio male/female, \% & $35 / 65$ & $49 / 51$ \\
Number of eyes & 381 & 126 \\
Number of patients & 209 & 80 \\
MRSE, D & $-12.72 \pm 5.07$ (range -30.50 to 0.00) & $-6.52 \pm 8.52$ (range -22.25 to 7.50) \\
Cylinder, D & $-1.22 \pm 0.80$ (range -4.25 to 0.00) & $-3.52 \pm 1.58$ (range -8.50 to -1.00) \\
CDVA, logMAR & $0.13 \pm 0.18$ (range -0.18 to 1.70) & $0.11 \pm 0.15$ (range -0.18 to 0.70) \\
IOP, mmHg & $14.7 \pm 3.2$ (range 6.0 to 30.0) & $15.1 \pm 3.3$ (range 7.0 to 22.0) \\
ACD, ${ }^{*}$ mm & $3.68 \pm 0.34$ (range 2.64 to 4.80) & $3.49 \pm 0.35$ (range 2.82 to 4.99) \\
AXL, mm & $28.18 \pm 2.20$ (range 24.29 to 35.47) & $25.68 \pm 3.40$ (range 19.95 to 32.74) \\
Implanted Lens Power & $-13.15 \pm 3.83$ (range -23.5 to -5.0) & $-4.68 \pm 9.23$ (range -19.5 to 11.5) \\
Sphere, D & NA & $-3.54 \pm 1.80$ (range -8.0 to -1.0) \\
Cylinder, D & &
\end{tabular}

Year (y), manifest refractive spherical equivalent (MRSE), diopters (D), logarithm of the minimum angle of resolution (logMAR), corrected distance visual acuity (CDVA), intraocular pressure (IOP), anterior chamber depth (ACD), axial length (AXL). NA = not applicable. * Measured from the corneal epithelium.

Table 2. Mean endothelial cell density (ECD) in eyes implanted with a rigid iris-fixated myopic or toric phakic intraocular lens (mean \pm standard deviation [SD]).

\begin{tabular}{ccccc}
\hline & $\mathbf{n}$ & Artisan Myopia & $\mathbf{n}$ & Artisan Toric \\
\hline ECD (cells/mm²) & & & & \\
Preoperatively & 381 & $2670 \pm 365$ (range 1144 to 3753) & 126 & $2695 \pm 359$ (range 1760 to 3607) \\
Acute: 6 months & 267 & $2674 \pm 346$ (range 1757 to 3584) & 79 & $2665 \pm 368$ (range 1623 to 3466) \\
Chronic: 5 years & 193 & $2588 \pm 425$ (range 478 to 3711) & 40 & $2270 \pm 406$ (range 1296 to 3180) \\
Chronic: 10 years & 127 & $2302 \pm 451$ (range 556 to 3238) & 20 & $2009 \pm 475$ (range 1178 to 2807) \\
\hline
\end{tabular}

Number of eyes (n) 
Table 3. Incidence and indications of phakic intraocular lens explantations in patients implanted with rigid iris-fixated myopic $(n=381)$ and toric $(n=126)$ phakic intraocular lenses (mean \pm standard deviation $[\mathrm{SD}])$.

\section{Artisan Myopia}

$\begin{array}{ccc}\text { No. eyes } & \text { Ratio (\%) } & \text { Time } \\ \text { [patients] } & & \text { (months) }\end{array}$

\begin{tabular}{|c|c|c|c|}
\hline \multicolumn{4}{|l|}{ Explantation } \\
\hline Cataract & $44[30]$ & 11.55 & $100.4 \pm 33.1$ (range 20.7 to 163.7 ) \\
\hline EC-loss & 14 [9] & 3.67 & $145.9 \pm 35.0$ (range 44.4 to 182.9$)$ \\
\hline Cataract and EC-loss & $4[3]$ & 1.05 & $157.6 \pm 23.5$ (range 120.0 to 179.7 ) \\
\hline Corneal edema ${ }^{1,2}$ & $5[4]$ & 1.31 & $108.1 \pm 27.3$ (range 60.0 to 134.5 ) \\
\hline High IOP & $4[2]$ & 1.05 & $53.2 \pm 26.5$ (range 25.7 to 80.3 ) \\
\hline Anisometropia & $1[1]$ & 0.26 & 15.6 \\
\hline Decentration & $1[1]$ & 0.26 & 1.4 \\
\hline Recurrent retinal detachment ${ }^{3}$ & $1[1]$ & 0.26 & 82.8 \\
\hline Unstable VA & NA & NA & NA \\
\hline \multicolumn{4}{|l|}{ Combined explantation } \\
\hline DSAEK ${ }^{1}$ & $1[1]$ & 0.26 & 60.0 \\
\hline $\mathrm{PK}^{2}$ & $1[1]$ & 0.26 & 102.6 \\
\hline Retinal surgery ${ }^{3}$ & $1[1]$ & 0.26 & 82.8 \\
\hline
\end{tabular}

Not applicable (NA), endothelial cell (EC) loss, intraocular pressure (IOP), visual acuity (VA), Descemet stripping automated endothelial keratoplasty (DSAEK), penetrating keratoplasty (PK). 


\section{Artisan Toric}

\begin{tabular}{|c|c|c|}
\hline $\begin{array}{l}\text { No. eyes } \\
\text { [patients] }\end{array}$ & Ratio (\%) & $\begin{array}{c}\text { Time } \\
\text { (months) }\end{array}$ \\
\hline $3[3]$ & 2.38 & $50.5 \pm 26.6$ (range 13.8 to 75.8$)$ \\
\hline $5[4]$ & 3.97 & $79.4 \pm 24.2$ (range 48.6 to 121.7$)$ \\
\hline $1[1]$ & 0.79 & 136.9 \\
\hline NA & NA & NA \\
\hline NA & NA & NA \\
\hline NA & NA & NA \\
\hline NA & NA & NA \\
\hline NA & NA & NA \\
\hline $1[1]$ & 0.79 & 10.6 \\
\hline NA & NA & NA \\
\hline NA & NA & NA \\
\hline NA & NA & NA \\
\hline
\end{tabular}

${ }^{1}$ Corneal edema requiring DSAEK in one eye of one patient.

${ }^{2}$ Corneal edema requiring PK in one eye of one patient.

${ }^{3}$ Recurrent retinal detachment requiring retinal surgery in one eye of one patient. 
Table 4. Changes in endothelial cell (EC) loss over 5 and 10 years (y) with altering preoperative age and anterior chamber depth in eyes implanted with iris-fixated myopic $(n=381)$ or toric $(n=126)$ phakic intraocular lenses.

\begin{tabular}{|c|c|c|c|c|}
\hline & \multirow[b]{3}{*}{$(\mathrm{mm})$} & \multicolumn{3}{|c|}{ Preoperative Anterior Chamber Depth* } \\
\hline & & Mean - 2SD & Mean & Mean + 2SD \\
\hline & & 2.94 & 3.64 & 4.34 \\
\hline \multicolumn{5}{|l|}{ EC-Ioss: 5 y } \\
\hline Preoperative Age & (years) & & & \\
\hline Mean - 2SD & 18.7 & $17.4 \%$ & $12.3 \%$ & $6.7 \%$ \\
\hline Mean & 40.6 & $15.3 \%$ & $9.5 \%$ & $3.3 \%$ \\
\hline Mean + 2SD & 62.5 & $12.6 \%$ & $6.1 \%$ & $N A^{\#}$ \\
\hline \multicolumn{5}{|l|}{ EC-loss: 10 y } \\
\hline Preoperative Age & (years) & & & \\
\hline Mean - 2SD & 18.7 & $34.9 \%$ & $24.5 \%$ & $13.4 \%$ \\
\hline Mean & 40.6 & $30.5 \%$ & $19.0 \%$ & $6.5 \%$ \\
\hline Mean + 2SD & 62.5 & $25.3 \%$ & $12.3 \%$ & $N A^{\#}$ \\
\hline
\end{tabular}

Standard deviation (SD), not applicable (NA).

*Measured from the corneal epithelium to the anterior pole of the crystalline lens.

"Gain in endothelial cell density.

Table 5. Changes in endothelial cell (EC) loss over 5 and 10 years (y) with altering distance from the central or peripheral phakic intraocular lens ( $\mathrm{plOL}$ ) edge to the corneal endothelium in eyes implanted with iris-fixated myopic $(n=381)$ or toric $(n=126)$ phakic intraocular lenses.

\begin{tabular}{|c|c|c|c|c|}
\hline & & \multicolumn{3}{|c|}{ Central pIOL-edge to the Endothelium Distance } \\
\hline & & Mean-2SD & Mean & Mean + 2SD \\
\hline & $(\mathrm{mm})$ & 1.60 & 2.17 & 2.74 \\
\hline EC-loss: 5 y & & $13.5 \%$ & $10.3 \%$ & $6.7 \%$ \\
\hline \multirow[t]{4}{*}{ EC-loss: 10 y } & & $27.0 \%$ & $20.5 \%$ & $13.4 \%$ \\
\hline & & \multicolumn{3}{|c|}{ Peripheral pIOL-edge to the Endothelium Distance } \\
\hline & & Mean - 2SD & Mean & Mean + 2SD \\
\hline & $(\mathrm{mm})$ & 1.00 & 1.55 & 2.10 \\
\hline EC-loss: 5 y & & $13.0 \%$ & $10.2 \%$ & $6.9 \%$ \\
\hline EC-loss: $10 y$ & & $26.0 \%$ & $20.3 \%$ & $13.8 \%$ \\
\hline
\end{tabular}

Standard deviation (SD). 


\section{DISCUSSION}

Reporting long-term ECD and EC loss data in studies on pIOLs is important because it can provide data for establishing guidelines on risk assessment and follow-up strategies for implantation of pIOLs. In both the distant and recent past, a multitude of anterior chamber angle-supported and iris-fixated pIOLs have been taken of the market due to excessive EC loss and complications like pupil ovalization and cataract formation.1,2,11,12 Subsequently, researchers and authorities have been pressed to formulate guidelines specifying safety criteria for implantation of anterior chamber pIOLs. 1,2, 11, 17, 28-30 In the current study, we applied recently formulated criteria by the AAO Task Force and the AFSSAPS on EC analysis after pIOL implantation to a cohort of myopic and toric pIOL patients with a follow-up of 10 years. ${ }^{11,12}$ We believe that our patient cohort is unique in that over the entire 10-year follow-up period the same protocol and the same specular microscope was used, thereby decreasing the variability in data acquisition and increasing the reliability of our ECD data. ${ }^{23-26}$

\section{Endothelial Cell Density}

In this study, annual EC loss was calculated in cells $/ \mathrm{mm}^{2}$ per year using mixed-model linear regression analysis, enabling us to make full use of all gathered data from patients implanted with an iris-fixated myopic or toric $\mathrm{IOL}$, and calculating a generalized mean EC loss on the basis of the loss per patient (i.e., individual slopes).

Our results showed a linear decrease in ECD over a 10-year period, without any signs of exponential EC loss or reaching a so-called plateau or stable ECD during this time. The results of these analyses were used to calculate the percentage of total EC loss and the percentage of total EC loss corrected for an annual physiological loss of 0.6\%.5,10 Our 5-year results computed by linear mixed-model analysis are in line with previous studies reporting a total EC loss of $4.6 \%$ after 6 months $^{4} ; 3.6 \%$ and $4.8 \%$ after 3 years ${ }^{6,7} ; 1.5 \%, 2.07 \%, 12.5 \%$, and $13.4 \%$ after 4 years ${ }^{3,7,9}$; $3.26 \%$ after 6 years ${ }^{* 5} ; 8.5 \%$ after 7 years $* 8$; and $8.9 \%$ after 10 years ${ }^{*} *^{*}=$ adjusted for $0.6 \%$ of annual physiological loss). ${ }^{5}$

Key to understanding the difference between the 10-year results reported in this study and the literature is the ECD measurement method and data analysis. Contrary to the current study, a higher variability will be induced in the data of previous studies because different specular microscopes were used during follow-up,, 5 the ECD measurement method was altered during follow-up, ${ }^{8}$ the type of specular microscope used was not specified, ${ }^{4,31,32}$ the location of ECD measurements varied (i.e., centrally or peripherally), and the method of ECD measurements was not mentioned. 4, 5, 7,9,31,32 Moreover, it appears that most studies compared means or only used descriptive statistics instead of performing a longitudinal analysis, such as a mixed-model linear regression analysis..$^{3-7,31-33}$ Mixed-model linear 
regression analyses as performed in this study are especially useful when testing for significant changes over time (i.e., per year) and are to be preferred over tests assessing the mean differences between 2 individual time points (i.e., $t$ test). The results of the direct subgroup analysis, implying a nonlinear increase in EC loss between 5 and 10 years in the myopic group, should be interpreted only as an indication for continued follow-up rather than a definitive finding. Additional research on EC loss 15 or 20 years after pIOL implantation is required to put these results into perspective.

Over the past years, widely accepted guidelines have been implemented with regard to standardized reporting of refractive and visual outcomes in studies on refractive surgery. ${ }^{34}$ However, no standardized guidelines exist for reporting ECD data after refractive surgery (e.g., implantation of phakic IOLs). In early 2017, the AAO Task Force published a guideline with regard to standardized reporting on EC loss in studies on new types of pIOLs. ${ }^{12}$ The key point of this guideline is to report the percentage of eyes with $\geq 25 \%$ EC loss 3 years after pIOL implantation. However, the guideline does not provide a recommendation with respect to the percentage of eyes with $\geq 25 \%$ EC loss that would warrant withdrawal of a specific pIOL from the market, nor does it make a statement whether any individual case with $\geq 25 \%$ EC loss warrants explantation of the pIOL in that particular eye. The AFSSAPS however, has recommended an ECD $<1500$ cells $/ \mathrm{mm}^{2}$ or a total EC loss of $30 \%$ as thresholds for $\mathrm{pIOL}$ explantation. ${ }^{11}$ This value of 1500 cells $/ \mathrm{mm}^{2}$ is selected because it is assumed that this ECD threshold will tolerate pIOL explantation and cataract surgery without compromising the integrity of the corneal endothelium in the long run. Given the difficult decision to explant plOLs in individual cases of highly myopic patients that desire spectacle independency, a global consensus on explantation criteria would be highly desirable; therefore, we propose to compose an international working group that sets thresholds for EC loss that warrant pIOL explantation. Following the AAO guidelines, $1.6 \%$ and $0.8 \%$ of eyes in our myopic and toric group reached the endpoint of EC loss $\geq 25 \%$ after 3 years, values that increased to $7.9 \%$ and $6.3 \%$ of eyes after 10 years. Given the young age of most patients undergoing a pIOL implantation, we believe that 10 years of endothelial safety data certainly should be included in the decision making for explantation of plOLs. Pending international consensus, we have meanwhile adopted the threshold level of $<1500$ cells $/ \mathrm{mm}^{2}$ in our clinic as a criterion for pIOL explantation. In the present study, $0.8 \%$ and $3.9 \%$ of eyes from the myopic group had an ECD $<1500$ cells $/ \mathrm{mm}^{2}$ after 5 and 10 years, while these figures were $3.2 \%$ and $4.0 \%$ in the toric group, respectively. Endothelial cell loss resulted in plOL explantation in 4 eyes of 4 patients in the myopic (1.0\%) and toric (3.8\%) groups after 10 years. In total, $6.0 \%$ of the implanted myopic and $4.8 \%$ of the implanted toric plOLs had to be explanted due to EC loss after a mean 11.9 and 7.4 years, respectively. Unfortunately, it was not possible to compare our results with previous reports because no previous study reported the percentage of eyes with an $E C D<1500$ cells $/ \mathrm{mm}^{2}$. Because of the small number of eyes requiring $\mathrm{pIOL}$ 
explantation due to EC loss, it was also not possible to compose a median survival describing how long it would take until $50 \%$ of eyes would reach an ECD $<1500$ cells $/ \mathrm{mm}^{2}$ or require pIOL explantation due to EC loss. This underlines earlier findings with angle-supported anterior chamber pIOLs in that it may take many years before the endothelial safety profile of a pIOL is known. ${ }^{35}$

In addition to presenting new guidelines on reporting ECD, the AAO guideline also refers to clause D.4.2 of American National Standards Institute (ANSI) standard Z80.13 (ANSI Z80.13 Phakic Intraocular Lenses standard [clause D.4.2]) for recommendations on how ECD measurements should be performed. Clause D.4.2 recommends 3 acceptable specular microscopy measurements of the central cornea to account for differences in the measurement location and issues an ECD measurement of at least 100 clearly identifiable cells using the center-to-center method. To decrease variance, measurements should be performed using the mean of multiple ECD measurements, while using the same non-contact specular microscope. In this study, all our ECD data is comprised of the mean of 3 repeated specular microscopy measurements of the central cornea, measured with 1 noncontact specular microscope (Noncon Robo Pachy SP9000 S/N PK1-1137), while using the center-to-center method as specified in the referenced ANSI standard (ANSI Z80.13, clause D.4.2). However, clear identification of the advised number of 100 cells was not possible in a large number of measurements. ${ }^{12}$ It is our opinion that a measurement method of 50 instead of 100 contiguous cells is unlikely to significantly affect our results because we reported the mean of three central measurements performed on primarily healthy corneas, which decreases the possibility of misrepresentation of the data. We would like to highlight our doubts about the practical feasibility of marking 100 contiguous cells in 1 noncontact specular microscopic image, given the variation in image quality within one patient and between patients. The ANSI standard might press researchers in selecting cells that would not qualify as clearly identifiable, resulting in misrepresentation of ECD and morphology. This could be especially worrisome in studies reporting data on a small number of eyes with a short follow-up period because a small error can have a large influence on the data.

The ECD follow-up schedule of the AAO Task Force is in accordance with our past and current follow-up schedule and describes regular visits at 6, 12, 24 and 36 months after pIOL implantation, whereas the NGRC guidelines strongly recommend patients to come in every other year. ${ }^{12,15}$ We applied an annual follow-up pattern in the current study, as suggested by the AAO Task Force and would suggest lifelong continuation based on our 10-year results. Furthermore, the recently formatted guidelines recommend additional visits with a 4 - to 6-month interval in eyes with $>20 \%$ EC loss or an ECD $<1500$ cells $/ \mathrm{mm}^{2}$, a policy we agree with and implement in current practice. ${ }^{12}$ 


\section{Risk factors}

In line with previous studies, our results showed a smaller distance between the central and peripheral plOL edge and the endothelium, as well as a smaller preoperative ACD as risk factors for increased EC loss. 8, 17, 18,30 The effects of ACD and distance between central and peripheral pIOL edge to the endothelium on both EC loss and survival can be explained by the close proximity of the $\mathrm{pIOL}$ to the endothelium, resulting in a higher risk of (intermittent) contact between $\mathrm{PIOL}$ and corneal endothelium, ultimately leading to cell damage and increased EC loss. ${ }^{10,36}$ The multivariate linear-mixed model focused around the preoperative ACD also identified a younger age as a risk factor for EC loss, but this effect was not described in the literature or reciprocated in any of our other analyses. With every diopter of accommodation, the anterior pole of the crystalline lens moves into the direction of the endothelium by 30 $\mu \mathrm{m}$, resulting in a similar decrease in ACD. It is known that the accommodative capacity is greater in younger patients, ranging up to $10 \mathrm{D}$, whereas it decreases gradually until reaching an accommodative capacity of $O D$ at approximately age 65 years..$^{35}$ This fluctuating ACD in younger patients could induce a shallower ACD during the day, attributing to the effect of $A C D$ in the described analysis.

Our survival analyses confirmed the significant roles of ACD, central and peripheral pIOL edge to the endothelium distance on the described ECD-related outcome measures: AAO endpoint (i.e., $\geq 25 \%$ total EC loss) or AFSSAPS explantation criterion (i.e., ECD $<1500$ cells $/ \mathrm{mm}^{2}$ ) and pIOL explantation due to EC loss.

\section{Recommendations}

This study reported a total chronic EC loss of $16.6 \%$ and $21.4 \%$ from 6 months to 10 years in the myopic and toric groups, respectively, as well as $6.0 \%$ and $4.8 \%$ explantations due to EC loss, respectively. Our analyses confirm those of previous studies describing a smaller, crowded anterior chamber as a risk factor for EC loss. 8, 17,18

Application of the recently defined AAO endpoints 10 years after implantation showed $7.9 \%$ of myopic and $6.3 \%$ of toric eyes with a total $\mathrm{EC}$ loss $\geq 25 \%$. This is in line with a linear annual ECD decline of 48 cells $/ \mathrm{mm}^{2}$ and 61 cells $/ \mathrm{mm}^{2}$ in the myopic and toric groups, respectively. Our data showed the importance of preoperative ACD as a risk factor for increased EC loss and suggests the need for a higher threshold of preoperative age-related ECD in order to ensure the cornea is healthy enough to endure future cataract surgery and pIOL explantation. In our study cohort, patients undergoing plOL explantation due to cataract formation had a mean age of $56.1 \pm 8.5$ in the myopic group and 57.1 \pm 5.9 in the toric group (data on file). The mean age at pIOL implantation was 41.2 years in the myopic group and 38.8 in the toric group, meaning that a patient at the time of implantation would need a preoperative ECD of at least $2215 \mathrm{cells} / \mathrm{mm}^{2}$ in the myopic group and 2616 cells $/ \mathrm{mm}^{2}$ in the toric group in order to maintain a safe ECD of 
$\geq 1500$ cells $/ \mathrm{mm}^{2}$ until cataract surgery is required. However, an 18-year-old patient scheduled for pIOL implantation should have a preoperative ECD of at least 3310 cells $/ \mathrm{mm}^{2}$ in the myopic group and 3885 cells $/ \mathrm{mm}^{2}$ in the toric group in order to maintain an ECD of $\geq 1500$ cells $/ \mathrm{mm}^{2}$ until cataract surgery is performed.

On the basis of our study, we recommend to scheduling patients with plOL for annual follow-up visits to evaluate the corneal endothelium. International guidelines are needed to set thresholds for plOL explantation in case of increased EC loss. 


\section{REFERENCES}

1. Guell JL, Morral M, Kook D, Kohnen T. Phakic intraocular lenses part 1: historical overview, current models, selection criteria, and surgical techniques. J Cataract Refract Surg 2010;36(11):1976-93.

2. Kohnen T, Kook D, Morral M, Guell JL. Phakic intraocular lenses: part 2: results and complications. J Cataract Refract Surg 2010;36(12):2168-94.

3. Menezo JL, Cisneros AL, Rodriguez-Salvador V. Endothelial study of iris-claw phakic lens: four year follow-up. J Cataract Refract Surg 1998;24(8):1039-49.

4. Dick HB, Alio J, Bianchetti M, et al. Toric phakic intraocular lens: European multicenter study. Ophthalmology 2003;110(1):150-62.

5. Tahzib NG, Nuijts RM, Wu WY, Budo CJ. Long-term study of Artisan phakic intraocular lens implantation for the correction of moderate to high myopia: ten-year follow-up results. Ophthalmology 2007;114(6):1133-42.

6. Stulting RD, John ME, Maloney RK, et al. Three-year results of Artisan/Verisyse phakic intraocular lens implantation. Results of the United States Food And Drug Administration clinical trial. Ophthalmology 2008;115(3):464-72.e1.

7. Guell JL, Morral M, Gris O, et al. Five-year follow-up of 399 phakic Artisan-Verisyse implantation for myopia, hyperopia, and/or astigmatism. Ophthalmology 2008;115(6):1002-12.

8. Saxena R, Boekhoorn SS, Mulder PG, et al. Long-term follow-up of endothelial cell change after Artisan phakic intraocular lens implantation. Ophthalmology 2008;115(4):608-13.e1.

9. Titiyal JS, Sharma N, Mannan R, et al. Iris-fixated intraocular lens implantation to correct moderate to high myopia in Asian-Indian eyes: five-year results. J Cataract Refract Surg 2012;38(8):1446-52.

10. Bourne WM, Nelson LR, Hodge DO. Central corneal endothelial cell changes over a ten-year period. Invest Ophthalmol Vis Sci 1997;38(3):779-82.

11. Bernard P, Fournier M. Definitive stop of marketing, product recall and follow-up of implanted patients. Presbyopic intraocular lenses NEWLIFE/VIVARTE PRESBYOPIC. Agence Française de Sécurité Sanitaire des Produits de Santé (AFSSAPS), 2007; v. 2016.

12. MacRae S, Holladay JT, Hilmantel G, et al. Special Report: American Academy of Ophthalmology Task Force Recommendations for Specular Microscopy for Phakic Intraocular Lenses. Ophthalmology 2017;124(1):141-2.

13. Baikoff G. Anterior segment OCT and phakic intraocular lenses: a perspective. J Cataract Refract Surg 2006;32(11):1827-35.

14. Baikoff G, Bourgeon G, Jodai HJ, et al. Pigment dispersion and Artisan phakic intraocular lenses: crystalline lens rise as a safety criterion. J Cataract Refract Surg 2005;31(4):674-80.

15. Aalders-Deenstra V, Bartels M, Beerthuizen J, et al. Consensus Refractie Chirurgie. 3 ed: Nederlands Gezelschap voor Refractie Chirurgie (NGRC), 2013.

16. Doors M, Eggink FA, Webers CA, Nuijts RM. Late-onset decentration of iris-fixated phakic intraocular lenses: a case series. Am J Ophthalmol 2009;147(6):997-1003, .e1-2.

17. Doors M, Berendschot TT, Webers CA, Nuijts RM. Model to predict endothelial cell loss after irisfixated phakic intraocular lens implantation. Invest Ophthalmol Vis Sci 2010;51(2):811-5.

18. Doors M, Cals DW, Berendschot TT, et al. Influence of anterior chamber morphometrics on endothelial cell changes after phakic intraocular lens implantation. J Cataract Refract Surg 2008;34(12):2110-8.

19. Visser N, Berendschot TT, Bauer NJ, Nuijts RM. Vector analysis of corneal and refractive astigmatism changes following toric pseudophakic and toric phakic IOL implantation. Invest Ophthalmol Vis Sci 2012;53(4):1865-73. 
20. van der Heijde GL, Fechner PU, Worst JG. [Optical consequences of implantation of a negative intraocular lens in myopic patients]. Klin Monbl Augenheilkd 1988;193(1):99-102.

21. Guell JL, Morral M, Gris O, et al. Evaluation of Verisyse and Artiflex phakic intraocular lenses during accommodation using Visante optical coherence tomography. J Cataract Refract Surg 2007;33(8):1398-404.

22. Baumeister M, Buhren J, Kohnen T. Position of angle-supported, iris-fixated, and ciliary sulcusimplanted myopic phakic intraocular lenses evaluated by Scheimpflug photography. Am J Ophthalmol 2004;138(5):723-31.

23. Cheung SW, Cho P. Endothelial cells analysis with the TOPCON specular microscope SP-2000P and IMAGEnet system. Curr Eye Res 2000;21(4):788-98.

24. Ding $X$, Huang $Q$, Zheng $Y$, et al. Measurement area and repeatability of semiautomated assessment of corneal endothelium in the Topcon specular microscope SP-2000P and IMAGEnet system. Cornea 2012;31(10):1111-8.

25. Prinz A, Varga J, Findl O. Reliability of a video-based noncontact specular microscope for assessing the corneal endothelium. Cornea 2007;26(8):924-9.

26. van Schaick W, van Dooren BT, Mulder PG, Volker-Dieben HJ. Validity of endothelial cell analysis methods and recommendations for calibration in Topcon SP-2000P specular microscopy. Cornea 2005;24(5):538-44.

27. McCarey BE, Edelhauser HF, Lynn MJ. Review of corneal endothelial specular microscopy for FDA clinical trials of refractive procedures, surgical devices, and new intraocular drugs and solutions. Cornea 2008;27(1):1-16.

28. Alfonso JF, Lisa C, Abdelhamid A, et al. Three-year follow-up of subjective vault following myopic implantable collamer lens implantation. Graefes Arch Clin Exp Ophthalmol 2010;248(12):1827-35.

29. Doors M, Berendschot TT, Hendrikse F, et al. Value of preoperative phakic intraocular lens simulation using optical coherence tomography. J Cataract Refract Surg 2009;35(3):438-43.

30. Shajari M, Scheffel M, Koss MJ, Kohnen T. Dependency of endothelial cell loss on anterior chamber depth within first 4 years after implantation of iris-supported phakic intraocular lenses to treat high myopia. J Cataract Refract Surg 2016;42(11):1562-9.

31. Guell JL, Vazquez M, Malecaze F, et al. Artisan toric phakic intraocular lens for the correction of high astigmatism. Am J Ophthalmol 2003;136(3):442-7.

32. Budo C, Hessloehl JC, Izak M, et al. Multicenter study of the Artisan phakic intraocular lens. J Cataract Refract Surg 2000;26(8):1163-71.

33. Benedetti S, Casamenti V, Benedetti M. Long-term endothelial changes in phakic eyes after Artisan intraocular lens implantation to correct myopia: five-year study. J Cataract Refract Surg 2007;33(5):784-90.

34. Reinstein DZ, Archer TJ, Randleman JB. JRS standard for reporting astigmatism outcomes of refractive surgery. J Refract Surg 2014;30(10):654-9.

35. Baikoff G, Lutun E, Ferraz C, Wei J. Static and dynamic analysis of the anterior segment with optical coherence tomography. J Cataract Refract Surg 2004;30(9):1843-50.

36. Armitage WJ, Dick AD, Bourne WM. Predicting endothelial cell loss and long-term corneal graft survival. Invest Ophthalmol Vis Sci 2003;44(8):3326-31. 


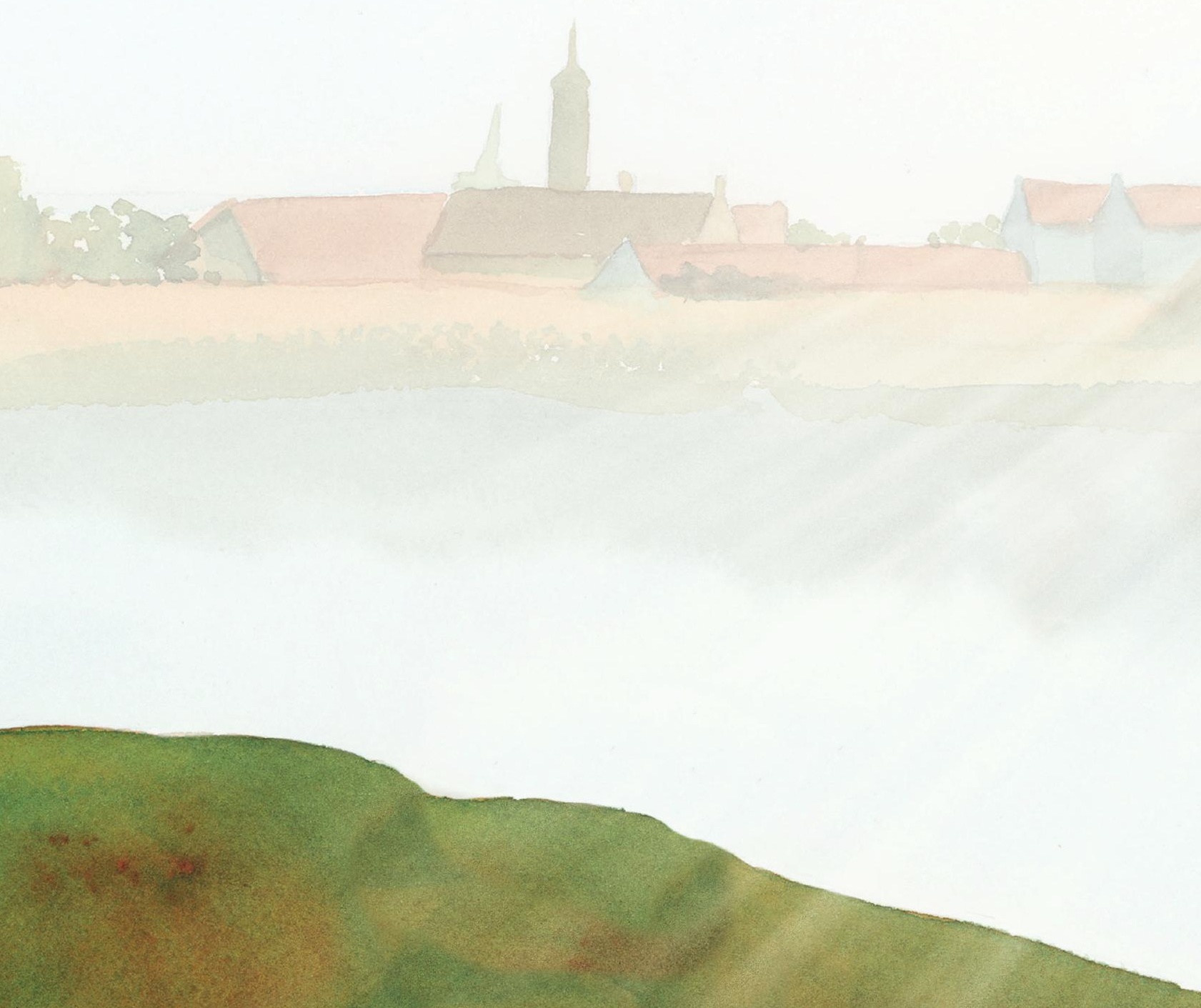




\section{CHAPTER 4}

Five-year endothelial cell loss after implantation with Artiflex Myopia and Artiflex Toric phakic intraocular lenses 


\section{ABSTRACT}

Purpose: To evaluate the long-term changes in endothelial cell density (ECD) after the implantation of 2 types of foldable iris-fixated phakic intraocular lenses (pIOLs) for the treatment of myopia and astigmatism.

Design: Prospective clinical cohort study.

Methods: Two-hundred and ninety-three and 188 eyes implanted with, respectively, the Artiflex Myopia and Artiflex Toric (Ophtec B.V., Groningen, the Netherlands) iris-fixated pIOL for the treatment of myopia or astigmatism at the University Eye Clinic Maastricht as of January 2004. One-hundred and forty-six eyes from the myopic and 64 eyes from the toric groups completed a 5-year follow-up. Main outcome measures were chronic endothelial cell (EC) loss, percentage of eyes with $a \geq 25 \%$ decrease in ECD, and the percentage of eyes with an $\mathrm{ECD}<1500$ cells $/ \mathrm{mm}^{2}$.

Results: Chronic EC loss showed an annual decline of 64 cells $/ \mathrm{mm}^{2}$ in the myopic $(P<.001$, standard error 3.58) and 62 cells $/ \mathrm{mm}^{2}$ in the toric $(P<.001$, standard error 3.77$)$ groups. Total chronic EC loss from 6 months to 5 years postoperatively was $10.5 \%$ in the myopic and $10.2 \%$ in the toric groups. After 5 years, an ECD decrease of $\geq 25 \%$ occurred in $4.4 \%$ and $4.3 \%$ of eyes, and an ECD $<1500$ cells $/ \mathrm{mm}^{2}$ was reported in $3.0 \%$ and $0.0 \%$ of eyes, respectively. Explantation of a pIOL owing to EC loss was required in $3.1 \%$ and $0 \%$ of eyes.

Conclusion: Chronic EC loss was around 10\% over a 5-year period in eyes implanted with the foldable myopic (toric) pIOL. In up to $3.1 \%$ of eyes significant EC loss resulted in subsequent pIOL explantation. 


\section{INTRODUCTION}

The iris-fixated Artiflex Myopia and Artiflex Toric phakic intraocular lenses (plOLs) (Ophtec B.V., Groningen, the Netherlands) were introduced in 2005 and 2007, respectively, as an addition to the already marketed rigid iris-fixated Artisan Myopia and Artisan Toric pIOLs (Ophtec B.V.). Owing to the configuration of the new lens, incorporating a foldable polysiloxane optic, incision size and surgically induced astigmatism (SIA) decreased significantly, and good results were obtained with respect to visual acuity (VA) and refractive correction. ${ }^{1-5}$ The lower refractive index of the polysiloxane material, 1.43 vs 1.49 in the rigid polymethyl methacrylate (PMMA) lens, results in a slightly thicker lens, bringing the peripheral edges of the optic closer to the corneal endothelium for a similar myopic correction. ${ }^{6}$ The importance of endothelial cell (EC) loss in reporting the safety of plOLs was emphasized by guidelines formatted by the French Health Products and Safety Agency (AFSSAPS) and American Academy of Ophthalmology (AAO) in 2007 and 2016, respectively. The 2007 AFSSAPS statement regards an endothelial cell density (ECD) less than 1500 cells $/ \mathrm{mm}^{2}$ as a criterion for pIOL explantation. ${ }^{7}$ The AAO-defined endpoint refers to the percentage of eyes with a total EC loss of $\geq 25 \%$ after 3 years as a safety parameter in studies on pIOLs. ${ }^{8}$ Currently there are no studies describing both the AFSSAPS and $\mathrm{AAO}$ defined endpoints or any data exceeding a 1- or 2-year follow-up in patients implanted with these foldable iris-fixated plOLs.

This prospective study aims to report data on EC loss, the percentage of eyes with $\geq 25 \%$ EC loss, and the percentage of eyes with an ECD $<1500$ cells $/ \mathrm{mm}^{2}$ after a 5 year follow-up in myopic patients implanted with a foldable iris-fixated myopic or toric $\mathrm{plOL}$. 


\section{METHODS}

\section{Design}

From January 1, 2004 to June 30, 2016, 479 eyes of 276 patients were implanted with a myopic or (myopic) toric iris-fixated pIOL at the University Eye Clinic Maastricht, Maastricht University Medical Center, Maastricht, the Netherlands. Patients were prospectively evaluated preoperatively, and at 1 day, 1 week, and 1, 3, 6 and 12 months postoperatively in the first postoperative year. Regular follow-up continued with annual visits. The myopic pIOL was implanted in 293 eyes of 166 patients, and 137 eyes completed the 5-year follow-up. The toric pIOL was implanted in 188 eyes of 109 patients, and 63 eyes completed the 5-year follow-up.

The current study was performed in adherence to the tenets of the Declaration of Helsinki; the Maastricht University Medical Center Institutional Review Board stated that approval was not required for this study.

\section{Implantation criteria}

Prior to $\mathrm{plOL}$ implantation a patient had to be $\geq 18$ years old and had to have a stable refraction for at least 2 years. Anterior chamber depth (ACD) from the corneal endothelium to the anterior plane of the crystalline lens had to be at least $2.8 \mathrm{~mm}$ with a maximal clear lens rise (CLR) of $600 \mu \mathrm{m}$ before pIOL implantation was performed. ${ }^{9-11}$ Guidelines for phakic IOL implantation were formulated in 2006 by the Netherlands Society for Refractive Surgery (Nederlands Gezelschap voor Refractie Chirurgie [NGRC]). Based on this guideline, preoperative minimal ECD depended on age, with $>2800$ cells $/ \mathrm{mm}^{2}$ required for patients from 21 to 25 years old, $>2650$ cells $/ \mathrm{mm}^{2}$ for patients from 26 to 30 years old, $>2400$ cells $/ \mathrm{mm}^{2}$ for patients from 31 to 35 years old, $>2200$ cells $/ \mathrm{mm}^{2}$ for patients from 36 to 45 years old, and $>2000$ cells $/ \mathrm{mm}^{2}$ in patients over 45 years old. ${ }^{9,12}$

This article does not contain data of patients treated with iris-fixated plOLs in keratoconus, irregular astigmatism, or after corneal transplantation. Data from a subset of these patients was reported in previous studies. 1,3,6,13,14

\section{Phakic intraocular lenses and surgical technique}

The Artiflex Myopia pIOL is a 3-piece, polysiloxane and PMMA, foldable lens with a convexconcave optic. It consists of a $6.0 \mathrm{~mm}$ flexible optic, has a total diameter of $8.5 \mathrm{~mm}$, and ranges from -2.0 to -14.5 diopters (D).

The Artiflex Toric pIOL is a 3-piece, polysiloxane and PMMA, foldable lens with a convex-concave optic. It consists of a $6.0 \mathrm{~mm}$ flexible optic and has a total diameter of $8.5 \mathrm{~mm}$; it ranges from -1.0 to -13.5 D and has a cylindrical power of up to -5.0 D. Lens power calculations were performed by the manufacturer using the van der Heijde formula. ${ }^{15}$ 
One surgeon (R.N.) performed all pIOL implantations under general or local anesthesia at the University Eye Clinic Maastricht. Previous studies by our group have described the surgical procedure and postoperative medication regimen. $6,13,16,17$

\section{Evaluation}

Preoperative examination consisted of subjective and cycloplegic refraction, Snellen uncorrected and corrected distance visual acuity (UDVA and CDVA) measurements and slitlamp examination, including Goldmann applanation tonometry and fundoscopy. Additional measurements consisted of corneal topography (Orbscan [Bausch and Lomb, Rochester, New York, USA], Pentacam HR [OCULUS Optikgeräte GmbH, Wetzlar, Germany], Sirius [Schwind eye-tech-solutions GmbH \& Co. KG, Kleinostheim, Germany]), biometry (A2500 [SonomedEscalon, New Hyde Park, New York, USA], IOLMaster [Carl Zeiss AG, Oberkochen, Germany]), and specular microscopy (NONCON ROBO PACHY SP9000 S/N PK1-1137 [KONAN MEDICAL Inc., Nishinomiya, Japan], SP 3000 [Topcon Corporation, Tokyo, Japan]). All preoperative measurements were performed 1 week after removal of soft contact lenses and 2 weeks after removal of rigid gas permeable contact lenses.

From 2006 onwards, the Visante OCT was used to perform preoperative pIOL simulation to measure the $A C D$, the vault between the $\mathrm{PIOL}$ and crystalline lens, the distance between the anterior $\mathrm{PIOL}$ and the endothelium, and CLR, as reported previously. 6, 9, 11, 18-20

In respect of the known variation between specular microscopes and the influence of this variation on the correct calculation of endothelial cell loss, all eyes continued their follow-up measurements with the same specular microscope used during preoperative measurements. More specifically, patients measured preoperatively with the SP9000 specular microscope continued their follow-up with this device, whereas patients measured preoperatively with the SP 3000 continued their measurements with the SP 3000 specular microscope. Per protocol, the mean ECD in each eye was calculated by determining the mean of 3 consecutive measurements of 50 central endothelial cells using the manual center-to-center method. ${ }^{21}$

\section{Outcome measures}

The definitions of outcome measures were based on the recent guidelines of the AAO and AFSSAPS, describing the percentage of eyes reaching the AAO endpoint (ie, ECD decrease $\geq 25 \%$ compared to the preoperative measurement) and AFSSAPS explantation criterion (ie, ECD $<1500$ cells $/ \mathrm{mm}^{2}$ ). ${ }^{7,8}$ We calculated the mean ECD 5 years after pIOL implantation, as well as the annual EC loss. To adhere to the AAO defined guidelines we did not only present the percentage of eyes meeting the AAO-defined endpoint after 5 years, but also added the percentage of eyes meeting this endpoint after 3 years. 


\section{Statistical analysis}

Statistical analysis was performed using SPSS for Windows (version 23; IBM, Armonk, New York, USA). All visual acuity measurements were converted from Snellen VA to logarithm of the minimal angle of resolution (logMAR) prior to statistical analysis. Descriptive analyses were performed to compute mean and standard deviation (SD) in primary outcome measures and preoperative characteristics. Longitudinal changes over time were analyzed using a linear mixedmodel analysis with an eye identification number as a grouping variable and time as a covariate. The best-fitted covariance structure was selected using the Bayesian information criterion. Similar to previous reports on EC loss, the effect of plOL implantation on the endothelium was assessed from preoperatively until 6 months postoperatively (ie, acute EC loss), whereas chronic EC loss was assessed from 6 months postoperatively until the end of follow-up. Kaplan Meier and multivariate Cox regression analyses were performed to assess survival from implantation to the occurrence of the AAO-defined endpoint (ie, total EC loss $\geq 25 \%$ ) and the AFSSAPS explantation criterion (ie, ECD $<1500$ cells $/ \mathrm{mm}^{2}$ ). $P$ values were considered significant if the $P<.05$. 


\section{RESULTS}

Between January 2004 and June 2016, 293 eyes of 166 patients and 188 eyes of 109 patients were implanted with the iris-fixated myopic and toric $\mathrm{plOL}$, respectively. Baseline characteristics of both groups are depicted in Table 1. Mean duration of follow-up was $56.9 \pm 39.8$ months in the myopic and $42.5 \pm 31.1$ months in the toric group.

In 3 eyes of 2 patients, aged 48 and 52, the preoperative endothelial cell density (ECD) was between 1900 and 2000 cells $/ \mathrm{mm}^{2}$. In the toric group 5 eyes of 4 patients had an ECD <2000 cells $/ \mathrm{mm}^{2}$; their mean preoperative age was $52 \pm 4$ years and their mean preoperative ECD was $1817.3 \pm 112.8 \mathrm{cell} s / \mathrm{mm}^{2}$. All patients with a preoperative ECD $<2000$ cells $/ \mathrm{mm}^{2}$ were informed on the risks of pIOL implantation in case of lower preoperative ECD counts, before opting for surgery.

\section{Endothelial Cell Density}

Mean preoperative, 6-month, and 5-year ECD of the myopic and toric group are reported in Table 2 and Figure 1. From preoperatively to 6 months postoperatively, we found a significant acute ECD decline of 51 cells $/ \mathrm{mm}^{2}(P=.001$, standard error [SE] 15.59) in the myopic group and a significant 6-month ECD decline of 55 cells $/ \mathrm{mm}^{2}(P=.007$, SE 19.97) in the toric group.

In order to separate the effect of surgical trauma on ECD, chronic EC loss was measured from 6 months until the end of follow-up. Longitudinally, using linear mixed-model analysis, we found a significant annual ECD decline of 64 cells $/ \mathrm{mm}^{2}(P<.001$, SE 3.58) in the myopic group and a significant annual ECD decline of 62 cells $/ \mathrm{mm}^{2}(P<.001$, SE 3.77) in the toric group. The total loss from 6 months to 5 years postoperatively was $10.5 \%$ in the myopic and $10.2 \%$ in the toric group. When correcting for an annual physiological EC loss of $0.6 \%,{ }^{22,23}$ our results show a pIOL-related total EC loss of 7.4\% in the myopic and $7.5 \%$ in the toric group from 6 months to 5 years postoperatively.

Three years after implantation $2.9 \%$ of the myopic plOL-implanted and $1.6 \%$ of the toric $\mathrm{plOL-}$ implanted eyes met the AAO-defined endpoint (ie, a decrease in ECD $\geq 25 \%$ ). After 5 years a decrease in ECD $\geq 25 \%$ was seen in $4.4 \%$ and $4.3 \%$ of eyes, whereas an ECD $<1500$ cells $/ \mathrm{mm}^{2}$ (ie, AFSSAPS explantation criterion) was reported in 3.0\% and $0.0 \%$ of eyes in the myopic and toric groups, respectively. None of the eyes with a preoperative ECD $<2000$ cells $/ \mathrm{mm}^{2}$ lost 120 cells $/ \mathrm{mm}^{2}$ or more in the first year after $\mathrm{plOL}$ implantation. Furthermore, none of these eyes suffered $\mathrm{a} \geq 25 \%$ decrease in ECD, reached an ECD $<1500$ cells $/ \mathrm{mm}^{2}$ or required explantation of their pIOL at any time during follow-up. Median survival time (ie, until 50\% reached the AAO endpoint or AFSSAPS explantation criterion) was 120 months in the myopic group. Survival time could not be calculated in the toric group (Figure 2), since too few eyes had reached the defined clinical endpoints. 
EC loss resulted in pIOL explantation in 9 eyes of 5 patients (3.1\%) implanted with a myopic pIOL at $86 \pm 26$ months (range 42-127 months), postoperatively. Three out of 4 patients with bilateral explantation were prone to eye rubbing because of severe pollen allergy (1 patient), chronic irritation related to topical glaucoma therapy (1 patient), and a medical history reporting suspected Sjögrens disease that was ruled out after a salivary gland biopsy (1 patient). In 2 eyes of 2 patients from the myopic group pIOL explantation owing to EC loss had to be performed after a follow-up less than 5 years. No explantations were performed in the toric group (Table 3). Unfortunately, it was not possible to compute a median survival time (ie, time until $50 \%$ of eyes requires explantation), because of the small number of explantations.

\section{Risk factors}

Possible predictive factors for EC loss included preoperative ACD, distance from the central $\mathrm{pIOL}$ edge to the endothelium, distance from the peripheral pIOL edge to the endothelium, preoperative age, preoperative ECD, preoperative AXL, and plOL type. Additional univariate linear mixed-model analyses were performed, but no significant predictive factors were identified $(P>$.05).

Similarly, additional univariate Cox regression analyses evaluating survival until reaching the AAO endpoint or AFSSAPS explantation criterion (ie, $\geq 25 \%$ EC loss or ECD $<1500$ cells $/ \mathrm{mm}^{2}$ ), as well as survival until pIOL explantation owing to EC loss, did not identify any significant influencing factors. Preoperative ACD, distance from the central pIOL edge to the endothelium, distance from the peripheral $\mathrm{pIOL}$ edge to the endothelium, preoperative age, preoperative ECD, preoperative AXL and pIOL-type were all analyzed and deemed insignificant ( $P>$.05). 
Table 1. Patient and phakic intraocular lens characteristics at baseline

\begin{tabular}{|c|c|c|c|c|}
\hline & \multicolumn{2}{|r|}{ Artiflex Myopia } & \multicolumn{2}{|r|}{ Artiflex Toric } \\
\hline \multicolumn{3}{|l|}{ Age $(y)$} & \multicolumn{2}{|c|}{$40.1 \pm 11.4$ (range 19.4 to 63.4 ) } \\
\hline \multicolumn{2}{|c|}{ Ratio male/female (\%) } & $35 / 65$ & \multicolumn{2}{|r|}{$38 / 62$} \\
\hline \multicolumn{2}{|l|}{ Number of eyes } & 293 & \multicolumn{2}{|r|}{188} \\
\hline \multicolumn{2}{|c|}{ Number of patients } & 166 & \multicolumn{2}{|r|}{109} \\
\hline \multicolumn{5}{|l|}{ Refractive } \\
\hline MRSE (D) & \multicolumn{2}{|c|}{$-9.09 \pm 2.89($ range -20.5 to -1.25$)$} & \multicolumn{2}{|c|}{$-9.22 \pm 2.84$ (range -15.25 to -2.50$)$} \\
\hline Cylinder (D) & \multicolumn{2}{|c|}{$-0.80 \pm 0.51$ (range -2.50 to 0.00 ) } & \multicolumn{2}{|c|}{$-2.32 \pm 0.88$ (range -5.25 to -1.00$)$} \\
\hline \multicolumn{5}{|l|}{ Implanted Lens } \\
\hline Sphere (D) & \multicolumn{2}{|c|}{$-9.67 \pm 2.59$ (range -19.5 to -2.0 ) } & \multicolumn{2}{|c|}{$-8.48 \pm 2.83$ ( range -13.5 to -1.5 ) } \\
\hline Cylinder (D) & \multicolumn{2}{|r|}{ NA } & \multicolumn{2}{|c|}{$-2.13 \pm 0.87$ (range -5.0 to -1.0$)$} \\
\hline CDVA (logMAR) & \multicolumn{2}{|c|}{$-0.007 \pm 0.086($ range -0.18 to 0.52$)$} & \multicolumn{2}{|c|}{$0.018 \pm 0.117$ (range -0.24 to 0.60) } \\
\hline $\mathrm{IOP}(\mathrm{mmHg})$ & \multicolumn{2}{|r|}{$15.3 \pm 2.9$ (range 8.0 to 24.0 ) } & \multicolumn{2}{|c|}{$15.6 \pm 2.9$ (range 10.0 to 23.0 ) } \\
\hline $\operatorname{ACD}(\mathrm{mm})^{\mathrm{a}}$ & \multicolumn{2}{|c|}{$3.27 \pm 0.31$ (range 2.75 to 3.96 ) } & \multicolumn{2}{|c|}{$3.24 \pm 0.35$ (range 2.68 to 4.47 ) } \\
\hline $\mathrm{AXL}(\mathrm{mm})^{\mathrm{a}}$ & \multicolumn{2}{|c|}{$26.78 \pm 1.27$ (range 23.88 to 30.21$)$} & \multicolumn{2}{|c|}{$26.92 \pm 1.37$ (range 23.48 to 31.03 ) } \\
\hline \multicolumn{5}{|c|}{$\begin{array}{l}\text { ACD = anterior chamber depth; } A X L=\text { axial lengthy; CDVA = corrected distance visual acuity; } D= \\
\text { diopters; IOP = intraocular pressure; logMAR = logarithm of the minimum angle of resolution; } M R S E= \\
\text { manifest refractive spherical equivalent; } N A=\text { not applicable. } \\
\text { Results are mean } \pm \text { standard deviation unless indicated. } \\
\text { aMeasured from the corneal epithelium. } \\
\text { Table 2. Mean endothelial cell density in eyes implanted with a foldable iris-fixated myopic or toric } \\
\text { phakic intraocular lens }\end{array}$} \\
\hline \multirow[b]{2}{*}{ Time period } & \multicolumn{2}{|r|}{ Artiflex Myopia } & \multicolumn{2}{|r|}{ Artiflex Toric } \\
\hline & $\begin{array}{l}\text { Numer of } \\
\text { Eyes }\end{array}$ & $\begin{array}{c}\text { Cells } / \mathrm{mm}^{2}, \text { Mean } \pm \mathrm{SD} \\
\text { (range) }\end{array}$ & $\begin{array}{l}\text { Numer of } \\
\text { Eyes }\end{array}$ & $\begin{array}{c}\text { Cells } / \mathrm{mm}^{2}, \text { Mean } \pm \mathrm{SD} \\
\text { (range) }\end{array}$ \\
\hline Preoperatively & 293 & $2739 \pm 286(1915-3531)$ & 188 & $2769 \pm 370(1643-3871)$ \\
\hline Acute: 6 Months & 206 & $2680 \pm 336(943-3445)$ & 140 & $2697 \pm 418(1644-3813)$ \\
\hline Chronic: 1 Year & 202 & $2657 \pm 352(1227-3447)$ & 131 & $2669 \pm 426(1641-3588)$ \\
\hline Chronic: 5 Years & 95 & $2487 \pm 363(1274-3423)$ & 38 & $2505 \pm 343(1892-3327)$ \\
\hline
\end{tabular}


Table 3. Incidence and indications of phakic intraocular lens explantations in patients implanted with foldable iris-fixated myopic and toric phakic intraocular lenses

\begin{tabular}{lccc}
\hline & \multicolumn{3}{c}{ Artiflex Myopia (N=293) } \\
\cline { 2 - 4 } & No. eyes [patients] & Ratio(\%) & Time (mo) \\
\hline Cataract & $14[11]$ & 4.78 & $75.4 \pm 34.2(4.7-130.7)^{a}$ \\
EC-loss & $9[5]$ & 3.07 & $85.6 \pm 25.742 .5-126.6)^{\mathrm{a}}$ \\
Cataract after retinal surgery & $2[2]$ & 0.68 & 21.0 and 18.0 \\
EC-loss after retinal surgery & $1[1]$ & 0.34 & 23.4 \\
High IOP & $1[1]$ & 0.34 & 15.4 \\
Excessive pigment on plOL & $\mathrm{NA}$ & $\mathrm{NA}$ & $\mathrm{NA}$
\end{tabular}

$\mathrm{EC}=$ endothelial cell; IOP = intraocular pressure; $\mathrm{NA}=$ not applicable; $\mathrm{pIOL}$ = phakic intraocular lens; VA = visual acuity.

\section{Endothelial Cell Density}

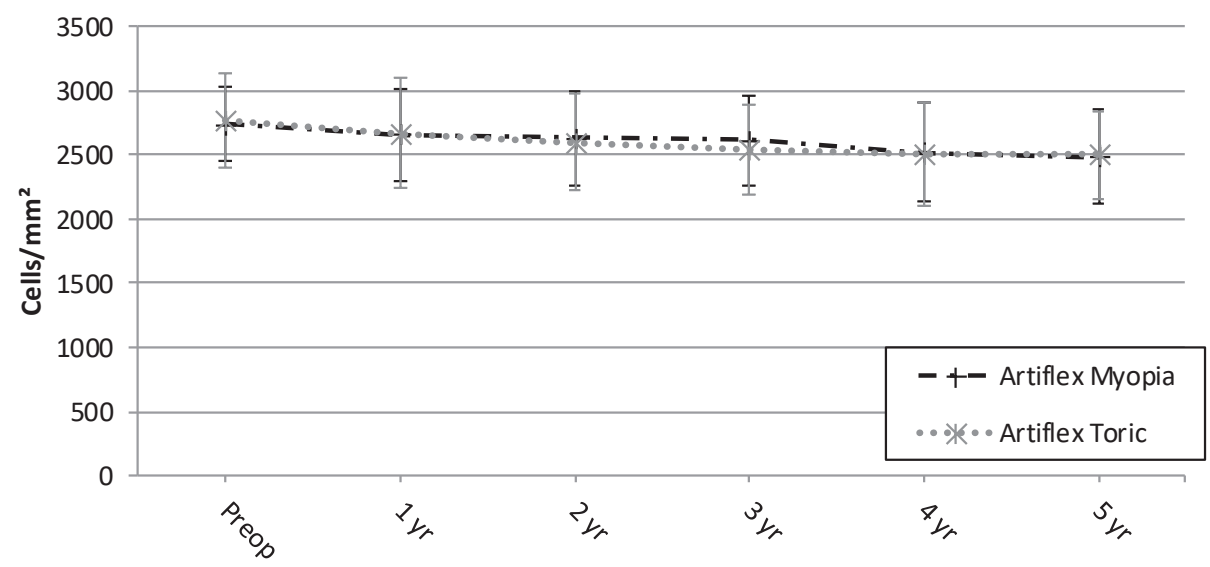

Figure 1. Mean endothelial cell density from preoperatively to 10 years postoperatively in patients implanted with foldable myopic $(n=293)$ and toric $(n=188)$ phakic intraoclar lenses (mean \pm standard deviation). 


\section{Artiflex Toric $(\mathrm{N}=188)$}

\begin{tabular}{ccc}
\hline No. eyes [patients] & Ratio (\%) & Time (mo) \\
\hline $1[1]$ & 0.53 & 7.8 \\
NA & NA & NA \\
$2[2]$ & 1.06 & 15.0 and 23.0 \\
NA & NA & NA \\
NA & NA & NA \\
$1[1]$ & 0.53 & 6.4 \\
\hline
\end{tabular}

a Mean \pm SD (range).



Figure 2. Survival curve for reaching the American Academy of Ophthalmology (AAO) endpoint (ie, $\geq 25 \%$ total endothelial cell loss) or French Health Products and Safety Agency (AFSSAPS) explantation criterion (ie, endothlial cell density < 1500 cells $/ \mathrm{mm}^{2}$ ), in eyes implanted with foldable myopic $(\mathrm{n}=293$ ) and toric ( $n=188$ ) phakic intraocular lenses. 


\section{DISCUSSION}

Despite the multitude of anterior chamber pIOLs taken of the market owing to excessive EC loss in the past, no guidelines existed on management of corneal safety in patients implanted with pIOLs until the recent publication of the AAO Task Force and AFSSAPS criteria. ${ }^{7-9,24}$

The current study is the first to apply the AAO and AFSSAPS criteria over a 5-year followup period in eyes implanted with foldable myopic or toric pIOLs. This study stands out from previous papers on the foldable iris-fixated myopic and toric plOLs because all surgeries were performed by the same surgeon (R.N.), all measurements were performed with the same specular microscope used prior to implantation, and all measurements were performed using the same protocol, cutting out most variation that can be induced by changing surgeons or measurement methods. ${ }^{25-28}$

\section{Endothelial Cell Density}

We calculated the percentage of total EC loss and the percentage of total EC loss corrected for an annual physiological loss of $0.6 \%$ by using the results of the mixed-model linear regression analyses. ${ }^{22,23}$ After 6 months, the acute EC loss in the myopic and toric groups was similar to the 0.05 to $4.3 \%$ short-term EC loss after 6 months reported in the literature, ${ }^{1,3,29}$ with $0.7 \%$ and $1.6 \%$ of eyes showing a decrease in ECD $\geq 25 \%$ after uncomplicated surgery, respectively (data on file). From 6 months to 5 years postoperatively, we found a chronic total EC loss of $10.5 \%$ and $10.2 \%$ in the myopic and toric groups, respectively. No published study has reported 5-year follow-up data, but studies with a shorter follow-up showed a total EC loss of $9.0 \%$ and $9.4 \%$ after 1 year, and $1.1 \%$ and $7.4 \%$ after 2 years., 3, 5, 30 In over half of all cited articles the groups were relatively small ${ }^{2,5,29,30}$ and all papers discussed the results after a relatively short follow-up. ${ }^{1-3,5,29,30}$ The results of the current study show similar or lower EC loss than the results of most previous papers, 1, 2, 5, 29, 30 with the exception of 1 study published in 2009. ${ }^{3}$ The latter reported a total EC loss of $1.07 \%$ with a high standard deviation of $16.35 \%$ after 2 years, which might be explained by the study being a multicenter study. Patients were included in 12 countries, resulting in more than 12 different surgeons and sites. In that study, neither the method nor the specular microscope used to measure endothelial cell density was described. Variable and insufficiently specified measurement methods, as well as the use of different specular microscopes in multiple clinics, may lead to a high variability and a large standard deviation, as well as less reliable outcomes. Additionally, all previously mentioned studies relied on comparing means (ie, $t$ test), using nonparametric tests or descriptive statistics to present their work. ${ }^{1-3,5,29,30}$ However, when testing for a longitudinal change during a follow-up period with multiple visits, mixed-linear regression analyses are preferred. 
Additional outcome parameters were added based on guidelines published by the AAO Task Force and AFSSAPS.7.8 As previously mentioned, prior to the January 2017 publication by the AAO Task Force no guidelines existed on standardized reporting of ECD after refractive surgery. ${ }^{8}$ The AAO guideline focuses on reporting the percentage of eyes that had lost $\geq 25 \%$ of ECD after 3 years with a pIOL present. Application and interpretation of this guideline is complicated by the fact that no cutoff points are reported with respect to the percentage of eyes that are allowed to experience an EC loss $\geq 25 \%$ before a pIOL is deemed unsafe and should be taken of the market, nor does it specify whether a $\geq 25 \%$ EC loss requires plOL explantation in an individual patient. Contrary to the AAO Task Force, the AFSSAPS did report either an ECD $<1500$ cells $/ \mathrm{mm}^{2}$ or $\geq 30 \%$ EC loss as reasons for explantation in an individual patient but also failed to supply criteria that should indicate when the plOL should be taken of the market.? Because pIOL explantation will have an enormous impact on young, highly myopic patients who want to remain spectacle independent, the decision to explant a pIOL should be very well substantiated and preferably based on a global consensus.

Adhering to the AAO guidelines $2.9 \%$ and $4.4 \%$ of eyes in the myopic group reached an endpoint of $\geq 25 \%$ EC loss after 3 and 5 years, respectively. Similarly, the toric group showed $1.6 \%$ and $4.3 \%$ of eyes with $\geq 25 \%$ EC loss. The only other study reporting the AAO endpoint focused on rigid myopic and toric iris-fixated pIOLs and reported a lower percentage of eyes with $\geq 25 \% \mathrm{EC}$ loss after 5 years (ie, 1.8\% and 3.2\%, respectively). ${ }^{31}$ In line with the abovementioned study on rigid pIOLs, we reported an ECD $<1500$ cells $/ \mathrm{mm}^{2}$ after 5 years in up to $3.0 \%$ of eyes, as well as EC loss related pIOL explantations in up to $0.7 \%$ of eyes after 5 years. ${ }^{31}$ Comparison of the total explantation rate and mean time until explantation between foldable and rigid plOLs is complicated by the large difference in mean follow-up between plOLs types, because the rigid pIOLs were launched prior to 2001, as opposed to the foldable plOLs, which were launched after 2003. As a result of the differences in follow-up, mean time to EC loss-related explantation was 7.2 years in the foldable myopic group (3.1\% explantations), as opposed to 11.9 years in the rigid myopic group (6.0\% explantations). No plOL was explanted due to EC loss in the foldable toric group, as opposed to $4.8 \%$ of rigid toric pIOLs after 7.4 years. ${ }^{31}$ Survival analyses would normally enable a reliable comparison of the foldable and rigid lens types because they function by reporting a median survival, defined as the time until $50 \%$ of eyes is expected to reach a previously defined endpoint. Unfortunately, because of the small number of events, median survival until EC loss-related explantation could not be computed in any of the foldable or rigid, myopic or toric groups, and median survival until reaching either the AAO or AFSSAPS criterion could only be computed in the myopic groups. ${ }^{31}$ Median survival until reaching the AAO or AFSSAPS criterion differed by 5 years, with a longer median survival in the rigid myopic group that can be explained by the longer mean follow-up as well as the slower ECD decline in the rigid myopic group. 


\section{Risk factors}

Based on the design of the foldable pIOL described in this study, there are 2 possible opticrelated explanations for the reported increased EC loss in the foldable pIOL type. Because of a smaller refractive index of the polysiloxane material, the foldable optic is slightly thicker than the rigid PMMA optic, which could result in a smaller distance between the central and peripheral pIOL edge and the corneal endothelium. ${ }^{6}$ Despite the fact that ACD decreased significantly in the myopic ( $P=.029)$ and toric $(P=.001)$ groups (data on file), and although previous studies have shown increased EC loss in eyes with a smaller ACD as well as a smaller distance between the central and peripheral pIOL edge and corneal endothelium, we did not find similar results in the current study. ${ }^{6,14,31-33}$ Similarly, neither ACD nor central or peripheral distance from the $\mathrm{pIOL}$ to the endothelium influenced the time between $\mathrm{PIOL}$ implantation and losing $\geq 25 \%$ of ECD (ie, AAO endpoint) or reaching an ECD $<1500$ cells $/ \mathrm{mm}^{2}$ (ie, AFSSAPS explantation criterion), nor did it influence the time until EC-related $\mathrm{pIOL}$ explantation. Furthermore, no significant differences were reported when comparing central and peripheral $\mathrm{pIOL}$ edge to the endothelium distance between eyes implanted with the foldable or rigid pIOL ( $P>$.05, data on file). Additional analyses did show a significant difference in EC loss between foldable and rigid pIOLs ( $P=.034$, data on file), that could not be explained by differences in lens position between the 2 lens types. Looking closer at the data, a smaller plOL edge to the endothelium distance was associated with a statistically insignificant increased EC loss in the foldable group, but this effect was much larger - and only significant - in the rigid group (data on file). It should be noted that when the foldable plOL was first introduced in a clinical trial in 2003, the optic-haptic junction and the vault between this junction and the iris-plane was shaped differently than the finally marketed type 2 iris-fixated pIOL. ${ }^{1,3}$ During the clinical trial with the first pIOL model a higher incidence of iris pigment (4.8\%) and giant cell (1.4\%) precipitates was reported, which were believed to be caused by compression of the iris between the pIOL and the crystalline lens., 34,35 This compression was most likely caused by the lower vault between optic-haptic junction and iris in the first foldable model $(0.13 \mathrm{~mm})$, as compared to the rigid $\mathrm{plOL}(0.20 \mathrm{~mm})$, resulting in an alteration of the optic-haptic junction to create a higher, $0.20 \mathrm{~mm}$, vault between junction and iris. As a result, the marketed type 2 iris-fixated pIOL has a vault height similar to the rigid iris-fixated pIOL. ${ }^{1,3}$ Because lens type (1 or 2) did not significantly influence EC loss in the current study, all 27 eyes of the 14 patients implanted with the first foldable model were combined with the 454 eyes of the 261 patients implanted with the second foldable model (data on file).

Lens precipitates developed in the first postoperative year in $40.6 \%$ and $23.4 \%$ of eyes in the foldable myopic and toric groups, respectively, whereas these numbers were only $0.3 \%$ and $1.6 \%$ in the respective rigid groups (data on file). Precipitates were transient in most cases, with some cases requiring additional application of topical anti-inflammatory drops before clearing up. The higher rates of iris pigment and giant cell precipitates in the foldable group 
serve as an indicator for inflammation, and pose the question whether the increased EC loss in the foldable pIOL type could be attributed to an inflammatory response induced by the foldable polysiloxane material. ${ }^{36}$ One previous study evaluated EC loss in a randomized paired eye comparison and showed similar EC loss in rigid and foldable plOLs, but did not investigate long-term changes or objectively tested the inflammatory response. ${ }^{2}$ Previous studies assessing the role of the $1 \mathrm{OL}$ material on inflammation have mainly been conducted on eyes with cataract and a history of uveitis. ${ }^{37,38}$ Eyes with a history of uveitis are especially suitable for evaluation of the inflammatory response because their chronic - disease specific - inflammation induces a weakened blood-aqueous barrier, resulting in an intensified cellular response that is easier to detect in a clinical setting. The results of these studies point toward a higher inflammatory response in eyes implanted with a silicone material, whereas PMMA and hydrophobic acrylic seem to result in less pigment and giant cell precipitates on the IOL. ${ }^{37,38}$ Unfortunately not all pIOL-or IOL-oriented studies objectively quantified the inflammatory responses, and all studies showed a high degree of variation in inflammation between different durations of follow-up. 2, 37-

${ }^{39}$ Despite the fact that combined evidence is leaning somewhat towards a silicone material as a risk factor for inflammation, we must conclude that more research should be conducted directly comparing rigid and foldable pIOLs in a larger number of eyes to take a closer look at the influence of the optic material on long-term EC loss. Further research on the intraocular inflammatory response after implantation with both optic materials is required to provide a more definitive answer to this problem.

A third theory of EC loss has been suggested in one previous report that showed that intraocular presence of an iris-fixated $\mathrm{plOL}$ changed the aqueous flow pattern..$^{40}$ The authors assumed that the altered aqueous flow would result in an insufficient distribution of nutrients over the corneal endothelial cells, as well as insufficient drainage of waste, eventually resulting in endothelial cell death. No other study has been conducted to test this hypothesis and there is no reason to assume a different aqueous flow, shear stress and nutrient distribution in eyes implanted with the foldable versus in eyes implanted with a rigid pIOL.

\section{Other phakic intraocluar lenses}

Other types of plOLs that have been implanted over recent years are the anterior chamber, angle-supported, Cachet pIOL (Alcon, Fort Worth, Texas, USA), and several types of the posterior chamber Visian Implantable Collamer Lens pIOL (ICL; STAAR Surgical, Nidau, Switzerland). The single-piece foldable angle-supported $\mathrm{pIOL}$ is made of a cross-linked acrylate and methacrylate copolymer, and has recently been taken of the market owing to excessive EC loss in some patients. ${ }^{41-43}$ Two recent studies reported the 5-year results with these pIOLs in a nonrandomized setting, and showed a mean total EC loss of $8.9 \%$ and $13.7 \%$ from preoperatively to 5 years postoperatively that was similar to - or only slightly higher than - the results with the iris-fixated pIOLs described in the current paper. ${ }^{42,43}$ The 2016 article described the results of 
1087 eyes and reported a decrease in ECD > 30\% in 8.0\% and an ECD $\leq 1500$ cells $/ \mathrm{mm}^{2}$ in $2.7 \%$ of eyes. ${ }^{43}$ Both studies emphasized the importance of sufficient distance between both central and peripheral pIOL and endothelium, but no study assessed the effect of these distances on EC loss. 42,43

No previous study reported data on inflammatory responses after implantation with the foldable angle-supported pIOL, so it remains unclear if accelerated EC loss in this group of patients is caused by differences in design of the $\mathrm{PIOL}$ - with the haptics touching the peripheral endothelium or bringing the optic closer to the endothelium - or might be caused by an increased inflammatory response induced by the pIOL material. Studies assessing the inflammatory response of different IOL materials in patients with a history of uveitis reported the lowest rate of inflammation in eyes implanted with a foldable hydrophobic acrylic material, a material similar to that of the foldable angle-supported pIOL. ${ }^{37}$ This could imply that the higher rates of EC loss in the angle-supported $\mathrm{pIOL}$ are caused by a closer proximity between $\mathrm{PIOL}$ and endothelium - attributed to a different lens design - rather than an enhanced inflammatory response. Alterations in aqueous humour circulation have not been investigated yet, but the position of the pIOL in front of the pupil, as well as the absence of a peripheral iridectomy, will result in an altered flow pattern.

The abovementioned foldable hydrophilic porcine collagen (0.1\%)/hydroxyethyl copolymer (ie, collamer) posterior chamber plOLs have been hypothesized to cause less EC loss due to their position away from the endothelium, while this same - retropupillary - position has been reported to result in contact between $\mathrm{pIOL}$ and crystalline lens, thus inducing cataract. ${ }^{44,45}$ This adverse effect has resulted in several alterations in lens design, creating a larger lens vault to prevent touch between the phakic and crystalline lens, as well as additional - central - holes in the optic to change the direction of aqueous flow. ${ }^{45-47}$ Almost all ICL papers report ECD data by comparing means (ie, $t$ test) or by using descriptive statistics. In a sub-study of the FDA trial a total EC loss after 3 and 4 years of $8.9 \%$ and 9.4\% was described, which was in line with EC loss in both the current study and in previous studies on iris-fixated pIOLs with a similar follow-up. ${ }^{31,48}$ The main idea of posterior chamber pIOLs is that their position induces less EC loss, but since the additional holes in the optic are unlikely to result in a major change in $\mathrm{PIOL}$ position, one should wonder if EC loss is not just caused by chronic - subclinical - inflammation related to the presence of any type of pIOL in the eye. Previous research assessing inflammation in eyes implanted with the ICL looked at clinical signs of inflammation as well as signs of inflammation using a flare cell meter, and showed a minor increase in inflammation that was similar to the increase in inflammation after cataract surgery as reported in studies from the early 1990s. ${ }^{49-51}$ However, since all studies reported data on a small number of patients, no study reported the effect of the collamer material in eyes with uveitis, and both surgical technique and 
measurements have evolved since the early 1990s, we feel that revisiting the inflammatory response in eyes implanted with collamer posterior chamber plOLs is required to assess inflammation as well as the influence of inflammation on EC loss.

One study simulated aqueous humour flow in eyes implanted with an ICL with a central hole with a peripheral iridectomy, and in eyes with an ICL with a central hole but without a peripheral iridectomy. Their results showed that aqueous humour flow is likely sufficient to prevent an increase in intraocular pressure in eyes without a peripheral iridectomy, but they did not specify if these changes in might increase shear stress on the endothelial cells or alter the nutrient distribution in the anterior chamber. ${ }^{22}$

\section{Recommendations}

In contrast to previous studies, a smaller ACD or a crowded anterior chamber did not significantly affect EC loss or EC loss-related outcome measures in the current study. The results of both the current study and previous literature give reason to believe that the silicone optic material might cause subclinical inflammation, probably serving as a risk-factor for EC loss. Research on iris-fixated pIOLs should focus on evaluating the effects of different materials (eg, silicone vs acrylic polymers) on EC loss and subclinical inflammation, in order to evaluate if development of new materials is required to safeguard the corneal endothelium. 


\section{REFERENCES}

1. Doors M, Budo CJ, Christiaans BJ, et al. Artiflex Toric foldable phakic intraocular lens: short-term results of a prospective European multicenter study. Am J Ophthalmol 2012;154(4):730-9.e2.

2. Coullet J, Guell JL, Fournie P, et al. Iris-supported phakic lenses (rigid vs foldable version) for treating moderately high myopia: randomized paired eye comparison. Am J Ophthalmol 2006;142(6):909-16.

3. Dick HB, Budo C, Malecaze F, et al. Foldable Artiflex phakic intraocular lens for the correction of myopia: two-year follow-up results of a prospective European multicenter study. Ophthalmology 2009;116(4):671-7.

4. Hashemi H, Taherzadeh M, Khabazkhoob M. Correction of high myopia with foldable Artiflex Phakic intraocular lenses: 1 year follow-up results. Acta Med Iran 2013;51(9):620-5.

5. Ozerturk Y, Kubaloglu A, Sari ES, et al. Foldable iris-fixated phakic intraocular lens implantation for the correction of myopia: two years of follow-up. Indian J Ophthalmol 2012;60(1):23-8.

6. Doors M, Cals DW, Berendschot TT, et al. Influence of anterior chamber morphometrics on endothelial cell changes after phakic intraocular lens implantation. J Cataract Refract Surg 2008;34(12):2110-8.

7. Bernard P, Fournier M. Definitive stop of marketing, product recall and follow-up of implanted patients. Presbyopic intraocular lenses NEWLIFE/VIVARTE PRESBYOPIC. Agence Française de Sécurité Sanitaire des Produits de Santé (AFSSAPS), 2007; v. 2016.

8. MacRae S, Holladay JT, Hilmantel G, et al. Special Report: American Academy of Ophthalmology Task Force Recommendations for Specular Microscopy for Phakic Intraocular Lenses. Ophthalmology 2017;124(1):141-2.

9. Guell JL, Morral M, Kook D, Kohnen T. Phakic intraocular lenses part 1: historical overview, current models, selection criteria, and surgical techniques. J Cataract Refract Surg 2010;36(11):1976-93.

10. Baikoff G. Anterior segment OCT and phakic intraocular lenses: a perspective. J Cataract Refract Surg 2006;32(11):1827-35.

11. Baikoff G, Lutun E, Ferraz C, Wei J. Static and dynamic analysis of the anterior segment with optical coherence tomography. J Cataract Refract Surg 2004;30(9):1843-50.

12. Aalders-Deenstra V, Bartels M, Beerthuizen J, et al. Consensus Refractie Chirurgie. 3 ed: Nederlands Gezelschap voor Refractie Chirurgie (NGRC), 2013.

13. Visser N, Berendschot TT, Bauer NJ, Nuijts RM. Vector analysis of corneal and refractive astigmatism changes following toric pseudophakic and toric phakic IOL implantation. Invest Ophthalmol Vis Sci 2012;53(4):1865-73.

14. Doors M, Berendschot TT, Webers CA, Nuijts RM. Model to predict endothelial cell loss after irisfixated phakic intraocular lens implantation. Invest Ophthalmol Vis Sci 2010;51(2):811-5.

15. van der Heijde GL, Fechner PU, Worst JG. [Optical consequences of implantation of a negative intraocular lens in myopic patients]. Klin Monbl Augenheilkd 1988;193(1):99-102.

16. Tahzib NG, BootsmaSJ, Eggink FA, Nuijts RM. Functional outcome and patient satisfaction after Artisan phakic intraocular lens implantation for the correction of myopia. Am J Ophthalmol 2006;142(1):31-9.

17. Doors M, Eggink FA, Webers CA, Nuijts RM. Late-onset decentration of iris-fixated phakic intraocular lenses: a case series. Am J Ophthalmol 2009;147(6):997-1003, .e1-2.

18. Guell JL, Morral M, Gris O, et al. Evaluation of Verisyse and Artiflex phakic intraocular lenses during accommodation using Visante optical coherence tomography. J Cataract Refract Surg 2007;33(8):1398-404. 
19. Baumeister M, Buhren J, Kohnen T. Position of angle-supported, iris-fixated, and ciliary sulcusimplanted myopic phakic intraocular lenses evaluated by Scheimpflug photography. Am J Ophthalmol 2004;138(5):723-31.

20. Baikoff G, Bourgeon G, Jodai HJ, et al. Pigment dispersion and Artisan phakic intraocular lenses: crystalline lens rise as a safety criterion. J Cataract Refract Surg 2005;31(4):674-80.

21. McCarey BE, Edelhauser HF, Lynn MJ. Review of corneal endothelial specular microscopy for FDA clinical trials of refractive procedures, surgical devices, and new intraocular drugs and solutions. Cornea 2008;27(1):1-16.

22. Tahzib NG, Nuijts RM, Wu WY, Budo CJ. Long-term study of Artisan phakic intraocular lens implantation for the correction of moderate to high myopia: ten-year follow-up results. Ophthalmology 2007;114(6):1133-42.

23. Bourne WM, Nelson LR, Hodge DO. Central corneal endothelial cell changes over a ten-year period. Invest Ophthalmol Vis Sci 1997;38(3):779-82.

24. Kohnen T, Kook D, Morral M, Guell JL. Phakic intraocular lenses: part 2: results and complications. J Cataract Refract Surg 2010;36(12):2168-94.

25. Cheung SW, Cho P. Endothelial cells analysis with the TOPCON specular microscope SP-2000P and IMAGEnet system. Curr Eye Res 2000;21(4):788-98.

26. Ding $X$, Huang $Q$, Zheng $Y$, et al. Measurement area and repeatability of semiautomated assessment of corneal endothelium in the Topcon specular microscope SP-2000P and IMAGEnet system. Cornea 2012;31(10):1111-8.

27. Prinz A, Varga J, Findl O. Reliability of a video-based noncontact specular microscope for assessing the corneal endothelium. Cornea 2007;26(8):924-9.

28. van Schaick W, van Dooren BT, Mulder PG, Volker-Dieben HJ. Validity of endothelial cell analysis methods and recommendations for calibration in Topcon SP-2000P specular microscopy. Cornea 2005;24(5):538-44.

29. Ruckhofer J, Seyeddain O, Dexl AK, et al. Correction of myopic astigmatism with a foldable iris-claw toric phakic intraocular lens: short-term follow-up. J Cataract Refract Surg 2012;38(4):582-8.

30. Munoz G, Cardoner A, Albarran-Diego C, et al. Iris-fixated toric phakic intraocular lens for myopic astigmatism. J Cataract Refract Surg 2012;38(7):1166-75.

31. Jonker SMR, Berendschot T, Ronden AE, et al. Long-Term Endothelial Cell Loss in Patients with Artisan Myopia and Artisan Toric Phakic Intraocular Lenses: 5- and 10-Year Results. Ophthalmology 2017.

32. Saxena R, Boekhoorn SS, Mulder PG, et al. Long-term follow-up of endothelial cell change after Artisan phakic intraocular lens implantation. Ophthalmology 2008;115(4):608-13.e1.

33. Shajari M, Scheffel M, Koss MJ, Kohnen T. Dependency of endothelial cell loss on anterior chamber depth within first 4 years after implantation of iris-supported phakic intraocular lenses to treat high myopia. J Cataract Refract Surg 2016;42(11):1562-9.

34. Tahzib NG, Eggink FA, Frederik PM, Nuijts RM. Recurrent intraocular inflammation after implantation of the Artiflex phakic intraocular lens for the correction of high myopia. J Cataract Refract Surg 2006;32(8):1388-91.

35. Koss MJ, Cichocki M, Kohnen T. Posterior synechias following implantation of a foldable silicone irisfixated phakic intraocular lens for the correction of myopia. J Cataract Refract Surg 2007;33(5):905-9.

36. Kohnen T, Cichocki M, Koss MJ. Position of rigid and foldable iris-fixated myopic phakic intraocular lenses evaluated by Scheimpflug photography. J Cataract Refract Surg 2008;34(1):114-20.

37. Alio JL, Chipont E, BenEzra D, Fakhry MA. Comparative performance of intraocular lenses in eyes with cataract and uveitis. J Cataract Refract Surg 2002;28(12):2096-108. 
38. Abela-Formanek C, Amon M, Schauersberger J, et al. Results of hydrophilic acrylic, hydrophobic acrylic, and silicone intraocular lenses in uveitic eyes with cataract: comparison to a control group. J Cataract Refract Surg 2002;28(7):1141-52.

39. Braga-Mele R, Cohen S, Rootman DS. Foldable silicone versus poly(methyl methacrylate) intraocular lenses in combined phacoemulsification and trabeculectomy. J Cataract Refract Surg 2000;26(10):1517-22.

40. Repetto R, Pralits JO, Siggers JH, Soleri P. Phakic iris-fixated intraocular lens placement in the anterior chamber: effects on aqueous flow. Invest Ophthalmol Vis Sci 2015;56(5):3061-8.

41. Aerts AA, Jonker SM, Wielders LH, et al. Phakic intraocular lens: Two-year results and comparison of endothelial cell loss with iris-fixated intraocular lenses. J Cataract Refract Surg 2015;41(10):2258-65.

42. Alio JL, Plaza-Puche AB, Cavas F, et al. An angle-supported foldable phakic intraocular lens for correction of myopia: A five-year follow-up. Arch Soc Esp Oftalmol 2017;92(1):4-11.

43. Kohnen T, Maxwell WA, Holland S. Correction of Moderate to High Myopia with a Foldable, Angle-Supported Phakic Intraocular Lens: Results from a 5-Year Open-Label Trial. Ophthalmology 2016;123(5):1027-35.

44. Bleckmann H, Keuch RJ. Results of cataract extraction after implantable contact lens removal. J Cataract Refract Surg 2005;31(12):2329-33.

45. Lindland A, Heger $\mathrm{H}$, Kugelberg M, Zetterstrom C. Vaulting of myopic and toric Implantable Collamer Lenses during accommodation measured with Visante optical coherence tomography. Ophthalmology 2010;117(6):1245-50.

46. Fernandes P, Gonzalez-Meijome JM, Madrid-Costa D, et al. Implantable collamer posterior chamber intraocular lenses: a review of potential complications. J Refract Surg 2011;27(10):765-76.

47. Shimizu K, Kamiya K, Igarashi A, Shiratani T. Early clinical outcomes of implantation of posterior chamber phakic intraocular lens with a central hole (Hole ICL) for moderate to high myopia. Br J Ophthalmol 2012;96(3):409-12.

48. Edelhauser HF, Sanders DR, Azar R, Lamielle H. Corneal endothelial assessment after ICL implantation. J Cataract Refract Surg 2004;30(3):576-83.

49. Sanders DR. Postoperative inflammation after implantation of the implantable contact lens. Ophthalmology 2003;110(12):2335-41.

50. el-Maghraby A, Marzouki A, Matheen TM, et al. Reproducibility and validity of laser flare/cell meter measurements of intraocular inflammation. J Cataract Refract Surg 1993;19(1):52-5.

51. Shah SM, Spalton DJ, Taylor JC. Correlations between laser flare measurements and anterior chamber protein concentrations. Invest Ophthalmol Vis Sci 1992;33(10):2878-84.

52. Kawamorita T, Shimizu K, Shoji N. Theoretical study on the need for laser iridotomy in an implantable collamer lens with a hole using computational fluid dynamics. Eye (Lond) 2017;31(5):795-801. 


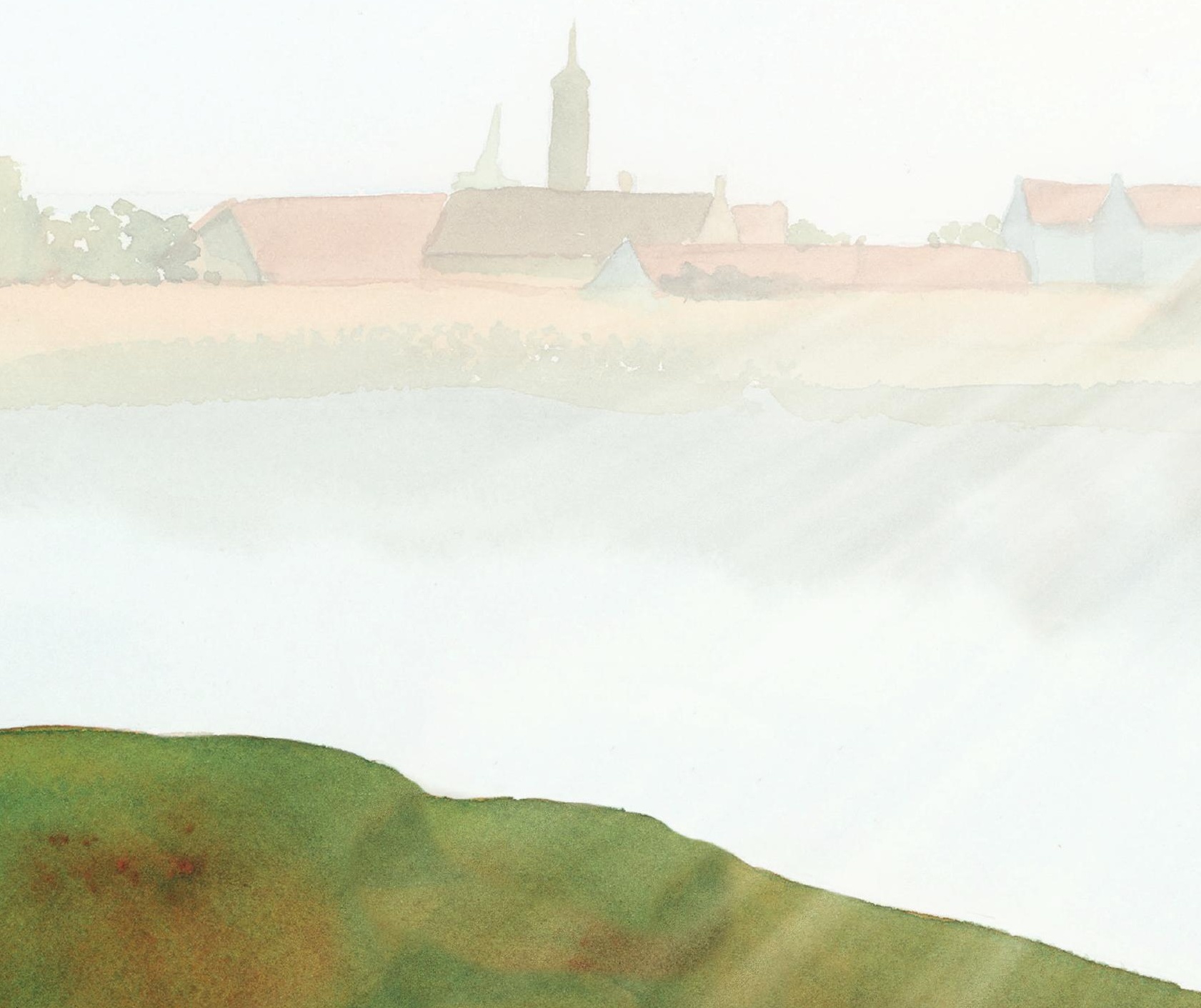




\title{
CHAPTER 5
}

\author{
Long-term changes in visual outcomes \\ and ocular morphometrics after myopic and \\ toric phakic intraocular lens implantation: \\ five- and 10-year results
}




\section{ABSTRACT}

Purpose: To evaluate the long-term refractive and visual outcomes, anterior chamber depth, and axial length (AL) changes and complications after rigid iris-fixated phakic intraocular lens (plOL) implantation to treat myopia or astigmatism.

Setting: University Eye Clinic Maastricht, Maastricht UMC+, the Netherlands

Design: Prospective case series.

Methods: The study evaluated patients who had implantation of an Artisan myopic or toric iris-fixated pIOL as of January 1998. Changes were measured annually, and reported after 1,5 and 10 years postoperatively.

Results: The study comprised 460 eyes (250 patients; mean age 41.1 years \pm 10.7 [SD]). Over 10 years, the mean myopisation was -0.79 diopters $(D)(P<.001)$, with $52 \%$ of eyes within $\pm 1.0 \mathrm{D}$ of target. The mean increase in the logarithm of the minimum angle of resolution (logMAR) corrected distance visual acuity (CDVA) over 10 years was $0.05(P<.001) ; 95 \%$ of eyes had a CDVA $20 / 40$ or more and $7 \%$ lost 2 or more lines of CDVA. The mean logMAR uncorrected visual acuity (UDVA) increased by $0.14(P<.001)$ over 10 years; $96 \%$ had a UDVA $20 / 40$ or better. The AL increased by $1.14 \mathrm{~mm}$ over 10 years $(P=.009)$. Ten percent of plOLs were explanted because of cataract formation after a mean of $97.9 \pm 34.9$ months. A higher preoperative age (hazard ratio [HR], 1.08; $P<.001)$ and longer $A L(H R, 1.34 ; P<.001)$ were risk factors for shorter survival because of cataract formation.

Conclusion: Ten years after rigid iris-fixated pIOL implantation, the CDVA and UDVA decreased significantly as a result of significant myopisation caused by an increase in AL unrelated to the pIOL. 


\section{INTRODUCTION}

For more than a decade, phakic intraocular lenses (plOLs) have been the preferred treatment for high myopia and the correction of myopia in patients unsuited for laser refractive correction because of a thin or ectatic cornea. ${ }^{1,2}$ Previous studies report good visual acuity, predictability, and stability in patients with anterior chamber (angle-supported, iris-fixated) or posterior chamber pIOLs. ${ }^{1-5}$ However, to our knowledge only 1 study of iris-fixated Artisan plOLs reported results after a 10-year follow-up ${ }^{4}$ and no previous study assessed the influence of morphological changes in refractive and visual outcomes.

The purpose of the current prospective study was to report 5-year and 10-year follow-up data on refractive and visual outcomes, morphometric changes and complications in patients who had implantation of 1 of 2 types of rigid iris-fixated pIOLs. 


\section{PATIENTS AND METHODS}

From January 1998 to June 2016, patients had implantation of an Artisan myopic or myopic toric rigid iris-fixated pIOL. The study was performed in adherence with the tenets of the Declaration of Helsinki. The Maastricht University Medical Center Institutional Review Board stated that approval was not required for this study.

Patients were evaluated preoperatively and 1 day, 1 week, and 1, 3, 6 and 12 months postoperatively. Regular follow-up continued with annual visits. All surgeries were performed by the same surgeon (R.M.M.A.N) using general or local anesthesia. The inclusion criteria, surgical procedure (including peripheral iridectomy) and postoperative medication used in the current study have been described. ${ }^{6-8}$

\section{Patient evaluations}

The preoperative examination consisted of subjective and cycloplegic refractions, Snellen uncorrected (UDVA) and corrected (CDVA) distance visual acuity measurements, and slit-lamp evaluation, including Goldmann applanation tonometry and fundoscopy. Additional evaluations were corneal topography (Orbscan, Bausch and Lomb, Inc), Scheimpflug tomography (Pentacam HR, Oculus Optikgeräte GmbH), Scheimpflug camera-Placido topography (Sirius, Schwind eye-tech-solutions GmbH \& Co. KG), biometry (A2500, Sonomed Escalon), partial coherence interferometry (IOLMaster, Carl Zeiss AG), anterior segment optical coherence tomography (AS-OCT) (Visante, Carl Zeiss AG), and specular microscopy (Noncon Robo SP9000 S/N PK11137, Konan Medical, Inc.). All preoperative measurements were performed 1 week after removal of soft contact lenses and 2 weeks after removal of rigid gas permeable contact lenses.

From 2006 onward AS-OCT was used to perform preoperative pIOL simulation to measure the anterior chamber depth (ACD), vault between the pIOL and crystalline lens, distance between the anterior $\mathrm{PIOL}$ and the endothelium, and clear lens rise as reported previously.

Postoperative annual follow-up visits consisted of subjective refraction, Snellen UDVA and CDVA measurements, slit-lamp examination, tonometry, corneal topography, AS-OCT and specular microscopy.

\section{Outcome measures}

Refractive and visual outcome measures were based on the 2014 guidelines of the Journal of Refractive Surgery, ${ }^{10}$ which describe the manifest refractive spherical equivalent (MRSE), target MRSE versus achieved MRSE, change in MRSE, refractive astigmatism, CDVA, change in CDVA, UDVA, and change in UDVA as the outcome measures for refractive surgery. The target induced astigmatism (TIA) vector, surgically induced astigmatism (SIA) vector, difference vector 
(between TIA and SIA), correction index (SIA divided by TIA), index of success (difference vector divided by TIA), and mean angle of error were calculated using refractive data in eyes with the myopic toric PIOL. The safety index (postoperative CDVA divided by preoperative CDVA) and efficacy index (postoperative UDVA divided by preoperative CDVA) were computed, and changes in the indices reported.

In addition, the ACD and axial length $(A L)$ and the changes over time were assessed to evaluate possible age-related changes in ocular biometry. Changes in endothelial cell density (ECD) were reported in a previous paper. ${ }^{6}$

\section{Statistical analysis}

Statistical analysis was performed using SPSS for Windows software (version 23, IBM Corp.). The UDVA and CDVA were converted from Snellen values to logarithm of the minimum angle of resolution (logMAR) notation for statistical analysis. Descriptive analyses were performed to compute the mean \pm SD of primary outcome measures and preoperative characteristics, and vector analyses according to Alpins were performed to assess refractive astigmatism in eyes with the myopic toric plOL. ${ }^{11}$

Longitudinal changes were assessed using linear mixed-model analysis with the eye identification number as a grouping variable and time as a covariate. In each model, the best fit covariance structure was selected using the Bayesian information criterion. To determine long-term changes in the study groups, longitudinal analyses were used to assess short-term changes from preoperatively to 12 months postoperatively and long-term changes from 12 months postoperatively until the end of follow-up. Hotelling trace multivariate analysis of variance (MANOVA) analyses were performed to determine whtether the vectorial change from 1 to 5 years and 1 to 10 years postoperatively was significantly different from zero.

In a subset of patients, longitudinal analyses and cross-sectional analyses of the effect of age on AL were performed using linear mixed-model (24 eyes; longitudinal data) and analysis of variance (ANOVA) (181 eyes; preimplantation data), respectively, in a subset of patients. KaplanMeier and multivariate Cox regression analyses were performed to measure the survival from pIOL implantation to pIOL explantation for cataract formation. A P values less than 0.05 was considered significant. 


\section{RESULTS}

The study comprised 460 eyes of 250 patients; the rigid myopic pIOL was implanted in 379 eyes of 207 patients and the rigid myopic toric pIOL in 81 eyes of 51 patients. Table 1 shows the patients' baseline characteristics. The mean follow-up was 90 months \pm 60 (SD). After extensive parental consultation 4 eyes of 3 contact-lens-intolerant patients younger than 18 years had implantation of a myopic plOL because of anisometropia $(n=2)$ or a high preoperative refraction ( $n$ =2). Between 1998 and 2006, no definitive cutoff points were formulated (neither internationally nor by the Netherlands Society for Refractive Surgery) with respect to the preoperative ECD. As a result, a pIOL was implanted in 20 eyes of 16 patients with an ECD lower than 2000 cells $/ \mathrm{mm}^{2}$.

\section{Predictability}

Table 1 shows the MRSE results over time. Figure 1 shows the target MRSE correction versus the achieved MRSE correction at the 3 postoperative timepoints (1 year, 5 years, and 10 years). Figure 2 shows the percentage of eyes within \pm 0.50 diopter ( $D$ ) and $\pm 1.00 \mathrm{D}$ of the target refraction at the 3 postoperative timepoints. Figure 3 shows the change in MRSE over 10 years and the percentage of eyes with a greater than 0.5 D change in the MRSE change from 1 year to 5 and 10 years postoperatively. Figure 4 shows the preoperative and postoperative residual refractive astigmatism and percentage of eyes with refractive astigmatism of $\pm 0.50 \mathrm{D}$ or less and \pm 1 . $0 \mathrm{D}$ or less from zero. Figures 5 to 7 show single-angle polar plots representing TIA vector, SIA vector, difference vector, and correction index at 1 year, 5 years, and 10 years, respectively. Figure 8 shows the distribution of the angle of error at the 3 postoperative timepoints. The mean index of success was $0.27 \pm 0.28,0.21 \pm 0.19$ and $0.28 \pm 0.22$ at 1 year, 5 years, and 10 years, respectively.

The MRSE decreased by 0.079 D each year; the decrease was statistically significant $(p<.001)$. On vector analysis, the mean change in refractive cylinder in eyes with the toric $\mathrm{plOL}$ was 0.38 $\pm 0.62 \mathrm{D}$ at 149 degrees from 1 to 5 years $(P=.023)$ and $0.31 \pm 0.50 \mathrm{D}$ at 112 degrees from 1 to 10 years postoperatively $(P=.29)$.

\section{Safety}

Table 1 shows logMAR CDVA over time. Figure 9 shows the change in Snellen lines of CDVA 5 years and 10 years postoperatively as well as the percentage of eyes losing 2 or more Snellen CDVA lines. One year after pIOL implantation, the CDVA was 20/40 or better in 371 eyes (97\%) and $20 / 20$ or better in 252 eyes (66\%). At 5 years, the CDVA was 20/40 or better in 240 eyes (96\%) and 20/20 or better in 153 eyes (61\%). The results at 10 years were 129 eyes (95\%) and 63 eyes (46\%), respectively. The annual increase in the logMAR CDVA was 0.005, which was statistically significant $(P<.001)$. The safety index decreased by 0.010 per year (Table 1$)$. The change was statistically significant $(P<.001)$. 

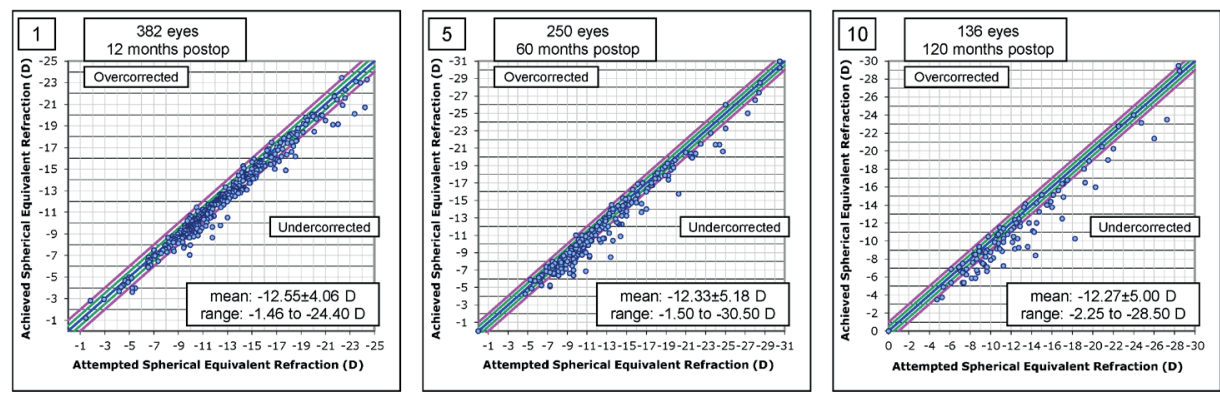

Figure 1. Target versus achieved manifest refraction spherical equivalent correction 1 year, 5 years, and 10 years potoperatively.
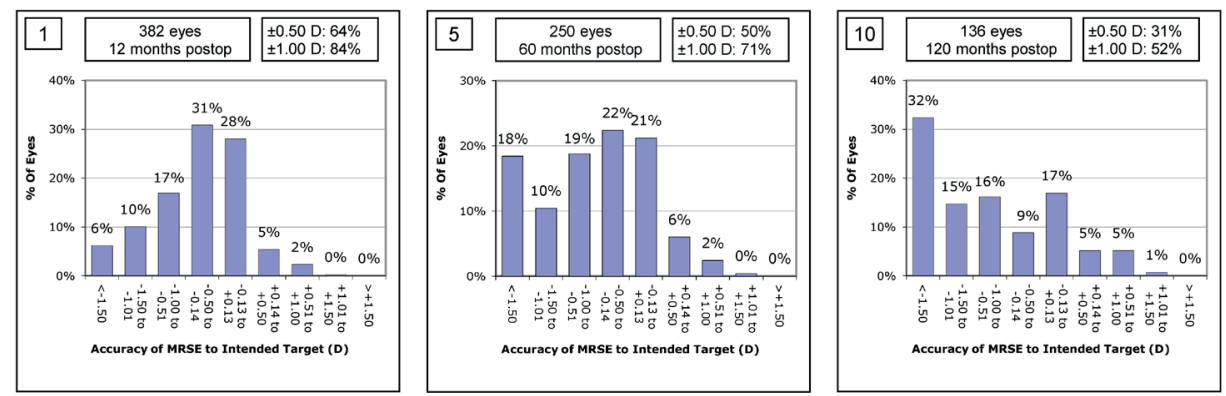

Figure 2. Accuracy of the MRSE 1 year, 5 years, and 10 years postoperatively. MRSE = manifest refractive spherical equivalent


Figure 3. Change in MRSE from preoperatively to 1 year, 5 years, and 10 years postoperatively. MRSE = manifest refractive spherical equivalent. 

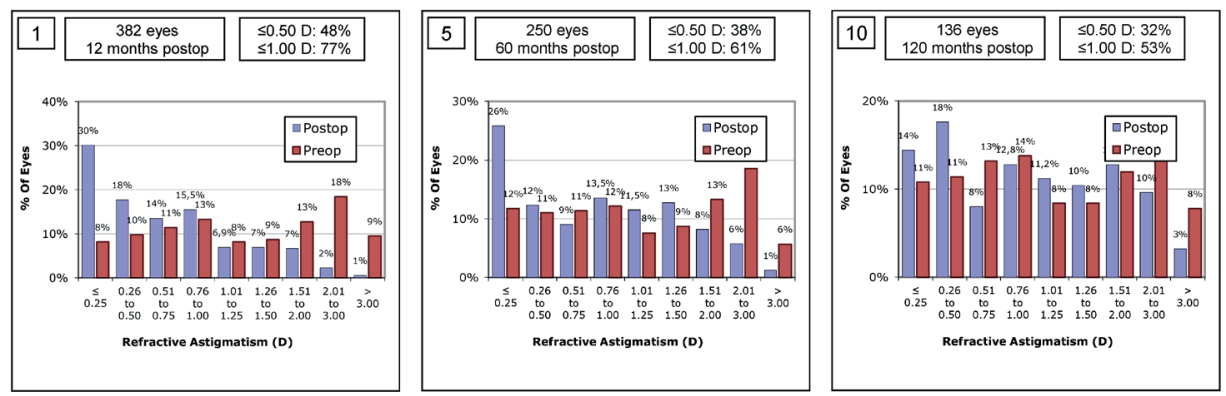

Figure 4. Refractive astigmatism preoperatively and 1 year, 5 years, and 10 years postoperatively.
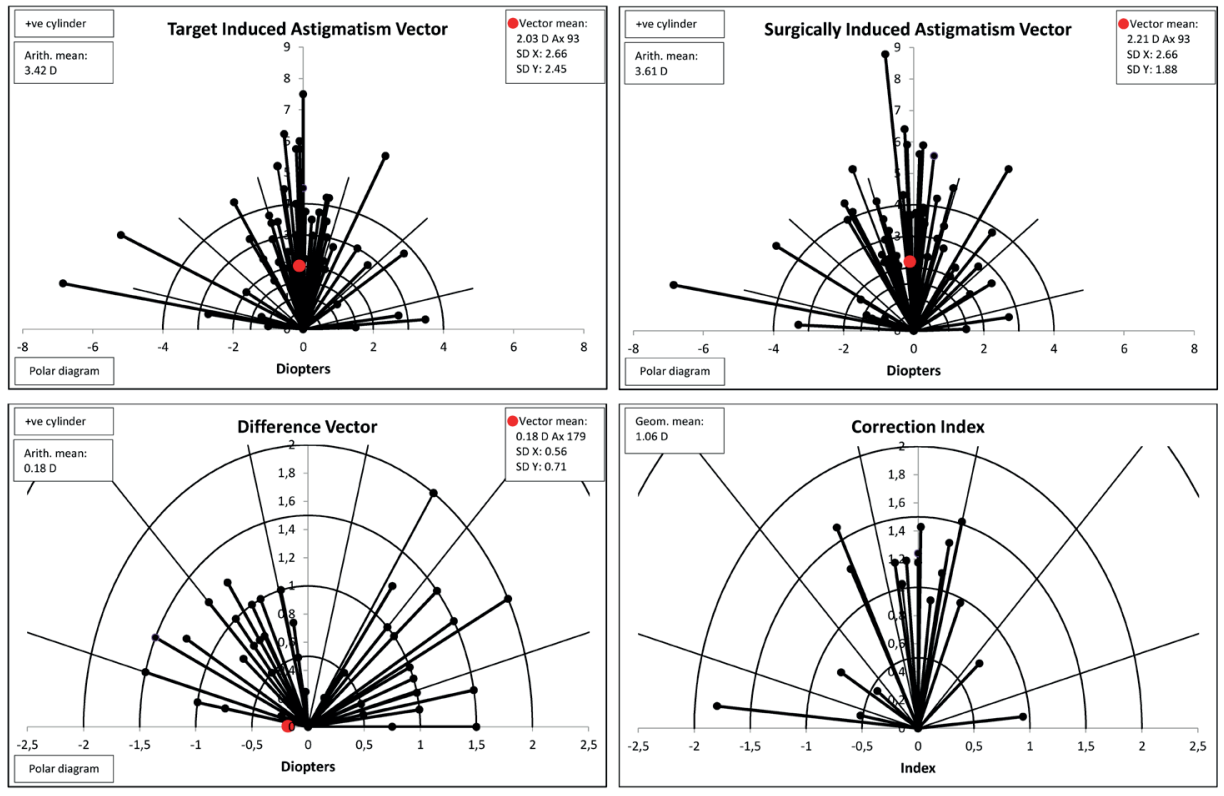

Figure 5. Single-angle polar plots of target induced astigmatism vector, surgically induced astgimatism vector, difference vector and correction index, 1 year after implantation of a iris-fixated toric phakic intraocular lens (53 eyes). Arith. = arithmetic; Geom = geometric.

\section{Efficacy}

Table 1 shows the mean logMAR UDVA over time. Figure 10 shows the cumulative Snellen UDVA and Figure 11, the differences in Snellen lines between the UDVA at the 3 postoperative timepoints and the preoperative CDVA. The logMAR UDVA increased by 0.014 each year, which was statistically significant $(P<.001)$.

Table 1 also shows the efficacy index at the 3 postoperative timepoints. Annually the efficacy index decreased by 0.017 each year, which was statistically significant $(P<.001)$. 

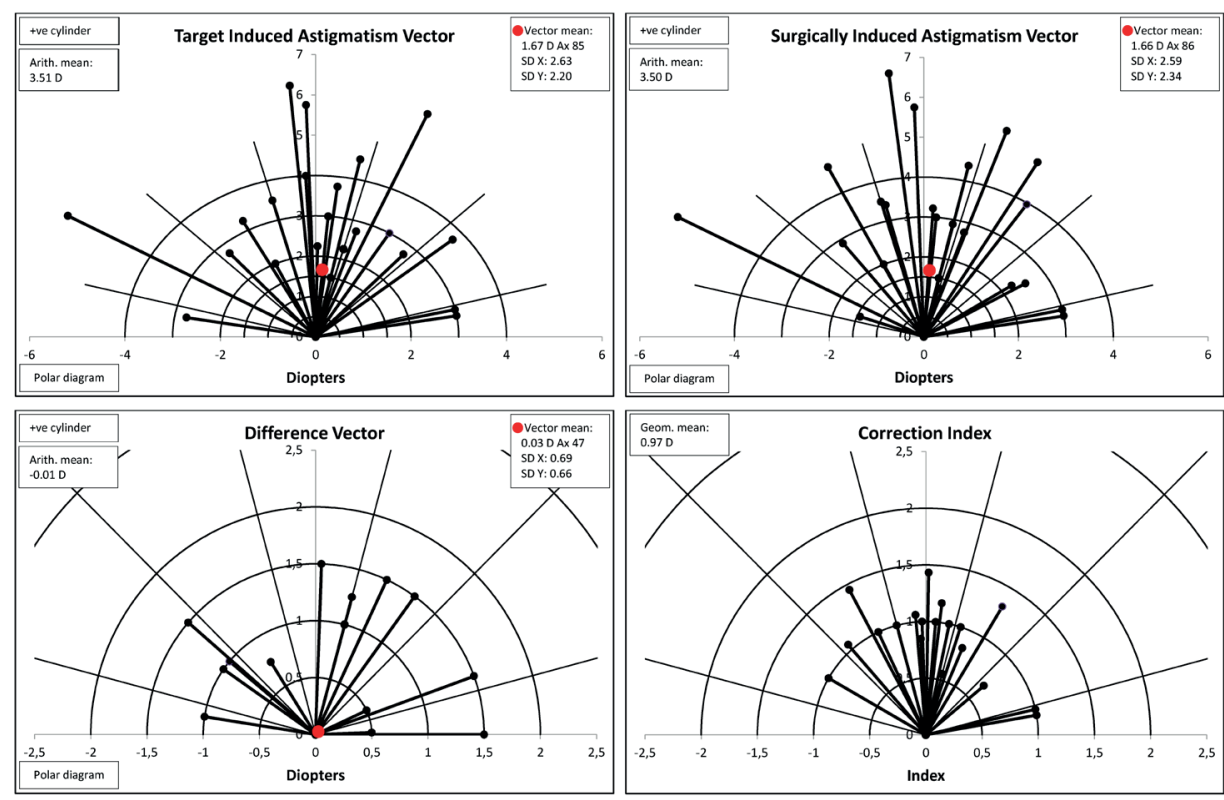

Figure 6. Single-angle polar plots of target induced astigmatism vector, surgically induced astgimatism vector, difference vector and correction index, 5 years after implantation of a iris-fixated toric phakic intraocular lens (23 eyes). Arith. = arithmetic; Geom = geometric.

\section{Ocular biometry}

Table 1 shows the mean ACD preoperatively and postoperatively. A longitudinal analysis showed no change in ACD over time $(P=.42)$. Longitudinal analysis of $A L$ was performed in a subgroup of 24 eyes that had pIOL implantation as well as combined explantation and cataract surgery at a later date and for which the IOL calculations were performed based on optical biometry $\mathrm{AL}$ measurements on both occasions. The mean preoperative $\mathrm{AL}$ (measured from the corneal epithelium) was $28.09 \pm 2.24 \mathrm{~mm}$. There was a statistically significant increase in AL of 0.11 $\mathrm{mm}$ per year $(P=.009)$, equaling a total increase of $0.57 \mathrm{~mm}$ and $1.14 \mathrm{~mm}$ after 5 years and 10 years, respectively. A secondary cross-sectional analysis (ANOVA) was performed to look at the correlation between age and AL measured with optical biometry devices before pIOL implantation. Analysis of 181 eyes found a similar trend, with the AL increasing significantly by $0.059 \mathrm{~mm}$ each year $(P<.001)$.

\section{Complications and interventions}

Table 2 shows the postoperative complications and reasons for additional surgery, including pIOL exchange and explantation. No rhegmatogenous retinal detachments (RRDs) occurred in any eye after cataract surgery. 

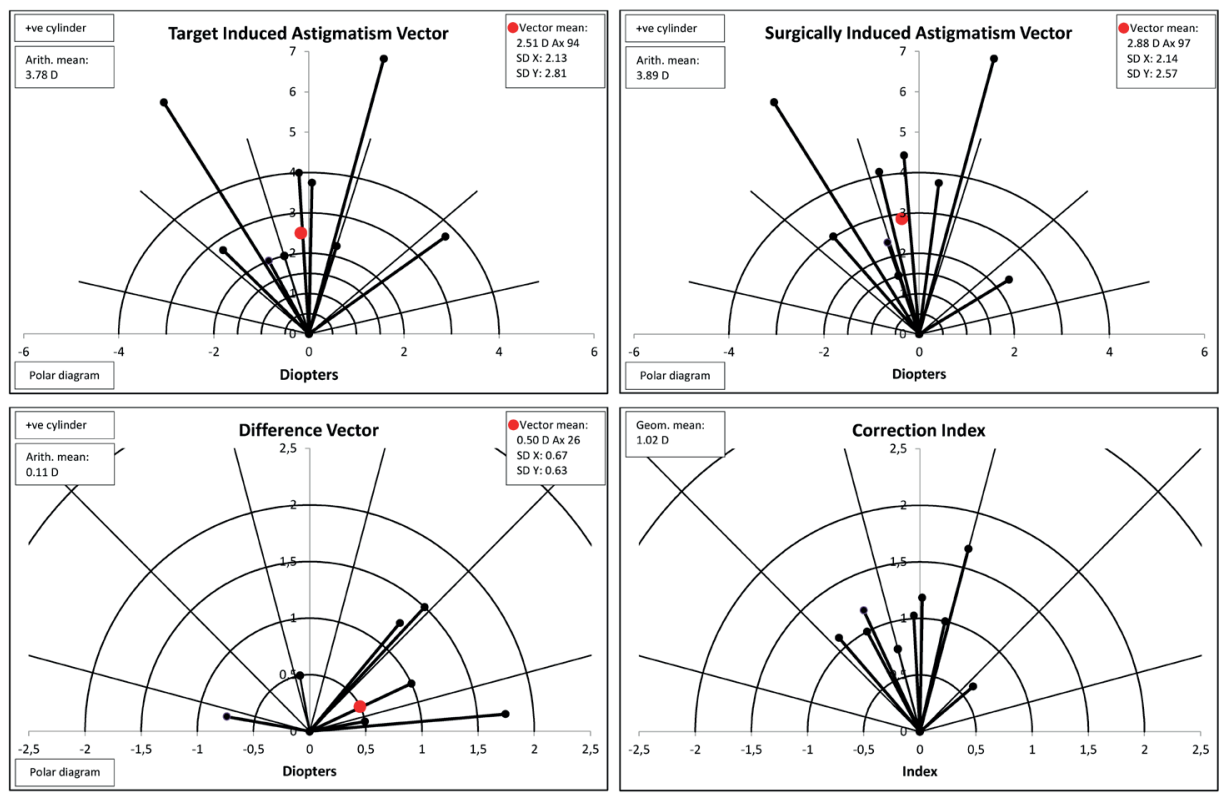

Figure 7. Single-angle polar plots of target induced astigmatism vector, surgically induced astgimatism vector, difference vector and correction index, 10 years after implantation of a iris-fixated toric phakic intraocular lens (9 eyes). Arith. = arithmetic; Geom = geometric .

\section{Risk factors}

After insignificant risk factors were excluded, the Cox regression multivariate analysis identified higher preoperative age (hazard ratio [HR], 1.08; 95\% confidence interval [CI], 1.05-1.12; $P$ $<.001)$ and longer preoperative $\mathrm{AL}(\mathrm{HR}, 1.34 ; 95 \% \mathrm{Cl}, 1.19-1.50 ; \mathrm{P}<.001)$ as significant risk factors for a shorter survival.
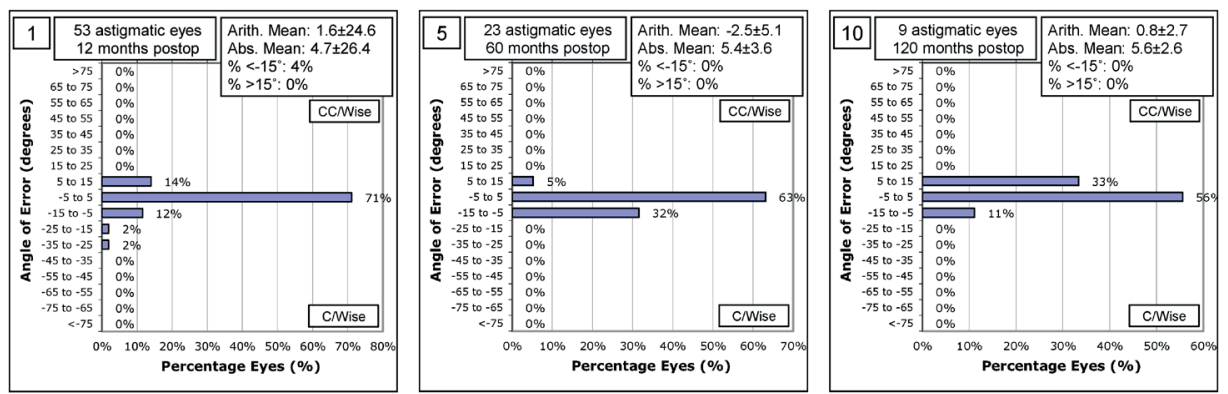

Figure 8. The refractive astigmatism angle of error 1,5 and 10 years after implantation with an irisfixated phakic intraocular lens. Abs. = absolute; Arith. = Arithmetic; CC/wise = counterclockwise; $\mathrm{C} /$ wise = clockwise. 

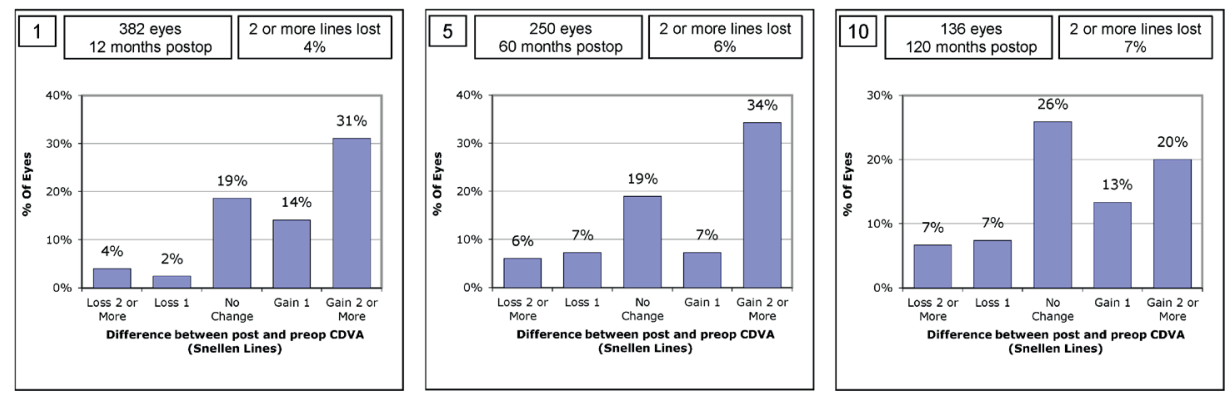

Figure 9. Change in Snellen lines of CDVA 1 year, 5 years, and 10 years postoperatively. CDVA = corrected distance visual acuity.
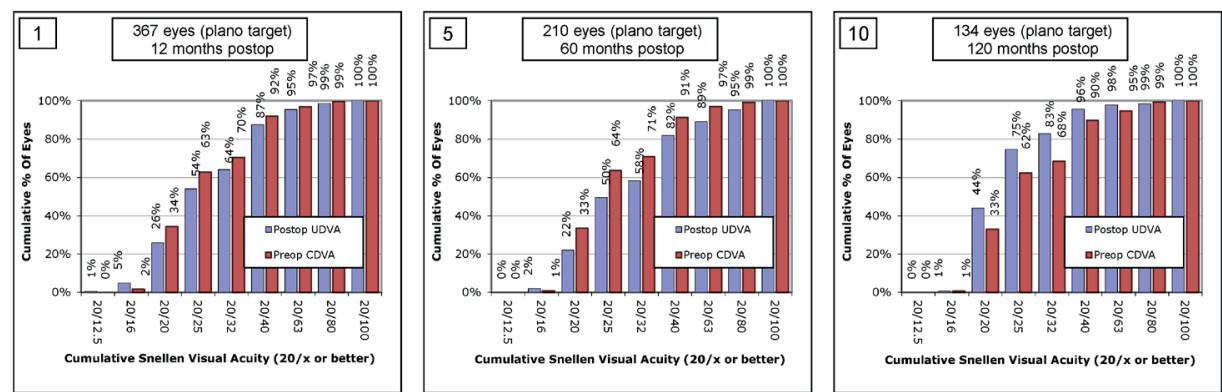

Figure 10. Snellen preoperative CDVA and UDVA 1 year, 5 years, and 10 years postoperatively. CDVA = corrected distance visual acuity; UDVA = uncorrected distance visual acuity.
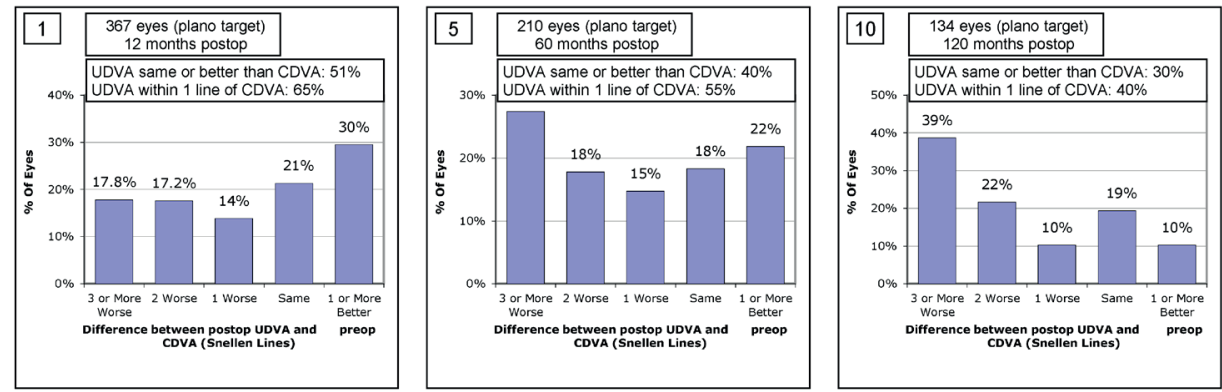

Figure 11. Difference in Snellen lines between postoperative UDVA and preoperative CDVA 1 year, 5 years, and 10 years postoperatively. CDVA = corrected distance visual acuity; UDVA = uncorrected distance visual acuity. 
Table 1. Preoperative characteristics and postoperative results

\begin{tabular}{|c|c|c|c|c|}
\hline & \multirow[b]{2}{*}{ Preoperative } & \multicolumn{3}{|c|}{ Postoperative } \\
\hline & & 1 Year & 5 Year & 10 Year \\
\hline \multicolumn{5}{|c|}{ Patient Characteristics } \\
\hline \multicolumn{5}{|l|}{ Age $(y)$} \\
\hline Mean \pm SD & $41.1 \pm 10.7$ & NR & NR & NR \\
\hline Range & 5.3 to 68.2 & NR & NR & NR \\
\hline Men / women (\%) & $37 / 63$ & NR & NR & NR \\
\hline Eyes (n) & 460 & 382 & 250 & 136 \\
\hline \multicolumn{5}{|l|}{ Predictability } \\
\hline \multicolumn{5}{|l|}{ MRSE (D) } \\
\hline Mean \pm SD & $-12.58 \pm 5.15$ & $-0.51 \pm 0.69$ & $-0.81 \pm 0.98$ & $-0.72 \pm 1.48$ \\
\hline Range & -30.50 to 0.00 & -3.50 to 1.13 & -4.88 to 1.13 & -8.00 to 3.00 \\
\hline \multicolumn{5}{|c|}{ Refractive cylinder (D) } \\
\hline Mean \pm SD & $-1.64 \pm 1.35$ & $-0.75 \pm 0.65$ & $-0.95 \pm 0.77$ & $-1.25 \pm 0.87$ \\
\hline Range & -8.50 to 0.00 & -3.50 to 0.00 & -3.50 to 0.00 & -4.50 to 0.00 \\
\hline \multicolumn{5}{|l|}{ Safety } \\
\hline \multicolumn{5}{|l|}{ CDVA (logMAR) } \\
\hline Mean \pm SD & $0.13 \pm 0.18$ & $0.03 \pm 0.16$ & $0.04 \pm 0.15$ & $0.10 \pm 0.23$ \\
\hline Range & -0.18 to 1.70 & -0.20 to 1.78 & -0.18 to 1.00 & -0.18 to 2.08 \\
\hline \multicolumn{5}{|l|}{ Safety index } \\
\hline Mean \pm SD & NA & $1.29 \pm 0.32$ & $1.22 \pm 0.33$ & $1.24 \pm 0.45$ \\
\hline Range & NA & 0.50 to 2.67 & 0.50 to 2.50 & 0.04 to 3.00 \\
\hline \multicolumn{5}{|l|}{ Efficacy } \\
\hline \multicolumn{5}{|l|}{ UDVA (logMAR) } \\
\hline Mean \pm SD & NA & $0.17 \pm 0.23$ & $0.23 \pm 0.27$ & $0.29 \pm 0.29$ \\
\hline Range & NA & -0.20 to 1.78 & -0.10 to 1.48 & -0.08 to 1.30 \\
\hline \multicolumn{5}{|l|}{ Efficacy index } \\
\hline Mean \pm SD & NA & $0.96 \pm 0.32$ & $0.83 \pm 0.32$ & $0.77 \pm 0.35$ \\
\hline Range & NA & 0.10 to 2.33 & 0.06 to 1.60 & 0.06 to 2.00 \\
\hline \multicolumn{5}{|l|}{$\mathrm{IOP}(\mathrm{mmHg})$} \\
\hline Mean \pm SD & $14.8 \pm 3.3$ & $15.5 \pm 3.0$ & $15.9 \pm 3.1$ & $16.4 \pm 2.6$ \\
\hline Range & 6.0 to 30.0 & 8.0 to 26.0 & 10.0 to 24.0 & 11.0 to 25.0 \\
\hline \multicolumn{5}{|l|}{$\mathrm{ACD}^{*}(\mathrm{~mm})$} \\
\hline Mean \pm SD & $3.13 \pm 0.38$ & $3.12 \pm 0.28$ & $3.11 \pm 0.15$ & $2.86 \pm 0.34$ \\
\hline Range & 2.54 to 4.51 & 2.50 to 3.60 & 2.90 to 3.46 & 2.12 to 3.40 \\
\hline
\end{tabular}

ACD = anterior chamber depth; CDVA = corrected distance visual acuity; IOP = intraocular pressure; $\log M A R=$ logarithm of the minimum angle of resolution; MRSE = manifest refractive spherical equivalent; NA = not applicable; NR = not reported; UDVA = uncorrected distance visual acuity *Measured from the corneal endothelium. 
Table 2. Sight threatening events, secondary surgical interventions, and phakic intraocular lens exchanges and explantations in the entire cohort (460 eyes)

\begin{tabular}{|c|c|c|c|c|}
\hline & \multirow{2}{*}{$\begin{array}{c}\text { Eyes / } \\
\text { patients (n) }\end{array}$} & \multirow[b]{2}{*}{ Ratio, \% } & \multicolumn{2}{|c|}{ Time (mo) } \\
\hline & & & Mean \pm SD & Range \\
\hline \multicolumn{5}{|l|}{ Retinal Events } \\
\hline Retinal detachment & $5 / 5$ & 1.09 & $37.8 \pm 30.6$ & 0.9 to 80.1 \\
\hline Myopic macular degeneration & $8 / 6$ & 1.74 & $102.2 \pm 45.5$ & 1.0 to 144.8 \\
\hline Retinoschisis & $2 / 2$ & 0.43 & 36.0 and 108.0 & NA \\
\hline Macular hole & $1 / 1$ & 0.22 & 3.0 & NA \\
\hline Central serous chorioretinopathy & $1 / 1$ & 0.22 & 84.0 & NA \\
\hline \multicolumn{5}{|l|}{ Secondary Surgical Intervention } \\
\hline \multicolumn{5}{|l|}{ Laser Refractive Correction } \\
\hline PRK & $15 / 9$ & 3.26 & $37.5 \pm 21.4$ & 3.2 to 63.1 \\
\hline \multicolumn{5}{|l|}{ pIOL Refixation } \\
\hline Traumatic subluxation & $2 / 2$ & 0.43 & 9.0 and 29.4 & NA \\
\hline Insufficient enclavation & $1 / 1$ & 0.22 & 34.5 & NA \\
\hline Glare & $1 / 1$ & 0.22 & 4.6 & NA \\
\hline Misalignment & $1 / 1$ & 0.22 & 4.4 & NA \\
\hline \multicolumn{5}{|l|}{ plOL Exchange } \\
\hline Undercorrected & $2 / 2$ & 0.43 & 1.4 and 1.4 & NA \\
\hline Overcorrected & $1 / 1$ & 0.22 & 3.9 & NA \\
\hline Refractive change & $1 / 1$ & 0.22 & 84.2 & NA \\
\hline Additional toric correction & $1 / 1$ & 0.22 & 15.8 & NA \\
\hline \multicolumn{5}{|l|}{ plOL Explantation } \\
\hline Cataract & $46 / 32$ & 10.00 & $97.9 \pm 34.9$ & 13.8 to 163.7 \\
\hline EC loss* & $22 / 15$ & 4.78 & $126.9 \pm 41.7$ & 44.4 to 182.9 \\
\hline Cataract and EC-loss & $5 / 4$ & 1.09 & $153.4 \pm 22.6$ & 120.0 to 179.7 \\
\hline High IOP & $4 / 2$ & 0.87 & $53.2 \pm 26.5$ & 25.7 to 80.3 \\
\hline Anisometropia & $1 / 1$ & 0.22 & 15.6 & NA \\
\hline Decentration & $1 / 1$ & 0.22 & 1.4 & NA \\
\hline Recurrent retinal detachment ${ }^{\#}$ & $1 / 1$ & 0.22 & 82.8 & NA \\
\hline
\end{tabular}

$\mathrm{EC}=$ endothelial cell; IOP = intraocular pressure; $\mathrm{NA}=$ not applicable; $\mathrm{PRK}=$ photorefractive keratectomy ${ }^{*}$ Corneal edema requiring Descemet stripping automated endothelial keratoplasty in 1 eye of 1 patient and corneal edema requiring penetrating keratoplasty in 1 eye of 1 patient.

"Recurrent retinal detachment requiring retinal surgery in one eye of one patient. 


\section{DISCUSSION}

The current study assessed the refractive and visual outcomes 10 years after iris-fixated pIOL implantation. 1-5, 12-18 The key finding is the age-related AL elongation, which caused significant myopisation and affected the long-term predictability and efficacy. We applied linear mixedmodel analysis, which is designed to use all available data from each individual subject, and is especially useful when testing for significant changes over time (ie, per annum). As such, the current article might serve as a reference for longitudinal change and as a catalyst for further research on AL changes in high myopia.

Regarding predictability, even though our 10-year results resemble those in studies with a much shorter follow-up, 4, 5, 12,13,15-18 they are slightly different from the results in the only other study with a 10-year follow-up (ie, MRSE -0.70 D and $43.8 \%$ and $68.8 \%$ of eyes within \pm 0.5 and $\pm 1.0 \mathrm{D}$ of target refraction, respectively). ${ }^{4}$ The lower percentage of eyes within \pm 0.5 and $\pm 1.0 \mathrm{D}$ of the target correction in our group is likely related to the fact that 48 eyes in our study developed cataract requiring surgery, as opposed to 2 eyes in the previous study. ${ }^{4}$ We believe that the higher preoperative age and higher myopia in our group (41.1 years and -12.58 D, respectively, in our group versus 38.35 years and $-10.36 \mathrm{D}$, respectively, in the previous study) resulted in a higher risk for developing cataract within 10 years of pIOL implantation. Another explanation is the reported increase in AL over the 10 years of follow-up, which caused axial myopia. Unfortunately, cataract was not graded on a regular basis in the current study; thus, the influence of cataract formation versus $A L$ elongation on myopisation remains uncertain. Despite the significant change in refractive cylinder from 1 year to 5 years postoperatively all vector analyses after 5 years showed excellent results. The mean difference vector was 0.03 $\mathrm{D}$ at 47 degrees (0.00 D being the preferred result), and the mean correction index was 0.97 ( 1.00 being the preferred result). Two previous studies used double-angle plots to show the refractive cylinder 6 months after toric pIOL implantation; both found a significant reduction in preoperative astigmatism that was equal to our long-term results after 5 years..$^{15,17}$

Regarding safety, $7 \%$ of eyes lost 2 or more Snellen CDVA lines, a proportion higher than reported values, which vary from $0.9 \%$ to $2.6 \%$ after 3 to 10 years. ${ }^{4,12-15}$ This might be attributed to the higher incidences of eyes requiring cataract requiring surgery in our study than in other studies (7.6\% after 10 years in our group versus $0.0 \%$ to $2.25 \%$ of eyes after 3 to 6 years in the literature) , $^{12-14}$ as well as the higher incidence of retinal complications (ie, detachment, hemorrhage, myopic or macular degeneration, macular hole, retinoschisis) (3.5\% in our group versus in $0.51 \%$ to $3.5 \%$ in the literature [data on file]). ${ }^{4,12-14}$ However, the safety index was 1.24 in the myopic plOL group, higher than the safety index of 1.10 in the only other study with a follow-up of 10 years. ${ }^{4}$ 
Our efficacy results agree with previous findings. The LogMAR UDVA, percentage of eyes with a UDVA of 20/40 or better or 20/20 or better, and efficacy index after 10 years were similar to previous studies with a follow up of 3 to 10 years., 5, 12-16,18

In our study population, there was not a significant change in ACD measured by ocular biometry. This is in contrast with previous reports using either ultrasound ${ }^{19,20}$ or OCT ${ }^{21}$; these studies found an annual decrease in ACD ranging from $-0.011 \mathrm{~mm}$ to $-0.018 \mathrm{~mm}$. Although we found a myopic shift with advancing time, the mean preoperative age of 40 years makes nuclear sclerosis a less likely explanation for this shift, leading us to focus on a possible increase in AL related to age. Therefore, we evaluated the AL changes in 2 subsets of patients.

In the first subset comprised of 24 eyes that had a combined pIOL explantation and cataract surgery. Longitudinal analysis showed that the AL in these eyes increased $0.11 \mathrm{~mm}$ per year, a statistically significant change. To explore the relationship between age and AL, measurements using optical biometry obtained before $\mathrm{plOL}$ implantation were analyzed in relation to preoperative age. This cross-sectional analysis showed a significant effect of age, with an expected increase in AL of $0.059 \mathrm{~mm}$ per year. The $\mathrm{AL}$ was not reported in the preceding longterm follow-up study, ${ }^{4}$ and previous epidemiological studies assessing the AL changes in an adult population used ultrasonound for longitudinal evaluation or assessed emmetropic eyes only. ${ }^{20,22,23}$ Because of the small size of our subgroup and because previous publications did not focus on AL changes in eyes with high myopia, our results, rather than a standard age-related effect, should be regarded as a possible trend in AL changes in an adult population of patients with high myopia.

Retinal detachment (RD) occurred in 1.09\% of eyes in our study; other studies report an incidence of $0.25 \%$ to $0.39 \%$ after a 3 to 5 years follow-up. ${ }^{5,13}$ Previous studies identified high myopia, defined as either -3.0 D or -6.0 D, as a significant risk factor for RRD.1,24-26 As a result, the high preoperative MRSE of $-12.58 \mathrm{D}$ and mean preoperative $\mathrm{AL}$ of $28.09 \mathrm{~mm}$ likely contributed to the higher total percentage of RD and myopic macular degeneration. In addition, other studies found the risk for RD to be higher in pseudophakic eyes as a result of volumetric changes of the vitreous and an inflammatory reaction after phacoemulsification, leading to RRD in 0.55\% and $1.17 \%$ of eyes after a mean follow-up of 4.3 and 3.3 years, respectively. ${ }^{25}, 26$ Combined pIOL explantation and cataract surgery did not result in RRD in any patient in this cohort. Myopic macular degeneration in high myopes with an AL similar to that in our cohort (mean $29.8 \pm 1.7$ $\mathrm{mm}$ ) and mean follow-up of 13 years resulted in choroidal neovascularization in $10.2 \%$ of eyes in a 2003 study. ${ }^{27}$ It might be advisable to alert patients with myopic macular degeneration who request pIOL implantation of this risk for visual complications and to keep in mind that high myopia in itself can cause severe visual complications regardless of intraocular surgery. 
Additional laser refractive touch-up surgery (eg, photorefractive keratectomy) was required in $3.26 \%$ of eyes in the current study versus rates of 5.95\% to $14.85 \%$ reported in the literature. ${ }^{5,28}$ Guëll et al. hypothesized that laser in situ keratomileusis in an eye with an anterior chamber pIOLs might induce contact between the corneal endothelium and the $\mathrm{plOL}$ when the microkeratome is used, which could be a good reason to perform photorefractive keratectomy instead in eyes with an anterior chamber pIOL. ${ }^{29}$

Cataract formation rates were higher in our group than in previous studies, which reported cataract in $0.25 \%$ of eyes after 3 years and in $3.04 \%$ of eyes after 8 years. ${ }^{14,30}$ We do not believe that cataract formation was caused by the pIOL but rather that higher mean patient age and longer mean AL might have been causative factors. ${ }^{1,31,32}$ This hypothesis was validated by additional Kaplan-Meier and Cox regression analyses that assessed survival until plOL explantation performed because of cataract formation in the current study. A recent paper by our group provided an in-depth evaluation of survival until plOL explantation in all patients implanted with iris-fixated pIOLs at our clinic. It estimated that $25 \%$ and $50 \%$ of iris-fixated pIOLs would be explanted after 134.3 months and 182.9 months, respectively. ${ }^{33}$

In conclusion, age-related $\mathrm{AL}$ elongation, possibly together with cataract formation, resulted in significant myopisation and caused a decrease in CDVA and UDVA. To our knowledge, no previous study has reported axial elongation in highly myopic eyes, mainly because these studies were cross-sectional, focused on emmetropic eyes, and used error-prone techniques (ie, ultrasound) to measure AL. 20,22,23 Based on our results, we believe that the myopic shift and higher rates of cataract formation should be attributed to a higher preoperative age and longer $\mathrm{AL}$ rather than to the intraocular presence of the $\mathrm{pIOL}$. Myopisation induced by AL elongation might suggest implantation of plOLs with a slight hyperopic target to anticipate this refractive change. However, inducing hyperopia in a formerly highly myopic patient is likely to result in unhappy patients and is not advised. Additional research on longitudinal changes in refractive error and AL in a highly myopic population is indicated to map physiological changes against our results after pIOL implantation. Refractive surgeons should counsel patients on the long-term changes in visual outcomes after pIOL implantation in cases of high myopia. 


\section{WHAT WAS KNOWN}

- Implantation of iris-fixated phakic intraocular lenses ( $\mathrm{p} \mid \mathrm{OLs}$ ) provides excellent visual and refractive results in highly myopic patients

- Over time, increased crystalline lens swelling decreases the anterior chamber depth, causing the $\mathrm{PIOL}$ to rise.

\section{WHAT THIS PAPER ADDS}

- Significant myopisation might occur in highly myopic adults as a result of axial elongation

- Combined iris-fixated pIOLs explantation and cataract surgery did not seem to result in increased rates of retinal detachments in a group of highly myopic patients. 


\section{REFERENCES}

1. Kohnen T, Kook D, Morral M, Guell JL. Phakic intraocular lenses: part 2: results and complications. J Cataract Refract Surg 2010;36(12):2168-94.

2. Huang D, Schallhorn SC, Sugar A, et al. Phakic intraocular lens implantation for the correction of myopia: a report by the American Academy of Ophthalmology. Ophthalmology 2009;116(11):224458.

3. Kohnen T, Maxwell WA, Holland S. Correction of Moderate to High Myopia with a Foldable, Angle-Supported Phakic Intraocular Lens: Results from a 5-Year Open-Label Trial. Ophthalmology 2016;123(5):1027-35.

4. Tahzib NG, Nuijts RM, Wu WY, Budo CJ. Long-term study of Artisan phakic intraocular lens implantation for the correction of moderate to high myopia: ten-year follow-up results. Ophthalmology 2007;114(6):1133-42.

5. Guell JL, Morral M, Gris O, et al. Five-year follow-up of 399 phakic Artisan-Verisyse implantation for myopia, hyperopia, and/or astigmatism. Ophthalmology 2008;115(6):1002-12.

6. Jonker SMR, Berendschot T, Ronden AE, et al. Long-Term Endothelial Cell Loss in Patients with Artisan Myopia and Artisan Toric Phakic Intraocular Lenses: 5- and 10-Year Results. Ophthalmology 2018;125(4):486-94.

7. Doors M, Cals DW, Berendschot TT, et al. Influence of anterior chamber morphometrics on endothelial cell changes after phakic intraocular lens implantation. J Cataract Refract Surg 2008;34(12):2110-8.

8. Aalders-Deenstra V, Bartels M, Beerthuizen J, et al. Consensus Refractie Chirurgie. 3 ed: Nederlands Gezelschap voor Refractie Chirurgie (NGRC), 2013.

9. Baikoff G. Anterior segment OCT and phakic intraocular lenses: a perspective. J Cataract Refract Surg 2006;32(11):1827-35.

10. Reinstein DZ, Archer TJ, Randleman JB. JRS standard for reporting astigmatism outcomes of refractive surgery. J Refract Surg 2014;30(10):654-9.

11. Alpins NA, Goggin M. Practical astigmatism analysis for refractive outcomes in cataract and refractive surgery. Surv Ophthalmol 2004;49(1):109-22.

12. Titiyal JS, Sharma N, Mannan R, et al. Iris-fixated intraocular lens implantation to correct moderate to high myopia in Asian-Indian eyes: five-year results. J Cataract Refract Surg 2012;38(8):1446-52.

13. Budo C, Hessloehl JC, Izak M, et al. Multicenter study of the Artisan phakic intraocular lens. J Cataract Refract Surg 2000;26(8):1163-71.

14. Stulting RD, John ME, Maloney RK, et al. Three-year results of Artisan/Verisyse phakic intraocular lens implantation. Results of the United States Food And Drug Administration clinical trial. Ophthalmology 2008;115(3):464-72.e1.

15. Bartels MC, Saxena R, van den Berg TJ, et al. The influence of incision-induced astigmatism and axial lens position on the correction of myopic astigmatism with the Artisan toric phakic intraocular lens. Ophthalmology 2006;113(7):1110-7.

16. Tehrani M, Dick HB. Iris-fixated toric phakic intraocular lens: Three-year follow-up. J Cataract Refract Surg 2006;32(8):1301-6.

17. Dick HB, Alio J, Bianchetti M, et al. Toric phakic intraocular lens: European multicenter study. Ophthalmology 2003;110(1):150-62.

18. Guell JL, Vazquez M, Malecaze F, et al. Artisan toric phakic intraocular lens for the correction of high astigmatism. Am J Ophthalmol 2003;136(3):442-7. 
19. Richdale K, Bullimore MA, Sinnott LT, Zadnik K. The Effect of Age, Accommodation, and Refractive Error on the Adult Human Eye. Optom Vis Sci 2016;93(1):3-11.

20. Atchison DA, Markwell EL, Kasthurirangan S, et al. Age-related changes in optical and biometric characteristics of emmetropic eyes. J Vis 2008;8(4):29.1-0.

21. Baikoff G, Lutun E, Ferraz C, Wei J. Static and dynamic analysis of the anterior segment with optical coherence tomography. J Cataract Refract Surg 2004;30(9):1843-50.

22. McBrien NA, Adams DW. A longitudinal investigation of adult-onset and adult-progression of myopia in an occupational group. Refractive and biometric findings. Invest Ophthalmol Vis Sci 1997;38(2):321-33.

23. Gudmundsdottir E, Arnarsson A, Jonasson F. Five-year refractive changes in an adult population: Reykjavik Eye Study. Ophthalmology 2005;112(4):672-7.

24. Mitry D, Charteris DG, Fleck BW, et al. The epidemiology of rhegmatogenous retinal detachment: geographical variation and clinical associations. Br J Ophthalmol 2010;94(6):678-84.

25. Bhagwandien AC, Cheng YY, Wolfs RC, et al. Relationship between retinal detachment and biometry in 4262 cataractous eyes. Ophthalmology 2006;113(4):643-9.

26. Russell M, Gaskin B, Russell D, Polkinghorne PJ. Pseudophakic retinal detachment after phacoemulsification cataract surgery: Ten-year retrospective review. J Cataract Refract Surg 2006;32(3):442-5.

27. Ohno-Matsui K, Yoshida T, Futagami S, et al. Patchy atrophy and lacquer cracks predispose to the development of choroidal neovascularisation in pathological myopia. Br J Ophthalmol 2003;87(5):570-3.

28. Meltendorf C, Cichocki M, Kohnen T. Laser in situ keratomileusis following the implantation of irisfixated phakic intraocular lenses. Ophthalmologica 2008;222(2):69-73.

29. Guell JL, Vazquez M, Gris O. Adjustable refractive surgery: 6-mm Artisan lens plus laser in situ keratomileusis for the correction of high myopia. Ophthalmology 2001;108(5):945-52.

30. Menezo JL, Peris-Martinez C, Cisneros-Lanuza AL, Martinez-Costa R. Rate of cataract formation in 343 highly myopic eyes after implantation of three types of phakic intraocular lenses. J Refract Surg 2004;20(4):317-24.

31. Prokofyeva E, Wegener A, Zrenner E. Cataract prevalence and prevention in Europe: a literature review. Acta Ophthalmol 2013;91(5):395-405.

32. Pan CW, Cheng CY, Saw SM, et al. Myopia and age-related cataract: a systematic review and metaanalysis. Am J Ophthalmol 2013;156(5):1021-33.e1.

33. Jonker SMR, Van Averbeke AAC, Berendschot TTJM, et al. Risk factors for explantation of iris-fixated phakic intraocular lenses. Journal of Cataract and Refractive Surgery 2019;45(8):1092-8. 


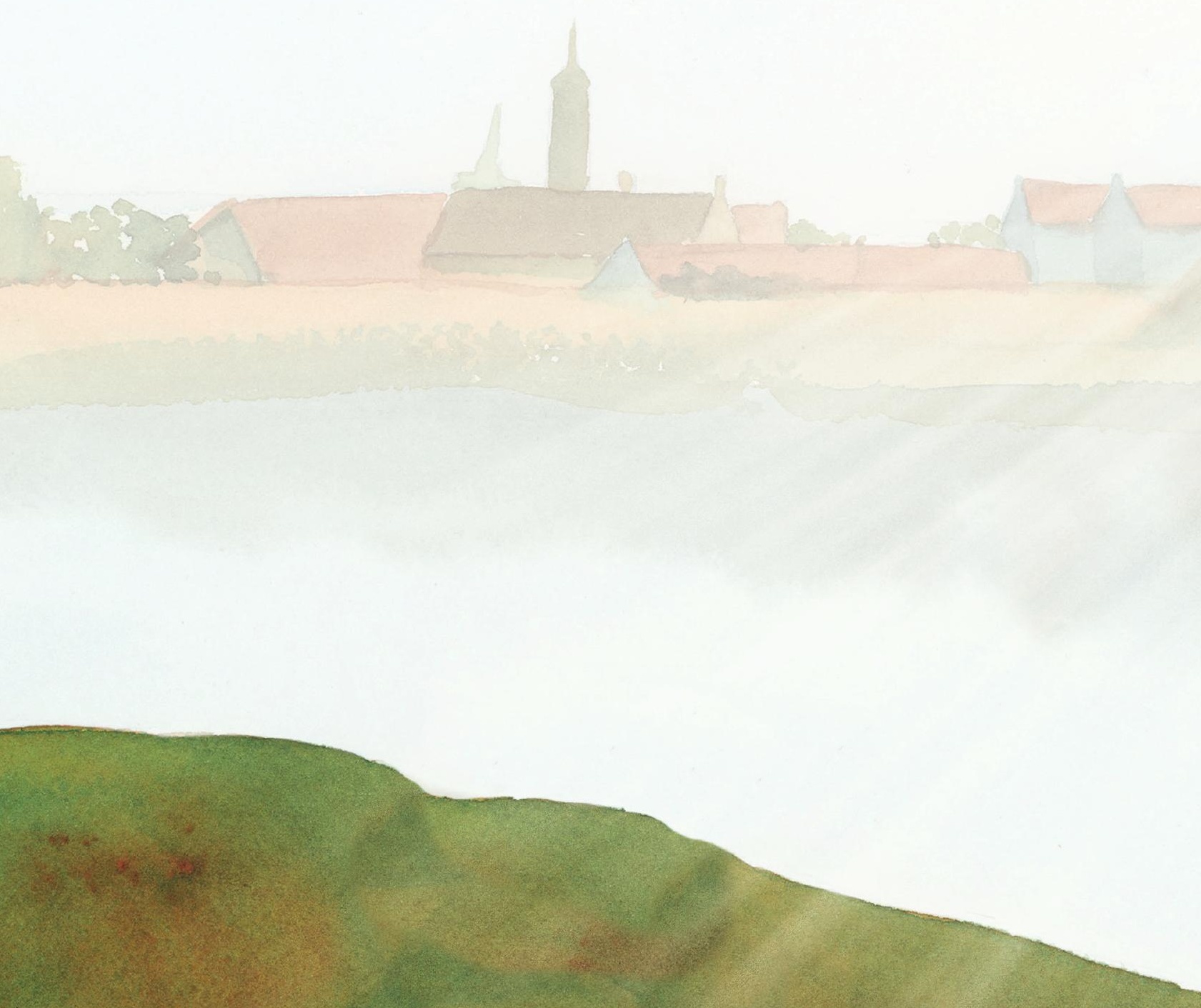




\section{CHAPTER 6}

\section{Changes in visual outcomes and ocular morphometrics after foldable myopic and toric intraocular lens implantation: 5 year results.}




\section{ABSTRACT}

Purpose: To evaluate the 5-year refractive, visual, and morphometric changes after implantation with a foldable iris-fixated phakic intraocular lens ( $p / O L)$ to correct myopia or astigmatism.

Setting: University Eye Clinic Maastricht, Maastricht UMC+, the Netherlands.

Design: Prospective case series.

Methods: The study evaluated patients implanted with the Artiflex Myopia (Toric) iris-fixated pIOL as of January 2004. Measurements were performed annually and reported after 1 and 5 years postoperatively.

Results: The study included 481 eyes (277 patients; preoperative age $39.8 \pm 10.9$ years [SD]). Five years postoperatively $91 \%$ of eyes were within $\pm 1.0 \mathrm{D}$ of target, and the mean myopisation over a 5 year period was 0.22 diopters $(p<0.001)$. The logarithm of the minimum angle of resolution (logMAR) corrected distance visual acuity (CDVA) increased by a mean 0.015 ( $p=0.015$ ) over 5 years; $88 \%$ of eyes had a CDVA of $20 / 20$ or better and $5.5 \%$ lost 2 or more lines of CDVA. Mean uncorrected distance visual acuity (UDVA) increased by 0.045 logMAR over 5 years ( $p<0.001$ ); $96 \%$ reached an UDVA of 20/40 or more. Anterior chamber depth (ACD) decreased by $0.04 \mathrm{~mm}(p<0.001)$, and axial length $(A X L)$ increased by $0.23 \mathrm{~mm}$ $(p<0.001$ ) over 5 years. Cataract resulted in pIOL explantation in $4.0 \%$ of eyes (mean survival $59.0 \pm 40.0$ months); higher preoperative age (hazard ratio [HR], 1.13; $p<0.001$ ) and smaller $A C D(H R, 6.80 ; p=0.035)$ were risk factors for shorter survival due to cataract formation.

Conclusion: Over 5 years logMAR CDVA and UDVA decreased significantly due to myopisation caused by lenticular changes and AXL elongation. 


\section{INTRODUCTION}

Previous studies have proved implantation with anterior chamber (angle supported, iris-fixated) and posterior chamber phakic intraocular lenses ( $\mathrm{plOLs)}$ to be superior to laser refractive surgery in patients with high myopia and myopic patients with thin corneas. ${ }^{1}$ The iris-fixated Artiflex Myopia and Artiflex Myopia Toric pIOL were introduced in 2005 and 2007, respectively, as an addition to the rigid iris-fixated Artisan Myopia and Artisan Toric pIOLs (all IOLs by Ophtec B.V., Groningen, the Netherlands). Studies on the rigid myopic and toric iris-fixated plOLs have shown good results with respect to visual acuity and predictability. ${ }^{1-3}$ However, the rigid polymethyl methacrylate (PMMA) material requires a large main incision for implantation of these plOLs, creating a higher surgically induced corneal astigmatism (SICA). The foldable myopic (toric) irisfixated pIOLs are composed of a flexible polysiloxane optic and PMMA haptics requiring a much smaller main incision, resulting in less SICA while still achieving good visual acuity, refractive correction, safety and efficacy.4-8

Few papers have previously described the results of foldable iris-fixated pIOLs after a follow-up of 5 years or more 9,10 , and no previous report has performed longitudinal analyses describing visual, refractive and morphometric outcomes over time as the current paper. 


\section{METHODS}

\section{Design}

From January 2004 to June 2016, 277 patients were implanted with an Artiflex myopic or myopic toric foldable iris-fixated pIOL at the University Eye Clinic Maastricht, Maastricht University Medical Center, Maastricht, the Netherlands. Patients were prospectively evaluated preoperatively, 1 day, 1 week, 1, 3, 6 and 12 months postoperatively in the first postoperative year, followed by annual visits.

All surgeries were performed by the same surgeon (RN) under general or local anesthesia. The current study was performed in adherence to the tenets of the Declaration of Helsinki. The Maastricht University Medical Center Institutional Review Board stated that approval was not required for this study.

Previous reports by our group have described the inclusion criteria, measurements, surgical procedure (including peripheral iridectomy) and postoperative medication used in the current study. ${ }^{4,11-13}$

\section{Outcome measures}

Refractive and visual outcome measures were based on the 2014 guidelines of the Journal of Refractive Surgery (JRS), ${ }^{14}$ describing manifest refractive spherical equivalent (MRSE), target vs. achieved MRSE, change in MRSE, refractive astigmatism, corrected distance visual acuity (CDVA), change in CDVA, uncorrected distance visual acuity (UDVA), and change in UDVA as outcome measures for refractive surgery. Target induced astigmatism (TIA) vector, surgically induced astigmatism (SIA) vector, difference vector (between TIA and SIA), correction index (SIA divided by TIA), index of success (difference vector divided by TIA) and mean angle of error were calculated using refractive data in eyes implanted with the myopic toric pIOL. Safety indices (postoperative CDVA divided by preoperative CDVA), and efficacy indices (postoperative UDVA divided by preoperative (DVA) were computed, and changes in safety and efficacy indices reported.

Additionally, anterior chamber depth (ACD) and axial length (AXL), as well as changes over time were assessed in order to evaluate possible age-related changes in ocular biometry. Changes in endothelial cell density (ECD) were reported in a previous paper. ${ }^{13}$

\section{Statistical analysis}

Statistical analysis was performed using SPSS for Windows (version 23, IBM Corp, Armonk, NY, USA). The UDVA and CDVA were converted from Snellen values to logarithm of the minimum angle of resolution ( $\log M A R)$ prior to statistical analysis. Descriptive analyses were performed 
to compute mean and standard deviation (SD) in primary outcome measures and preoperative characteristics. Vector analyses according to Alpins were performed to assess refractive astigmatism in eyes implanted with the myopic toric plOL. ${ }^{15}$

Longitudinal changes were analyzed using a linear mixed-model analysis with an eye identification number as a grouping variable and time as a covariate. In each model the best fitted covariance structure was selected using the Bayesian information criterion (BIC). In order to assess long-term changes in the study groups, analyses were performed to separate the short-term from long-term changes results. Longitudinal analyses assessed short-term changes from preoperatively to 12 months postoperatively and long-term changes from 12 months postoperatively until the end of follow-up. Hotelling Trace multivariate analysis of variance (MANOVA) analyses were performed to assess if vectorial change from 1 to 5 years postoperatively was significantly different from zero.

In a subset of patients, longitudinal and cross-sectional analyses on the effect of age on AXL were performed using linear mixed-model analysis (20 eyes, longitudinal data) and analysis of variance (ANOVA) (298 eyes, preimplantation data), respectively. Kaplan-Meier and multivariate Cox regression analyses were performed to measure survival from plOL implantation to $\mathrm{pIOL}$ explantation due to cataract formation. Risk factors for pIOL explantation due to cataract formation were identified using univariate Cox regression analyses. Multivariate analyses were performed to correct for possible correlation between risk factors, while excluding insignificant risk factors. $P$ values were considered significant if $P<0.05$. 


\section{RESULTS}

The study included 481 eyes of 277 patients; the foldable myopic pIOL was implanted in 293 eyes of 166 patients, and the foldable myopic toric pIOL was implanted in 188 eyes of 111 patients. Table 1 depicts the baseline characteristics of this study population. Mean follow-up was $51 \pm 37$ months.

One eye of 1 patient (0.2\%) was implanted with a myopic pIOL one month before turning 18. In 8 eyes of 6 patients (1.7\%) the preoperative endothelial cell density (ECD) was lower than 2000 cells $/ \mathrm{mm}^{2}$. This group, with a mean preoperative age of $51.8 \pm 3.6$ years, had a mean preoperative ECD of $1872 \pm 115$ cells $/ \mathrm{mm}^{2}$. All patients with a preoperative ECD $<2000$ cells/ $\mathrm{mm}^{2}$ were extensively informed on the risks of $\mathrm{plOL}$ implantation in case of lower preoperative ECD counts, before opting for surgery.

\section{Predictability}

Table 1 shows the mean manifest refraction spherical equivalent (MRSE) and refractive cylinder over time. Target versus achieved MRSE correction 1 and 5 years after implantation is reported in Figure 1. Figure 2 shows the percentage of eyes within 0.5 D and 1.0 D of intended correction 1 and 5 years after pIOL implantation and Figure 3 shows the percentage of eyes with a MRSE change of > $0.5 \mathrm{D}$ over a 5 year period. The percentage of eyes with a refractive astigmatism within $0.5 \mathrm{D}$ and $1.0 \mathrm{D}$ of zero is reported in Figure 4.

Single-angle polar plots representing TIA vector, SIA vector, difference vector and correction index 1 and 5 years after toric pIOL implantation are depicted in Figures 5 and 6, respectively. Figure 7 shows the distribution of the angle of error 1 and 5 years after implantation. The mean index of success after 1 and 5 years was $0.26 \pm 0.25$ and $0.23 \pm 0.27$, respectively.

Longitudinally, the MRSE decreased significantly ( $p$ < 0.001) by $0.043 \mathrm{D}$ each year. On vector analyses the toric $\mathrm{plOL}$ group supported a change in refractive cylinder of $0.41 \pm 0.53 \mathrm{D}$ at $9^{\circ}$ from 1 to 5 years postoperatively $(p=0.024)$.

\section{Efficacy}

LogMAR UDVA 1 and 5 years after implantation is reported in Table 1. Cumulative Snellen UDVA 1 and 5 years after implantation is shown in Figure 9. The postoperative UDVA was compared to the preoperative CDVA in order to compute the efficacy indices after 1 and 5 years, as reported in Figure 10, and Table 1. Annually the logMAR UDVA increased significantly $(p<0.001$ ) by 0.009 , resulting in a significant decrease in efficacy index of 0.016 each year ( $p$ $<0.001)$. 

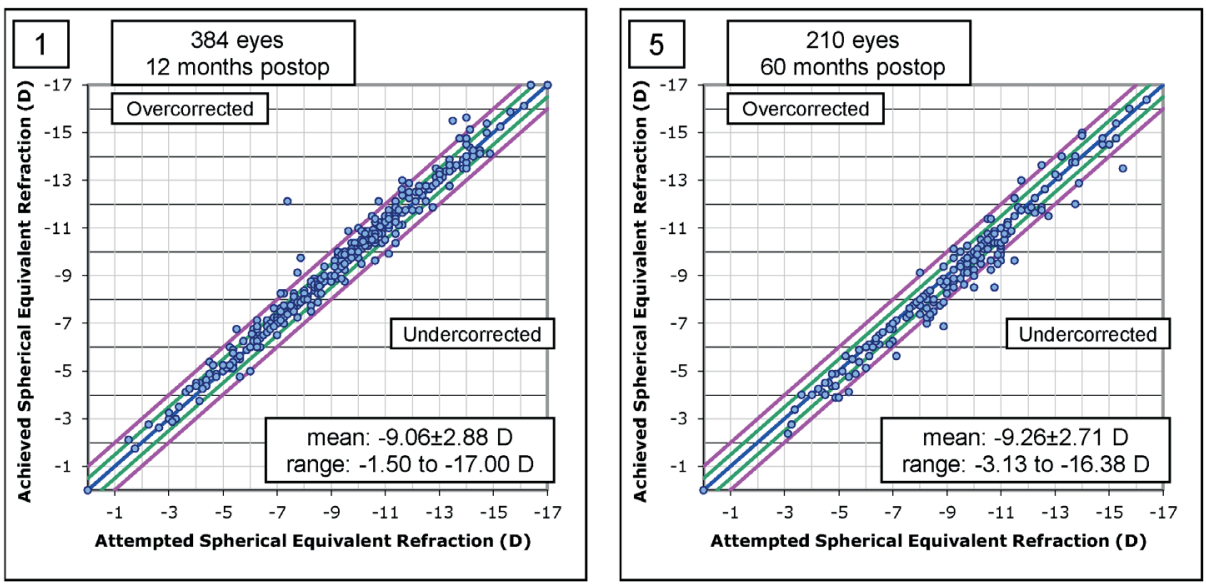

Figure 1. Target versus achieved manifest refraction spherical equivalent (MRSE) correction after 1 and 5 years in eyes implanted with iris-fixated myopic (toric) phakic intraocular lens.

Diopters (D).
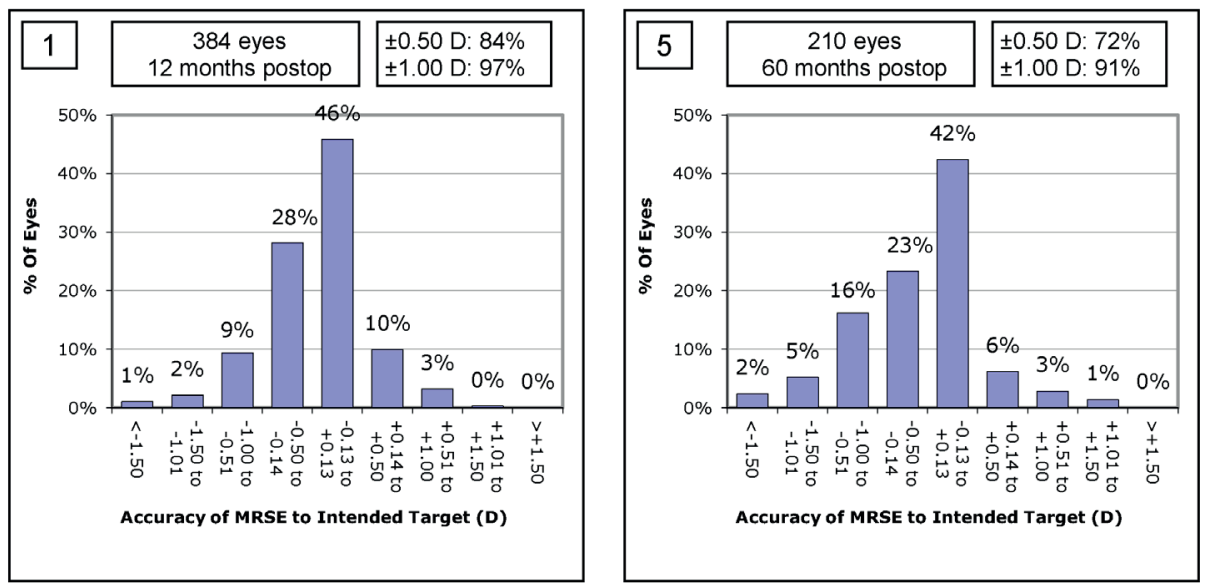

Figure 2. Accuracy of the manifest refractive spherical equivalent (MRSE) 1 and 5 years after implantation with iris-fixated myopic (toric) phakic intraocular lens.

Diopters (D). 



Figure 3. Change in manifest refraction spherical equivalent (MRSE) over 5 years after implantation with iris-fixated myopic (toric) phakic intraocular lens.

Standard deviation (SD), diopters (D).

\section{Safety}

Mean logMAR CDVA over time is portrayed in Table 1. Figure 8 shows the change in Snellen CDVA lines from preoperatively to 1 and 5 years postoperatively. Five years after implantation 205 eyes (98\%) and 185 eyes (88\%) had a CDVA of $\geq 20 / 40$ and $\geq 20 / 20$, respectively.

The logMAR CDVA increased significantly by 0.003 each year $(p=0.015)$, causing a significant decrease in safety index of 0.007 each year $(p=0.043)$ (Table 1$)$.

\section{Ocular biometry}

Mean pre- and postoperative ACD is summarized in Table 1, with longitudinal analyses showing a statistically significant annual decrease in ACD of $0.014 \mathrm{~mm}(p<0.001)$.

Subgroup analyses were performed describing longitudinal changes in 20 eyes that were measured using optical biometry prior to $\mathrm{plOL}$ implantation, as well as prior to combined plOL explantation and cataract surgery at a later date. The mean preoperative AXL was $27.21 \pm 1.38$ $\mathrm{mm}$ in this subgroup, and analyses showed a statistically significant increase in AXL of $0.046 \mathrm{~mm}$ each year ( $p<0.001$ ). Secondary cross-sectional ANOVA analyses were performed to assess correlations between age and preoperative AXL measured with optical biometry in a larger subgroup of 298 eyes. Mean preoperative AXL was $26.79 \pm 1.26 \mathrm{~mm}$ in this subgroup, with results indicating an annual increase in $A X L$ of $0.016 \mathrm{~mm}$ ( $p=0.018)$. 

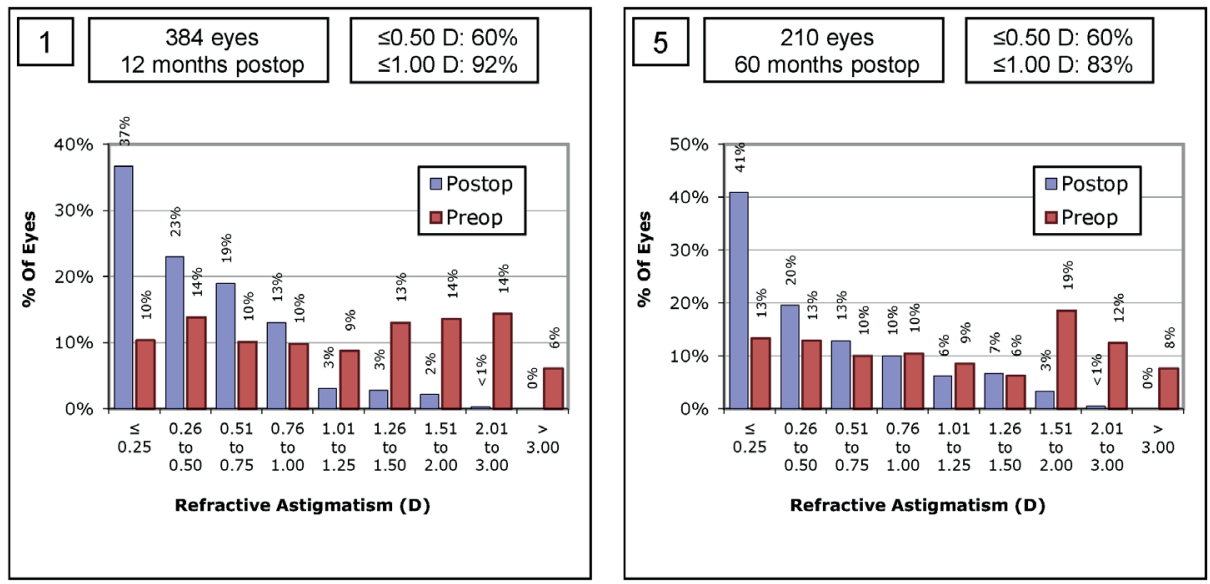

Figure 4. Refractive astigmatism preoperatively and 1 and 5 years after implantation with iris-fixated myopic (toric) phakic intraocular lens.

Diopters (D).

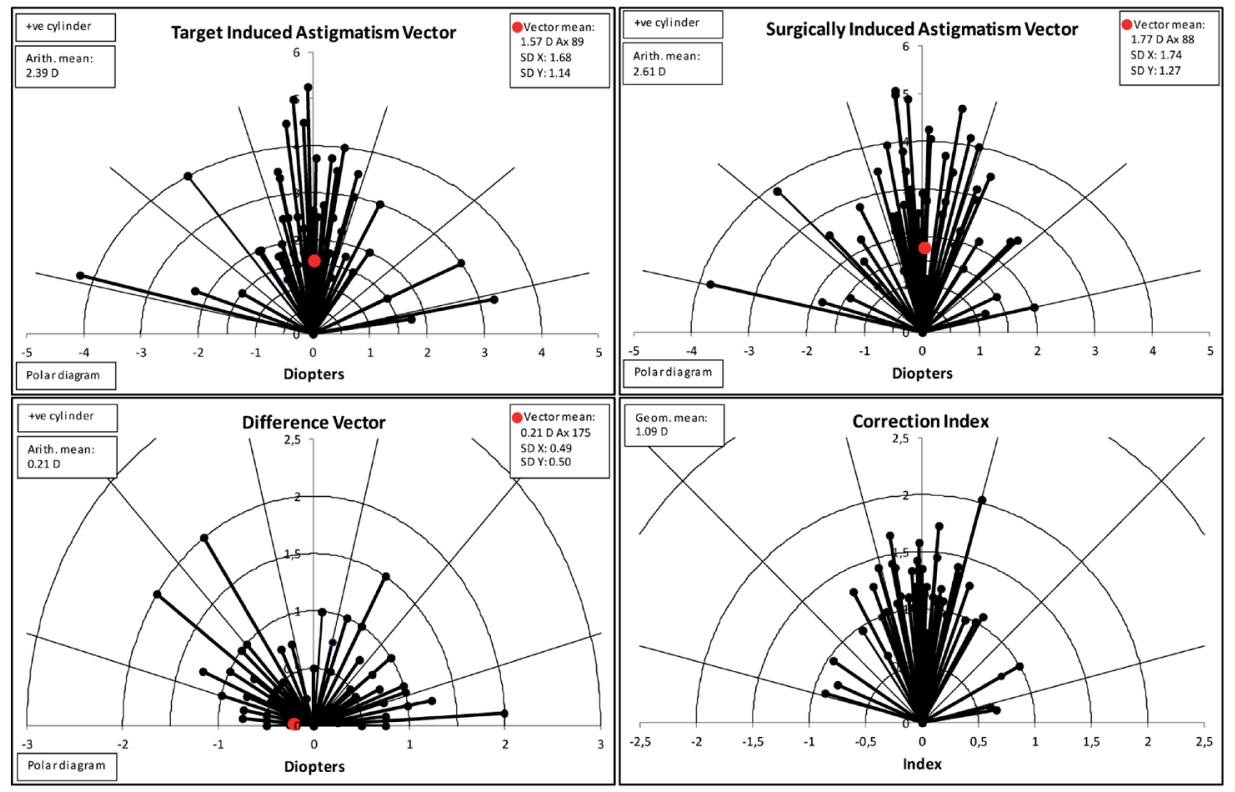

Figure 5. Single-angle polar plots representing target induced astigmatism (TIA) vector, surgically induced astgimatism (SIA) vector, difference vector and correction index, one year after implantation with irisfixated toric phakic intraocular lens (116 eyes).

Diopters (D), standard deviation (SD). 


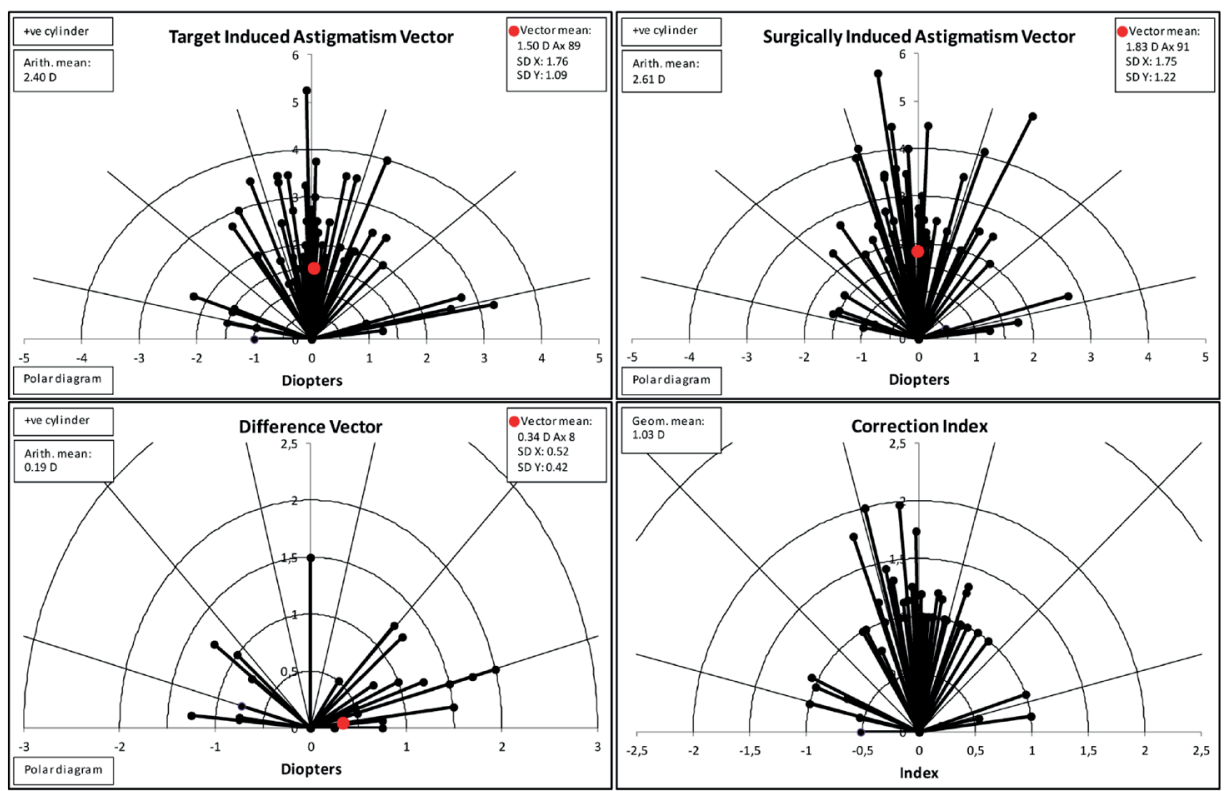

Figure 6. Single-angle polar plots representing target induced astigmatism (TIA) vector, surgically induced astgimatism (SIA) vector, difference vector and correction index, five years after implantation with irisfixated toric phakic intraocular lens (63 eyes).

Diopters (D), standard deviation (SD).
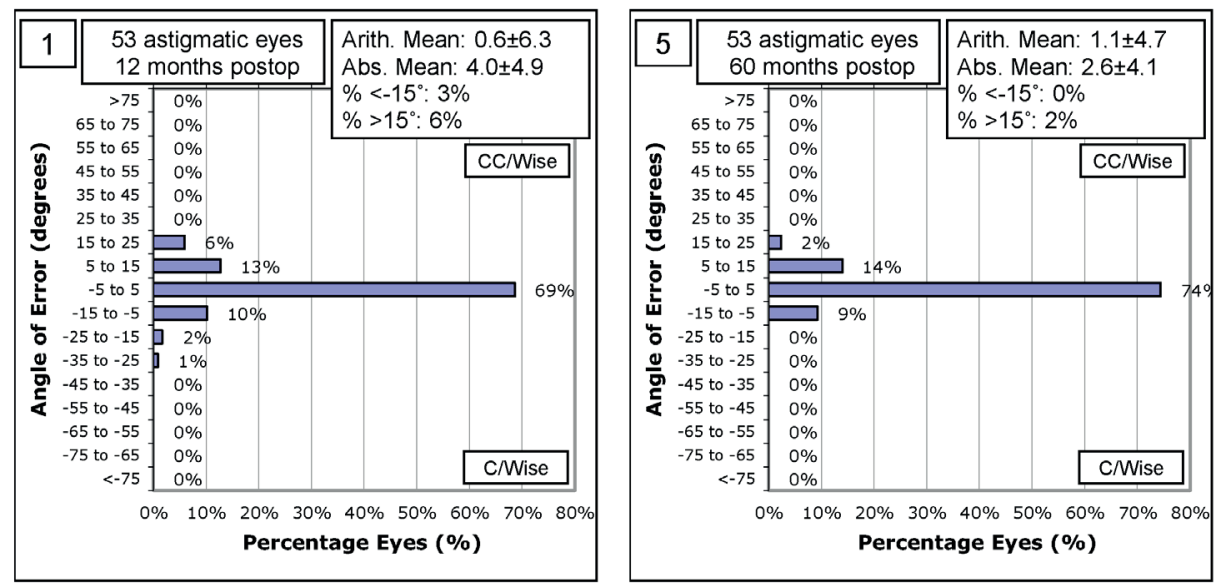

Figure 7. The refractive astigmatism angle of error 1 and 5 years after implantation with iris-fixated toric phakic intraocular lens.

Counterclockwise (CC/wise), clockwise (C/wise). 

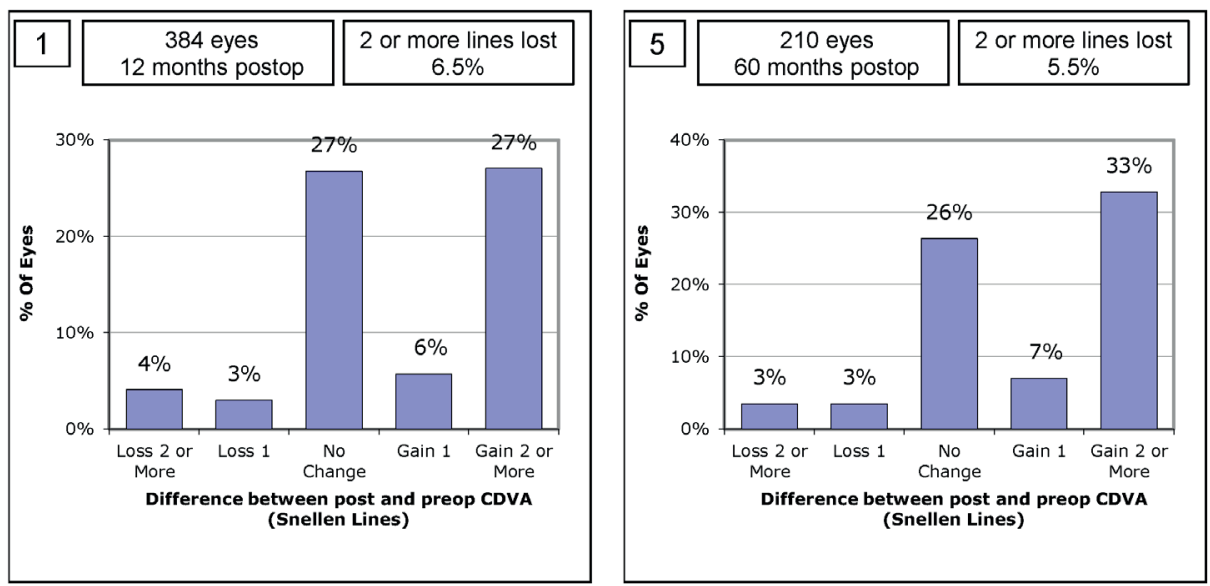

Figure 8. Change in snellen lines of corrected distance visual acuity (CDVA) after 1 and 5 years in eyes implanted with the iris-fixated myopic (toric) phakic intraocular lens.
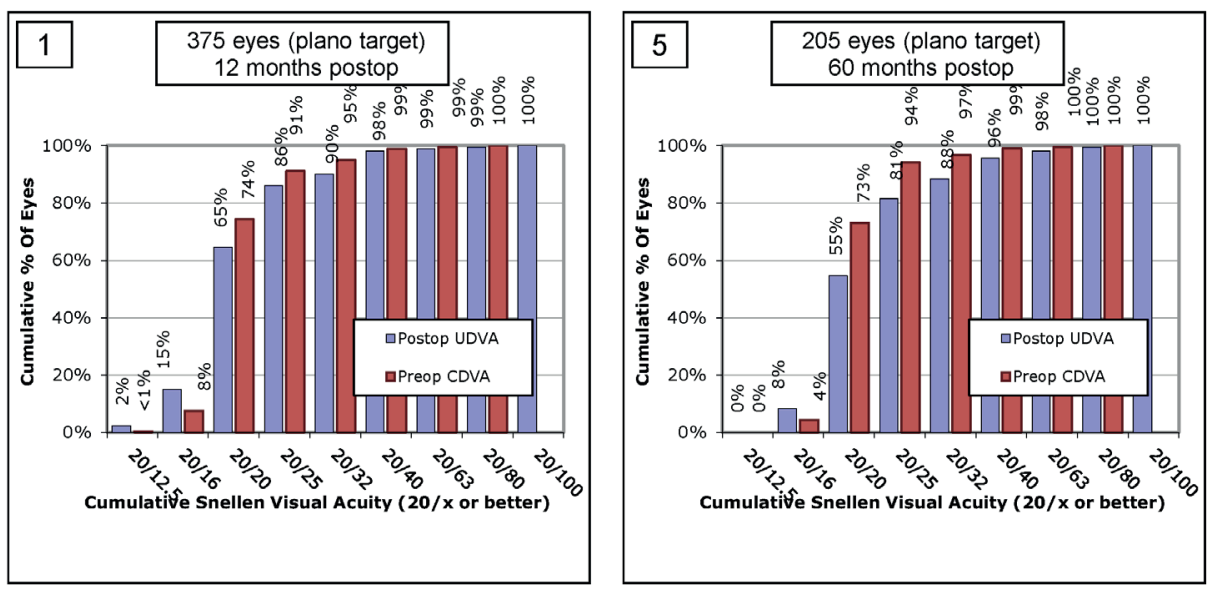

Figure 9. Snellen preoperative corrected distance visual acuity (CDVA) and uncorrected distance visual acuity (UDVA) 1 and 5 years after implantation with the iris-fixated myopic (toric) phakic intraocular lens. 

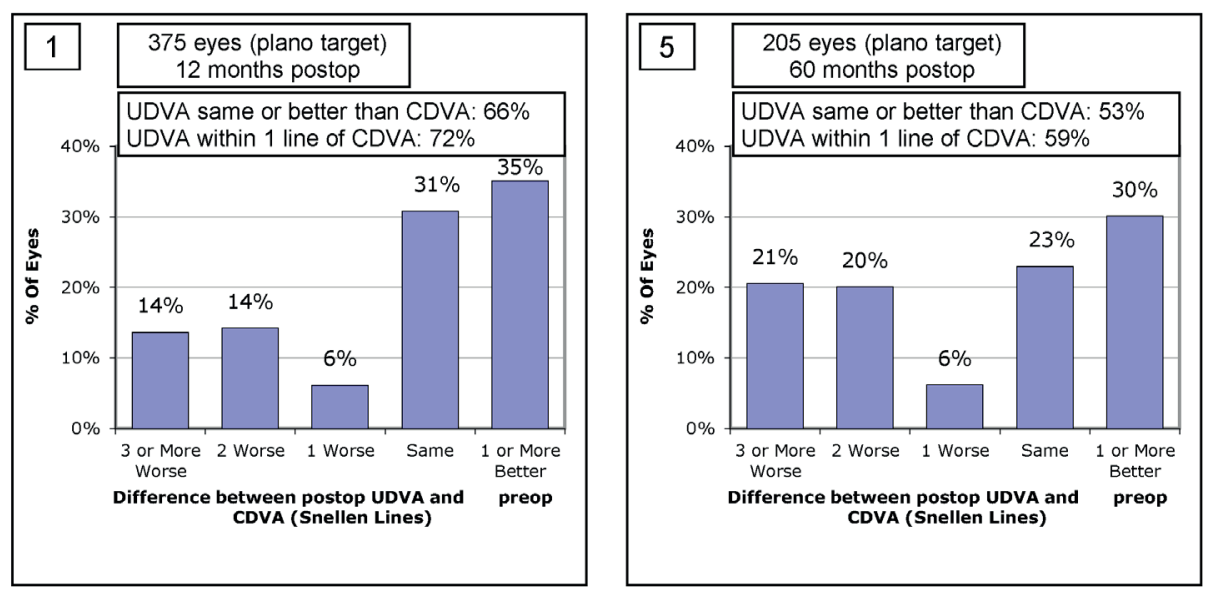

Figure 10. Difference in snellen lines between postoperative uncorrected distance visual acuity (UDVA) and preoperative corrected distance visual acuity (CDVA) 1 and 5 years after implantation with the irisfixated myopic (toric) phakic intraocular lens.

\section{Complications and interventions}

Table 2 shows the complication profile on all eyes implanted with myopic (toric) plOLs in the current study, and presents an overview of reasons for additional surgery, plOL exchange and pIOL explantation. Rhegmatogenous retinal detachments (RRD) did not occur after cataract surgery in any patient.

\section{Risk factors}

After excluding insignificant risk factors, the Cox regression multivariate analyses registered higher preoperative age (Hazard Ratio $[\mathrm{HR}]=1.13 /$ year [95\% Confidence Interval (Cl) 1.061.20], $p<0.001)$ and smaller ACD (HR = 6.80/mm [95\% Cl 1.14-40.58], p = 0.035) as significant risk factors for a shorter survival due to cataract formation. 
Table 1. Preoperative characteristics and results one and five years after implantation with the foldable iris-fixated myopic (toric) phakic intraocular lens (mean \pm standard deviation [SD]).

\begin{tabular}{|c|c|c|c|}
\hline & Preop & 1y Follow-Up & 5y Follow-Up \\
\hline \multicolumn{4}{|l|}{ Patient Characteristics } \\
\hline \multicolumn{4}{|l|}{ Age, y } \\
\hline Mean \pm SD & $39.8 \pm 10.9$ & NR & NR \\
\hline Range & 17.9 to 63.4 & NR & NR \\
\hline Ratio male/female, \% & $36 / 64$ & $N R$ & $N R$ \\
\hline Number of eyes & 481 & 375 & 210 \\
\hline \multicolumn{4}{|l|}{ Predictability } \\
\hline \multicolumn{4}{|l|}{ MRSE, D } \\
\hline Mean \pm SD & $-8.98 \pm 2.79$ & $-0.19 \pm 0.52$ & $-0.35 \pm 0.22$ \\
\hline Range & -20.50 to -1.50 & -4.75 to 1.38 & -2.25 to 1.25 \\
\hline \multicolumn{4}{|l|}{ Refractive cylinder, D } \\
\hline Mean \pm SD & $-2.32 \pm 0.88$ & $-0.57 \pm 0.46$ & $-0.76 \pm 0.52$ \\
\hline Range & -5.25 to -1.00 & -2.00 to 0.00 & -2.50 to 0.00 \\
\hline \multicolumn{4}{|l|}{ Safety } \\
\hline \multicolumn{4}{|l|}{ CDVA, logMAR } \\
\hline Mean \pm SD & $0.003 \pm 0.10$ & $-0.06 \pm 0.11$ & $-0.05 \pm 0.09$ \\
\hline Range & -0.24 to 0.60 & -0.20 to 0.70 & -0.30 to 0.40 \\
\hline \multicolumn{4}{|l|}{ Safety index } \\
\hline Mean \pm SD & NA & $1.20 \pm 0.27$ & $1.17 \pm 0.24$ \\
\hline Range & NA & 0.17 to 2.67 & 0.40 to 2.40 \\
\hline \multicolumn{4}{|l|}{ Efficacy } \\
\hline \multicolumn{4}{|l|}{ UDVA, logMAR } \\
\hline Mean \pm SD & NA & $0.02 \pm 0.14$ & $0.05 \pm 0.15$ \\
\hline Range & NA & -0.20 to 1.30 & -0.18 to 0.70 \\
\hline \multicolumn{4}{|l|}{ Efficacy index } \\
\hline Mean \pm SD & NA & $1.02 \pm 0.28$ & $0.96 \pm 0.28$ \\
\hline Range & NA & 0.04 to 2.67 & 0.20 to 2.00 \\
\hline \multicolumn{4}{|l|}{ IOP, mmHg } \\
\hline Mean \pm SD & $15.4 \pm 2.9$ & $15.4 \pm 3.2$ & $15.9 \pm 3.0$ \\
\hline Range & 8.0 to 24.0 & 8.0 to 28.0 & 10.0 to 23.0 \\
\hline \multicolumn{4}{|l|}{$\mathrm{ACD}^{\#}, \mathrm{~mm}$} \\
\hline Mean \pm SD & $3.25 \pm 0.34$ & $3.31 \pm 0.34$ & $2.98 \pm 0.26$ \\
\hline Range & 2.68 to 4.47 & 2.79 to 4.47 & 2.32 to 3.67 \\
\hline
\end{tabular}

Years (y), manifest refraction spherical equivalent (MRSE), diopters (D), logarithm of the minimum angle of resolution (logMAR), corrected distance visual acuity (CDVA), uncorrected distance visual acuity (UDVA), intraocular pressure (IOP), anterior chamber depth (ACD), axial length (AXL).

Not applicable (NA), not reported (NR)

\#Measured from the corneal endothelium. 
Table 2. Overview of sight threatening events, secondary surgical interventions, phakic intraocular lens exchanges and explantations in eyes implanted with a foldable iris-fixated myopic (toric) phakic intraocular lens $(n=481)$ (mean \pm standard deviation [SD]).

\begin{tabular}{lccc}
\hline & $\begin{array}{c}\text { No. eyes } \\
\text { [patients] }\end{array}$ & Ratio, \% & $\begin{array}{c}\text { Time, months } \\
\text { (range) }\end{array}$ \\
\hline Complications & & & NA \\
\hline Intraoperative iris hemorrhage & $10[10]$ & 2.1 & 1 day and 27 days \\
Retinal detachment & $4[3]$ & 0.8 & $29.9 \pm 36.3$ (range 2.9 to 92.4) \\
Acute glaucoma & $2[1]$ & 0.4 & 55.9 \\
Macular hole & $1[1]$ & 0.2 & 7.1 \\
\hline
\end{tabular}

\section{Secondary Surgical Intervention}

Laser Refractive Correction

\begin{tabular}{|c|c|c|c|}
\hline PRK & $15[14]$ & 3.1 & $13.3 \pm 14.4$ (range 1.2 to 61.2 ) \\
\hline \multicolumn{4}{|l|}{ pIOL Refixation } \\
\hline Traumatic subluxation & $1[1]$ & 0.2 & 24.6 \\
\hline Insufficient enclavation & $2[2]$ & 0.4 & 71.5 and 141.4 \\
\hline Decentration & $2[2]$ & 0.4 & 3.7 and 3.7 \\
\hline \multicolumn{4}{|l|}{ pIOL Exchange } \\
\hline Undercorrected & $1[1]$ & 0.2 & 9.4 \\
\hline Overcorrected & $3[3]$ & 0.6 & $11.5 \pm 6.6$ (range 2.3 to 17.4 ) \\
\hline Incorrect labelling ${ }^{a}$ & $2[1]$ & 0.4 & 1.1 and 4.6 \\
\hline \multicolumn{4}{|l|}{ pIOL Explantation } \\
\hline Cataract & $19[14]$ & 4.0 & $59.0 \pm 40.0$ (range 4.7 to 130.7 ) \\
\hline EC-loss & $9[5]$ & 1.9 & $85.6 \pm 25.7$ (range 42.5 to 126.6$)$ \\
\hline High IOP & $1[1]$ & 0.2 & 15.4 \\
\hline Excessive pigment on plOL & $1[1]$ & 0.2 & 6.4 \\
\hline
\end{tabular}

Months (mo), non arteritic anterior ischemic optic neuropathy (NA-AION), photorefractive keratectomy (PRK), endothelial cell (EC) loss, intraocular pressure (IOP).

${ }^{a}$ Cylindrical axis was reported incorrectly on the packaging of the foldable toric plOL. Modified quality control functions have been administered by the supplier, no further complications have occurred since. 


\section{DISCUSSION}

The current study presents visual acuity and refractive outcomes five years after foldable irisfixated pIOL implantation. The main finding of this study is a slight deterioration of all visual and refractive parameters that can be attributed to age-related increase in crystalline lens thickness and $\mathrm{AXL}$ elongation. Linear mixed-model analyses were performed to test for significant changes over time (e.g., annually). Albeit a similar trend, a previous study by our group showed greater changes in AXL, visual acuity and refraction after implantation with rigid plOLs in high myopes that warrants additional research in order to validate these changes in epidemiological studies. ${ }^{16}$

Five years after implantation the MRSE, and percentage of eyes within 0.5D and 1.0D of target refraction were similar to previous studies with a follow-up of 6 months to 6 years. ${ }^{4-7,9,10,17-20}$ Vector analyses indicated a significant change in refractive cylinder from 1 to 5 years postoperatively, but the mean values after 5 years showed excellent results. The mean difference vector was $0.34 \mathrm{D}$ at $8^{\circ}(0.00 \mathrm{D}$ being the preferred result) and the mean correction index was 1.03 (1.0 being the preferred result). The correction index results are similar to two previous studies using double angle polar plots to describe a significant reduction in refractive cylinder after 6 months and 1 year. ${ }^{4,8}$

The logMAR CDVA, percentage of eyes with $\geq 20 / 40$ and $\geq 20 / 20$ vision, with $\geq 2$ Snellen CDVA lines lost, and safety index 5 years after implantation were similar or superior to the results of previous studies with a maximum follow up of 6 years. ${ }^{4-7,9,17-20}$

Results similar or superior to studies with a follow-up of up to 6 years were reported regarding logMAR UDVA, percentage of eyes with $\geq 20 / 40$ and $\geq 20 / 20$ vision, and efficacy index, 5 years after implantation with the myopic (toric) pIOL.4-7, 9, 17, 19, 20

In line with previous studies describing an annual decrease in ACD of 0.011 to $0.018 \mathrm{~mm}$, our study showed an annual decrease in ACD of $0.014 \mathrm{~mm}$ that can be attributed to the ageing lens resulting in increased lens thickness. ${ }^{21-23}$ Ageing initially results in a hyperopic shift followed by a myopic shift when patients develop nuclear cataract. It is likely that the myopisation observed in this study is partly due to an advanced myopic shift, considering high myopia is both a reason for pIOL implantation and a risk for cataract formation at a younger age. ${ }^{23-26}$ Additional analyses were performed, following the results of a previous study by our group, to assess the possibility of annual AXL increase in an adult population with high myopia. ${ }^{16}$ The results of the abovementioned study showed high rates of myopisation that could in part be attributed to changes in axial length. Two subsets of patients were analyzed to evaluate the hypothesis posed in the previous study. The first subset of patients included 20 eyes that had received optical biometry $A X L$ measurements prior to $\mathrm{pIOL}$ implantation, and prior to combined 
pIOL explantation and cataract surgery at a later date. The second subset was analyzed using a cross-sectional (ANOVA) analysis in order to evaluate the possibility of a correlation between age and $A X L$ in 298 eyes measured using optical biometry prior to $\mathrm{pIOL}$ implantation. Both analyses showed a statistically significant increase in AXL that would result in an AXL increase of $0.23 \mathrm{~mm}$ and $0.08 \mathrm{~mm}$ over 5 years, respectively. These slight but statistically significant changes were much less than the previous report on rigid iris-fixated pIOLs and would require additional population based studies to evaluate the presence and significance of AXL changes in an adult population. ${ }^{16}$

Retinal detachment occurred in 4 eyes (0.8\%) implanted with the myopic (toric) plOL in the current study after a mean follow-up of 2.5 years. Previous studies on foldable iris-fixated myopic (toric) pIOLs did not report any cases of retinal detachments, whereas studies on rigid pIOLs showed RRD rates of $0.25 \%$ to $1.09 \%$ after a follow up of up to 10 years. 2, 4-7, 16, 17, 20, 27 Myopia of-3.0 D or stronger is well defined as a significant risk-factor for increased rates of RRD, a relevant criterion in the highly myopic population described in this study (ie, MRSE -9.89 \pm 2.79 D). ${ }^{1,28-30}$ Cataract surgery is a second known risk-factor for RRD, attributed to changes in volume of the vitreous as well as the inflammatory reaction after surgery. The results of this study are in line with the data of pseudophakic patients, but the position of the plOL anterior to the crystalline lens does not create volumetric changes. ${ }^{29,30}$ In our opinion, the higher RRD rates are likely the result of the highly myopic configuration, and less likely attributed to inflammation or volumetric changes.

No previous study reported the occurrence of other complications such as a macular hole, non arteritic anterior ischemic optic neuropathy (NA-AION), or additional laser refractive correction in patients with foldable plOLs. Additional laser refractive correction (photorefractive keratotomy) was required in 9 eyes (3.1\%) in the current study, comparable to data on rigid pIOLs in a previous report by our group. ${ }^{16}$ This is the only study describing faulty packaging as a reason for iris-fixated pIOL exchange. Lens exchange was described in one paper where $0.34 \%$ of eyes required this procedure in order to obtain an optimal correction, results that were only mildly different to the rate of pIOL exchanges performed in the current study (4 eyes, 0.8\%). ${ }^{6}$

When the foldable myopic plOL was first introduced in a clinical trial in 2003, the optic-haptic junction and the vault between the junction and the iris-plane was shaped differently. ${ }^{6}$ During the clinical trial with the first pIOL model a higher incidence (4.8\%) of iris pigment precipitates was reported, which was believed to be caused by compression of the iris between the $\mathrm{pIOL}$ and the crystalline lens. This was most likely caused by the lower vault between optic-haptic junction and iris in the initial model $(0.13 \mathrm{~mm})$, as compared to the rigid iris-fixated plOL ( $0.20 \mathrm{~mm})$. The optic-haptic junction was altered to create a higher $(0.20 \mathrm{~mm})$ vault between junction and iris that is similar between the rigid and foldable iris-fixated pIOLs. ${ }^{6}$ 
In the current study all results of the 27 eyes of the 14 patients implanted with the initial myopic model were combined with the 266 eyes of the 152 patients implanted with the second, improved, myopic model, because lens type (1 or 2) did not have a significant influence on any of the outcome measures described in the current paper (data on file).

\section{Recommendation}

The slight myopisation and decrease in visual acuity shown in this study are likely caused by a combination of nuclear cataract formation and slight AXL elongation over time. More extensive AXL elongation, as well as corresponding cases of myopic macular degeneration, were reported in a previous paper by our group. ${ }^{16}$ Prior to implantation with a foldable iris-fixated plOL, patients with (high) myopia should be informed by their refractive surgeon about the possible changes in refraction and visual acuity. Phakic IOLs should not be considered a permanent solution for refractive errors, and regularly be followed up to monitor safety and efficacy. 


\section{REFERENCES}

1. Kohnen T, Kook D, Morral M, Guell JL. Phakic intraocular lenses: part 2: results and complications. J Cataract Refract Surg 2010;36(12):2168-94.

2. Guell JL, Morral M, Gris O, et al. Five-year follow-up of 399 phakic Artisan-Verisyse implantation for myopia, hyperopia, and/or astigmatism. Ophthalmology 2008;115(6):1002-12.

3. Tahzib NG, Nuijts RM, Wu WY, Budo CJ. Long-term study of Artisan phakic intraocular lens implantation for the correction of moderate to high myopia: ten-year follow-up results. Ophthalmology 2007;114(6):1133-42.

4. Doors M, Budo CJ, Christiaans BJ, et al. Artiflex Toric foldable phakic intraocular lens: short-term results of a prospective European multicenter study. Am J Ophthalmol 2012;154(4):730-9.e2.

5. Coullet J, Guell JL, Fournie P, et al. Iris-supported phakic lenses (rigid vs foldable version) for treating moderately high myopia: randomized paired eye comparison. Am J Ophthalmol 2006;142(6):909-16.

6. Dick HB, Budo C, Malecaze F, et al. Foldable Artiflex phakic intraocular lens for the correction of myopia: two-year follow-up results of a prospective European multicenter study. Ophthalmology 2009;116(4):671-7.

7. Ozerturk Y, Kubaloglu A, Sari ES, et al. Foldable iris-fixated phakic intraocular lens implantation for the correction of myopia: two years of follow-up. Indian J Ophthalmol 2012;60(1):23-8.

8. Visser N, Berendschot TT, Bauer NJ, Nuijts RM. Vector analysis of corneal and refractive astigmatism changes following toric pseudophakic and toric phakic IOL implantation. Invest Ophthalmol Vis Sci 2012;53(4):1865-73.

9. Monteiro T, Correia FF, Franqueira N, et al. Long-term efficacy and safety results after iris-fixated foldable phakic intraocular lens for myopia and astigmatism: 6-year follow-up. J Cataract Refract Surg 2020.

10. Yildirim Y, Cakmak S, Sucu ME, et al. Comparative study of small-incision lenticule extraction and phakic intraocular lens implantation for the correction of high myopia: six-year results. J Cataract Refract Surg 2020.

11. Jonker SMR, Berendschot T, Ronden AE, et al. Long-Term Endothelial Cell Loss in Patients with Artisan Myopia and Artisan Toric Phakic Intraocular Lenses: 5- and 10-Year Results. Ophthalmology 2018;125(4):486-94.

12. Doors M, Cals DW, Berendschot TT, et al. Influence of anterior chamber morphometrics on endothelial cell changes after phakic intraocular lens implantation. J Cataract Refract Surg 2008;34(12):2110-8.

13. Jonker SMR, Berendschot T, Ronden AE, et al. Five-Year Endothelial Cell Loss After Implantation With Artiflex Myopia and Artiflex Toric Phakic Intraocular Lenses. Am J Ophthalmol 2018;194:110-9.

14. Reinstein DZ, Archer TJ, Randleman JB. JRS standard for reporting astigmatism outcomes of refractive surgery. J Refract Surg 2014;30(10):654-9.

15. Alpins NA, Goggin M. Practical astigmatism analysis for refractive outcomes in cataract and refractive surgery. Surv Ophthalmol 2004;49(1):109-22.

16. Jonker SMR, Berendschot $T$, Ronden $A E$, et al. Long-term changes in visual outcomes and ocular morphometrics after myopic and toric phakic intraocular lens implantation: Five- and 10-year results. J Cataract Refract Surg 2019;45(10):1470-9.

17. Ghoreishi M, Kashfi A, Peyman M, Mohammadinia M. Comparison of Toric Implantable Collamer Lens and Toric Artiflex Phakic IOLs in terms of Visual Outcome, A paired Contralateral Eye Study. Am J Ophthalmol 2020. 
18. Peris-Martinez C, Artigas JM, Sanchez-Cortina I, et al. Influence of optic quality on contrast sensitivity and visual acuity in eyes with a rigid or flexible phakic intraocular lens. J Cataract Refract Surg 2009;35(11):1911-7.

19. Munoz G, Cardoner A, Albarran-Diego C, et al. Iris-fixated toric phakic intraocular lens for myopic astigmatism. J Cataract Refract Surg 2012;38(7):1166-75.

20. Ruckhofer J, Seyeddain O, Dexl AK, et al. Correction of myopic astigmatism with a foldable iris-claw toric phakic intraocular lens: short-term follow-up. J Cataract Refract Surg 2012;38(4):582-8.

21. Richdale K, Bullimore MA, Sinnott LT, Zadnik K. The Effect of Age, Accommodation, and Refractive Error on the Adult Human Eye. Optom Vis Sci 2016;93(1):3-11.

22. Baikoff G, Lutun E, Ferraz C, Wei J. Static and dynamic analysis of the anterior segment with optical coherence tomography. J Cataract Refract Surg 2004;30(9):1843-50.

23. Atchison DA, Markwell EL, Kasthurirangan S, et al. Age-related changes in optical and biometric characteristics of emmetropic eyes. J Vis 2008;8(4):29.1-0.

24. Sawada A, Tomidokoro A, Araie M, et al. Refractive errors in an elderly Japanese population: the Tajimi study. Ophthalmology 2008;115(2):363-70.e3.

25. Pan CW, Cheng CY, Saw SM, et al. Myopia and age-related cataract: a systematic review and metaanalysis. Am J Ophthalmol 2013;156(5):1021-33.e1.

26. Fotedar R, Mitchell P, Burlutsky G, Wang JJ. Relationship of 10-year change in refraction to nuclear cataract and axial length findings from an older population. Ophthalmology 2008;115(8):1273-8, 8.e1.

27. Budo C, Hessloehl JC, Izak M, et al. Multicenter study of the Artisan phakic intraocular lens. J Cataract Refract Surg 2000;26(8):1163-71.

28. Mitry D, Charteris DG, Fleck BW, et al. The epidemiology of rhegmatogenous retinal detachment: geographical variation and clinical associations. Br J Ophthalmol 2010;94(6):678-84.

29. Bhagwandien AC, Cheng YY, Wolfs RC, et al. Relationship between retinal detachment and biometry in 4262 cataractous eyes. Ophthalmology 2006;113(4):643-9.

30. Russell M, Gaskin B, Russell D, Polkinghorne PJ. Pseudophakic retinal detachment after phacoemulsification cataract surgery: Ten-year retrospective review. J Cataract Refract Surg 2006;32(3):442-5. 


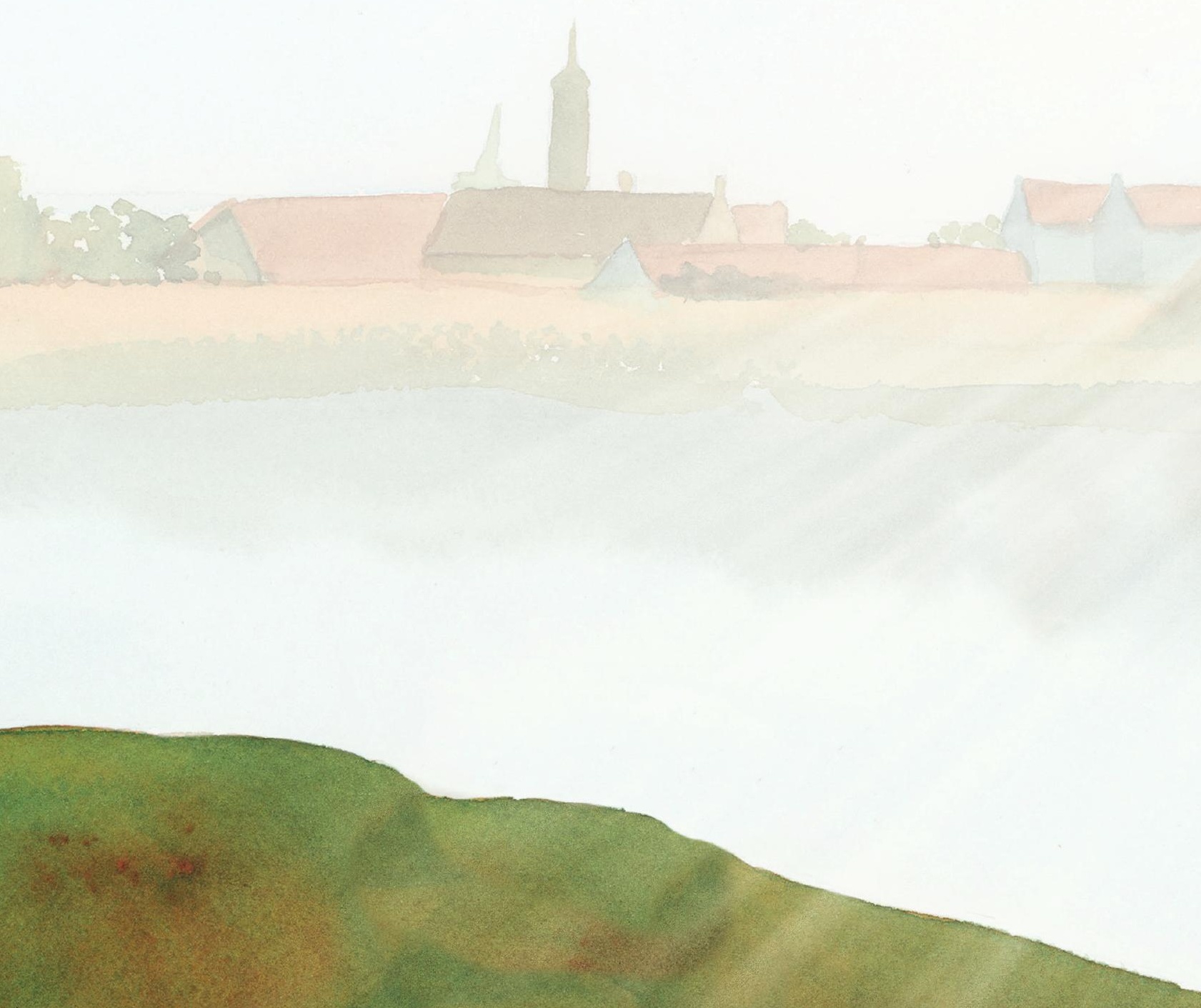




\title{
CHAPTER 7
}

\author{
Risk factors for explantation \\ of iris-fixated phakic intraocular lenses
}




\section{ABSTRACT}

Purpose: To determine risk factors for explantation of iris-fixated phakic intraocular lenses (plOLs) with a maximal follow-up of 17-year follow-up.

Setting: University Eye Clinic Maastricht, Maastricht UMC+, the Netherlands.

Design: Prospective case series.

Methods: Eyes that had implantation of 1 of various iris-fixated pIOL models from 1998 to 2016 were evaluated. Primary outcome measures were the rate and proportion of pIOL explantations and the survival time (ie, time to pIOL explantation) in general and specifically as a result of cataract formation or endothelial cell (EC) loss.

Results: The study comprised 1037 eyes. The mean follow-up was 69.3 months \pm 52.8 (SD) and the mean preoperative age, $40.2 \pm 10.9$ years. The overall explantation rate was $12 \%$ after a mean of 166.1 months \pm 3.0 (standard error). Phakic IOL explantations were performed in $59 \%$ because of cataract formation and in $32 \%$ because of EC loss. Shorter survival was seen with a higher preoperative age (hazard ratio [HR], 1.07/y; $P<.001$ ), longer axial length (AL) $(H R, 1.10 / \mathrm{mm} ; P=.009)$, and smaller anterior chamber depth (ACD)(HR, 4.47/mm; $P<.001)$. Factors for shorter survival resulting from cataract were older preoperative age, longer $\mathrm{AL}$, and larger ACD. Risk factors contributing to shorter survival due to EC loss were smaller ACD, lower EC density, and implantation with an Artisan hyperopia (toric) or Artiflex myopia (toric) plOL.

Conclusion: The explantation rate of iris-fixated pIOLs was $12 \%$ after almost 14 years of follow-up, with $59 \%$ of plOL explantations caused by cataract formation and $32 \%$ caused by EC loss. An older preoperative age, longer AL, and smaller ACD were risk factors for a shorter survival. 


\section{INTRODUCTION}

Phakic intraocular lenses (pIOLs) have been used for many years in young (ie, prepresbyopic) patients unsuitable for laser refractive surgery. Three types of plOLs have gained access to the market: anterior chamber angle-supported, anterior chamber iris-fixated and posterior chamber. Multiple previous studies have found excellent refractive and visual results for all 3 plOL types. ${ }^{1-7}$

Although studies have assessed the short-term and long-term changes in visual and refractive outcomes as well as endothelial cell density (ECD) after pIOL implantation, none has assessed the rate of explantation and risk factors for a shorter survival. ${ }^{8-10}$ Unlike anterior chamber anglesupported and posterior chamber pIOLs, the design of iris-fixated pIOLs has not been modified over time, allowing researchers to collect data over an extended period, thus increasing the suitability for long-term analyses. ${ }^{1,5,8}$

The aim of the current prospective follow-up study was to determine the reasons for explantation and risk factors for shorter survival in eyes with an Artisan myopia (toric), Artisan hyperopia (toric), or Artiflex myopia (toric) iris-fixated pIOL (all Ophtec BV). 


\section{PATIENTS AND METHODS}

This study evaluated eyes that had implantation of an iris-fixated pIOL from January 1998 to November 2016 at Maastricht, Maastricht University Medical Center, the Netherlands. Patients were prospectively evaluated preoperatively and 1 day, 1 week, and 1, 3, 6 and 12 months during the first postoperative year. Regular follow-up continued with annual visits. The current study was performed in adherence with the tenets of the Declaration of Helsinki. The Maastricht University Medical Center Institutional Review Board stated that medical ethical approval was not required for this study.

\section{Implantation criteria}

Before $\mathrm{pIOL}$ implantation, patients had to be 18 years or older and have a stable refraction for at least 2 years. The anterior chamber depth (ACD) from the corneal endothelium to the anterior plane of the crystalline lens had to be at least $2.8 \mathrm{~mm}$ with a maximal clear lens rise of $600 \mu \mathrm{m} .1,8,11,12$ The criteria for minimum preoperative ECD depended on age with more than 2800 cells $/ \mathrm{mm}^{2}$ required for patients from 21 to 25 years old, more than 2650 cells $/ \mathrm{mm}^{2}$ for patients from 26 to 30 years old, more than 2400 cells $/ \mathrm{mm}^{2}$ for patients from 31 to 35 years old, more than 2200 cells $/ \mathrm{mm}^{2}$ for patients from 36 to 45 years old, and more than 2000 cells/ $\mathrm{mm}^{2}$ in patients older than 45 years. ${ }^{13}$ This article does not contain data on patients treated with iris-fixated pIOLs who had keratoconus, irregular astigmatism, or corneal transplantation. Data on a subset of patients from the present study was previously presented. 3,8,9, 14-19

\section{Phakic intraocular lenses}

The Artisan myopia pIOL is a 1-piece polymethyl methacrylate (PMMA) rigid lens with a convexconcave optic and a total diameter of $8.5 \mathrm{~mm}$. The optic diameter is variable and depends on the required refractive correction; plOLs with a power from - 1.0 to -15.5 diopters (D) are available in a $6.0 \mathrm{~mm}$ optic diameter and powers from -1.0 to -23.5 D in a $5.0 \mathrm{~mm}$ optic diameter.

The Artisan hyperopia pIOL is a 1-piece PMMA rigid lens with a convex-concave optic and a spherical power ranging from $+1.0 \mathrm{D}$ to $+12.0 \mathrm{D}$. The total diameter is $8.5 \mathrm{~mm}$ and the optic diameter, $5.0 \mathrm{~mm}$.

The Artisan toric pIOL is a 1-piece PMMA rigid lens with a convex-concave optic, a spherical power ranging from +14.0 to $-22.0 \mathrm{D}$, and a cylindrical power of up to -7.5 D. The total diameter is $8.5 \mathrm{~mm}$ and the optic diameter, $5.0 \mathrm{~mm}$.

The Artiflex myopia pIOL is a 3-piece IOL with a polysiloxane optic and PMMA haptics. It is a foldable lens with a convex-concave optic and spherical power ranging from - 2.0 to -14.5 D. The total diameter is $8.5 \mathrm{~mm}$ and the optic diameter, $6.0 \mathrm{~mm}$. 
The Artiflex toric $\mathrm{pIOL}$ is a foldable lens with a convex-concave polysiloxane optic and PMMA haptics. The spherical power ranges from -1.0 to -13.5 D and the cylindrical power from -1.0 to -5.0 D. The total diameter is $8.5 \mathrm{~mm}$ and the optic diameter, $6.0 \mathrm{~mm}$. Intraocular lens power calculations were performed by the manufacturer using the van der Heijde formula. ${ }^{20}$

\section{Surgical technique}

All surgeries were performed by the same surgeon (R.N.) at the University Eye Clinic Maastricht under general or local anesthesia. Previous reports described the surgical procedure and postoperative medication regimen. ${ }^{9,15,17,18}$

\section{Patient evaluation}

The preoperative examination consisted of subjective and cycloplegic refractions, Snellen uncorrected and corrected distance visual acuity measurements, slitlamp examination, Goldmann applanation tonometry, and fundoscopy. Additional measurements consisted of corneal topography (Orbscan, Bausch + Lomb, Inc.; Pentacam HR, Oculus Optikgeräte GmbH; Sirius, Schwind eye-tech-solutions GmbH \& Co. KG), biometry (A2500, Sonomed Escalon; IOLMaster, Carl Zeiss Meditec AG), anterior segment optical coherence tomography (Visante, Carl Zeiss Meditec AG), and specular microscopy (Noncon Robo pachy SP9000 S/N PK1-1137; TOPCON SP3000, Konan Medical Inc.). All preoperative measurements were performed 1 week after removal of soft contact lenses and 2 weeks after removal of rigid gas permeable contact lenses. Annual follow-up visits consisted of subjective refraction, Snellen uncorrected and corrected distance visual acuity measurements, slitlamp examination, tonometry, corneal topography, anterior segment optical coherence tomography and specular microscopy. ${ }^{8}$

Based on the known variation between specular microscopes and the influence of this variation on the correct calculation of endothelial cell (EC) loss, the same specular microscope used during preoperative measurements was used for all follow-up measurements in each eye..$^{21,22}$ Per protocol, analysis of the mean ECD in each eye was calculated by determining the mean of 3 consecutive measurements of 50 central endothelial cells using the manual center-to-center method. $^{23}$

\section{Outcome measures}

The primary outcome measures were the explantation rate of each pIOL model and the proportion of eyes that had pIOL explantation because of cataract formation or EC loss. Survival analyses were performed to assess how long it would take until the plOL was explanted in $50 \%$ of eyes (ie, median survival). The secondary outcome measures where the mean survival and time until $25 \%$ of plOLswould be explanted (ie, 75\% survival). Survival analyses were performed with the following 3 endpoints: explantation in general, explantation because of cataract formation, and explantation because of EC loss. 
The preoperative patient age, axial length (AL), ACD, and endothelial cell density (ECD) were evaluated as possible contributors to survival as were the intraocular pressure (IOP), patient sex, pIOL type, and refractive error (myopia versus hypermetropia). To assess the effect of the different pIOL models, the following 3 subgroups were created: rigid myopic (toric), consisting of rigid myopia pIOLs (ie, Artisan myopia and Artisan myopia toric), rigid hyperopic (toric), consisting of rigid hyperopia pIOLs (ie, Artisan hyperopia and Artisan hyperopia toric); and foldable myopia (toric), consisting of foldable myopia pIOLs.

\section{Statistical analysis}

Statistical analysis was performed using SPSS for Windows (version 23, IBM Corp.). Descriptive analyses were performed to compute mean \pm SD of the preoperative characteristics, and analysis of variance (ANOVA) was used to test for preoperative between-group differences. Kaplan-Meier analyses were performed to assess the number of explantations as well as to assess mean, 75\% and median survival. Additional univariate and multivariate Cox regression analyses were performed to identify risk factors for a shorter survival. A P value less than 0.05 was considered statistically significant in all analyses.

Eight probable risk factors (ie, preoperative age, sex, ACD, AL, ECD, IOP, manifest refractive spherical equivalent [MRSE], lens group) were evaluated in univariate Cox regression analyses. Risk factors identified as significant in univariate analyses were combined in a multivariate Cox regression analysis followed by backward exclusion of insignificant risk factors until only significant risk factors remained. This process was repeated 3 times to report risk factors for $\mathrm{pIOL}$ explantation in general, pIOL explantation resulting from cataract formation, and $\mathrm{plOL}$ explantation resulting from EC loss. The output of risk factor analyses is described as a hazard ratio (HR), indicating the relative risk for the event to take place. A HR less than 1 indicates a lower risk of a shorter survival, whereas a HR greater than 1 indicates a higher risk for a shorter survival.

Numerical variables were implemented as continuous risk factors in all models, resulting in a $\mathrm{HR}$ per cells $/ \mathrm{mm}^{2}$ or per year change. The $\mathrm{pIOL}$ type was implemented as a categorical variable for comparison between groups. 


\section{RESULTS}

The study evaluated 1037 eyes. An Artisan myopia pIOL was implanted in 381 eyes, an Artisan hyperopia plOL in 38 eyes, an Artisan toric pIOL in 130 eyes, an Artiflex myopia plOL in 299 eyes, and an Artiflex toric pIOL in 199 eyes. Table 1 shows the preoperative characteristics, including age, sex, AXL, ACD, IOP, ECD, and MRSE, in the entire cohort and in each pIOL subgroup.

Overall, explantation was performed in $12 \%$ of eyes (120/1037). The main reasons for explantation were cataract formation and EC loss (Table 2), in 17\% of eyes (80/466) implanted with the rigid myopic (toric) plOL, in $12 \%$ of eyes (9/77) with the rigid hyperopic (toric) plOL, and in $6 \%$ of eyes (31/494) in the foldable myopic (toric) plOL. Explantation was performed for other reasons in 11 eyes (9\%) as follows: high IOP (5 eyes), plOL decentration after a blunt trauma (1 eye), after a transpars plana vitrectomy and phacoemulsification for retinal detachment repair (1 eye), visual loss unrelated to cataract formation ( 1 eye), plOL decentration and visual impairment ( 1 eye), diplopia caused by anisometropia ( 1 eye), and pigment depositions on the optic (1 eye). Figure 1 shows the proportion of eyes requiring pIOL explantation because of cataract formation or EC loss in the total cohort and in each pIOL subgroup. Table 2 shows the number of pIOL explantations and the mean (ie, 50\%), 75\%, and median survival for the total cohort and in each subgroup.

\section{Risk factors for explantation}

The mean patient age at $\mathrm{pIOL}$ explantation was $54.6 \pm 8.3$ years, with a mean of 166.1 months until explantation (Table 2). Univariate risk factors for a shorter survival in general were a higher preoperative age $(P<.001)$, longer $\operatorname{AL}(P=.023)$, smaller preoperative $A C D(P<.001)$, and lower preoperative ECD $(P<.001)$. After insignificant $(P>.05)$ risk factors were removed using multivariate Cox regression analysis, the final model identified a higher preoperative age (HR, 1.07/y; 95\% confidence interval [Cl], 1.04-1.09; $P<.001)$, longer $\mathrm{AL}(\mathrm{HR}, 1.10 / \mathrm{mm} ; 95 \% \mathrm{Cl}$, 1.02-1.18; $P=.009)$, and smaller ACD (HR, 4.47/mm; 95\% CI, 2.43-8.22; $P<.001)$ as risk factors for a shorter survival. Figure 2 shows the survival curve for $\mathrm{PIOL}$ explantation in general.

\section{Risk factors for explantation resulting from cataract formation}

The mean survival until pIOL explantation resulting from cataract formation was 181.4 months (Table 2); explantation was performed at a mean age of $56.2 \pm 8.0$ years. A higher preoperative age $(P<.001)$, longer AL $(P<.001)$, larger preoperative ACD $(P=.004)$, and lower ECD $(P=$ .008 ) were identified as significant risk factors for a shorter survival in univariate Cox regression analyses. The final multivariate Cox regression analysis pointed toward a higher preoperative age (HR, 1.09/year; 95\% Cl, 1.06-1.13; $P<.001$ ), longer $\mathrm{AL}$ (HR, 1.79/mm; 95\% Cl, 1.49-2.15; $P<.001)$, and larger ACD (HR, 5.29/mm; 95\% Cl, 2.265-12.38; $P<.001)$ as risk factors for a shorter survival. Figure 3 shows the survival curve for pIOL explantation because of cataract formation. 


\section{Risk factors for explantation resulting from endothelial cell loss}

Explantation related to EC loss was performed at a mean age of $53.7 \pm 7.8$ years, with a mean survival of 187.0 months (Table 2). The mean ACD and ECD at time of explantation were 3.20 $\pm 0.28 \mathrm{~mm}$ and $1254 \pm 371$ cells $/ \mathrm{mm}^{2}$, respectively.

Univariate Cox regression analyses identified a higher preoperative age ( $P=.008)$, female sex $(P=.003)$, shorter $\mathrm{AL}(P=.004)$, smaller preoperative ACD $(P<.001)$, lower ECD $(P<.001)$, and hyperopic refractive error $(P=.008)$ as risk factors for a shorter survival. Subsequently, the influence of the pIOL group was evaluated, showing an increased risk for a shorter survival after implantation with a rigid hyperopic (toric) or foldable myopic (toric) plOL compared with implantation of a rigid myopic (toric) pIOL ( $P=.002$ ). The final multivariate analysis identified a smaller preoperative ACD (HR, 9.62/mm; 95\% Cl, 2.97-31.17; $P<.001)$ and lower ECD (HR, 1.002/cells $/ \mathrm{mm}^{2} ; 95 \% \mathrm{Cl}, 1.001-1.002 ; P<.001$ ) as factors increasing the risk for a shorter survival and identified implantation with a rigid hyperopic (toric) (HR, 3.09; 95\% Cl, 1.09-8.77; $P=.034$ ) or foldable myopic (toric) plOL ( $\mathrm{HR}, 4.45 ; 95 \% \mathrm{Cl}, 1.70-11.69 ; \mathrm{P}=.002$ ) as a risk factor compared with implantation of a rigid myopic (toric) pIOL. There was no significant difference in risk for $\mathrm{EC}$ loss-related $\mathrm{pIOL}$ explantation between eyes with a rigid hyperopic (toric) and foldable myopic (toric) pIOL ( $P=$.58). Figure 4 shows the 3 survival curves corresponding toEC loss-related explantation in all subgroups.

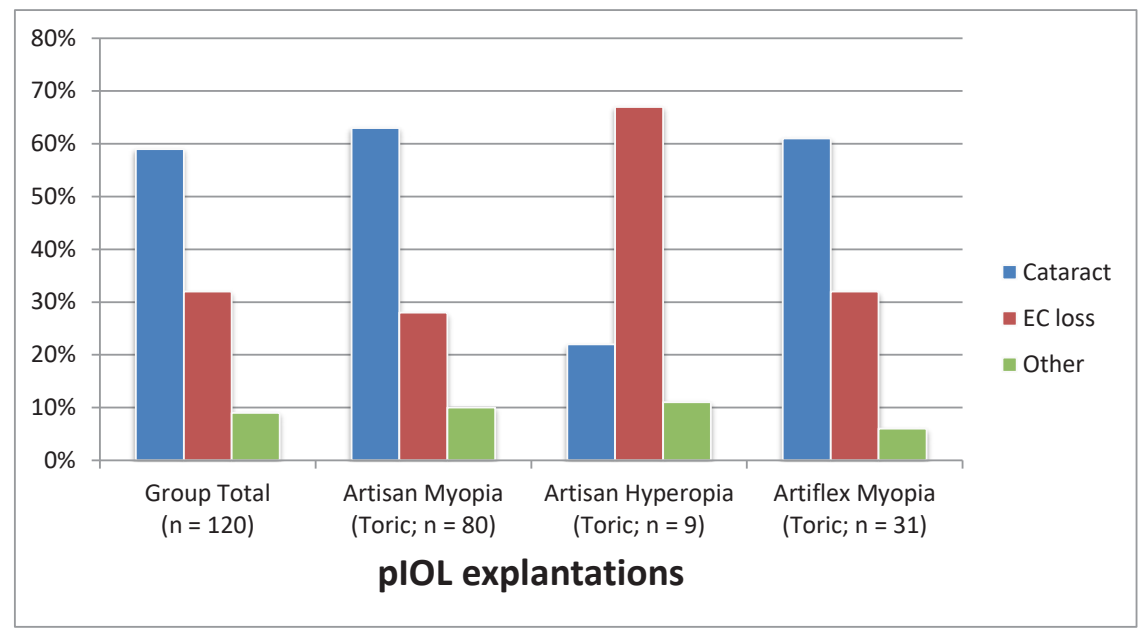

Figure 1. Reasons for phakic intraocular lens explantation.

( $E C=$ endothelial cell; $n=$ number of eyes; $\mathrm{plOL}=$ phakic intraocular lens). 




Figure 2. Survival curve for reaching phakic intraocular lens explantation in the total cohort.

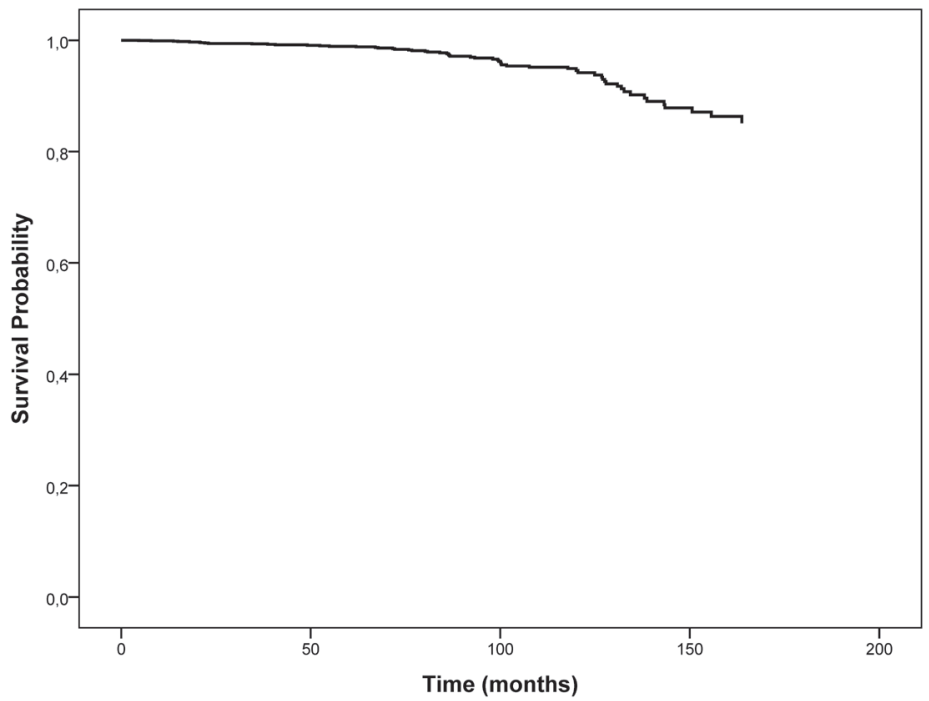

Figure 3. Survival for reaching phakic intraocular lens explantation related to cataract formation in the total cohort. 


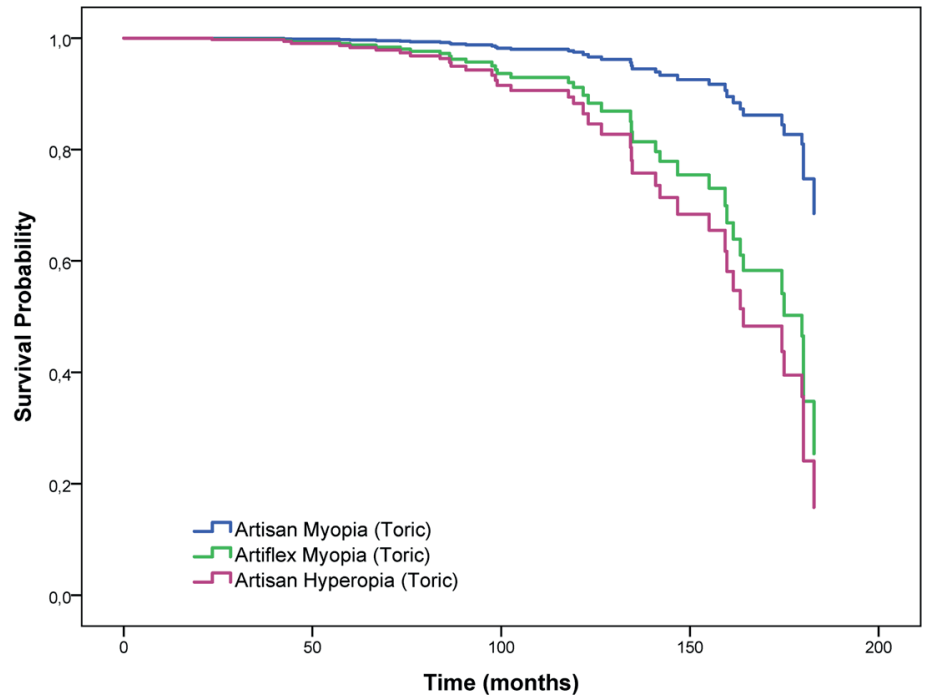

Figure 4. Survival curve for reaching phakic intraocular lens explantation related to endothelial cell loss.

Table 1. Preoperative characteristics in patients implanted with iris-fixated phakic intraocular lenses.

\begin{tabular}{lccccc}
\hline & $\begin{array}{c}\text { Group } \\
\text { Total }\end{array}$ & $\begin{array}{c}\text { Artisan } \\
\text { Myopia } \\
\text { (Toric) }\end{array}$ & $\begin{array}{c}\text { Artisan } \\
\text { Hyperopia } \\
\text { (Toric) }\end{array}$ & $\begin{array}{c}\text { Artiflex } \\
\text { Myopia } \\
\text { (Toric) }\end{array}$ & P-Value \\
\hline Implants/ patients (n) & $1037 / 522$ & $466 / 255$ & $77 / 45$ & $494 / 270$ & - \\
Mean age (y) & $40.2 \pm 10.9$ & $41.1 \pm 10.8$ & $37.3 \pm 11.7$ & $39.7 \pm 10.9$ & $.007^{*}$ \\
Males / Female (\%) & $38 / 62$ & $38 / 62$ & $53 / 47$ & $36 / 64$ & - \\
Mean AXL (mm) & $27.04 \pm 2.27$ & $28.08 \pm 2.28$ & $21.87 \pm 1.53$ & $26.84 \pm 1.31$ & $<.001^{*}$ \\
Mean ACD (mm) & $3.63 \pm 0.35$ & $3.67 \pm 0.35$ & $3.39 \pm 0.35$ & $3.63 \pm 0.33$ & $<.001^{*}$ \\
Mean IOP (mmHg) & $15.1 \pm 3.1$ & $14.7 \pm 3$ & $14.8 \pm 3.1$ & $15.4 \pm 2.9$ & $.008^{*}$ \\
Mean ECD (cells/mm²) & $2713 \pm 350$ & $2669 \pm 367$ & $2739 \pm 401$ & $2748 \pm 32$ & $.002^{*}$ \\
Mean MRSE (D) & $-9.63 \pm 5.87$ & $-12.50 \pm 5.04$ & $3.80 \pm 2.03$ & $-9.13 \pm 2.84$ & $<.001^{*}$ \\
\hline
\end{tabular}

Means \pm SD

$A C D=$ anterior chamber depth; $A X L=$ axial length; $E C D=$ endothelial cell density; $I O P=$ intraocular pressure; MRSE = manifest refraction spherical equivalent

*Statistically significant difference 
Table 2. Explantation rate and survival

\begin{tabular}{|c|c|c|c|c|}
\hline & $\begin{array}{c}\text { Total } \\
\text { Cohort }\end{array}$ & $\begin{array}{l}\text { Artisan } \\
\text { Myopia } \\
\text { (Toric) }\end{array}$ & $\begin{array}{c}\text { Artisan } \\
\text { Hyperopia } \\
\text { (Toric) }\end{array}$ & $\begin{array}{c}\text { Artiflex } \\
\text { Myopia } \\
\text { (Toric) }\end{array}$ \\
\hline Implants / patients $(\mathrm{n})$ & $1037 / 522$ & $466 / 255$ & $77 / 45$ & $494 / 270$ \\
\hline Mean follow-up (mo) & $69.3 \pm 52.8$ & $90.0 \pm 59.7$ & $68.3 \pm 44.9$ & $50.3 \pm 37.7$ \\
\hline \multicolumn{5}{|l|}{ plOL explantation } \\
\hline Total explantations, n (\%) & $120(12)$ & $80(17)$ & $9(12)$ & $31(6)$ \\
\hline Explantations at 5 y, n (\%) & $28(3)$ & $13(3)$ & $1(1)$ & $14(3)$ \\
\hline Explantation at 10 y, n (\%) & $78(8)$ & $43(9)$ & $8(10)$ & $27(5)$ \\
\hline Mean survival (mo) \pm SEM & $166.1 \pm 3.0$ & $168.3 \pm 3.3$ & $149.0 \pm 8.9$ & $128.5 \pm 2.6$ \\
\hline $75 \%$ survival (mo) \pm SEM & $134.3 \pm 3.9$ & $138.0 \pm 6.6$ & $119.2 \pm 10.5$ & $126.6 \pm 12.8$ \\
\hline Median survival (mo) & 182.9 & 182.9 & $*$ & * \\
\hline \multicolumn{5}{|c|}{ Cataract as reason for plOL explantation } \\
\hline Total explantations, n (\%) & $71(7)$ & $50(11)$ & $2(3)$ & $19(4)$ \\
\hline Explantations at 5 y, n (\%) & $16(2)$ & $7(2)$ & NA & $9(2)$ \\
\hline Explantation at 10 y, n (\%) & $49(5)$ & $30(6)$ & $2(3)$ & $17(3)$ \\
\hline Mean survival $(\mathrm{mo}) \pm \mathrm{SEM}$ & $181.4 \pm 2.5$ & $181.5 \pm 2.9$ & $173.7 \pm 4.3$ & $134.5 \pm 2.3$ \\
\hline $75 \%$ survival (mo) \pm SEM & * & * & * & * \\
\hline Median survival (mo) & $*$ & * & * & * \\
\hline \multicolumn{5}{|c|}{ EC loss as reason for plOL explantation } \\
\hline Total explantations, n (\%) & $38(4)$ & $22(5)$ & $6(8)$ & $10(2)$ \\
\hline Explantations at 5 y, n (\%) & $5(<1)$ & $2(<1)$ & $3(<1)$ & NA \\
\hline Explantation at 10 y, n (\%) & $18(2)$ & $5(1)$ & $8(2)$ & $5(6)$ \\
\hline Mean survival $(\mathrm{mo}) \pm \mathrm{SEM}$ & $187.0 \pm 2.7$ & $190.5 \pm 2.7$ & $155.9 \pm 8.6$ & $137.1 \pm 2.3$ \\
\hline $75 \%$ survival (mo) \pm SEM & $180.1 \pm 3.8]$ & $180.1 \pm 4.1$ & $121.7 \pm 3.1$ & * \\
\hline Median survival (mo) & * & $*$ & * & * \\
\hline
\end{tabular}

SEM = standard error of the mean

*could not be computed 


\section{DISCUSSION}

To our knowledge, this prospective study is the first to use survival analyses to evaluate the explantation rate, time to explantation (ie, survival), and risk factors for explantation of irisfixated pIOLs in a single-center single surgeon setting.

The mean follow-up in this study ranged from 90 months in the rigid myopic (toric) (Artisan) group to 50 months in the foldable myopic (toric) (Artiflex) group, which is longer than in most previous studies of iris-fixated plOLs; the follow-up was 50 months or less in the vast majority of these studies. ${ }^{4,10,24-36}$ Only 9 of these studies reported pIOL explantations as well as the reason for pIOL explantation (Table 3)., 10, 24-30 In this study, the explantation rate was 12\% (17\% rigid myopic [toric] plOLs after a mean of 168 months; 12\% rigid hyperopic [toric] plOLs after a mean of 110 months; 6\% foldable myopic [toric] plOLs after a mean of 127 months).

Explantation rates have been reported only in studies of rigid plOLs. The explantation rate in these studies was highly variable ( $0.2 \%$ after 4 months ${ }^{30} ; 1.1$ to $2.8 \%$ after 3 years ${ }^{10,24,27} ; 1.2$ to $7.6 \%$ after 5 to 6 years $4,25,26,28,29 ; 2.3 \%$ after 10 years ${ }^{4}$ ). In the current study, all 3 groups had explantation rates similar to the rates in these previous papers after 5 years, 25, 26, 28, 29; however, explantation rates after 10 years were slightly higher in our groups than in a previous study. ${ }^{4}$

The median survival in all groups combined was 183 months, similar to the median survival in the rigid myopic (toric) group. The median survival could not be computed in the rigid hyperopic (toric) and foldable myopic (toric) groups because of too few explantations. There were no significant differences in the mean follow-up between plOL groups, even though the successive launch dates of the different pIOL types resulted in fewer rigid hyperopic (toric) pIOLs and foldable myopic (toric) pIOLs reaching a 10-year follow-up.

To aid clinicians in their preoperative counseling, we performed supplementary analyses computing how long it would take until plOL explantation is performed in $25 \%$ of patients. Referred to as 75\% survival in this paper, it took 119 to 138 months until 25\% of plOLs would be explanted depending on the subgroup. In the rigid hyperopic (toric) group, the $25 \% \mathrm{plOL}$ explantation threshold resulting from EC loss was reached after a significantly shorter followup than in the rigid myopic (toric) group (122 months versus 180). Unfortunately, because of the small number of explantations, it was not possible to compute this value for cataract formation as an indication for explantation. No previous study performed any of these analyses for angle-supported or iris-fixated plOLs, and only 1 study reported survival for posterior chamber pIOLs. ${ }^{37}$ In the latter study, cataract-related explantation rates afer implantation of an ICL V4 posterior chamber pIOL (STAAR surgical Co.) were $4.9 \%$ at 5 years and $18.3 \%$ at 10 years. Neither the $75 \%$ survival nor the median survival was computed in this paper; however, 
the reported survival curve shows a trend similar to our study, with slightly higher rates of explantation 10 years after pIOL implantation. ${ }^{37}$ As reflected in the median survival, a large number of explantations in our study take place after more than 10 years, which we attribute to the steepened decline in survival in the final years of follow-up (Figure 4).

The main reason for explantation in the current study was cataract formation in the myopic (toric) groups and EC loss in the hyperopic (toric) group. The results of the myopic groups are in line with earlier findings in the literature describing cataract formation as an agerelated process occurring at a younger age in a highly myopic (ie, longer AL, larger ACD) target group. ${ }^{38,39}$ Cataract formation was not related to the iris fixation of the plOL per se, given that early postoperative cataract formation was not detected. The etiology of EC loss in eyes with a plOLs is not completely understood; however, consensus has been reached regarding the importance of adequate preoperative ECD and sufficient distance between the pIOL and the corneal endothelium as potentially protecting against increased EC loss. 9, 10, 17 A shallow anterior chamber, as in hyperopic eyes, will bring the iris-fixated pIOL closer to the endothelium. Hypotheses suggest that intermittent contact between the edges of the $\mathrm{plOL}$ and the endothelium result in exaggerated EC loss. ${ }^{8,40,41}$ However, dynamic studies showing minimal movement of the iris-fixated plOL during accommodation and taking into account that patients are strictly forbidden to rub their eyes postoperatively seem to contradict this theory. ${ }^{42}$ Also, application of strict preoperative safety margins for the distance between the $\mathrm{plOL}$ and the central and peripheral corneal endothelium, as performed in this study, is believed to protect the patient against EC loss. Other etiologies for EC loss might be subclinical inflammation and changes in aqueous humour flow that disturb the supply of nutrients or the disposal of waste material, creating a cytotoxic environment in which endothelial cell death increases. ${ }^{43,44}$ Most likely, a combination of the above is responsible for the differences in EC loss as shown in the current and a previous paper. ${ }^{14}$

In summary, the current study assessed the survival of 3 subgroups of iris-fixated plOLs. Because plOLs are implanted in relatively young, healthy, phakic eyes, it is important to analyze the long-term safety of these IOLs. Our results can aid surgeons during preoperative counseling and inform patients about the survival profile of iris-fixated plOLs. Because we detected a steep decline in survival in the final years of follow-up, we recommend that patients having implantation of iris-fixated be informed preoperatively and actively approached postoperatively to comply with a strict long-term follow-up regimen including ECD measurements on a regular (bi)annual basis to detect and monitor EC loss at an early stage. 
Table 3. Previous studies reporting explantation rates in eyes with iris-fixated pIOLS

\begin{tabular}{|c|c|c|c|c|}
\hline Author*/Year & plOL Type & Eyes (n) & Pts (n) & Follow-up (y) \\
\hline Budo / $2000^{25}$ & Artisan myopia & 249 & NR & 3 \\
\hline Tahzib / $2007^{4}$ & Artisan myopia & 89 & NR & 10 \\
\hline Guell / $2008^{26}$ & Artisan myopia & 101 & 61 & 5 \\
\hline Saxena / $2008^{10}$ & $\begin{array}{l}\text { Artisan myopia (toric), } \\
\text { Artiflex myopia }\end{array}$ & 318 & NR & $2.9^{\#}$ \\
\hline Silva / $2008^{27}$ & Artisan myopia & 19 & NR & 5 \\
\hline Stulting / $2008^{28}$ & Artisan myopia & 1179 & 662 & 3 \\
\hline Titiyal / $2012^{29}$ & Artisan myopia & 85 & 44 & 5 \\
\hline Moshirfar / $2014^{30}$ & Artisan myopia & 213 & $N R$ & $5.6^{\#}$ \\
\hline Kamiya / $2017^{31}$ & NR (iris-fixated) & 50 & NR & 0.33 \\
\hline \multicolumn{5}{|c|}{$\begin{array}{l}\mathrm{EC}=\text { endothelial cell; } \mathrm{NA}=\text { not applicable; } \mathrm{NR}=\text { not reported; } \mathrm{plOL}=\text { phakic intraocular lens; } \mathrm{Pts}= \\
\text { patients }\end{array}$} \\
\hline
\end{tabular}

\section{WHAT WAS KNOWN}

- $\quad$ The presence of a phakic intraocular lens (plOL) increases annual endothelial cell (EC) loss

- A known risk factor for increased EC loss after plOL implantation is a smaller anterior chamber depth

- Cataract formation occurs at an earlier age in highly myopic patients

WHAT THIS PAPER ADDS

- $\quad$ Explantation rates of iris-fixated plOLs increased after 10 years of follow-up

- Long-term follow-up of iris-fixated plOLs is mandatory because cataract formation and EC loss were reasons for explantation in one-third and two-thirds of cases, respectively 


\section{Explantation (\%)}

\begin{tabular}{lccl}
\hline Total & Cataract & EC loss & Remarks \\
2.80 & 1.20 & 0.40 & Other reasons for explantation not reported \\
2.25 & 2.25 & NA & - \\
1.25 & 0.50 & 0.75 & $\begin{array}{l}\text { Two explantated after } 3 \text { years due to cataract; } 2 \\
\text { explanted due to EC loss after 3y, 1 after } 5 \text { years }\end{array}$ \\
1.26 & 1.26 & NA & -
\end{tabular}




\section{REFERENCES}

1. Guell JL, Morral M, Kook D, Kohnen T. Phakic intraocular lenses part 1: historical overview, current models, selection criteria, and surgical techniques. J Cataract Refract Surg 2010;36(11):1976-93.

2. Barsam A, Allan BD. Excimer laser refractive surgery versus phakic intraocular lenses for the correction of moderate to high myopia. Cochrane Database Syst Rev 2014;6:Cd007679.

3. Doors M, Budo CJ, Christiaans BJ, et al. Artiflex Toric foldable phakic intraocular lens: short-term results of a prospective European multicenter study. Am J Ophthalmol 2012;154(4):730-9.e2.

4. Tahzib NG, Nuijts RM, Wu WY, Budo CJ. Long-term study of Artisan phakic intraocular lens implantation for the correction of moderate to high myopia: ten-year follow-up results. Ophthalmology 2007;114(6):1133-42.

5. Kohnen T, Kook D, Morral M, Guell JL. Phakic intraocular lenses: part 2: results and complications. J Cataract Refract Surg 2010;36(12):2168-94.

6. Kohnen T, Maxwell WA, Holland S. Correction of Moderate to High Myopia with a Foldable, Angle-Supported Phakic Intraocular Lens: Results from a 5-Year Open-Label Trial. Ophthalmology 2016;123(5):1027-35.

7. Shimizu K, Kamiya K, Igarashi A, Kobashi H. Long-Term Comparison of Posterior Chamber Phakic Intraocular Lens With and Without a Central Hole (Hole ICL and Conventional ICL) Implantation for Moderate to High Myopia and Myopic Astigmatism: Consort-Compliant Article. Medicine (Baltimore) 2016;95(14):e3270.

8. Jonker SMR, Berendschot T, Ronden AE, et al. Long-Term Endothelial Cell Loss in Patients with Artisan Myopia and Artisan Toric Phakic Intraocular Lenses: 5- and 10-Year Results. Ophthalmology 2018;125(4):486-94.

9. Doors M, Berendschot TT, Webers CA, Nuijts RM. Model to predict endothelial cell loss after irisfixated phakic intraocular lens implantation. Invest Ophthalmol Vis Sci 2010;51(2):811-5.

10. Saxena R, Boekhoorn SS, Mulder PG, et al. Long-term follow-up of endothelial cell change after Artisan phakic intraocular lens implantation. Ophthalmology 2008;115(4):608-13.e1.

11. Baikoff G. Anterior segment OCT and phakic intraocular lenses: a perspective. J Cataract Refract Surg 2006;32(11):1827-35.

12. Baikoff G, Bourgeon G, Jodai HJ, et al. Pigment dispersion and Artisan phakic intraocular lenses: crystalline lens rise as a safety criterion. J Cataract Refract Surg 2005;31(4):674-80.

13. Aalders-Deenstra V, Bartels M, Beerthuizen J, et al. Consensus Refractie Chirurgie. 3 ed: Nederlands Gezelschap voor Refractie Chirurgie (NGRC), 2013.

14. Jonker SMR, Berendschot T, Ronden AE, et al. Five-Year Endothelial Cell Loss After Implantation With Artiflex Myopia and Artiflex Toric Phakic Intraocular Lenses. Am J Ophthalmol 2018;194:110-9.

15. Doors M, Eggink FA, Webers CA, Nuijts RM. Late-onset decentration of iris-fixated phakic intraocular lenses: a case series. Am J Ophthalmol 2009;147(6):997-1003, .e1-2.

16. Doors M, Berendschot TT, Hendrikse F, et al. Value of preoperative phakic intraocular lens simulation using optical coherence tomography. J Cataract Refract Surg 2009;35(3):438-43.

17. Doors M, Cals DW, Berendschot TT, et al. Influence of anterior chamber morphometrics on endothelial cell changes after phakic intraocular lens implantation. J Cataract Refract Surg 2008;34(12):2110-8.

18. Visser N, Berendschot TT, Bauer NJ, Nuijts RM. Vector analysis of corneal and refractive astigmatism changes following toric pseudophakic and toric phakic IOL implantation. Invest Ophthalmol Vis Sci 2012;53(4):1865-73. 
19. Aerts AA, Jonker SM, Wielders LH, et al. Phakic intraocular lens: Two-year results and comparison of endothelial cell loss with iris-fixated intraocular lenses. J Cataract Refract Surg 2015;41(10):2258-65.

20. van der Heijde GL, Fechner PU, Worst JG. [Optical consequences of implantation of a negative intraocular lens in myopic patients]. Klin Monbl Augenheilkd 1988;193(1):99-102.

21. Cheung SW, Cho P. Endothelial cells analysis with the TOPCON specular microscope SP-2000P and IMAGEnet system. Curr Eye Res 2000;21(4):788-98.

22. Prinz A, Varga J, Findl O. Reliability of a video-based noncontact specular microscope for assessing the corneal endothelium. Cornea 2007;26(8):924-9.

23. McCarey BE, Edelhauser HF, Lynn MJ. Review of corneal endothelial specular microscopy for FDA clinical trials of refractive procedures, surgical devices, and new intraocular drugs and solutions. Cornea 2008;27(1):1-16.

24. Budo C, Hessloehl JC, Izak M, et al. Multicenter study of the Artisan phakic intraocular lens. J Cataract Refract Surg 2000;26(8):1163-71.

25. Guell JL, Morral M, Gris O, et al. Five-year follow-up of 399 phakic Artisan-Verisyse implantation for myopia, hyperopia, and/or astigmatism. Ophthalmology 2008;115(6):1002-12.

26. Silva RA, Jain A, Manche EE. Prospective long-term evaluation of the efficacy, safety, and stability of the phakic intraocular lens for high myopia. Arch Ophthalmol 2008;126(6):775-81.

27. Stulting RD, John ME, Maloney RK, et al. Three-year results of Artisan/Verisyse phakic intraocular lens implantation. Results of the United States Food And Drug Administration clinical trial. Ophthalmology 2008;115(3):464-72.e1.

28. Titiyal JS, Sharma N, Mannan R, et al. Iris-fixated intraocular lens implantation to correct moderate to high myopia in Asian-Indian eyes: five-year results. J Cataract Refract Surg 2012;38(8):1446-52.

29. Moshirfar M, Imbornoni LM, Ostler EM, Muthappan V. Incidence rate and occurrence of visually significant cataract formation and corneal decompensation after implantation of Verisyse/Artisan phakic intraocular lens. Clin Ophthalmol 2014;8:711-6.

30. Kamiya K, Igarashi A, Hayashi K, et al. A Multicenter Prospective Cohort Study on Refractive Surgery in 15011 Eyes. Am J Ophthalmol 2017;175:159-68.

31. Yuan X, Ping HZ, Hong WC, et al. Five-year follow-up after anterior iris-fixated intraocular lens implantation in phakic eyes to correct high myopia. Eye (Lond) 2012;26(2):321-6.

32. Ruckhofer J, Seyeddain O, Dexl AK, et al. Correction of myopic astigmatism with a foldable iris-claw toric phakic intraocular lens: short-term follow-up. J Cataract Refract Surg 2012;38(4):582-8.

33. Ozerturk Y, Kubaloglu A, Sari ES, et al. Foldable iris-fixated phakic intraocular lens implantation for the correction of myopia: two years of follow-up. Indian J Ophthalmol 2012;60(1):23-8.

34. Munoz G, Cardoner A, Albarran-Diego C, et al. Iris-fixated toric phakic intraocular lens for myopic astigmatism. J Cataract Refract Surg 2012;38(7):1166-75.

35. Dick HB, Budo C, Malecaze F, et al. Foldable Artiflex phakic intraocular lens for the correction of myopia: two-year follow-up results of a prospective European multicenter study. Ophthalmology 2009;116(4):671-7.

36. Qasem Q, Kirwan C, O'Keefe M. 5-year prospective follow-up of Artisan phakic intraocular lenses for the correction of myopia, hyperopia and astigmatism. Ophthalmologica 2010;224(5):283-90.

37. Guber I, Mouvet V, Bergin C, et al. Clinical Outcomes and Cataract Formation Rates in Eyes 10 Years After Posterior Phakic Lens Implantation for Myopia. JAMA Ophthalmol 2016.

38. McBrien NA, Adams DW. A longitudinal investigation of adult-onset and adult-progression of myopia in an occupational group. Refractive and biometric findings. Invest Ophthalmol Vis Sci 1997;38(2):32133. 
39. Gudmundsdottir E, Arnarsson A, Jonasson F. Five-year refractive changes in an adult population: Reykjavik Eye Study. Ophthalmology 2005;112(4):672-7.

40. Armitage WJ, Dick AD, Bourne WM. Predicting endothelial cell loss and long-term corneal graft survival. Invest Ophthalmol Vis Sci 2003;44(8):3326-31.

41. Bourne WM, Nelson LR, Hodge DO. Central corneal endothelial cell changes over a ten-year period. Invest Ophthalmol Vis Sci 1997;38(3):779-82.

42. Guell JL, Morral M, Gris O, et al. Evaluation of Verisyse and Artiflex phakic intraocular lenses during accommodation using Visante optical coherence tomography. J Cataract Refract Surg 2007;33(8):1398-404.

43. Repetto R, Pralits JO, Siggers JH, Soleri P. Phakic iris-fixated intraocular lens placement in the anterior chamber: effects on aqueous flow. Invest Ophthalmol Vis Sci 2015;56(5):3061-8.

44. Perez-Santonja JJ, Iradier MT, Benitez del Castillo JM, et al. Chronic subclinical inflammation in phakic eyes with intraocular lenses to correct myopia. J Cataract Refract Surg 1996;22(2):183-7. 







\title{
CHAPTER 8
}

\author{
Bilateral implantation of $+2.5 \mathrm{D}$ \\ multifocal intraocular lens and contralateral \\ implantation of +2.5 D and +3.0 D \\ multifocal intraocular lenses: \\ clinical outcomes
}




\section{ABSTRACT}

Purpose: To assess the clinical visual outcomes of bilateral implantation of ReSTOR +2.5 diopter (D) multifocal intraocular lenses (IOLs) and contralateral implantation of a ReSTOR +2.5 D multifocal IOL in the dominant eye and ReSTOR +3.0 D multifocal IOL in the fellow eye.

Setting: Multicenter study at 8 investigative sites.

Design: Prospective randomized parallel-group patient-masked 2-arm study.

Methods: This study comprised adults requiring bilateral cataract extraction followed by multifocal IOL implantation. The primary endpoint was corrected intermediate visual acuity (CIVA) at $60 \mathrm{~cm}$, and the secondary endpoint was corrected near visual acuity (CNVA) at $40 \mathrm{~cm}$. Both endpoints were measured at 3 months after implantation with a noninferiority margin of $\Delta=0.1 \log M A R$.

Results: In total, 103 subjects completed the study (53 bilateral, 50 contralateral). At 3 months, the mean CIVA at $60 \mathrm{~cm}$ was $0.13 \log$ MAR and $0.10 \log$ MAR in the bilateral group and contralateral group, respectively (difference $0.04 \log M A R$ ), achieving noninferiority. Noninferiority was not attained for CNVA at $40 \mathrm{~cm}$; mean values at 3 months for bilateral and contralateral implantation were $0.26 \log M A R$ and $0.11 \log M A R$, respectively (difference 0.15 logMAR). Binocular defocus curves suggested similar performance in distance vision between the 2 groups. Treatment-emergent ocular adverse events rates were similar between the groups.

Conclusions: Bilateral implantation of the $+2.5 \mathrm{D}$ multifocal $\mathrm{IOL}$ resulted in similar distance as contralateral implantation of the $+2.5 \mathrm{D}$ multifocal IOL and $+3.0 \mathrm{D}$ multifocal IOL for intermediate vision $(60 \mathrm{~cm})$, while noninferiority was not achieved for near distances $(40 \mathrm{~cm})$. 


\section{INTRODUCTION}

Cataract is the leading cause of blindness worldwide. In 2010, the World Health Organization reported that cataract is responsible for $51 \%$ of cases of blindness in the world, which represents approximately 20 million people. ${ }^{1}$ Over the past 25 years, the treatment of cataract has advanced because of improvements in surgical techniques for cataract extraction and the worldwide availability of intraocular lenses (IOLs). ${ }^{2}$ There is evidence that since the introduction of $\mathrm{IOLs}$, there has been an increase in cataract surgery rates, leading to a rise in the number of pseudophakic people throughout the world. ${ }^{3}$

Routine use of IOLs has resulted in an increase in the quality of visual outcomes for patients. ${ }^{4}$ Because many patients with cataract are still active members of the workforce, both good near and distance vision are required. Early IOL technology included monofocal IOLS, which result in good distance visual acuity but poor uncorrected near vision. ${ }^{5,6}$

Unlike monofocal IOLs, multifocal IOLs were designed to provide simultaneous focus of distant and near objects, with the goal of achieving good overall visual acuity for near, intermediate, and distance vision. ${ }^{7}$ The AcrySof IQ ReSTOR series (Alcon Laboratories, Inc.) has become the paradigm diffractive multifocal IOL since its introduction because its apodized diffractive design has been proven to produce satisfactory visual results ${ }^{8-12}$ and it has shown better spectacleindependence results than other multifocal IOLs. ${ }^{13}$ The ReSTOR +3.0 diopter (D) multifocal IOL is a commonly implanted multifocal IOL, producing near vision for up to $41 \mathrm{~cm} .{ }^{14}$ The newer +2.5 D IOL was designed to provide a range of vision from a distance up to $53 \mathrm{~cm}$ and good image quality. Data comparing near, intermediate, and distance vision between binocularly implanted ReSTOR +2.5 D multifocal IOLs, ReSTOR +3.0 D multifocal IOLs, and monofocal IOLs indicated that +2.5 multifocal IOLs provided good intermediate and near vision for patients who did not want to accept the higher likelihood of visual disturbances associated with +3.0 D multifocal IOLs but wanted better near vision than a monofocal IOL generally provides. ${ }^{15}$ Another study found that the $+2.5 \mathrm{D} \mathrm{IOL}$ produced better clarity of intermediate vision but might increase the likelihood for the need of optical aids and additional lighting for near vision when compared with the +3.0 D IOL. ${ }^{16}$

Historically, implantation of multifocal IOLs has been performed bilaterally, with both dominant eyes and fellow eyes receiving IOLs with equal power of near addition in the multifocal IOL. Although there have been studies of contralateral implantation, ${ }^{17}$ there is a need for further randomized trials comparing bilateral implantation with contralateral implantation. ${ }^{18-20}$ Bilateral implantation of the +3.0 D multifocal IOL can result in better near and intermediate vision, with good but slightly poorer quality distance vision than can be achieved with bilateral implantation of the +2.5 D multifocal IOL. ${ }^{16}$ Given that the +2.5 D and +3.0 D multifocal IOLs have unique 
properties, this raises a question about the potential incremental benefit from contralateral implantation of these IOL models and whether clinical outcomes differ from those with bilateral +2.5 D IOL implantation. This study assessed the clinical outcomes of bilateral implantation of the +2.5 D multifocal IOL and contralateral implantation of $+2.5 \mathrm{D}$ multifocal IOL in the dominant eye and the +3.0 D multifocal IOL in the fellow eye. 


\section{PATIENTS AND METHODS}

\section{Study design}

This was a prospective randomized parallel-group patient-masked multicenter 2-arm study of patients 21 years or older requiring bilateral cataract extraction followed by IOL implantation. The study was performed between November 2012 and August 2013 at 8 investigative sites in Argentina (1), Chile (1), Germany (2), the Netherlands (2), and Spain (2).

Patients at each study site were randomly assigned in a 1:1 ratio to the bilateral group or contralateral group. The bilateral group consisted of patients who had bilateral implantation of Acrysof IQ Restor +2.5 D multifocal IOLs in both the dominant and fellow eyes. The contralateral group consisted of patients who had implantation of an Acrysof IQ Restor +2.5 D multifocal IOL in the dominant eye and an Acrysof IQ Restor +3.0 D multifocal IOL in the fellow eye. After randomization, the $+2.5 \mathrm{D}$ multifocal IOLs were implanted first in the dominant eye of each patient; dominance was determined in each case by the investigator. Within 45 days after the first implantation (visit OOA), the second eye had implantation of the $+2.5 \mathrm{D}$ multifocal IOL or the +3.0 D multifocal IOL, depending on the group to which the patient had been randomized (Figure 1).

In this trial, patients were assessed up to 2 months preoperatively and up to 3 months postoperatively to determine the patient's range of vision in eyes with an $I O L$ and the patientreported outcomes. All routine testing and basic ophthalmic examinations were carried out at each study visit. During the preoperative visit, partial coherence interferometry optical biometry and SRK/T IOL calculations were performed. ${ }^{21}$ Postoperatively, patients were assessed 1 day (visit 1 and 1A), 1 month (visit 2A), and 3 months (visit 3A) after IOL implantation (Figure 1). All routine postoperative measures plus monocular visual acuity testing, slitlamp examination, IOL position, and adverse events were monitored. Here, "post-implantation" refers to after the second surgery throughout. The dominant eye was identified and recorded for comparison with preoperative data (visit 0). At visit 3A, binocular visual acuity testing, manifest refraction spherical equivalent (MRSE), monocular and binocular defocus testing, binocular Radner reading speed, monocular and binocular contrast sensitivity with and without glare, mesopic and photopic pupil size, and quality-of-life assessments were performed.

Before any procedure, voluntary informed consent was obtained from all patients in accordance with the ethical principles of the Declaration of Helsinki.22 A local ethics committee approved the study and informed consent. 


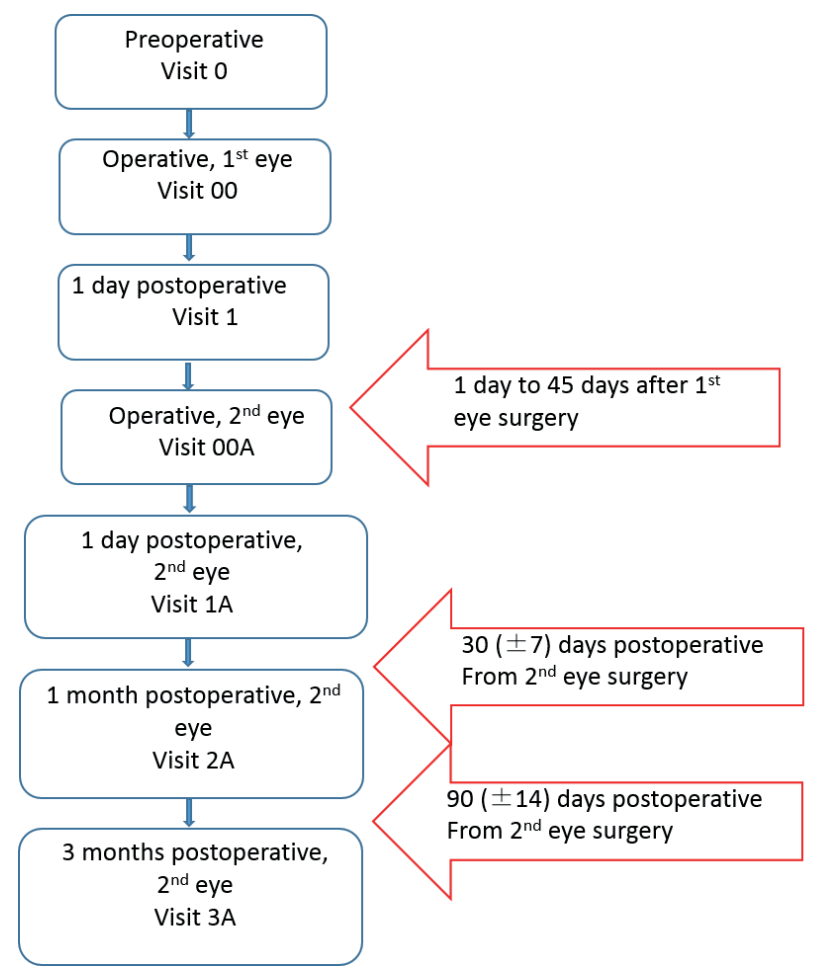

Figure 1. Visit schedule for patient preoperative and postoperative assessment.

\section{Patient eligibility}

Patients eligible for the study were 21 years or older at the time of surgery, required cataract extraction followed by posterior IOL implantation used as an on-label procedure in both eyes, and were willing to have second-eye surgery within the 45 days of first-eye surgery. Patients of either sex and of any ethnicity were eligible. The patients had to be able to understand and agree to sign an informed consent form and be willing and able to attend postoperative examinations per protocol schedule.

Eligible patients also had to be free of severe disease or conditions listed in the "Warnings" and "Precautions" sections of the Acrysof IQ Restor +2.5 D and Acrysof IQ Restor + 3.0 D multifocal IOL package inserts ${ }^{18,19}$ and were expected to have postoperative astigmatism less than $1.0 \mathrm{D}$ in both eyes as measured by keratometry. Patients were not considered eligible for the study if they met any of the exclusion criteria, which included a corrected distance VA (CDVA) worse than $0.06 \log$ MAR in either eye, significant irregular corneal astigmatism as demonstrated by corneal topography, severe degenerative visual disorders (eg, macular degeneration, retinal disorders), amblyopia, or previous corneal surgery. Patients with planned multiple procedures, including laser-assisted in situ keratomileusis, were also excluded from the study. Furthermore, 
patients with clinically significant corneal endothelial dystrophy (eg, Fuchs dystrophy), a history of retinal detachment, and severe conditions of acute or chronic diseases as well as any patient currently participating in another drug or device study were excluded. Exclusion criteria also included patients with significant vitreous loss or anterior chamber hyphema, uncontrollable intraocular pressure, significant zonular or capsular rupture, and any other complication that would compromise the stability of the IOL in the capsular bag during the phacoemulsification procedure.

\section{Study objectives}

The primary objective of the study was to show noninferiority of bilateral IOL implantation versus contralateral IOL implantation in binocular corrected intermediate visual acuity (CIVA) at $60 \mathrm{~cm}$ at 3 months \pm 14 days (SD). A noninferiority margin of 0.1 logMAR for the difference in means in CIVA of bilateral IOL implantation versus contralateral IOL implantation was specified in the protocol. The secondary objective was to show noninferiority of the bilateral group to the contralateral group in binocular corrected near visual acuity (CNVA) at $40 \mathrm{~cm}$ at 3 months \pm 14 days. The endpoint was noninferiority defined as a difference of $0.1 \log M A R$ between bilateral IOL implantation and contralateral IOL implantation at 3 months \pm 14 days.

In this study, data for supportive efficacy parameters included monocular and binocular defocus curves (logMAR), MRSE (performed with 100\% contrast Early Treatment Diabetic Retinopathy Study [ETDRS] chart at $4 \mathrm{~m}$ under photopic lighting conditions [>85 candelas $\left./ \mathrm{m}^{2}\right]$ ), binocular photopic contrast sensitivity with and without glare (at the 3-month postoperative visit), and Radner reading speed examination in words per minute (wpm).

Preoperative reading performance was measured in all patients with spectacle near correction in place. At the 3-month postoperative visit, reading performance was measured (without correction, and with the patient's distance correction in place), and a quality-of-life visual problems questionnaire was completed.

\section{Safety evaluation}

Safety assessments included adverse events that were recorded and coded with the use of the medical dictionary for regulatory activities system, secondary surgical interventions, slitlamp examination, dilated fundus examination, and IOL position change (tilt and decentration). Quality complaints or device deficiencies defined as an adverse event relating to the use of a medical device or comparator also were recorded, including adverse events resulting in insufficient or inadequate instructions for use, deployment, implantation, installation, or operation, any malfunction, and user error or intentional misuse of the medical device or comparator. 


\section{Statistical analysis}

All patients with successful implantations were included in the data analysis. All patients with attempted IOL implantation in 1 eye or more (successful or aborted after contact with the eye) were considered evaluable for the safety analyses, and data were provided for all safety measurements, including any adverse events experienced by a patient during screening procedures.

The null hypothesis for the primary objective was that the bilateral group was noninferior to the contralateral group in mean binocular CIVA at $60 \mathrm{~cm}$. The null hypothesis for the study secondary objective was that the bilateral group was noninferior to the contralateral group in mean binocular CNVA at $40 \mathrm{~cm}$. The 1-sided alternative hypothesis for both the primary and secondary objectives was that the bilateral group was noninferior to the contralateral group.

The primary and secondary hypotheses were tested using a 2 -sided $90 \%$ confidence interval (CI) for the difference in mean binocular CIVA (at $60 \mathrm{~cm}$ for the primary endpoint) and CNVA (at 40 $\mathrm{cm}$ for the secondary endpoint) between the 2 groups at 3 months \pm 14 days from a repeatedmeasures analysis of variance. The study site was included as a covariate, which corresponded to a 1-tailed test at the $a=0.5$ level of significance. The noninferiority margin for binocular CIVA at $60 \mathrm{~cm}$ and for CNVA at $40 \mathrm{~cm}$ is $\Delta=0.1 \log M A R$, denoting a clinical equivalent of 1 line on the ETDRS chart. The family-wise error rate was controlled at the 5\% level, 1-sided, and consistent with guidance documents International Organization for Standardization 11979-9, $2006{ }^{23}$ and American National Standards Institute Z80.12-2007. ${ }^{24}$ No multiplicity adjustments were planned for the primary effectiveness analyses because inference was to be based on 1 variable tested at 1 timepoint.

Supportive parameters were reported using descriptive statistics. Summary statistics for binary parameters of safety endpoints included sample size, number with the event, and percent with the event. Defocus curve data were presented by generating line plots of the average visual acuity measurements at each defocus testing across all patients in each treatment group for binocular defocus testing and across all patients in each eye (primary versus fellow) in each treatment group for monocular defocus testing. A sensitivity analysis was performed on defocus and monocular contrast sensitivity data to exclude any patients in whom (1) the first eye to have IOL implantation was not the dominant eye determined at baseline or (2) the dominant eye changed after the baseline visit so that the robustness of the results could be tested. Leastsquares mean comparisons between groups were performed, and $P$ values were generated for binocular assessment of uncorrected distance visual acuity (UDVA) and CDVA at all corrected distances; $P$ values were also generated for all monocular assessments of CDVA between the first operative eye and second operative eye for patients in the contralateral group. 


\section{RESULTS}

\section{Patient disposition and demographics}

Although there were 112 enrolled patients, 9 failed the screening; thus, this study consisted of 103 patients (206 eyes) for the implantation the $+2.5 \mathrm{D}$ multifocal IOL in the dominant eye, with either bilateral implantation of the $+2.5 \mathrm{D}$ multifocal IOL $(n=53)$ in the fellow eye or contralateral implantation of the $+3.0 \mathrm{D}$ multifocal IOL $(n=50)$ in the fellow eye. All eyes were targeted for emmetropia. There were no discontinuations throughout the study. Patient demographics were similar between the bilateral and contralateral groups (Table 1). Of the 66 women and 37 men in the study, the majority was white.

\section{Primary study efficacy: corrected intermediate visual acuity at $60 \mathrm{~cm}$}

At 3 months, the mean (standard error [SE]) binocular CIVA at $60 \mathrm{~cm}$ was $0.13 \pm 0.015 \mathrm{log} M A R$ in the bilateral group and $0.10 \pm 0.016 \log M A R$ in the contralateral group, with a difference of 0.04 $\log$ MAR (90\% Cl, 0.00-0.07). Noninferiority of the bilateral group to the contralateral group was shown by comparison of means based on the upper confidence limit of $0.07 \log M A R$ at 3 months.

\section{Secondary study efficacy: corrected near visual acuity at $40 \mathrm{~cm}$}

At 3 months, the mean binocular CNVA (SE) was $0.26 \pm 0.016 \log$ MAR in the bilateral group and $0.11 \pm 0.016 \log M A R$ in the contralateral group, with a difference of $0.15 \log M A R(90 \% \mathrm{Cl}$, 0.12-0.19). Noninferiority of the bilateral group to the contralateral group was not shown by comparison of means based on the upper confidence limit of $0.19 \log M A R$ at 3 months.

\section{Supporting efficacy}

Overall, results from the supportive parameters, specifically the defocus curve results, indicated a good range of postoperative vision (0.3 logMAR; 20/40 or better) across all distances in both treatment groups, with better CNVA $(40 \mathrm{~cm}$ ) in the contralateral group (Figure 2). Binocular photopic contrast sensitivity with and without glare was similar between groups (Figure 3). Similar results were also seen between groups in reading speed, with numerically better reading scores (LogRAD and wpm) for the contralateral group (Table 2). However, this was not statistically tested.

At 3 months, the mean MRSE (all eyes with IOLs) was 0.14 in the bilateral group $(n=106)$ and a similar 0.19 in the contralateral group $(n=100)$. The UDVA results also showed similar outcomes in the bilateral and contralateral groups. At 3 months, the mean binocular UDVA at 4 $m$ was $-0.04 \pm 0.10 \log$ MAR in the bilateral group $(n=53)$ and $-0.02 \pm 0.13$ in the contralateral group ( $n=50$ ), the mean uncorrected intermediate visual acuity (UIVA) at $60 \mathrm{~cm}$ was $0.13 \pm$ $0.15 \log M A R$ in the bilateral group $(n=53)$ and $0.12 \pm 0.14 \log M A R$ in the contralateral group $(n=50)$, and mean uncorrected near visual acuity (UNVA) at $40 \mathrm{~cm}$ was $0.25 \pm 0.15 \log M A R$ in the bilateral group $(n=53)$ and $0.11 \pm 0.13 \log M A R$ in the contralateral group $(n=50)$. 
Binocular CDVA at the near patient-preferred distance was better in the contralateral group. At 3 months, the mean binocular CDVA in the bilateral group was $0.24 \pm 0.17 \log M A R$ and $0.13 \pm 0.13 \log M A R$ in the contralateral group, with an overall difference (SE) of 0.10 (0.02) logMAR ( $P=.000)$. The quality-of-life visual problems questionnaire results also showed low scores for visual problems (indicating good quality of vision) in both groups (Table 3).

\section{Safety results}

Although no patient discontinued the study because of an adverse event, 5 device-associated adverse events were reported: 3 in the bilateral group (2 posterior capsule opacification [PCO] adverse events and 1 crossbar vision adverse event) and 2 in the contralateral group (2 PCO adverse events). Incidences of treatment-emergent ocular adverse events were also similar in the bilateral and contralateral groups (Table 4). The most frequently reported adverse event was dry eye (including Sjögren's syndrome), which occurred equally between the groups. There were no reports of quality complaints or device deficiencies in this study.

A single incidence of late $\mathrm{IOL}$ decentration (approximately 1 month after surgery) was observed in the dominant eye of 1 patient in the bilateral group during $\mathrm{OL}$ position-change examinations. However, no surgical problems were noted during the operative procedure, and no adverse events or other ocular abnormalities were reported for this patient during the study. At study exit, the patient experienced glare, but no other visual disturbances were noted. The patient's UDVA in the left dominant eye was $0.04 \log$ MAR at 3 months. 


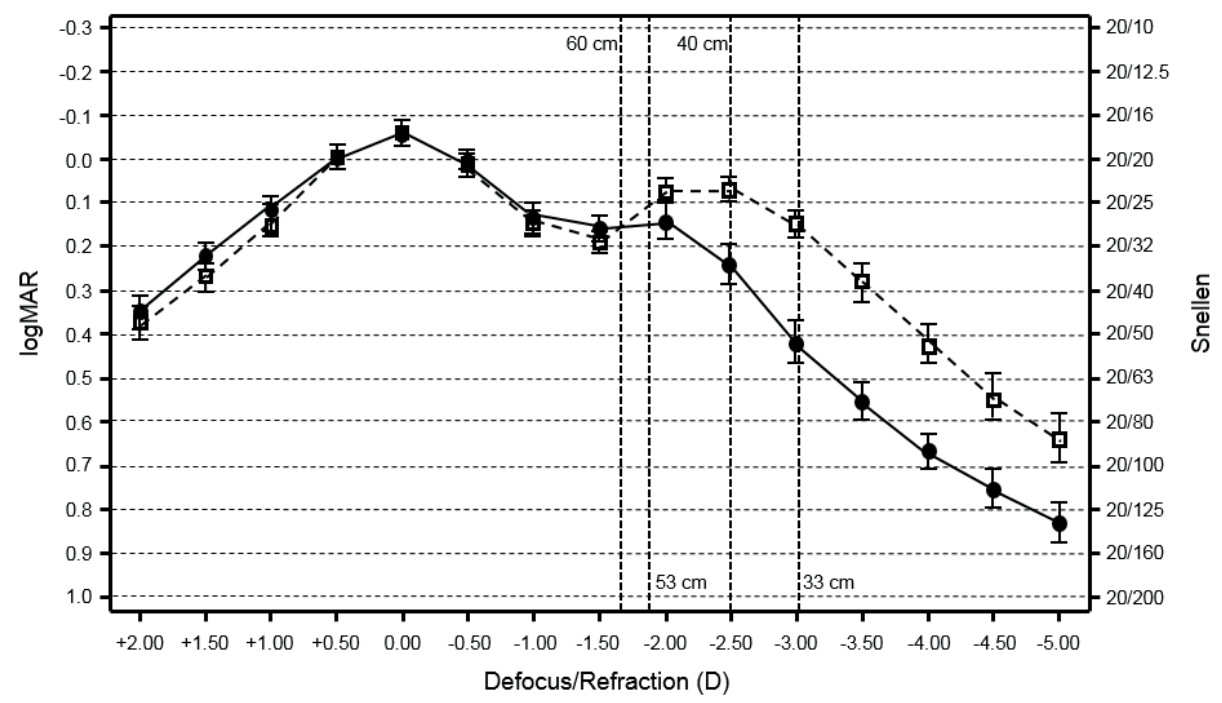

Contralateral $=\operatorname{ReSTOR}+2.5 \mathrm{D}$ in the dominant eye and +3.0 $\mathrm{D}$ in the fellow eye $(n=53)--\square-$ Bilateral $=\operatorname{ReSTOR}+2.5 \mathrm{D}$ in both eyes $(n=50)$

Figure 2. Mean and $90 \%$ confidence limits for binocular vision for defocus curves testing at visit 3A (all



Figure 3. Binocular photopic contrast sensitivity without and with glare at the 3-months postoperative visit (CPD = Cycles per degree). 
Table 1. Patient characteristics

\begin{tabular}{|c|c|c|c|}
\hline & $\begin{array}{c}\text { Overall } \\
(n=103)\end{array}$ & $\begin{array}{c}\text { Bilateral } \\
(n=53)\end{array}$ & $\begin{array}{c}\text { Contralateral } \\
(n=50)\end{array}$ \\
\hline Mean age $(y) \pm S D$ & $66.6 \pm 9.0$ & $67.2 \pm 7.9$ & $65.9 \pm 10.1$ \\
\hline \multicolumn{4}{|l|}{ Age group, n (\%) } \\
\hline $40-49 y$ & $6(5.8)$ & $3(5.7)$ & $3(6.0)$ \\
\hline $50-59 y$ & $15(14.6)$ & $5(9.4)$ & $10(20.0)$ \\
\hline $60-69 y$ & $41(39.8)$ & $23(43.4)$ & $18(36.0)$ \\
\hline $70-79 y$ & $37(35.9)$ & $20(37.7)$ & $17(34.0)$ \\
\hline$\geq 80 y$ & $4(3.9)$ & $2(3.8)$ & $2(4.0)$ \\
\hline \multicolumn{4}{|l|}{ Sex, n (\%) } \\
\hline Male & $37(35.9)$ & $18(34.0)$ & $19(38.0)$ \\
\hline Female & $66(64.1)$ & $35(66.0)$ & $31(62.0)$ \\
\hline \multicolumn{4}{|l|}{ Race, n (\%) } \\
\hline White & $101(98.1)$ & $51(96.2)$ & $50(100.0)$ \\
\hline Multiracial & $1(1.0)$ & $1(1.9)$ & $0(0.0)$ \\
\hline \multicolumn{4}{|l|}{ Ethnicity, n (\%) } \\
\hline Hispanic, Latino, or Spanish & $43(41.7)$ & $22(41.5)$ & $21(42.0)$ \\
\hline Not Hispanic, Latino, or Spanish & $60(58.3)$ & $31(58.5)$ & $29(58.0)$ \\
\hline
\end{tabular}


Table 2. Descriptive statistics for Radner reading tests at 3 months (visit 3A).

\begin{tabular}{|c|c|c|}
\hline & Bilateral & Contralateral \\
\hline \multicolumn{3}{|c|}{ LogRAD score (uncorrected) } \\
\hline Number & 51 & 47 \\
\hline Mean \pm SD & $0.33 \pm 0.16$ & $0.19 \pm 0.15$ \\
\hline Median & 0.3 & 0.2 \\
\hline Min, Max & $0.00,0.92$ & $-0.17,0.60$ \\
\hline $90 \% \mathrm{Cl}$ & $0.30,0.37$ & $0.15,0.23$ \\
\hline \multicolumn{3}{|c|}{ LogRAD score (best distance corrected) } \\
\hline Number & 46 & 43 \\
\hline Mean \pm SD & $0.30 \pm 0.18$ & $0.19 \pm 0.13$ \\
\hline Median & 0.3 & 0.2 \\
\hline Min, Max & $-0.10,0.80$ & $-0.10,0.52$ \\
\hline $90 \% \mathrm{Cl}$ & $0.25,0.34$ & $0.16,0.23$ \\
\hline \multicolumn{3}{|c|}{ Reading speed (wpm) (uncorrected) } \\
\hline Number & 51 & 47 \\
\hline Mean \pm SD & $69.13 \pm 22.46$ & $72.44 \pm 29.29$ \\
\hline Median & 63.73 & 62.78 \\
\hline Min, Max & $42.75,152.17$ & $42.60,168.00$ \\
\hline $90 \% \mathrm{Cl}$ & $63.86,74.40$ & $65.27,79.61$ \\
\hline \multicolumn{3}{|c|}{ Reading speed (wpm) (best distance corrected) } \\
\hline Number & 46 & 43 \\
\hline Mean \pm SD & $73.15 \pm 29.97$ & $76.84 \pm 27.33$ \\
\hline Median & 69.45 & 74.07 \\
\hline Min, Max & $42.42,200.00$ & $44.21,148.41$ \\
\hline $90 \% \mathrm{Cl}$ & $65.73,80.57$ & 69.83, 83.86 \\
\hline
\end{tabular}


Table 3. Quality-of-life visual problems at 3 months (Visit 3A).

\begin{tabular}{lcc}
\hline & \multicolumn{2}{c}{ Mean \pm SD } \\
\cline { 2 - 3 } Problem & $\begin{array}{c}\text { Bilateral } \\
(\mathbf{n}=\mathbf{5 3})\end{array}$ & $\begin{array}{c}\text { Contralateral } \\
(\mathbf{n}=\mathbf{5 3})\end{array}$ \\
\hline Glare/flare & $1.8 \pm 2.1$ & $1.6 \pm 2.0$ \\
Halos & $1.3 \pm 1.8$ & $0.9 \pm 1.5$ \\
Distorted near vision & $0.5 \pm 1.3$ & $0.1 \pm 0.8$ \\
Distorted far vision & $0.1 \pm 0.4$ & $0.0 \pm 0.1$ \\
Blurred near vision & $2.2 \pm 2.2$ & $1.2 \pm 1.8$ \\
Blurred far vision & $0.3 \pm 1.1$ & $0.1 \pm 0.5$ \\
Problems with night vision & $0.8 \pm 1.5$ & $0.5 \pm 1.4$ \\
Double vision with both eyes & $0.3 \pm 1.0$ & $0.1 \pm 0.4$ \\
Problem with color perception & $0.2 \pm 0.5$ & $0.0 \pm 0.1$ \\
\hline
\end{tabular}

Table 4. Summary of all treatment-emergent ocular adverse events (safety population).

\begin{tabular}{lcc}
\hline & \multicolumn{2}{c}{ Number (\%) } \\
\cline { 2 - 3 } Event & $\begin{array}{c}\text { Bilateral } \\
(106 \text { eyes })\end{array}$ & $\begin{array}{c}\text { Contralateral } \\
(100 \text { eyes })\end{array}$ \\
\hline Any adverse event & $19(1.79)$ & $18(18.0)$ \\
Anterior chamber cell & $2(1.9)$ & $1(1.0)$ \\
Conjunctival hemorrhage & $0(0.0)$ & $1(1.0)$ \\
Conjunctivitis (allergic) & $2(1.9)$ & $2(2.0)$ \\
Corneal erosion & $1(0.9)$ & $0(0.0)$ \\
Corneal edema & $1(0.9)$ & $1(1.0)$ \\
Dry eye & $4(3.8)$ & $4(4.0)$ \\
Eye pain & $2(1.9)$ & $0(0.0)$ \\
Intraocular pressure increased & $2(1.9)$ & $1(1.0)$ \\
Lacrimation increased & $0(0.0)$ & $2(2.0)$ \\
Post-procedural complication & $1(0.9)$ & $0(0.0)$ \\
Posterior capsule opacification & $2(1.9)$ & $3(3.0)$ \\
Refraction disorder & $1(0.9)$ & $0(0.0)$ \\
Retinal degeneration & $1(0.9)$ & $0(0.0)$ \\
Sjögren syndrome & $5(4.7)$ & $6(6.0)$ \\
Visual impairment (crossbar vision) & $1(0.9)$ & $0(0.0)$ \\
Vitreous detachment & $1(0.9)$ & $1(1.0)$ \\
\hline
\end{tabular}




\section{DISCUSSION}

In this multicenter study performed at 8 investigative sites worldwide, bilateral implantation of ReSTOR +2.5 D multifocal IOLs was noninferior to contralateral implantation of the ReSTOR +2.5 D multifocal IOL and ReSTOR +3.0 D multifocal IOL in terms of binocular CIVA at $60 \mathrm{~cm}$. Contralateral implantation of the $+2.5 \mathrm{D}$ multifocal IOL and $+3.0 \mathrm{D}$ multifocal IOL resulted in better visual acuity at near distances $(40 \mathrm{~cm}$ and closer). These results suggest that contralateral implantation may have a higher likelihood than bilateral implantation of patients attaining spectacle independence over a wide range of distances.

Multifocal IOLs were introduced in the 1980s, bringing improvements in near and distance vision without the need for spectacles. Studies have shown that diffractive multifocal IOLs produce excellent near and far vision; however intermediate vision may be poor. ${ }^{7}$ The incidence of halo, flare, and glare in patients with multifocal IOLs has limited the acceptance of this technology. ${ }^{8}$ Recent advances in multifocal IOL design and improved preoperative patient counselling, however, have reduced the occurrence of these disturbing optic phenomena. These have allowed patients the possibility of becoming spectacle free after multifocal IOL implantation, thus increasing patient satisfaction and quality of life. 4, 5,8 Dissatisfaction after multifocal IOL implantation is now rare and often amenable to treatment. ${ }^{25}$

In our study, we have shown that multifocal IOL implantation can be tailored for patients and therefore might improve patient visual outcomes. In contrast to results in some bilateral studies, ${ }^{26}$ in which straylight was an issue, bilateral implantation and contralateral implantation appeared to be similar in regard to photic phenomena and visual problems after 3 months after implantation. In other studies, unlike what we observed in this study, this difference in quality of vision with multifocal IOLs was believed to result from the adjustment of the apodization pattern within the IOLs because the $+2.5 \mathrm{D} \mathrm{IOL} \mathrm{had} \mathrm{fewer} \mathrm{rings} \mathrm{of} \mathrm{progressively} \mathrm{decreasing} \mathrm{diffractive}$ step height from the center to the periphery, than the +3.0 D IOL and hence was potentially responsible for fewer halos. Furthermore, it is less likely that glare and halos occurring in the nondominant (+3.0 D) eye would affect the quality of vision as much as glare and halos occurring in the dominant eye. These unwanted visual phenomena have been shown to have a large impact on postoperative patient satisfaction. ${ }^{8}$ In general, quality-of-life studies (eg, Kohnen et al ${ }^{9}$ ) report a high level of satisfaction with ReSTOR IOL implantation, as was the case in this study, and the possibility of increasing levels of spectacle independence might further improve the patient's quality of life.

Because of the strengths and weaknesses associated with bilateral and contralateral multifocal IOL implantation illustrated in this study (ie, bilateral offers good vision across most distances, but contralateral provides better near visual acuity), proper patient counseling is of paramount 
importance before implantation to best tailor treatment to the patient's vision needs. The form of optical correction should reflect patient's lifestyle needs, both occupational and recreational. As such, poor matching of implantation type (and hence visual outcomes) to patient's needs might mean the patient will fail to adapt and postoperative satisfaction with visual outcomes will be low. ${ }^{27}$

This study provides a perspective on clinical outcomes with bilateral implantation of $+2.5 \mathrm{D}$ IOLs and contralateral implantation of +2.5 D/+3.0 D IOLs at 3 months. The follow-up in this study was relatively short, and hence further follow-up data could be useful to characterize the long-term differences in multifocal IOL implantation modalities.

Another influence in outcome might be patient preoperative refractive status. A study by Petermeier et al. ${ }^{8}$ showed that preoperative refractive status might influence postoperative outcome after implantation of a ReSTOR multifocal IOL, where hyperopic patients showed a closer reading distance $(29.5 \mathrm{~cm})$ than emmetropic patients $(32.8 \mathrm{~cm})$ and myopic patients $(34.6$ $\mathrm{cm})$.

This study was not powered to perform a subanalysis of refractive groups with regard to reading distances; however, this would be interesting to explore in the future in a separate post hoc analysis. A comparison of UDVA and UNVA between the groups would also be of interest because in general, multifocal IOLs can provide excellent results at these distances, ${ }^{25}$ and uncorrected results are a better outcome indicator from a patient's perspective.

Overall, the study showed that binocular CIVA at $60 \mathrm{~cm}$ in the bilateral group was noninferior to that in the contralateral group. However, for binocular CNVA at $40 \mathrm{~cm}$, the contralateral group had better visual results. Thus, contralateral implantation could contribute to better visual performance (and perhaps more spectacle independence) for intermediate and near vision tasks. The results of the supportive parameters also indicate a good range of vision (20/40 or better) across a wide range of distances with both modalities. In addition, there was a low frequency of visual problems with both modalities and the contralateral group appeared to have better reading performance. Understanding the patient's needs helps the surgeon customize multifocal IOL options, and, as such, adequate education and counseling are critical to achieve successful results with multifocal IOLs. 


\section{WHAT WAS KNOWN}

- In patients requiring bilateral cataract extraction followed by multifocal IOL implantation, the +3.O D IOL is the most common IOL used because it gives effective near vision at $40 \mathrm{~cm}$.

- The newer +2.5 D IOL provides good distance and intermediate vision and produces better clarity of distance vision, with a near vision at a further point $(53 \mathrm{~cm})$ compared with the +3.0 D lens (maximal near vision at $41 \mathrm{~cm}$ ).

\section{WHAT THIS PAPER ADDS}

- Bilateral implantation of the +2.5 D multifocal IOL resulted in similar distance and intermediate vision $(60 \mathrm{~cm})$ compared with contralateral implantation of the $+2.5 \mathrm{D}$ multifocal IOL and +3.0 D multifocal IOL, while noninferiority was not achieved for near vision $(40 \mathrm{~cm})$. However, contralateral multifocal IOL implantation offered good near vision and noninferior intermediate and distance vision compared with bilateral $+2.5 \mathrm{D}$ implantation.

- Contralateral implantation might be more beneficial for reading than bilateral implantation; thus, patients demanding spectacle independence when reading would benefit from contralateral implantation. 


\section{REFERENCES}

1. WHO. Prevention of Blindness and Visual Impairment. In: Organisation WH, ed. 2010; v. 2014.

2. Foster A, Gilbert C, Johnson G. Changing patterns in global blindness: 1988 - 2008 Community Eye Health 2008;21(67):37-9.

3. Heijl A, Leske M. Cataract epidemiology. Ophthalmology 2007;114(1):201.

4. Cochener B, Lafuma A, Khoshnood B, et al. Comparison of outcomes with multifocal intraocular lenses: a meta-analysis. Clin Ophthalmol 2011;5:45-56.

5. Raluca I, Catalina C. Premium intraocular lenses use in patients with cataract and concurrent glaucoma: a review. MAEDICA - a Journal of Clinical Medicine 2013;8(3):290-6.

6. Cillino S, Casuccio A, Di Pace F, et al. One-year outcomes with new-generation multifocal intraocular lenses. Ophthalmology 2008;115(9):1508-16.

7. Barisic A, Dekaris I, Gabric N, et al. Comparison of diffractive and refractive multifocal intraocular lenses in presbyopia treatment. Coll Antropol 2008;32 Suppl 2:27-31.

8. Petermeier K, Messias A, Gekeler F, etal. Outcomes of the Acrysof ReSTOR IOL in myopes, emmetropes, and hyperopes. J Refract Surg 2009;25(12):1103-9.

9. Kohnen T, Allen D, Boureau C, et al. European multicenter study of the AcrySof ReSTOR apodized diffractive intraocular lens. Ophthalmology 2006;113(4):584 e1.

10. Souza CE, Gerente VM, Chalita MR, et al. Visual acuity, contrast sensitivity, reading speed, and wavefront analysis: pseudophakic eye with multifocal IOL (ReSTOR) versus fellow phakic eye in nonpresbyopic patients. J Refract Surg 2006;22(3):303-5.

11. Souza CE, Muccioli C, Soriano ES, et al. Visual performance of AcrySof ReSTOR apodized diffractive IOL: a prospective comparative trial. Am J Ophthalmol 2006;141(5):827-32.

12. Alfonso J, Fernandez-Vega L, Baamonde M, Montes-Mico R. Prospective visual evaluation of apodized diffractive intraocular lenses. J Cataract Refract Surg 2007;33(7):1235-43.

13. Maxwell WA, Cionni RJ, Lehmann RP, Modi SS. Functional outcomes after bilateral implantation of apodized diffractive aspheric acrylic intraocular lenses with a +3.0 or +4.0 diopter addition power Randomized multicenter clinical study. J Cataract Refract Surg 2009;35(12):2054-61.

14. Kohnen T, Nuijts R, Levy P, et al. Visual function after bilateral implantation of apodized diffractive aspheric multifocal intraocular lenses with a+3.0 D addition. J Cataract Refract Surg 2009;35(12):20629.

15. Gundersen KG, Potvin R. Comparative visual performance with monofocal and multifocal intraocular lenses. Clin Ophthalmol 2013;7:1979-85.

16. Mastropasqua M, Pedrotti E, Passilongo M, et al. Valuation of functional results after implantation of two different multifocal IOLs (SV25TO add +2.5 D, SN6AD1 add +3.0 D). 31st Congress of the ESCRS. Amsterdam, Holland2013.

17. Lin HT, Chen WR, Ding ZF, et al. Clinical evaluation of two multifocal intraocular lens implantation patterns. Int J Ophthalmol 2012;5(1):76-83.

18. Alcon. ReSTOR $®+3.0$ D lens [Product Information]. Fort Woth, Texas, USA2009.

19. Alcon. ReSTOR $®+2.5$ D lens [Product Information]. Fort Woth, Texas, USA2009.

20. Yoon SY, Song IS, Kim JY, et al. Bilateral mix-and-match versus unilateral multifocal intraocular lens implantation: long-term comparison. J Cataract Refract Surg 2013;39(11):1682-90.

21. Retzlaff JA, Sanders DR, Kraff MC. Development of the SRK/T intraocular lens implant power calculation formula. J Cataract Refract Surg 1990;16(3):333-40. 
22. WMA General Assembly t. Declaration of Helsinki - ethical principles of medical research involving human subjects. Fortaleza, Brazil2013.

23. Standardization IOf. Ophthalmic implants - Intraocular lenses - Part 9: Multifocal intraocular lenses. Geneva, Switzerland: ISO, 2006.

24. Institute ANS. American National Standards for Ophthalmics - Multifocal Intraocular Lenses. New York. NY2007.

25. de Vries N, Nuijts R. Multifocal intraocular lensesin cataract surgery: Literature review of benefits and side effects. J Cataract Refract Surg 2013;39:268-78.

26. Peng C, Zhao J, Ma L, et al. Optical performance after bilateral implantation of apodized aspheric diffractive multifocal intraocular lenses with +3.00-D addition power. Acta Ophthalmol 2012;90(8):e586-93.

27. McDonnell PJ, Lee P, Spritzer K, et al. Associations of presbyopia with vision-targeted health-related quality of life. Arch Ophthalmol 2003;121(11):1577-81. 







\section{CHAPTER 9}

\section{Comparison of a trifocal intraocular}

lens with a +3.0 D bifocal IOL:

Results of a prospective randomized clinical trial 


\section{ABSTRACT}

Purpose: To compare visual outcomes in patients with cataract surgery and bilateral implantation of a trifocal or bifocal intraocular lens (IOL).

Setting: University Eye Clinic Maastricht, the Netherlands.

Design: Prospective randomized clinical trial.

Methods: Eyes with cataract and less than 1.0 diopter (D) of corneal astigmatism were randomized to receive bilateral implantation of FineVision Micro F trifocal IOLs or Acrysof IQ ReSTOR +3.0 bifocal IOLs. Outcome measures were monocular and binocular uncorrected distance (UDVA), uncorrected intermediate (UIVA), and uncorrected near (UNVA) visual acuities; refractive outcomes; binocular defocus curve; contrast sensitivity; reading speed; patient satisfaction; and spectacle independence.

Results: Six months postoperatively, the mean binocular UDVA, UIVA, and UNVA in 56 eyes of 28 patients were $0.01 \log M A R \pm 0.11(\mathrm{SD}), 0.08 \pm 0.15 \log M A R$, and $0.15 \pm 0.13 \log M A R$ in the trifocal group $(n=15)$ and $0.00 \pm 0.09 \log M A R, 0.04 \pm 0.08 \log M A R$, and $0.12 \pm 0.08 \log M A R$ in the bifocal group $(n=13)$, respectively. The trifocal group showed a more continuous defocus curve and better results at $-1.0 \mathrm{D}$ of defocus $(P<.01)$. The mean mesopic contrast sensitivity was higher in the bifocal group $(P=.02)$. Complete spectacle independence was reported by $80 \%$ of trifocal patients and $50 \%$ of bifocal patients. There were no significant differences in refractive outcomes, reading speed, or patient satisfaction.

Conclusion: This study showed noninferiority of visual outcomes with the trifocal IOL compared with the bifocal IOL, although the defocus curve was better at an intermediate distance with the trifocal IOL. 


\section{INTRODUCTION}

Cataract is an age-related eye disease leading to an impairment of patients' daily functioning as well as optical disturbances such as glare and halos. ${ }^{1}$ In 2010, an estimated 95 million of people worldwide had cataracts. ${ }^{2}$ Surgical removal of the crystalline lens and replacement with an artificial intraocular lens $(\mathrm{IOL})$ is the only vision-restoring option. After implantation of a monofocal IOL, reading glasses are usually needed for near vision, whereas multifocal IOLs result in better uncorrected near visual acuity (UNVA) with a reduced overall spectacle dependence. ${ }^{1,3,4}$ Multifocal IOLs function by projecting multiple images on the retina, which may result in unwanted visual phenomena such as contrast reduction, glare, and halos. ${ }^{3-12}$ Because most multifocal IOLs have only 2 foci, near and far, the quality of intermediate visual acuity might be insufficient for successful functioning in daily life. ${ }^{13,14}$ Trifocal IOLs have been developed to improve vision at intermediate distances. ${ }^{13,15}$ The goal of this randomized clinical trial was to compare the visual outcomes of a new trifocal IOL with those of a commonly used bifocal IOL. 


\section{PATIENTS AND METHODS}

\section{Patient selection}

A randomized clinical study design was used to compare visual function and patient satisfaction after bilateral IOL implantation in patients treated for age-related cataract. Both patient enrollment and treatment took place at the University Eye Clinic Maastricht. Approval from the medical ethics committee was obtained, and all procedures were conducted according to the Declaration of Helsinki. Written informed consent was obtained from all patients.

Inclusion criteria were bilateral cataract, less than 1.0 diopter (D) corneal astigmatism in both eyes, age over 42 years, and an expected postoperative corrected distance visual acuity (CDVA) of $0.3 \log$ MAR or less. Exclusion criteria were combined ocular procedures, previous ocular surgery, ocular pathology that would limit postoperative visual outcome, suturing of the incision during surgery, and complications during surgery in the first eye.

After enrollment, random allocation of study patients was performed to bilateral implantation of a trifocal IOL (trifocal group) or a bifocal IOL (bifocal group). Patients and investigators were masked.

\section{Surgical technique}

Two experienced surgeons (N.B., R.N.) performed all surgical procedures, which consisted of a standard phacoemulsification technique through a 2.2 mm clear corneal incision. Surgery in the second eye was performed within 2 weeks of the first surgery in each patient. The same type of $\mathrm{IOL}$ was implanted in both eyes.

The study used 2 types of IOLs: the FineVision Micro F trifocal IOL (Physiol S.A.)(Figure 1) and the Acrysof ReSTOR IQ +3.0 D bifocal IOL (Alcon Surgical, Inc.)(Figure 2). The trifocal IOL is a foldable single-piece fully diffractive pupil-dependent aspheric IOL made of a hydrophilic acrylic with an ultraviolet (UV)- and blue-light inhibitor. ${ }^{13,15}$ It has an optic diameter of 6.15 $\mathrm{mm}$, an overall diameter of $10.75 \mathrm{~mm}$, and a 4-point haptic design for stability. It has $+3.5 \mathrm{D}$ additional power for near vision and $+1.75 \mathrm{D}$ additional power for intermediate vision, consists of 26 diffractive steps, and requires a minimum incision of $1.8 \mathrm{~mm}$. The bifocal IOL is a foldable, single-piece, pupil dependent aspheric biconvex $\mathrm{IOL}$ with a $3.6 \mathrm{~mm}$ center and 9 apodized diffractive steps. ${ }^{15}$ It is made of a hydrophobic acrylate/methacrylate copolymer with an UVlight and blue-light blocker. The optic diameter is $6.0 \mathrm{~mm}$, and the overall diameter is $13.0 \mathrm{~mm}$. It has +3.0 D additional power for near vision. 




Figure 1. The trifocal IOL.

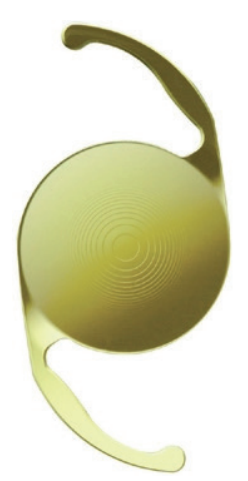

Figure 2. The bifocal IOL.

\section{Patient evaluation}

Eyes were evaluated at baseline and 1 week, and 1, 3, and 6 months postoperatively (Figure 3). A full ophthalmic examination was performed at every follow-up visit, including manifest refraction, monocular and binocular uncorrected distance visual acuity (UDVA) and CDVA measurements using the Early Treatment of Diabetic Retinopathy Study (ETDRS) chart at different reading distances, slitlamp examination, Scheimpflug photography (Pentacam, Oculus Optikgeräte $\mathrm{GmbH}$ ), and ophthalmoscopy. A binocular distance-corrected defocus curve was obtained using the ETDRS chart at $4 \mathrm{~m}$, adding lenses from -5.0 to $+2.0 \mathrm{D}$ in 0.5 steps. The measurement was performed under photopic (> 85 candelas $\left.[\mathrm{cd}] / \mathrm{m}^{2}\right)$ and mesopic $(\sim 3 \mathrm{~cd}$ / $\mathrm{m}^{2}$ ) conditions 3 months after surgery. Additional contrast sensitivity measurements were performed with a contrast-sensitivity chart (CSV-1000, VectorVision). The contrast-sensitivity chart measured contrast sensitivity at 4 spatial frequencies, each with 8 levels of contrast. When applying the manufacturers' conversion guidelines, individual values could be converted into values suitable for statistical analysis; ie, the area under the log contrast sensitivity function (AULCSF) curve. ${ }^{16}$ The uncorrected reading acuity and reading performance was measured at baseline and 3 months postoperatively with the Dutch Radner reading chart ${ }^{17}$ (Rotterdam Eye Hospital, Rotterdam, the Netherlands) using the Salzburg Reading Desk (SRD Vision). ${ }^{18}$ The Radner reading chart comprises standardized sentences, allowing evaluation in patients with different levels of education. To evaluate vision-related quality of life, the National Eye Institute Refractive Error Correction Quality of Life Instrument-42 (NEI-RQL 42) questionnaire ${ }^{19}$ was used preoperatively and 6 months postoperatively. It has of 42 questions divided in 13 scales and covering different aspects of vision-related quality of life. Each scale has a score from 0 to 100 , with higher scores indicating higher subjective quality of life. ${ }^{20,21}$ 


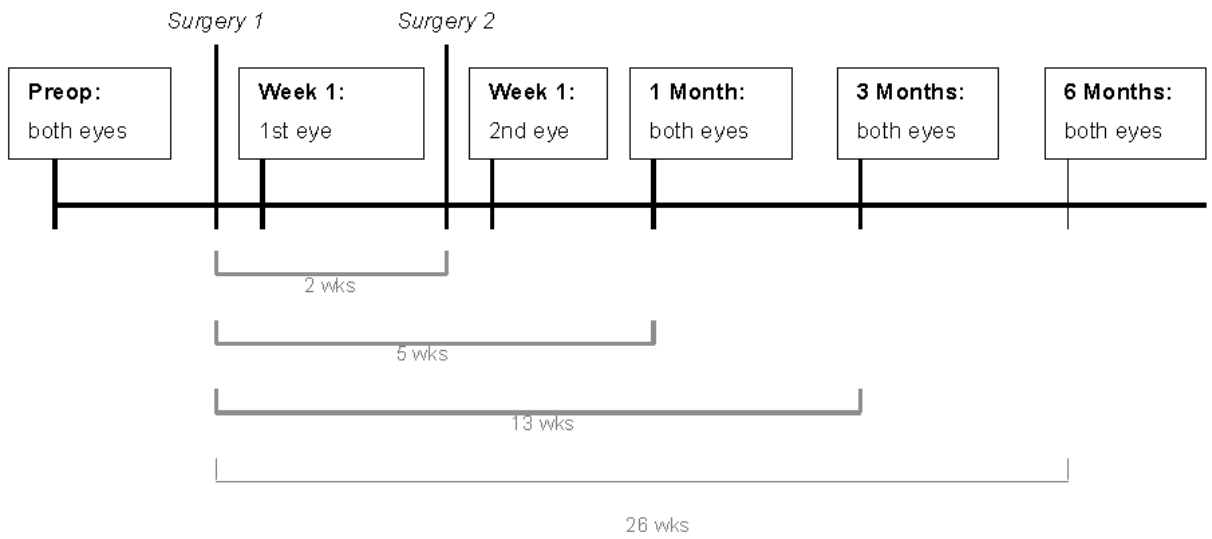

Figure 3. Schedule of postoperative visits.

\section{Outcome measures}

The primary outcome measure was the mean binocular distance-corrected visual acuity at intermediate distance (DCIVA) at $70 \mathrm{~cm}$ under mesopic $\left(\sim 3 \mathrm{~cd} / \mathrm{m}^{2}\right)$ conditions. Secondary outcome parameters were monocular and binocular visual acuities, including DCIVA at $70 \mathrm{~cm}$ under photopic conditions, UNVA and distance corrected near visual acuity (DCNVA) at $40 \mathrm{~cm}$, uncorrected intermediate visual acuity (UIVA) at $70 \mathrm{~cm}$, and UDVA and CDVA at 4 m under photopic and mesopic conditions. Contrast sensitivity was tested monocularly and binocularly under photopic and mesopic conditions, and reading speed was evaluated with $70 \%$ and $100 \%$ contrast levels. Perioperative and postoperative complications were documented.

\section{Sample size}

Calculation of the required sample size was based on the primary outcome parameter of binocular DCIVA at $70 \mathrm{~cm}$ under mesopic conditions. A pilot study with the trifocal IOL used in this study found a bilateral DCIVA of $0.12 \pm 0.17 \log$ MAR (data on file). To find a clinically significant difference between groups, a difference of 0.2 logMAR was assumed significant. Based on these assumptions, an alpha of 0.05 , and power of 0.8 , it was calculated that 12 patients were required in each group. While assuming a dropout rate of $15 \%$ on the primary outcome measure, this resulted in a total requirement of 28 patients.

\section{Statistical analysis}

Data are provided as mean \pm standard deviation (SD). The chi-square test was used to compare categorical data and the Student $t$ test for scale variables. Linear regression analysis was used to look for possible associations between preoperative values and outcomes 3 and 6 months after surgery. A P value of less than 0.05 was considered statistically significant. The statistical analysis was performed using SPSS for Windows software (version 22, International Business Machines Corp.). 


\section{RESULTS}

The trifocal group included 30 eyes of 15 patients and the bifocal group included 26 eyes of 13 patients. Table 1 shows the preoperative patient characteristics. A statistically significant difference was found in distance-corrected near visual acuity (DCNVA) at patient- preferred distance $(P=.01)$ and in pupil size under photopic $(P=.02)$ and high mesopic $(P=.01)$ conditions. All study patients completed the 6-month follow-up period.

\section{Refractive and visual outcomes}

Table 2 shows the monocular postoperative refraction and visual acuity results 1 and 6 months postoperatively. Monocular measurements (photopic and mesopic) at either timepoint showed no statistically significant differences between the $210 \mathrm{~L}$ groups.

Table 3 shows the binocular visual acuity and refractive results at 1 and 6 months after surgery. No statistically significant differences were observed under photopic and mesopic circumstances at 1 month or 6 months after surgery.

\section{Defocus curves}

Binocular defocus curves of both groups are shown in Figure 4. When comparing both groups under photopic circumstances, statistically significantly better visual acuity was present in the trifocal group for the defocus levels $-1.0 \mathrm{D}(P<.01)$ and $+1.0 \mathrm{D}(P=.02)$. Statistically significantly better visual acuity was present in the bifocal group for the defocus levels $-5.0 D(P<.01),-4.5$ $\mathrm{D}(P<.01)$, and $-4.0 \mathrm{D}(P=.01)$. When comparing both groups under mesopic circumstances, significantly better visual acuity was present in the trifocal group for the defocus levels -1.0 $\mathrm{D}(P<.01)$, +1.0 D ( $P=.02)$, and +1.5 D ( $P=.02)$. Statistically significantly better visual acuity was present in the bifocal group for the defocus levels $-5.0 \mathrm{D}(P<.01)$ and $-4.5 \mathrm{D}(P=.01)$. At the intermediate range, the defocus curves of the trifocal IOL showed a more continuous performance at the intermediate range under photopic and mesopic conditions.

\section{Contrast sensitivity}

Binocular contrast sensitivity curves with respect to the appropriate age-related cohort under both photopic and mesopic circumstances are shown in Figure 5 and Table A. Binocular measurements of individual contrast sensitivity values (AULCSF) were similar under photopic circumstances and significantly better in the bifocal group at a spatial frequency 6 cycles per degree (cpd) ( $P=.01)$ under mesopic conditions. As Figure 5 shows, all contrast sensitivity values are within or are only slightly lower than the normal age-related cohort. All mean photopic contrast sensitivity (mean AULCSF) results were similar in the trifocal group and the bifocal group ( $P>$.1). The mesopic mean binocular contrast sensitivity (mean AULCSF) was significantly higher in the bifocal group $(P=.02)$. 


\section{Reading speed}

Results of comparative measurements with the Radner reading chart are shown in Table B. No statistically significant difference was found in the mean reading distance, mean reading speed, or maximum reading speed under $70 \%$ and $100 \%$ contrast. Comparison of critical print size and visual acuity showed no statistically significant difference between the $2 \mathrm{IOL}$ groups.

\section{Patient-reported parameters}

Questionnaires were completed by 15 patients (100\%) in the trifocal group and 12 patients (92\%) in the bifocal group (Figure 6). Six months postoperatively, most patients were pleased with their quality of vision. The occurrence of side effects of multifocal IOLs, such as glare and halos, was similar to preoperative measurements with the NEI-RQL 42 questionnaire.

At 6 months, all patients were spectacle-free for distance, with 12 trifocal patients (80\%) and 9 bifocal patients (75\%) also reporting spectacle independence at near distance. Patients were also asked to report the duration of daily spectacle use (Figure 7). In the trifocal group, 12 patients (80\%) reported complete spectacle independence, and 2 (13\%) reported wearing spectacles less than $15 \%$ of a day. In the bifocal group, 6 patients (50\%) reported total spectacle independence and 5 (42\%) reported wearing spectacles less than $15 \%$ of a day.

\section{Complications and intraocular lens centration}

In 1 eye (3.3\%) of the trifocal group, intraoperative IOL exchange occurred because of a damaged haptic. During the follow-up period, there were no potentially sight-threatening complications in either group. No additional interventions in the postoperative period were required.

An IOL decentration of more than $1.5 \mathrm{~mm}$ occurred in both eyes of 1 patient (6.6\%) in the trifocal group, which did not lead to decreased patient satisfaction. In the bifocal group, 1 eye (3.8\%) of 1 patient had an $\mathrm{IOL}$ decentration of more than $1.5 \mathrm{~mm}$, resulting in glare, halos, and the perception of a shimmer, a vague dark contour in the corner of the eye. This patient did not opt for surgical repositioning of the IOL.

A

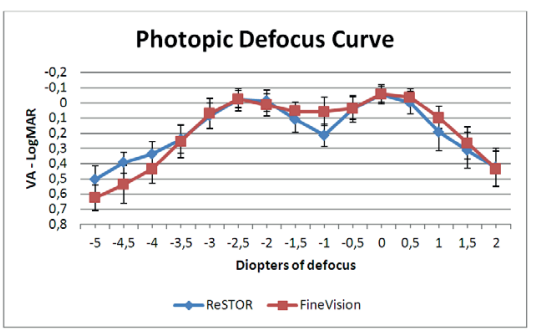

B



Figure 4. Left: Mean binocular photopic defocus curve 3 months postoperatively. Right: Mean binocular mesopic defocus curve 3 months postoperatively ( $\mathrm{OL}$ = intraocular lens). 


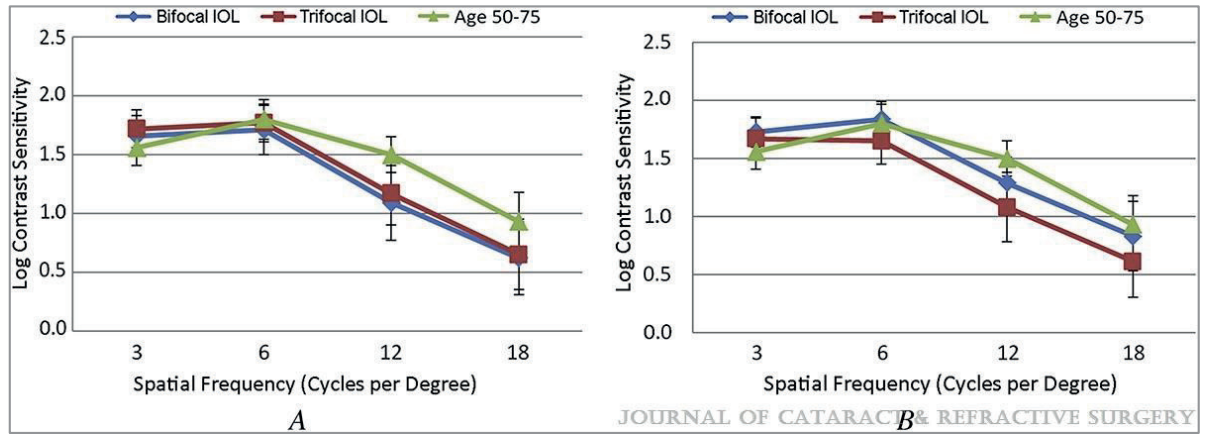

Figure 5. Left: Mean binocular photopic contrast sensitivity 3 months postoperatively. Right: Mean binocular mesopic contrast sensitivity 3 months postoperatively ( $\mathrm{OL}=$ intraocular lens).

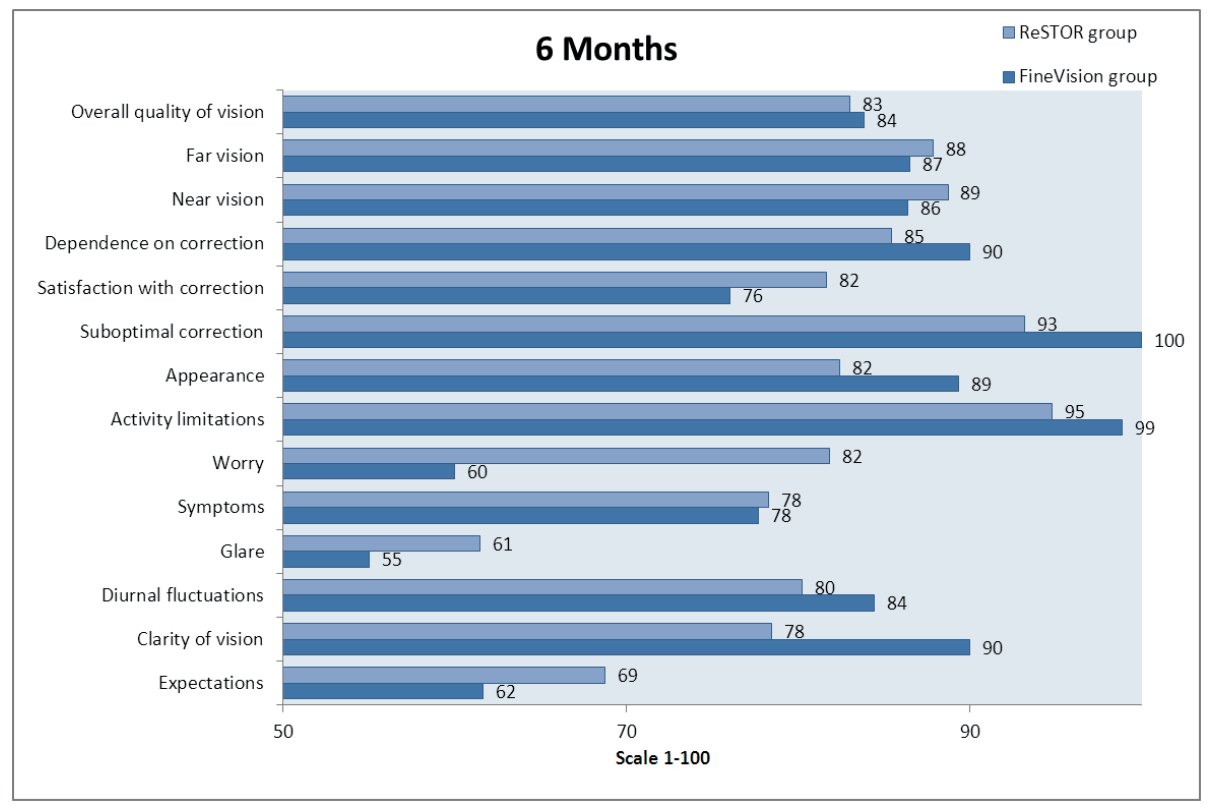

Figure 6. Mean vision-related quality-of-life scores 6 months postoperatively (NEI-RQL 42 questionnaire). A score of 100 refers to the best quality of life. 


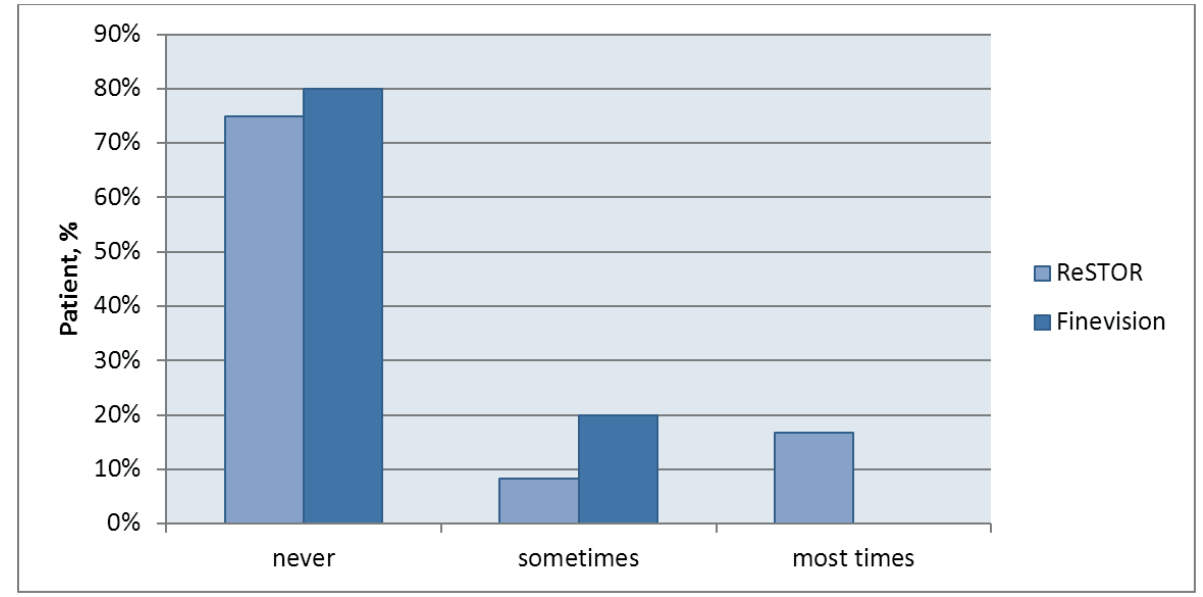

Figure 7. Patient-reported spectacle use 6 months postoperatively. 
Table 1. Baseline measurements.

\begin{tabular}{|c|c|c|c|}
\hline \multirow[b]{2}{*}{ Measurement* } & \multicolumn{2}{|c|}{ Mean \pm SD } & \multirow[b]{2}{*}{ P Value } \\
\hline & Trifocal IOL & Bifocal IOL & \\
\hline Age $(y)$ & $62.6 \pm 8.7$ & $64.0 \pm 8.8$ & .68 \\
\hline \multicolumn{4}{|l|}{ Preoperative data } \\
\hline Spherical equivalent (D) & $0.47 \pm 2.72$ & $0.82 \pm 2.46$ & .90 \\
\hline Astigmatism (D) & $-0.94 \pm 0.48$ & $-0.91 \pm 0.48$ & .80 \\
\hline \multicolumn{4}{|l|}{ Corrected monocular visual acuity (logMAR) } \\
\hline CDVA at $4 \mathrm{~m}$ & $0.06 \pm 0.16$ & $0.04 \pm 0.10$ & .72 \\
\hline DCIVA at $70 \mathrm{~cm}$ & $0.15 \pm 0.18$ & $0.13 \pm 0.12$ & .61 \\
\hline DCNVA at $40 \mathrm{~cm}$ & $0.24 \pm 0.30$ & $0.11 \pm 0.10$ & $.03 \dagger$ \\
\hline DCNVA at PP & $0.21 \pm 0.24$ & $0.08 \pm 0.11$ & $.01 \dagger$ \\
\hline \multicolumn{4}{|l|}{ Pupil size (mm) } \\
\hline Photopic & $5.66 \pm 0.71$ & $5.19 \pm 0.72$ & $.02 \dagger$ \\
\hline Mesopic high & $3.76 \pm 0.70$ & $3.30 \pm 0.48$ & $.01 \dagger$ \\
\hline Mesopic low & $4.75 \pm 1.10$ & $4.40 \pm 0.76$ & .18 \\
\hline \multicolumn{4}{|l|}{ Radner reading test (binocular) $\ddagger$} \\
\hline \multicolumn{4}{|l|}{$70 \%$ contrast } \\
\hline Reading distance (cm) & $39.4 \pm 12.0$ & $41.9 \pm 11.3$ & .64 \\
\hline Mean reading speed (words/min) & $145.3 \pm 32.9$ & $144.6 \pm 38.5$ & .96 \\
\hline Maximum reading speed (words/min) & $176.9 \pm 48.8$ & $196.3 \pm 38.5$ & .32 \\
\hline Reading visual acuity (LogRAD) & $0.19 \pm 0.20$ & $-0.02 \pm 0.27$ & .10 \\
\hline SWRVA & $0.71 \pm 0.26$ & $0.87 \pm 0.23$ & .13 \\
\hline \multicolumn{4}{|l|}{$100 \%$ contrast } \\
\hline Reading distance $(\mathrm{cm})$ & $39.6 \pm 11.9$ & $40.6 \pm 11.8$ & .86 \\
\hline Mean reading speed (words/min) & $141.8 \pm 39.7$ & $168.0 \pm 37.3$ & .12 \\
\hline Maximum reading speed (words/min) & $186.7 \pm 63.8$ & $236.1 \pm 52.4$ & .06 \\
\hline Reading visual acuity (LogRAD) & $0.12 \pm 0.15$ & $0.06 \pm 0.15$ & .36 \\
\hline SWRVA & $0.75 \pm 0.23$ & $0.88 \pm 0.20$ & .15 \\
\hline
\end{tabular}

CDVA = corrected distance visual acuity; DCIVA = distance-corrected intermediate visual acuity; DCNVA = distance-corrected near visual acuity; PP = patient-preferred distance; SWRVA = Snellen visual acuity at critical print size

*Except for Radner reading test data, $n=30$ eyes for trifocal IOL, $n=26$ eyes for bifocal IOL †Statistically significant $(P<.05)$

$\ddagger$ Trifocal $I O L=12$ patients; bifocal $I O L=11$ patients 
Table 2. Postoperative monocular refractive results and visual acuities at 1 month and 6 months.

\section{Postoperative Visit}

1 Month (Mean \pm SD)

\section{Measurement}

Trifocal*

Bifocal†

P Value

Spherical equivalent (D)

$0.08 \pm 0.39$

$0.10 \pm 0.32$

.84

Astigmatism (D)

$-1.02 \pm 0.60$

$-0.67 \pm 0.47$

$.02 \ddagger$

Photopic visual acuity (logMAR)

Uncorrected

$\begin{array}{llll}\text { UDVA at } 4 \mathrm{~m} & 0.12 \pm 0.15 & 0.07 \pm 0.11 & .17 \\ \text { UIVA at } 70 \mathrm{~cm} & 0.20 \pm 0.14 & 0.20 \pm 0.12 & .97 \\ \text { UNVA at } 40 \mathrm{~cm} & 0.21 \pm 0.16 & 0.15 \pm 0.11 & .12 \\ \text { UNVA at PP } & 0.19 \pm 0.16 & 0.13 \pm 0.10 & .11\end{array}$

Distance-corrected

CDVA at $4 \mathrm{~m}$

$-0.01 \pm 0.09$

$-0.04 \pm 0.07$

.16

DCIVA at $70 \mathrm{~cm}$

$0.15 \pm 0.11$

$0.18 \pm 0.13$

.35

DCNVA at $40 \mathrm{~cm}$

$0.13 \pm 0.11$

$0.09 \pm 0.09$

.11

DCNVA at PP

$0.10 \pm 0.13$

$0.11 \pm 0.11$

.78

Mesopic visual acuity (logMAR)

Uncorrected
UIVA at $70 \mathrm{~cm}$
$0.39 \pm 0.15$
$0.32 \pm 0.15$
.14
UNVA at $40 \mathrm{~cm}$
$0.39 \pm 0.20$
$0.34 \pm 0.17$
.27

Distance-corrected

DCIVA at $70 \mathrm{~cm}$

$0.38 \pm 0.13$

$0.31 \pm 0.18$

.08

DCNVA at $40 \mathrm{~cm}$

$0.31 \pm 0.17$

$0.31 \pm 0.13$

.81

CDVA = corrected distance visual acuity; DCIVA = distance-corrected intermediate visual acuity; DCNVA

= distance-corrected near visual acuity; PP = patient-preferred distance; UDVA = uncorrected distance visual acuity; UIVA = uncorrected intermediate visual acuity; UNVA = uncorrected near visual acuity 


\section{Postoperative Visit}

6 Month (Mean \pm SD)

$\begin{array}{ccc}\text { Trifocal* }^{*} & \text { Bifocal } & \text { P Value } \\ 0.03 \pm 0.52 & 0.11 \pm 0.25 & .46 \\ -0.90 \pm 0.61 & -0.66 \pm 0.42 & .11\end{array}$

$0.09 \pm 0.16$
$0.21 \pm 0.18$
$0.25 \pm 0.17$
$0.20 \pm 0.17$

$0.08 \pm 0.11$

.88

$0.17 \pm 0.15$

.46

$0.20 \pm 0.09$

.19

$0.19 \pm 0.10$

.77

$0.01 \pm 0.11$

$0.02 \pm 0.08$

.93

$0.19 \pm 0.15$

$0.18 \pm 0.14$

.89

$0.19 \pm 0.14$

$0.17 \pm 0.08$

.53

$0.14 \pm 0.14$

$0.16 \pm 0.08$

.55

$0.45 \pm 0.14$
$0.48 \pm 0.13$

$0.47 \pm 0.12$

.52

$0.54 \pm 0.13$

.12

$0.45 \pm 0.14$

$0.49 \pm 0.13$

.31

$0.46 \pm 0.12$

$0.52 \pm 0.14$

.08

*Trifocal $=30$ eyes at 1 month and 29 eyes at 6 months

†Bifocal $=26$ eyes at both visits

‡Statistically significant $(P<.05)$ 
Table 3. Postoperative binocular visual acuities at 1 month and 6 months.

Postoperative Visit

1 Month (Mean \pm SD)

\section{Visual Acuity}

Photopic visual acuity (logMAR)

Uncorrected

UDVA at $4 \mathrm{~m}$
UIVA at $70 \mathrm{~cm}$
UNVA at $40 \mathrm{~cm}$
UNVA at PP

Distance-corrected

CDVA at $4 \mathrm{~m}$
DCIVA at $70 \mathrm{~cm}$

DCNVA at $40 \mathrm{~cm}$

DCNVA at PP

Mesopic visual acuity (logMAR)

Uncorrected

$$
\begin{aligned}
& \text { UIVA at } 70 \mathrm{~cm} \\
& \text { UNVA at } 40 \mathrm{~cm}
\end{aligned}
$$$$
0.32 \pm 0.14
$$$$
-0.07 \pm 0.05
$$$$
0.05 \pm 0.11
$$$$
0.03 \pm 0.09
$$$$
0.03 \pm 0.11
$$$$
0.09 \pm 0.10
$$$$
0.11 \pm 0.11
$$$$
0.09 \pm 0.12
$$

Bifocal†

\section{P Value}

stance-corrected

DCIVA at $70 \mathrm{~cm}$
DCNVA at $40 \mathrm{~cm}$

$$
\begin{aligned}
& 0.28 \pm 0.15 \\
& 0.25 \pm 0.14
\end{aligned}
$$

$\begin{array}{cc}-0.02 \pm 0.07 & .26 \\ 0.08 \pm 0.12 & .94 \\ 0.10 \pm 0.08 & .65 \\ 0.07 \pm 0.07 & .63\end{array}$




\section{Postoperative Visit}

6 Month (Mean \pm SD)

Trifocal* $^{*}$

$-0.01 \pm 0.11$

$0.08 \pm 0.15$

$0.15 \pm 0.13$

$0.12 \pm 0.12$

$-0.04 \pm 0.09$

$0.07 \pm 0.11$

$0.08 \pm 0.08$

$0.07 \pm 0.10$

$0.34 \pm 0.14$

$0.36 \pm 0.11$

$0.34 \pm 0.12$

$0.34 \pm 0.13$
Bifocalt

$0.00 \pm 0.09$

.79

$0.04 \pm 0.08$

.33

$0.12 \pm 0.08$

.45

$0.10 \pm 0.08$

.60

$-0.05 \pm 0.06$

.79

$0.00 \pm 0.08$

.08

$0.11 \pm 0.08$

.31

$0.08 \pm 0.06$

.77

$0.36 \pm 0.12$

.75

$0.42 \pm 0.10$

.19

$0.34 \pm 0.12$

.92

$0.41 \pm 0.10$

.11

*Trifocal $=15$ patients at both visits

†Bifocal $=13$ patients at both visits

$\ddagger A$ P value less than 0.05 is statistically significant 


\section{DISCUSSION}

To our knowledge, this is the first study to compare the trifocal aspheric FineVision Micro F IOL (introduced in 2011) with a commonly used bifocal IOL, the ReSTOR IQ +3.O D, in a prospective randomized controlled manner. This trifocal IOL is designed to supply better intermediate visual acuity without impairing near and far vision ${ }^{13}$; however, dividing the light into 3 foci decreases the amount of energy directed to far and near and consequently might affect visual acuity at all distances. ${ }^{22}$ Preliminary studies of the FineVision IOL have shown a mean UDVA ranging from -0.04 to 0.19 logMAR, a mean UIVA ranging from -0.10 to 0.20 logMAR, and a mean UNVA ranging from 0.00 to 0.26 logMAR. ${ }^{23-26}$ Previous reports after implantation with the ReSTOR IOL showed a mean UDVA ranging from 0.00 to 0.45 IogMAR, a mean UIVA ranging from 0.1 to $0.56 \log M A R$, and a mean UNVA ranging from 0.00 to $0.1 \log M A R .{ }^{27-30}$

An experimental study ${ }^{22}$ comparing the FineVision trifocal IOL to the ReSTOR bifocal IOL showed that the image quality at near and far distance was better with the bifocal IOL, whereas the trifocal IOL provided better image quality at intermediate distance. Another available trifocal IOL, the AT Lisa tri 839MP (Carl Zeiss Meditec AG), showed similar results to the FineVision IOL. ${ }^{23-26,31}$

In the present study, the refractive results in both study groups were in accordance with those in previous studies on diffractive bifocal and trifocal IOLs. ${ }^{27,28,30,32}$ The present study did not find any statistically significant difference in postoperative refraction between the 2 groups. For visual acuity, our study did not find any differences between binocular and monocular UDVA and UNVA. Binocular UIVA was 0.3 logMAR without any intergroup difference. Comparing binocular UIVA with monocular UIVA showed better results in the binocular group, illustrating an important role for binocular summation in achieving good visual acuity.

Our results with the FineVision $\mathrm{IOL}$ are similar to those of other clinical studies. Cochener et al. ${ }^{25}$ and Vryghem and Heireman ${ }^{26}$ reported binocular UIVA outcomes $(0.10 \pm 0.15 \log M A R$ and $0.05 \pm 0.08 \log M A R$, respectively), our results showed a binocular UIVA of $0.08 \pm 0.15 \log M A R$. A possible explanation for this slight difference in outcomes is that in our study, visual acuity was assessed with the ETDRS charts (direct representation in logMAR values), whereas Cochener et al. ${ }^{25}$ and Vryghem and Heireman ${ }^{26}$ used Parinaud optotypes with subsequent conversion to $\log$ MAR values. Conversion of Parinaud optotypes to logMAR could lead to better results in the described studies. Our results in the bifocal group were in accordance with studies with similar study populations that assessed visual acuity at comparable distances. ${ }^{5,28}$ Because of variations in the age of study populations, different tests and variable distances used for intermediate visual acuity measurements, a direct comparison of the results in our trifocal group with findings in other studies is not possible. 
The trifocal IOL used in this study is designed to improve depth of focus and thus to provide good visual acuity, not only at far and near distances but also intermediate. Our study results showed photopic pseudoaccommodation (depth of focus) of roughly $-3.5 \mathrm{D}$ to $+1.75 \mathrm{D}$ in the trifocal group and $-3.75 \mathrm{D}$ to $+1.5 \mathrm{D}$ in the bifocal group. Under mesopic circumstances, pseudoaccommodation was roughly -3.5 to $+1.75 \mathrm{D}$ in the trifocal group and -3.75 to $+1.25 \mathrm{D}$ in the bifocal group. Both IOLs performed well at the diopters of defocus representing distance (0.0 D) and near (-2.5 D) visual acuity. The trifocal group had a more continuous performance, with a statistically significantly better performance at $-1.0 \mathrm{D}$ in all lighting conditions than the bifocal group $(P<.01)$. Although performance with the trifocal IOL was better at this point of defocus, no difference was found in binocular UIVA or DCIVA under photopic and mesopic conditions between the bifocal group and the trifocal group. Measurement of intermediate visual acuity took place at $70 \mathrm{~cm}$, similar to $-1.4 \mathrm{D}$ of defocus, a range in which the results in this study showed no statistically significant difference between IOL types. With this knowledge, it can be argued that measuring visual acuity at $1 \mathrm{~m}$ would probably show a substantially better performance with the trifocal IOL.

A decrease in contrast sensitivity is a well-known side effect of diffractive multifocal IOLs. Our results showed statistically significantly better binocular results in the bifocal group for both the AULCSF at $6 \mathrm{cpd}(P=.01)$ and the mean AULCSF $(P=.02)$. In our study, the binocular contrast sensitivity in both groups appeared similar or slightly lower than for the age-related cohort, and similar to previous reports about these IOLs (Figure 5). ${ }^{3-12,23,24}$ Even though use of the AULCSF enables us to compare contrast sensitivity function results with other tests using spatial frequencies (ie, F.A.C.T., Ophtec Vision tester), ${ }^{33,34}$ a substantial number of studies still use other outcome measures, which limits comparability of outcomes. ${ }^{3}$ Under photopic conditions, no statistically significant difference between the 2 groups was measured; however, under mesopic conditions, performance in the bifocal group was statistically significantly better at $6 \mathrm{cpd}(P=.01)$ and in general $(P=.02)$. However, it is unlikely that this is also clinically relevant because the results of the NEI-RQL questionnaire showed that $99 \%$ of trifocal patients and $95 \%$ of bifocal patients were not limited by their visual function during daily activities.

Near visual acuity measurements with standardized charts cannot fully represent the actual performance at near distance. Thus, assessment of the reading performance during real reading tasks was measured in this study. Similar preoperative performances were found in both groups. Postoperatively, there were no statistically significant differences between the groups in reading speed, reading acuity, or critical print size measured at $70 \%$ and $100 \%$ contrast levels. Compared with the results described by Rasp et al.,. ${ }^{35}$ our study found better reading acuity and speed but similar or slightly lower critical print size. A possible explanation is that our study population was younger than that described by Rasp et al. 
Spectacle independence, a desired outcome of cataract surgery with multifocal IOLs, was high and in line with results in previous studies. ${ }^{26,29,36}$ This resulted in a high degree of patient satisfaction in both groups 6 months postoperatively, results that are in accordance with other studies involving the trifocal $1 O L^{23,26}$ and the bifocal $1 O L^{27}$; however, because those studies used different questionnaires, it was not possible to make direct comparisons regarding patient satisfaction or the occurrence of side effects (eg, glare and halos). The questionnaire used in this study imposed several limitations; most important, it did not assess spectacle use or vision at the intermediate distance specifically. However, the secondary results of our study imply high spectacle independence, with $80 \%$ of trifocal patients and $50 \%$ of bifocal patients reporting complete spectacle independence. This suggests a good quality of vision at all distances.

A previous report ${ }^{13}$ suggested that $1.0 \mathrm{~mm}$ of decentration of the trifocal IOL theoretically could shift the energy balance toward far vision, with negative effects for near and intermediate visual acuity. Our study did not confirm those findings; the 1 patient with more than $1.5 \mathrm{~mm}$ of IOL decentration expressed no complaints.

Despite the randomized nature of this study, there were significant preoperative differences between the study groups. One difference was the mean DCNVA at the patient-preferred distance was better in the bifocal group. Another was that pupil size was larger in the trifocal group under photopic and high mesopic conditions. However, a linear regression analysis showed no correlation between preoperative differences and outcomes 3 and 6 months postoperatively. Furthermore, the difference in pupil size is not expected to be clinically relevant because the difference is less than $0.5 \mathrm{~mm}$. Also, the difference in visual acuity at the patient-preferred distance normalized during the follow-up period.

In conclusion, the FineVision Micro F trifocal IOL and the Acrysof ReSTOR IQ +3.O D bifocal $\mathrm{IOL}$ were safe and provided good uncorrected near and far visual acuity, with similar contrast sensitivity function and reading performance. The defocus curves for photopic and mesopic circumstances show similar results, with the trifocal IOL showing more continuous results at all ranges from $-2.5 \mathrm{D}$ to $0.0 \mathrm{D}$ and statistically significantly better visual acuity at $-1.0 \mathrm{D}$. Despite considerably lower intermediate visual acuity measurements (at $70 \mathrm{~cm}$ ) with both IOLs, the patients reported a high overall satisfaction with quality of vision and vision-related quality of life. Complete spectacle independency was higher in the trifocal group than in the bifocal group. 


\section{WHAT WAS KNOWN}

- Diffractive bifocal IOLs improve near and far uncorrected visual acuity, while intermediate visual acuity can be insufficient.

WHAT THIS PAPER ADDS

- The trifocal and bifocal IOLs provided similarly good uncorrected near, far, and intermediate visual acuity.

- Although a trifocal IOL might provide more spectacle independence, patients reported high levels of satisfaction with the bifocal IOL and the trifocal IOL. 


\section{SUPPLEMENTARY TABLES}

Table A. Binocular contrast sensitivity 3 months postoperatively.

\begin{tabular}{|c|c|c|c|c|}
\hline \multirow[b]{2}{*}{$\begin{array}{l}\text { Contrast Sensitivity } \\
\text { (logCSF) }\end{array}$} & \multicolumn{3}{|c|}{ Mean \pm SD } & \multirow[b]{2}{*}{ P Value } \\
\hline & $\begin{array}{l}\text { Age-Related } \\
(50-75 \text { year })\end{array}$ & Trifocal IOL* & Bifocal IOL* & \\
\hline \multicolumn{5}{|l|}{ Photopic $\left(85 \mathrm{~cd} / \mathrm{m}^{2}\right)$} \\
\hline 3 cycles per degree & $1.56 \pm 0.15$ & $1.66 \pm 0.17$ & $1.72 \pm 0.16$ & .34 \\
\hline 6 cycles per degree & $1.80 \pm 0.17$ & $1.71 \pm 0.21$ & $1.77 \pm 0.16$ & .40 \\
\hline 12 cycles per degree & $1.50 \pm 0.15$ & $1.09 \pm 0.32$ & $1.17 \pm 0.27$ & .49 \\
\hline 18 cycles per degree & $0.93 \pm 0.25$ & $0.62 \pm 0.31$ & $0.65 \pm 0.30$ & .76 \\
\hline \multicolumn{5}{|l|}{ Mesopic $\left(3 \mathrm{~cd} / \mathrm{m}^{2}\right)$} \\
\hline 3 cycles per degree & $1.56 \pm 0.15$ & $1.67 \pm 0.18$ & $1.73 \pm 0.13$ & .34 \\
\hline 6 cycles per degree & $1.80 \pm 0.17$ & $1.65 \pm 0.20$ & $1.84 \pm 0.15$ & $.01 \dagger$ \\
\hline 12 cycles per degree & $1.50 \pm 0.15$ & $1.08 \pm 0.30$ & $1.29 \pm 0.22$ & .07 \\
\hline 18 cycles per degree & $0.93 \pm 0.25$ & $0.61 \pm 0.31$ & $0.83 \pm 0.30$ & .08 \\
\hline
\end{tabular}

CSF $=$ contrast sensitivity function

*Trifocal $=13$ patients; bifocal $=12$ patients

†Statistically significant $(P<.05)$

Table B. Binocular reading speed 3 months postoperatively

\begin{tabular}{|c|c|c|c|}
\hline \multirow{2}{*}{$\begin{array}{l}\text { Radner Reading Test Results } \\
\text { at } 3 \text { Months }\end{array}$} & \multicolumn{2}{|c|}{ Mean \pm SD } & \multirow[b]{2}{*}{ P Value } \\
\hline & Trifocal IOL* & Bifocal IOL* & \\
\hline \multicolumn{4}{|l|}{$70 \%$ contrast } \\
\hline Reading distance (cm) & $39.1 \pm 5.39$ & $40.6 \pm 8.78$ & .80 \\
\hline Mean reading speed (words/min) & $152.7 \pm 62.0$ & $141.5 \pm 39.8$ & .59 \\
\hline Maximum reading speed (words/min) & $215.8 \pm 138.5$ & $171.9 \pm 55.7$ & .30 \\
\hline Reading visual acuity (logRAD) & $0.15 \pm 0.08$ & $0.09 \pm 0.14$ & .51 \\
\hline SWRVA & $0.82 \pm 0.19$ & $0.78 \pm 0.17$ & .64 \\
\hline \multicolumn{4}{|l|}{$100 \%$ contrast } \\
\hline Reading distance (cm) & $39.1 \pm 5.39$ & $36.4 \pm 1.64$ & .48 \\
\hline Mean reading speed (words/min) & $170.8 \pm 41.3$ & $154.0 \pm 48.8$ & .35 \\
\hline Maximum reading speed (words/min) & $233.2 \pm 80.9$ & $214.2 \pm 91.2$ & .58 \\
\hline Reading visual acuity (logRAD) & $0.06 \pm 0.10$ & $0.07 \pm 0.07$ & .77 \\
\hline SWRVA & $0.87 \pm 0.17$ & $0.90 \pm 0.14$ & .68 \\
\hline
\end{tabular}




\section{REFERENCES}

1. Nijkamp MD, Dolders MG, de Brabander J, et al. Effectiveness of multifocal intraocular lenses to correct presbyopia after cataract surgery: a randomized controlled trial. Ophthalmology 2004;111(10):18329.

2. Pascolini D, Mariotti SP. Global estimates of visual impairment: 2010. Br J Ophthalmol 2012;96(5):6148.

3. Calladine D, Evans JR, Shah S, Leyland M. Multifocal versus monofocal intraocular lenses after cataract extraction. Cochrane Database Syst Rev 2012(9):Cd003169.

4. Javitt JC, Steinert RF. Cataract extraction with multifocal intraocular lens implantation: a multinational clinical trial evaluating clinical, functional, and quality-of-life outcomes. Ophthalmology 2000;107(11):2040-8.

5. Kohnen T, Allen D, Boureau C, et al. European multicenter study of the AcrySof ReSTOR apodized diffractive intraocular lens. Ophthalmology 2006;113(4):584.e1.

6. Vingolo EM, Grenga P, lacobelli L, Grenga R. Visual acuity and contrast sensitivity: AcrySof ReSTOR apodized diffractive versus AcrySof SA60AT monofocal intraocular lenses. J Cataract Refract Surg 2007;33(7):1244-7.

7. Steinert RF, Aker BL, Trentacost DJ, et al. A prospective comparative study of the AMO ARRAY zonalprogressive multifocal silicone intraocular lens and a monofocal intraocular lens. Ophthalmology 1999;106(7):1243-55.

8. Hunkeler JD, Coffman TM, Paugh J, et al. Characterization of visual phenomena with the Array multifocal intraocular lens. J Cataract Refract Surg 2002;28(7):1195-204.

9. Montés-Micó R, Alió JL. Distance and near contrast sensitivity function after multifocal intraocular lens implantation. J Cataract Refract Surg 2003;29(4):703-11.

10. Alfonso JF, Fernández-Vega L, Baamonde MB, Montés-Micó R. Prospective visual evaluation of apodized diffractive intraocular lenses. J Cataract Refract Surg 2007;33(7):1235-43.

11. Pepose JS, Qazi MA, Davies J, et al. Visual performance of patients with bilateral vs combination Crystalens, ReZoom, and ReSTOR intraocular lens implants. Am J Ophthalmol 2007;144(3):347-57.

12. Montés-Micó R, España E, Bueno I, et al. Visual performance with multifocal intraocular lenses: mesopic contrast sensitivity under distance and near conditions. Ophthalmology 2004;111(1):85-96.

13. Gatinel D, Pagnoulle C, Houbrechts Y, Gobin L. Design and qualification of a diffractive trifocal optical profile for intraocular lenses. J Cataract Refract Surg 2011;37(11):2060-7.

14. Alfonso JF, Fernández-Vega L, Puchades C, Montés-Micó R. Intermediate visual function with different multifocal intraocular lens models. J Cataract Refract Surg 2010;36(5):733-9.

15. Gatinel D, Houbrechts Y. Comparison of bifocal and trifocal diffractive and refractive intraocular lenses using an optical bench. J Cataract Refract Surg 2013;39(7):1093-9.

16. Eppig T, Filser E, Goeppert H, et al. Index of contrast sensitivity (ICS) in pseudophakic eyes with different intraocular lens designs. Acta Ophthalmol 2015;93(3):e181-7.

17. Maaijwee K, Mulder P, Radner W, Van Meurs JC. Reliability testing of the Dutch version of the Radner Reading Charts. Optom Vis Sci 2008;85(5):353-8.

18. Dexl A, Schlögel H, Wolfbauer W, Grabner G. Die Entwicklung einer neuen Methode zur Bestimmung der Leseschärfe - Das "Salzburg Reading Desk (SRD)" - [The development of a new method for the evaluation of reading acuity - The "Salzburg Reading Desk (SRD)"]. Spektrum Augenheilkd 2009;23:435-8. 
19. Hays RD, Mangione CM, Ellwein L, et al. Psychometric properties of the National Eye InstituteRefractive Error Quality of Life instrument. Ophthalmology 2003;110(12):2292-301.

20. Nichols JJ, Mitchell GL, Saracino M, Zadnik K. Reliability and validity of refractive error-specific qualityof-life instruments. Arch Ophthalmol 2003;121(9):1289-96.

21. Nichols JJ, Twa MD, Mitchell GL. Sensitivity of the National Eye Institute Refractive Error Quality of Life instrument to refractive surgery outcomes. J Cataract Refract Surg 2005;31(12):2313-8.

22. Montés-Micó R, Madrid-Costa D, Ruiz-Alcocer J, et al. In vitro optical quality differences between multifocal apodized diffractive intraocular lenses. J Cataract Refract Surg 2013;39(6):928-36.

23. Sheppard AL, Shah S, Bhatt U, et al. Visual outcomes and subjective experience after bilateral implantation of a new diffractive trifocal intraocular lens. J Cataract Refract Surg 2013;39(3):343-9.

24. Alio JL, Montalban R, Pena-Garcia P, et al. Visual outcomes of a trifocal aspheric diffractive intraocular lens with microincision cataract surgery. J Refract Surg 2013;29(11):756-61.

25. Cochener B, Vryghem J, Rozot P, et al. Visual and refractive outcomes after implantation of a fully diffractive trifocal lens. Clin Ophthalmol 2012;6:1421-7.

26. Vryghem JC, Heireman S. Visual performance after the implantation of a new trifocal intraocular lens. Clin Ophthalmol 2013;7:1957-65.

27. Lane SS, Javitt JC, Nethery DA, Waycaster C. Improvements in patient-reported outcomes and visual acuity after bilateral implantation of multifocal intraocular lenses with +3.0 diopter addition: multicenter clinical trial. J Cataract Refract Surg 2010;36(11):1887-96.

28. de Vries NE, Webers CA, Montés-Micó R, et al. Visual outcomes after cataract surgery with implantation of a +3.00 D or +4.00 D aspheric diffractive multifocal intraocular lens: Comparative study. J Cataract Refract Surg 2010;36(8):1316-22.

29. Kohnen T, Nuijts R, Levy P, et al. Visual function after bilateral implantation of apodized diffractive aspheric multifocal intraocular lenses witha +3.0 D addition. J Cataract Refract Surg 2009;35(12):20629.

30. Ang R, Martinez G, Cruz E, et al. Prospective evaluation of visual outcomes with three presbyopiacorrecting intraocular lenses following cataract surgery. Clin Ophthalmol 2013;7:1811-23.

31. Madrid-Costa D, Ruiz-Alcocer J, Ferrer-Blasco T, et al. Optical quality differences between three multifocal intraocular lenses: bifocal low add, bifocal moderate add, and trifocal. J Refract Surg 2013;29(11):749-54.

32. Mojzis P, Pena-Garcia P, Liehneova I, et al. Outcomes of a new diffractive trifocal intraocular lens. J Cataract Refract Surg 2014;40(1):60-9.

33. Hitchcock EM, Dick RB, Krieg EF. Visual contrast sensitivity testing: a comparison of two F.A.C.T. test types. Neurotoxicol Teratol 2004;26(2):271-7.

34. Wachler BS, Krueger RR. Normalized contrast sensitivity values. J Refract Surg 1998;14(4):463-6.

35. Rasp M, Bachernegg A, Seyeddain $O$, et al. Bilateral reading performance of 4 multifocal intraocular lens models and a monofocal intraocular lens under bright lighting conditions. J Cataract Refract Surg 2012;38(11):1950-61.

36. Maxwell WA, Cionni RJ, Lehmann RP, Modi SS. Functional outcomes after bilateral implantation of apodized diffractive aspheric acrylic intraocular lenses with a +3.0 or +4.0 diopter addition power Randomized multicenter clinical study. J Cataract Refract Surg 2009;35(12):2054-61. 


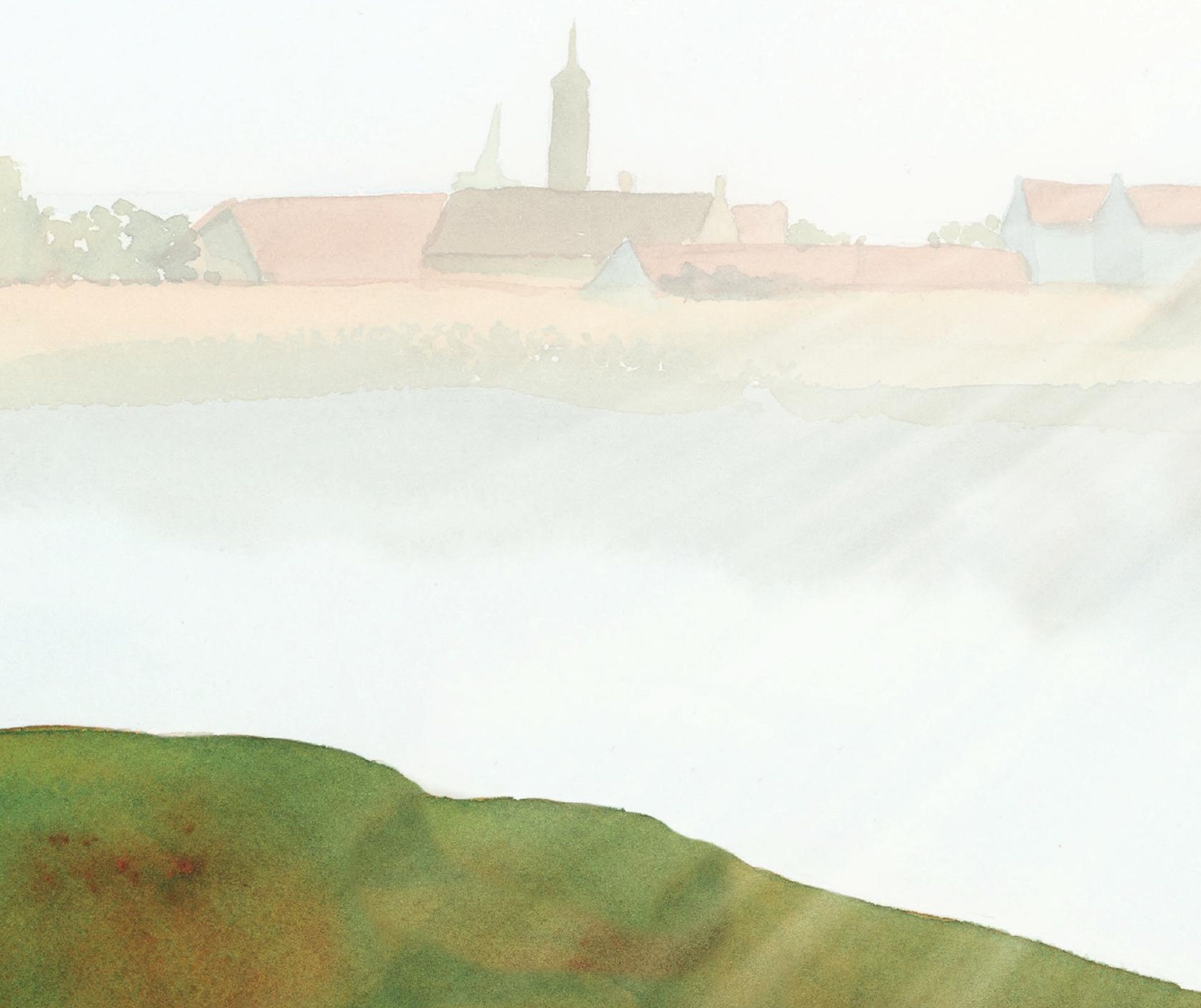




\section{CHAPTER 10}

\section{Discussion}

\section{Published in part as}

Phakic intraocular lenses: An overview.

Soraya MR Jonker, Tos TJM Berendschot, Isabelle EY Saelens,

Noël JC Bauer, Rudy MMA Nuijts

Indian J Ophthalmol. 2020 Dec;68(12):2779-96 


\section{PREFACE}

This thesis provides insights into the safety and efficacy of multifocal (mIOL) and phakic intraocular lens ( $\mathrm{plOL}$ ) implantation used in cataract and (lenticular) refractive surgery to correct refractive error and reduce spectacle dependence. Scientific studies are essential to ensure that these procedures are safe and live up to their promise of increased spectacle independence. 


\section{PHAKIC INTRAOCULAR LENSES}

In the Netherlands, patients who desire pIOL implantation require a thorough ophthalmological examination in order to evaluate whether it is safe to perform surgery. ${ }^{1}$ In addition to approval of morphological parameters (endothelial cell density [ECD], anterior chamber depth [ACD]), it is important to discuss the patients' expectations and the required follow-up schedule to monitor long-term corneal health (chapters 2, 3 and 4). Eczema, allergies or other conditions that might cause the patient to excessively rub their eyes are a relative contraindication for plOL implantation. Continuous rubbing of eyes leads to an intermittent decrease in ACD. ${ }^{2}$ This is thought to significantly increase endothelial cell (EC) loss. ${ }^{3}$

\section{Safety of phakic intraocular lenses}

Safety concerns of pIOL implantation can largely be divided into two main groups: (1) complications associated with high myopia or intraocular surgery in general and (2) chronic side effects related to the presence of the $\mathrm{pIOL}$ in the eye.

(1) Retinal complications like myopic macular degeneration, choroidal neovascularization, and rhegmatogenous retinal detachments occur more frequently in eyes with high myopia (this means a refractive error of $-5 \mathrm{D}$ or $-6 \mathrm{D}$ and stronger, definitions vary in the literature). This can result in a long-term or permanent decrease in visual acuity. ${ }^{4,5}$ As discussed in chapters 5 and $\mathbf{6}$, cataract surgery is associated with an increased incidence of rhegmatogenous retinal detachments. ${ }^{6-9}$ Studies hypothesize that volumetric changes caused by the removal of the crystalline lens result in traction on the retina, causing retinal defects and rhegmatogenous detachments. ${ }^{10}$ plOLs however do not alter the volume behind the lens, explaining why there does not seem to be an increased rate of rhegmatogenous detachments after pIOL implantation (chapters $\mathbf{5}$ and $\mathbf{6}$ ). Other complications contributed to intraocular surgery are a (prolonged) inflammatory response, pigment dispersion and deposition on the $\mathrm{pIOL}$ after implantation, perioperative intraocular hemorrhaging (i.e., during the creation of the peripheral iridectomy) and increased intraocular pressure. Less frequent complications such as plOL luxation might occur due to trauma or insufficient enclavation. ${ }^{11}$

(2) pIOL related complications are reported in multiple papers and include lens luxation, iris atrophy and corneal decompensation, sometimes resulting in complete withdrawal of that pIOL from the market. For example, all anterior chamber angle-supported pIOLs have been withdrawn due to either excessive pressure on the iris root (causing iritis, iris atrophy, uveitis, or correctopia), or due to excessive EC loss (causing corneal decompensation). ${ }^{11,12}$ Older types of posterior chamber pIOLs are associated with cataract formation and sizing differences, and have resulted in $\mathrm{O} O \mathrm{~L}$ withdrawal or $\mathrm{O} O \mathrm{~L}$ design modifications (i.e., creating one or more apertures to improve aqueous humour flow).11,12 One specific posterior chamber plOL was withdrawn 
due to multiple cases where the IOL had luxated into the vitreous, assumed to be the result of damaged zonular fibers caused by excessive friction by the IOL. ${ }^{13}$ Cataract formation is the second common complication related to posterior chamber pIOLs and has been attributed to either pIOL-crystalline lens touch (due to incorrect sizing), or altered aqueous circulation (due to insufficient nutrient distribution). ${ }^{14-16}$ Cataract formation in patients with plOLs can be caused by (A) ageing, (B) crystalline lens damage, or possibly by (C) insufficient aqueous humour circulation. ${ }^{11,14-16}$

(A) With advancing age the crystalline lens becomes sclerotic and loses flexibility, resulting in decreased accommodative capacity and requirement of reading glasses (i.e., presbyopia) (chapter 1). ${ }^{17-19}$ Age-related structural changes in the fibers and proteins of the crystalline lens result in refractive changes, increased light scatter and a decreased lens clarity (i.e., cataract). ${ }^{19}$

(B) Crystalline lens trauma due to forceful irrigation, complicated $\mathrm{pIOL}$ implantation, or intermittent touch of an incorrectly sized posterior chamber plOL have all been described in previous papers. ${ }^{11,14,20}$ Sizing of posterior chamber plOLs is especially difficult because there is no clear correlation between anterior segment measurements and sulcus diameter. Insufficient sizing induces higher risks of excessively small or large vaults, causing crystalline lens touch or angle closure, respectively. Numerous conference meetings and scientific papers report on the optimization of sizing of posterior chamber pIOLs, but further research will hopefully result in finding the 'gold standard' for preoperative sizing. ${ }^{21,22}$

(C) Aqueous humour circulation is responsible for the distribution of nutrients towards the surface of the crystalline lens. ${ }^{19}$ Computer simulations using iris-fixated and posterior chamber pIOLs have shown that altered aqueous humour flow is unlikely to cause cataract formation in iris-fixated plOLs and posterior chamber plOLs with a central hole. ${ }^{15}$ The models in these studies focus on the assessment of shear stress on the surface of the crystalline lens and corneal endothelium. Importantly, they show an increased shear stress on the surface of the crystalline lens in posterior chamber pIOLs with a small vault. ${ }^{15}$ It is currently unclear if daily eye movements (saccades) affect aqueous humour flow and nutrient distribution. New simulations need to be performed in order to assess whether flow is altered and if this might influence cataract formation or EC loss.

Cataract formation and increased EC loss are not limited to specific IOL types, but occur with any type of pIOL (chapter 1). It is important to report cataract, both as a complication of plOL implantation and as a possible cause of myopisation (chapters $\mathbf{5}$ and $\mathbf{6}$ ). Increasing axial length is presented in chapters $\mathbf{5}$ and $\mathbf{6}$ as an alternative hypothesis for myopisation. However, the confirmation of either hypothesis was not possible due to insufficient availability of data on longitudinal changes in axial length in adults. ${ }^{23-25}$ It is hard to confirm an association 
between progressive cataract formation and myopisation based on research since there are no guidelines defining how to describe the rate and progression of cataract formation in patients with pIOLs. Three options can be identified to gather information on cataract formation in a study population.

(I) Cataract formation results in altered refraction and visual acuity, and standardization of refractive and visual results are applied by a number of journals. The arrival of standardized six- and nine graphs has resulted in standardized outcome measures in the vast majority of newly published papers on refractive surgery. ${ }^{26,27}$ Via these criteria it can be computed how many eyes show a significant decrease in visual acuity or change in refractive error. To conclude if these changes are indeed related to cataract formation, ophthalmologists are dependent on the authors to provide an adequate and sufficient explanation of the cause of these changes.

(II) Structural evaluation of cataract formation using grading tools requires the investigator to visually quantify the amount of cataract. Unfortunately this divides patients into categories rather than assigning a numerical value that can be used to assess cataract progression (i.e., for the categories two versus four, the amount of cataract does not increase two-fold in the second category). ${ }^{28-33}$ Although some Scheimpflug and optical coherence tomography devices can objectively measure lens characteristics, this is not fully automated yet and further studies are needed to optimize clinical use..$^{34,35}$

(III) Chapters 5, 6 and $\mathbf{7}$ report the rate of cataract formation and apply survival analyses to provide an estimate as to how long it will take until a certain percentage of plOLs is explanted due to cataract formation, and report potential risk factors for a shorter survival. Survival analyses provide a definitive cut-off measure, working with a binary outcome measure (explantation yes/no). However, they do not provide insights into the progression of cataract formation and implementation is difficult in studies reporting short-term follow-up or small numbers of patients. For future reference, long-term studies with large numbers of patients are the preferred option, reporting refractive changes and their causes, as well as survival analyses and the total number of explantations due to cataract formation. Survival analyses should be attempted in small studies, but they should always be supplemented with the mean time and total number of explantations in order to provide sufficient standardization over time.

Endothelial cell loss is the second most common complication related to $\mathrm{plOL}$ implantation. Three hypotheses exist, attributing EC loss to either (i) the proximity of the plOL to the corneal endothelium, (ii) the plOL-related change in aqueous humour flow, or (iii) the chronic subclinical inflammatory response to the $\mathrm{pIOL}$ (chapters 3, 4 and 7). 
(i) A shorter distance between the anterior chamber $\mathrm{PIOL}$ and the corneal endothelium is associated with an increased EC loss (chapters 2, $\mathbf{3}$ and 7). Posterior chamber pIOLs are designed to be positioned further away from the endothelium and are therefore assumed to cause less EC loss. This theory cannot be definitely confirmed due to incomplete or absent reporting on EC loss in recent research on posterior chamber pIOLs (chapter 1). Chapter 4 casts additional doubt upon this theory, because it does not identify a smaller preoperative anterior chamber depth as a significant risk-factor for EC loss in eyes with foldable iris-fixated pIOLs. Adequately designed studies are needed to prove the validity of this hypothesis and assess if there is additional benefit to posterior chamber plOLs regarding EC loss.

(ii) Alterations in aqueous humour flow have been assessed in iris-fixated and posterior chamber plOLs using computer simulation, and have shown a significant change in aqueous humour flow that is unlikely to result in increased EC loss. As mentioned previously, none of these studies have implemented the daily movements (saccades) of the eye in their estimations. ${ }^{15}$ New simulations are required to assess whether these movements result in significant changes in aqueous humour flow that could explain EC loss, and to assess whether design changes are required in plOLs currently available for implantation.

(iii) Research regarding the possibility of subclinical inflammation has been met with technical difficulties in the past. ${ }^{36}$ Few methods are available to assess minimal inflammation - for example, in eyes not presenting with either cell, flare or the Tyndall Effect during slit lamp evaluation. Laser Flare Meters have been used in the past to assess inflammation, and the first study using a Laser Flare Cell Meter to assess inflammation in patients with a $\mathrm{plOL}$ was published in the early nineties. ${ }^{37}$ Studies that were performed in the years following showed increased flare in eyes with angle-supported and iris-fixated pIOLs, as compared to healthy patients without these lenses, and showed highly variable inflammation in eyes with iris-fixated p IOLs. ${ }^{38}$ However, high inter- and intra-observer variability, low repeatability, and the time-consuming nature of these measurements have prohibited the implementation of the Laser Flare Cell Meter in clinical practice.

Recently, new molecular techniques have been developed that can detect even small amounts of (inflammatory) cytokines from aqueous humour and tears and subsequently compute a specific "cytokine profile". This profile can provide information about the stage of inflammation and the progression of disease, as has been shown in patients with other ocular diseases associated with inflammation, such as keratoconus and bullous keratopathy. ${ }^{39,40}$ In order to reliably test the inflammatory response in patients with iris-fixated plOLs, the University Eye Clinic Maastricht is currently studying the aqueous and tear fluid cytokine profile in patients with iris-fixated plOLs undergoing cataract surgery. We will investigate 
a correlation between cytokine biomarkers in aqueous humour and in tears. In case inflammation is confirmed as the source of EC loss, additional research might focus on modifying the polymer composition of intraocular materials to decrease the inflammation profile and optimizing postoperative treatment.

Regardless of the cause of EC loss, EC monitoring is essential whenever a pIOL is implanted. In 2006, the AFSSAPS published a guideline reporting an ECD of 1500 cells $/ \mathrm{mm}^{2}$ or less as a reason for pIOL explantation, after the Vivarte angle-supported pIOL had to be taken of the market. ${ }^{41}$ After consulting with large numbers of specialists from the field, the AAO published a second, more extensive guideline in 2018. ${ }^{42}$ It describes the importance of correct ECD measurements and provides specific endpoints when reporting ECD (i.e., the proportion of eyes with $\geq 25 \%$ EC loss after 3 years). In addition, it also refers to clause D.4.2 of the ANSI standard Z80.13 Phakic Intraocular Lenses standard for recommendations on how to perform ECD measurements. In addition, studies should report the mean of three acceptable measurements of the central cornea, identifying at least 100 cells per frame, and use the center-to-center method with the same non-contact specular microscope throughout the study. ${ }^{42}$ Identifying 100 cells per image can be challenging: non-contact specular microscopes are capable of capturing 120 to 170 cells per image, depending on ECD and the quality of the image. Contact specular microscopes on the other hand can capture 700 to 3000 cells per image, depending on the skill of the technician. ${ }^{43}$ Contact specular microscopy however is time-consuming and invasive, as well as a skill that requires a certain level of training and upkeep, making it more difficult to implement in a busy practice. Another option to increase the number of analyzed cells is to use the corner method instead of the center-to centermethod. ${ }^{44} \mathrm{~A} 2010$ study confirmed that the corner method is likely to benefit representation of ECD and morphological characteristics in transplanted corneas, but did not find clinically relevant differences between these measurement methods in healthy corneas. ${ }^{44}$ The corner method takes up significantly more time in the clinic and probably only has additional value in studies on transplanted or diseased corneal endothelium, or in studies focusing on morphometric data. Selection of 100 contiguous cells in a non-contact specular microscopic image is challenging, even in healthy corneas. For this reason, most studies reporting ECD data select 50 contiguous cells and report the mean of three ECD measurements to provide reliable results. The ANSI standard might press researchers to select cells that would not qualify as clearly identifiable, possibly resulting in misrepresentation of ECD and EC morphology. It is important to acknowledge that neither the AFSSAPS, nor the AAO criteria present the researcher with cut-off values as to what proportion of eyes is considered 'safe' at a predefined time point. ${ }^{41,42}$ Chapters 3 and $\mathbf{4}$ report data on these outcomes after different follow-up periods and highlight the importance of restructured implantation criteria. The observed rates of EC loss in chapters $\mathbf{3}$ and $\mathbf{4}$ clearly indicate the need for higher preoperative ECD in each age group, in order to provide a safe number of $\geq 1500$ cells $/ \mathrm{mm}^{2}$, when cataract 
surgery becomes necessary. Additional risk-factors for increased EC loss differed between chapters $\mathbf{3}$ and $\mathbf{4}$, prompting the need for research on different intraocular materials (i.e., differences in intraocular inflammation) as a cause for increased EC loss.

\section{Efficacy of phakic intraocular lenses}

Chapter 1 shows that pIOL implantation yields excellent visual and refractive results. An analysis of the preoperative characteristics of patients implanted with plOLs identify (high) myopia as the main reason for surgery, followed by (high) astigmatism or (high) hyperopia. Preoperative spectacle independence with these high refractive errors is limited, whereas the small postoperative refractive error and good uncorrected visual acuity would suggest spectacle independence in the majority of patients (chapter 1). Multiple studies assessing patient satisfaction, spectacle independence and occurrence of bothersome side-effects have indeed reported excellent outcomes, and few bothersome side effects after implantation with different types of plOLs. ${ }^{45,46}$ Several questionnaires are available for the evaluation of refractive errors, with three questionnaires (i.e., Quality of Life Impact of Refractive Correction [QIRC], Quality of Vision [QoV], Near Activity Visual Questionnaire [NAVQ]) showing slightly superior results in the assessment of refractive surgery. ${ }^{47}$

Decreased visual acuity over time has been reported with plOLs, and can be attributed to refractive changes or occurrence of complications. Chapters 5 and $\mathbf{6}$ report significant changes in refractive error over time in a mainly myopic population. Age-related changes of the crystalline lens (i.e., myopisation due to cataract formation) did not entirely account for these changes. Subgroup analyses imply a significant increase in axial length over time in a highly myopic - but small - patient population. Increasing axial length is known to occur in the growing, adolescent eye, but is assumed to stop at around the age of 21 . These hypotheses are based on older epidemiological studies that have used cross-sectional analyses to report axial length, resulting in data implying a decrease in axial length with age. ${ }^{23-25}$ The data presented in chapters $\mathbf{5}$ and $\mathbf{6}$ suggest that axial length keeps increasing after reaching adulthood. New studies are necessary to determine if this is indeed the case, and if so, if it only occurs in (high) myopes. Until then, surgeons implanting pIOLs in highly myopic patients should inform their patients of the possibility that their refractive error might change slightly over time. 


\section{MULTIFOCAL INTRAOCULAR LENSES}

\section{Cataract surgery}

Cataract surgery is a routinely performed procedure, and is rarely associated with complications. Nevertheless, complications that can occur include posterior capsular rupture, vitreous loss, dropped nucleus and cystoid macular edema. Certain patient groups are at higher risk of these complications due to a needle track after intravitreal injection, mature cataract, zonular weakness, or previous retinal disease such as diabetic retinopathy. ${ }^{19}$ Intraocular lenses designed to correct presbyopia (multifocal or extended depth of focus [EDOF]) have additional, IOLspecific, side-effects such as glare, halo's and decreased contrast sensitivity. These can affect postoperative satisfaction (chapters $\mathbf{8}$ and $\mathbf{9}$ ). ${ }^{19,48-51}$

\section{Safety of multifocal intraocular lenses}

The light dispersing qualities of mIOLs (i.e., bifocal, trifocal, quadrifocal) and EDOF IOLs require a strict preoperative screening to optimize results. In order to generate multiple focal points, modern mIOLs use diffraction, but older IOLs used different powered annual zones (refraction) in the optic plane to get this result. To guarantee satisfactory results, patients need optimal clarity of other refracting media, an optimal central and stable positioning of the $\mathrm{IOL}$, and optimal processing of images (i.e., retina free of disease, no neurological disease). ${ }^{19,48-}$ 50, 52 The patient selection process should be supplemented with an assessment of the needs and expectations of the patient. Even an anatomically perfect result will inevitably result in a reduction of contrast (more so with diffractive $\mathrm{mIOLs}$ ), create fixed reading distances, and might also induce dysphotopsias like glare and halos (more so with refractive $\mathrm{mIOLs}$ ). ${ }^{48,50,52,53}$ Some patients never get used to these side-effects and will require more attention, either by additional consultations or additional surgery. ${ }^{49}$ In order to achieve high patient satisfaction, the general consensus is that the preoperative consultation should be conducted with one underlying thought in mind: 'under promise and over deliver'. 48,54

The ideal patient wants to be less spectacle dependent but will not mind using extra light when reading in a low contrast environment and accepts the possibility of glare and halos at night. The increased risk of seeing glare and halos with dilated pupils means that patients that are night-time drivers (taxi or lorry drivers), should be discouraged from multifocal or EDOF IOL implantation. A second group that should be excluded from implantation are patients that require excellent contrast function in order to perform their work (watchmakers, jewelers). Hyperopic or highly myopic patients are generally considered best suited for multifocal or EDOF IOL implantation. ${ }^{48}$ The reason for this is because when one considers the necessary preoperative spectacle dependence in these particular patient groups, the achievement of postoperative spectacle independence means that they are far more likely to tolerate IOL-related side-effects. Deciding if a patient has the lifestyle and temperament suited for multifocal or EDOF IOLs depends on 


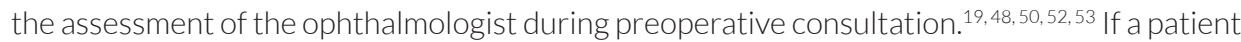
requires cataract surgery as a refractive procedure in the absence of cataract (refractive lens exchange [RLE]), a multifocal contact lens trial can be performed in order to test if the patient will accept this type of multifocal refractive solution. Additionally, a patient can be shown images of the glare, halos and visual acuity that can be experienced with a multifocal or EDOF IOL.

No consensus exists as to how questionnaires can be used to evaluate side-effects of multifocal and EDOF IOLs. Standardized questionnaires including pictures to illustrate the visual sideeffects (glare and halos), seem to fit these requirements best. Ideally, the level of spectacle independence and decreased contrast sensitivity as experienced by the patient should also be assessed in these questionnaires. Questionnaires should be easy to fill in by patients on their own, shouldn't be too lengthy, but on the other hand should contain enough questions to ensure internal validation. After validation, the questionnaire needs to be translated into different languages and validated again for use after translation. ${ }^{47,55-57}$

Contrast sensitivity testing consists of both subjective tests like questionnaires, and objective tests using charts with different levels of contrast. Two objective measurement methods have been described in this thesis. The first is the regularly used CSV-1000 chart applying the principle of recognition of spatially organized grey and white striped patterns with decreasing contrast. It is a straightforward technique and can be used with halo simulation and with glasses simulating contrast sensitivity in a dimly lit room. ${ }^{58} \mathrm{~A}$ second, less frequently used measurement is the Radner reading desk, designed to test reading speed at different distances and with different font sizes. Various modules enable to also assess reading at different levels of contrast. However, these measurements are time-consuming and require optimal patient cooperation and regular upkeep of the device and the technicians' skills.59-61 Multifocal or EDOF IOL implantation is known to change contrast sensitivity, and the need for reliable contrast sensitivity testing has been emphasized in previous papers. ${ }^{57,62,63}$ The need for standardized reporting is highlighted by the large variety of tests used to assess contrast sensitivity, making it difficult to compare their results.

In 2017, the AAO published a consensus statement for clinical studies on EDOF IOLs that provides clear instructions on the ideal environment for testing vision, defocus curve, and contrast sensitivity. ${ }^{64}$ It includes the type of contrast sensitivity that should be applied, lighting conditions and glare simulation, and shows a preference for digitized charts because of the possibility of randomization. ${ }^{51,64} \mathrm{New}$ developments in contrast sensitivity testing include computerized tests that use efficient adaptive measurements to test contrast sensitivity at a wider range of stimuli. ${ }^{63}$ To avoid the difficulties of comparing outcomes of studies, due to the variability between testing methods, standardization in reporting of quality of vision after $\mathrm{mIOL}$ implantation should be implemented by the relevant stakeholders in the field. 


\section{Efficacy of multifocal intraocular lenses}

Chapters 1,8 and $\mathbf{9}$ illustrated excellent visual and refractive outcomes after $\mathrm{mlOL}$ implantation. The large variety of IOLs means a personalized treatment can be applied to the patients' needs. The reported differences in intermediate and near visual acuity between bifocal, trifocal and quadrifocal IOLs are inherent to their optical design. Trifocal and quadrifocal IOLs show better results at an intermediate distance in comparison to bifocal IOLs, whereas mIOLs show better near vision when compared to EDOF lenses (chapter 1). Mini-monovision can be considered in order to acquire good visual acuity at intermediate distance by using two bifocal IOLs with different additions for near (chapter 8), while optimizing visual acuity at near distance can be obtained by using mini-monovision with two EDOF lenses with different power. ${ }^{50,65,66}$ With similar reports on glare and halos, as well as similar costs for bifocal, trifocal, quadrifocal and EDOF lenses in Europe, trifocal or quadrifocal IOLs are currently the most implanted types of $\mathrm{mIOL}$.

Efficacy-testing after mIOL implantation is generally composed of four objective tests: (1) residual refractive error, (2) visual acuity at far, intermediate and near distance, (3) a defocus curve that simulates visual acuity at different distances, and (4) contrast-sensitivity at standardized spatial frequencies. ${ }^{51,64,67,68}$ Manufacturers launching a new multifocal or EDOF $\mathrm{IOL}$ are required to include the abovementioned outcomes in their initial studies, as defined in the ANSI standards Z80.12 (on multifocal IOLs) and Z80.35 (on EDOF IOLs). ${ }^{51,64}$ In spite of these criteria, chapter $1 \mathrm{still}$ showed a lot of variation in outcome measures, including variation in reading distances, monocular versus binocular results, and charts (i.e., visual acuity, contrast sensitivity) reported in previous studies. Ophthalmological societies and medical journals should be in the lead to determine a standardized set of outcomes reported in medical journals, similar to the six- and nine-graphs, as reported previously. ${ }^{26,27,57,62,67}$ These new guidelines can be combined with a 2019 paper instructing researchers on how to perform visual acuity and defocus curve measurements. ${ }^{69}$ Results should include uncorrected monocular and binocular vision, as well as distance corrected far, intermediate and near visual acuity, presented in logMAR, using standardized charts such as the Early Treatment Diabetic Retinopathy (ETDRS) chart. Residual manifest refractive spherical equivalent, proportion of patients with monocular and binocular uncorrected 20/40 and 20/20 vision at far, intermediate and near distance, and spectacle-independence should be included in these standardized reports. Vector analyses according to Alpins should be performed in studies describing multifocal toric or EDOF toric IOLs. Defocus curves should be reported in logMAR, and can be monocular, binocular or both. Monocular - best distance corrected - defocus curves are used to prove the benefit of multifocal and EDOF IOLs versus monofocal IOLs at intermediate and near distance. Binocular defocus curves can represent the effect during day-to-day work, and can have an added benefit if they are performed without refractive correction in patients with (mini)monovision. 
Contrast sensitivity and patient reported outcome measures (PROMs) will in the future become more important when selecting an $\mathrm{IOL}$, because of the large number of multifocal and EDOF IOLs with good visual and refractive outcomes..$^{70}$ In an ideal situation one contrast sensitivity test and one questionnaire are selected in standardized reports. However, the possible investments required in computer-based contrast sensitivity testing, and the lack of reliable questionnaires might make it difficult for clinicians to adhere to these criteria. ${ }^{47,63}$ Future research should be focused on developing reliable tests for PROMs, describing patient satisfaction, spectacle independence, glare, and halos. ${ }^{64,70}$ The QIRC, QoV, and NAVQ questionnaires show good results in the assessment of refractive surgery, and can serve as a starting point for questionnaires ${ }^{47}$ : the AAO is currently working together with the industry to develop a reliable and relevant test for PROMs in patients with multifocal and EDOF IOLs. ${ }^{71}$ 


\section{REFERENCES}

1. Aalders-Deenstra V, Bartels M, Beerthuizen J, et al. Consensus Refractie Chirurgie. 4 ed: Nederlands Gezelschap voor Refractie Chirurgie (NGRC), 2018.

2. Henriquez MA, Cerrate M, Hadid MG, et al. Comparison of eye-rubbing effect in keratoconic eyes and healthy eyes using Scheimpflug analysis and a dynamic bidirectional applanation device. Journal of Cataract \& Refractive Surgery 2019;45(8):1156-62.

3. Guell JL, Morral M, Gris O, et al. Five-year follow-up of 399 phakic Artisan-Verisyse implantation for myopia, hyperopia, and/or astigmatism. Ophthalmology 2008;115(6):1002-12.

4. Holden BA, Fricke TR, Wilson DA, et al. Global Prevalence of Myopia and High Myopia and Temporal Trends from 2000 through 2050. Ophthalmology 2016;123(5):1036-42.

5. McCannel CA, Atebara NH, Kim SJ, et al. Retina and Vitreous. United States of America: American Academy of Ophthalmology, 2017.

6. Tuft SJ, Minassian D, Sullivan P. Risk factors for retinal detachment after cataract surgery: a casecontrol study. Ophthalmology 2006;113(4):650-6.

7. Bhagwandien AC, Cheng YY, Wolfs RC, et al. Relationship between retinal detachment and biometry in 4262 cataractous eyes. Ophthalmology 2006;113(4):643-9.

8. Mitry D, Charteris DG, Fleck BW, et al. The epidemiology of rhegmatogenous retinal detachment: geographical variation and clinical associations. Br J Ophthalmol 2010;94(6):678-84.

9. Russell M, Gaskin B, Russell D, Polkinghorne PJ. Pseudophakic retinal detachment after phacoemulsification cataract surgery: Ten-year retrospective review. J Cataract Refract Surg 2006;32(3):442-5.

10. Bjerrum SS, Mikkelsen KL, La Cour M. Risk of pseudophakic retinal detachment in 202,226 patients using the fellow nonoperated eye as reference. Ophthalmology 2013;120(12):2573-9.

11. Kohnen T, Kook D, Morral M, Guell JL. Phakic intraocular lenses: part 2: results and complications. J Cataract Refract Surg 2010;36(12):2168-94.

12. Guell JL, Morral M, Kook D, Kohnen T. Phakic intraocular lenses part 1: historical overview, current models, selection criteria, and surgical techniques. J Cataract Refract Surg 2010;36(11):1976-93.

13. Perez-Cambrodi RJ, Pinero DP, Ferrer-Blasco T, et al. The posterior chamber phakic refractive lens (PRL): a review. Eye (Lond) 2013;27(1):14-21.

14. Guber I, Mouvet V, Bergin C, et al. Clinical Outcomes and Cataract Formation Rates in Eyes 10 Years After Posterior Phakic Lens Implantation for Myopia. JAMA Ophthalmol 2016.

15. Fernandez-Vigo JI, Marcos AC, Agujetas R, et al. Computational simulation of aqueous humour dynamics in the presence of a posterior-chamber versus iris-fixed phakic intraocular lens. PLoS One 2018;13(8):e0202128.

16. Schmidinger G, Lackner B, Pieh S, Skorpik C. Long-term changes in posterior chamber phakic intraocular collamer lens vaulting in myopic patients. Ophthalmology 2010;117(8):1506-11.

17. Remington LA. Clinical Anatomy and Physiology of the Visual System. St. Louis, Missouri, United States of America: Elsevier Butterworth Heinemann, 2012.

18. Azar DT, Azar NF, Brodie SE, et al. Clinical Optics. United States of America: American Academy of Ophthalmology, 2017.

19. Jick SL, Beardsley TL, Brasington CR, et al. Lens and Cataract. United States of America: American Academy of Ophthalmology, 2018. 
20. Steinwender G, Varna-Tigka K, Shajari M, Kohnen T. Anterior subcapsular cataract caused by forceful irrigation during implantation of a posterior chamber phakic intraocular lens with a central hole. J Cataract Refract Surg 2017;43(7):969-74.

21. Gonzalez-Lopez F, Mompean B, Bilbao-Calabuig R, et al. Dynamic Assessment of Light-Induced Vaulting Changes of Implantable Collamer Lens With Central Port by Swept-Source OCT: Pilot Study. TransI Vis Sci Technol 2018;7(3):4.

22. Lee H, Kang DSY, Choi JY, et al. Analysis of pre-operative factors affecting range of optimal vaulting after implantation of 12.6-mm V4c implantable collamer lens in myopic eyes. BMC Ophthalmol 2018;18(1):163.

23. Atchison DA, Markwell EL, Kasthurirangan S, et al. Age-related changes in optical and biometric characteristics of emmetropic eyes. J Vis 2008;8(4):29.1-0.

24. Gudmundsdottir E, Arnarsson A, Jonasson F. Five-year refractive changes in an adult population: Reykjavik Eye Study. Ophthalmology 2005;112(4):672-7.

25. McBrien NA, Adams DW. A longitudinal investigation of adult-onset and adult-progression of myopia in an occupational group. Refractive and biometric findings. Invest Ophthalmol Vis Sci 1997;38(2):32133.

26. Reinstein DZ, Archer TJ, Randleman JB. JRS standard for reporting astigmatism outcomes of refractive surgery. J Refract Surg 2014;30(10):654-9.

27. Dupps WJ, Jr., Kohnen T, Mamalis N, et al. Standardized graphs and terms for refractive surgery results. J Cataract Refract Surg 2011;37(1):1-3.

28. Chylack LT, Jr., Leske MC, Sperduto R, et al. Lens Opacities Classification System. Arch Ophthalmol 1988;106(3):330-4.

29. Chylack LT, Jr., Leske MC, McCarthy D, et al. Lens opacities classification system II (LOCS II). Arch Ophthalmol 1989;107(7):991-7.

30. Chylack LT, Jr., Wolfe JK, Singer DM, et al. The Lens Opacities Classification System III. The Longitudinal Study of Cataract Study Group. Arch Ophthalmol 1993;111(6):831-6.

31. Hall AB, Thompson JR, Deane JS, Rosenthal AR. LOCS III versus the Oxford Clinical Cataract Classification and Grading System for the assessment of nuclear, cortical and posterior subcapsular cataract. Ophthalmic Epidemiol 1997;4(4):179-94.

32. Sparrow JM, Bron AJ, Brown NA, et al. The Oxford Clinical Cataract Classification and Grading System. Int Ophthalmol 1986;9(4):207-25.

33. Chylack LT, Jr., Wolfe JK, Friend J, et al. Quantitating cataract and nuclear brunescence, the Harvard and LOCS systems. Optom Vis Sci 1993;70(11):886-95.

34. Makhotkina NY, Berendschot T, van den Biggelaar F, et al. Comparability of subjective and objective measurements of nuclear density in cataract patients. Acta Ophthalmol 2018;96(4):356-63.

35. Chen D, Li Z, Huang J, et al. Lens nuclear opacity quantitation with long-range swept-source optical coherence tomography: correlation to LOCS III and a Scheimpflug imaging-based grading system. Br J Ophthalmol 2018.

36. Tahzib NG, Eggink FA, Frederik PM, Nuijts RM. Recurrent intraocular inflammation after implantation of the Artiflex phakic intraocular lens for the correction of high myopia. J Cataract Refract Surg 2006;32(8):1388-91.

37. Alio JL, Hoz Fde L, Ismail MM. Subclinical inflammatory reaction induced by phakic anterior chamber lenses for the correction of high myopia. Ocul Immunol Inflamm 1993;1(3):219-24.

38. Perez-Santonja JJ, Iradier MT, Benitez del Castillo JM, et al. Chronic subclinical inflammation in phakic eyes with intraocular lenses to correct myopia. J Cataract Refract Surg 1996;22(2):183-7. 
39. Yagi-Yaguchi Y, Yamaguchi T, Higa K, et al. Association between corneal endothelial cell densities and elevated cytokine levels in the aqueous humor. Sci Rep 2017;7(1):13603.

40. Nishtala K, Pahuja N, Shetty R, et al. Tear biomarkers for keratoconus. Eye Vis (Lond) 2016;3:19.

41. Bernard P, Fournier M. Definitive stop of marketing, product recall and follow-up of implanted patients. Presbyopic intraocular lenses NEWLIFENIVARTE PRESBYOPIC. Agence Française de Sécurité Sanitaire des Produits de Santé (AFSSAPS), 2007; v. 2016.

42. MacRae S, Holladay JT, Hilmantel G, et al. Special Report: American Academy of Ophthalmology Task Force Recommendations for Specular Microscopy for Phakic Intraocular Lenses. Ophthalmology 2017;124(1):141-2.

43. McCarey BE, Edelhauser HF, Lynn MJ. Review of corneal endothelial specular microscopy for FDA clinical trials of refractive procedures, surgical devices, and new intraocular drugs and solutions. Cornea 2008;27(1):1-16.

44. Patel SV, McLaren JW, Bachman LA, Bourne WM. Comparison of flex-center, center, and corner methods of corneal endothelial cell analysis. Cornea 2010;29(9):1042-7.

45. Tahzib NG, Bootsma SJ, Eggink FA, Nuijts RM. Functional outcome and patient satisfaction after Artisan phakic intraocular lens implantation for the correction of myopia. Am J Ophthalmol 2006;142(1):31-9.

46. Ieong A, Hau SC, Rubin GS, Allan BD. Quality of life in high myopia before and after implantable Collamer lens implantation. Ophthalmology 2010;117(12):2295-300.

47. Kandel H, Khadka J, Lundstrom M, et al. Questionnaires for Measuring Refractive Surgery Outcomes. J Refract Surg 2017;33(6):416-24.

48. Braga-Mele R, Chang D, Dewey S, et al. Multifocal intraocular lenses: relative indications and contraindications for implantation. J Cataract Refract Surg 2014;40(2):313-22.

49. de Vries NE, Webers CA, Touwslager WR, et al. Dissatisfaction after implantation of multifocal intraocular lenses. J Cataract Refract Surg 2011;37(5):859-65.

50. Rampat R, Gatinel D. Multifocal and Extended Depth-of-Focus Intraocular Lenses in 2020. Ophthalmology 2020.

51. Kohnen T, Suryakumar R. Extended depth-of-focus technology in intraocular lenses. J Cataract Refract Surg 2020;46(2):298-304.

52. Alio JL, Plaza-Puche AB, Férnandez-Buenaga R, et al. Multifocal intraocular lenses: An overview. Surv Ophthalmol 2017;62(5):611-34.

53. de Vries NE, Nuijts RM. Multifocal intraocular lenses in cataract surgery: literature review of benefits and side effects. J Cataract Refract Surg 2013;39(2):268-78.

54. Jonker SMR, Tahzib NG, Nuijts RMMA. Predicting the Unhappy Patient and Patient Expectations. In: Alio JL, Azar DT, eds. Management of Complications in Refractive Surgery. Verlag Berlin Heidelberg: Springer, 2018.

55. Kandel H, Khadka J, Goggin M, Pesudovs K. Patient-reported Outcomes for Assessment of Quality of Life in Refractive Error: A Systematic Review. Optom Vis Sci 2017;94(12):1102-19.

56. Nichols JJ, Mitchell GL, Saracino M, Zadnik K. Reliability and validity of refractive error-specific qualityof-life instruments. Arch Ophthalmol 2003;121(9):1289-96.

57. de Silva SR, Evans JR, Kirthi V, et al. Multifocal versus monofocal intraocular lenses after cataract extraction. Cochrane Database Syst Rev 2016;12:Cd003169.

58. Kelly SA, Pang Y, Klemencic S. Reliability of the CSV-1000 in adults and children. Optom Vis Sci 2012;89(8):1172-81.

59. Dexl AK, Schlogel H, Wolfbauer M, Grabner G. Device for improving quantification of reading acuity and reading speed. J Refract Surg 2010;26(9):682-8. 
60. Maaijwee K, Mulder P, Radner W, Van Meurs JC. Reliability testing of the Dutch version of the Radner Reading Charts. Optom Vis Sci 2008;85(5):353-8.

61. Mansfield JS, Legge GE. To the editor: Reliability testing of the Dutch version of the Radner Reading Charts. Optom Vis Sci 2008;85(12):1201-2; author reply 2-4.

62. Rosen E, Alio JL, Dick HB, et al. Efficacy and safety of multifocal intraocular lenses following cataract and refractive lens exchange: Metaanalysis of peer-reviewed publications. J Cataract Refract Surg 2016;42(2):310-28.

63. Pelli DG, Bex P. Measuring contrast sensitivity. Vision Res 2013;90:10-4.

64. MacRae S, Holladay JT, Glasser A, et al. Special Report: American Academy of Ophthalmology Task Force Consensus Statement for Extended Depth of Focus Intraocular Lenses. Ophthalmology 2017;124(1):139-41.

65. Cochener B. Clinical outcomes of a new extended range of vision intraocular lens: International Multicenter Concerto Study. J Cataract Refract Surg 2016;42(9):1268-75.

66. Ganesh S, Brar S, Pawar A, Relekar KJ. Visual and Refractive Outcomes following Bilateral Implantation of Extended Range of Vision Intraocular Lens with Micromonovision. J Ophthalmol 2018;2018:7321794.

67. Evans JR, de Silva SR, Ziaei M, et al. Outcomes in randomised controlled trials of multifocal lenses in cataract surgery: the case for development of a core outcome set. Br J Ophthalmol 2020.

68. Zamora-de La Cruz D, Zúñiga-Posselt K, Bartlett J, et al. Trifocal intraocular lenses versus bifocal intraocular lenses after cataract extraction among participants with presbyopia. Cochrane Database Syst Rev 2020;6(6):Cd012648.

69. Vargas $V$, Radner W, Allan BD, et al. Methods for the study of near, intermediate vision, and accommodation: an overview of subjective and objective approaches. Surv Ophthalmol 2019;64(1):90100.

70. Ribeiro F, Cochener B, Kohnen T, et al. Definition and clinical relevance of the concept of functional vision in cataract surgery ESCRS Position Statement on Intermediate Vision: ESCRS Functional Vision Working Group. J Cataract Refract Surg 2020;46 Suppl 1:S1-s3.

71. Lum F, Holladay JT, Glasser A, et al. Special Report: The American Academy of Ophthalmology Task Force for Developing Novel End Points for Premium Intraocular Lenses Introduction. Ophthalmology 2017;124(1):133-4. 


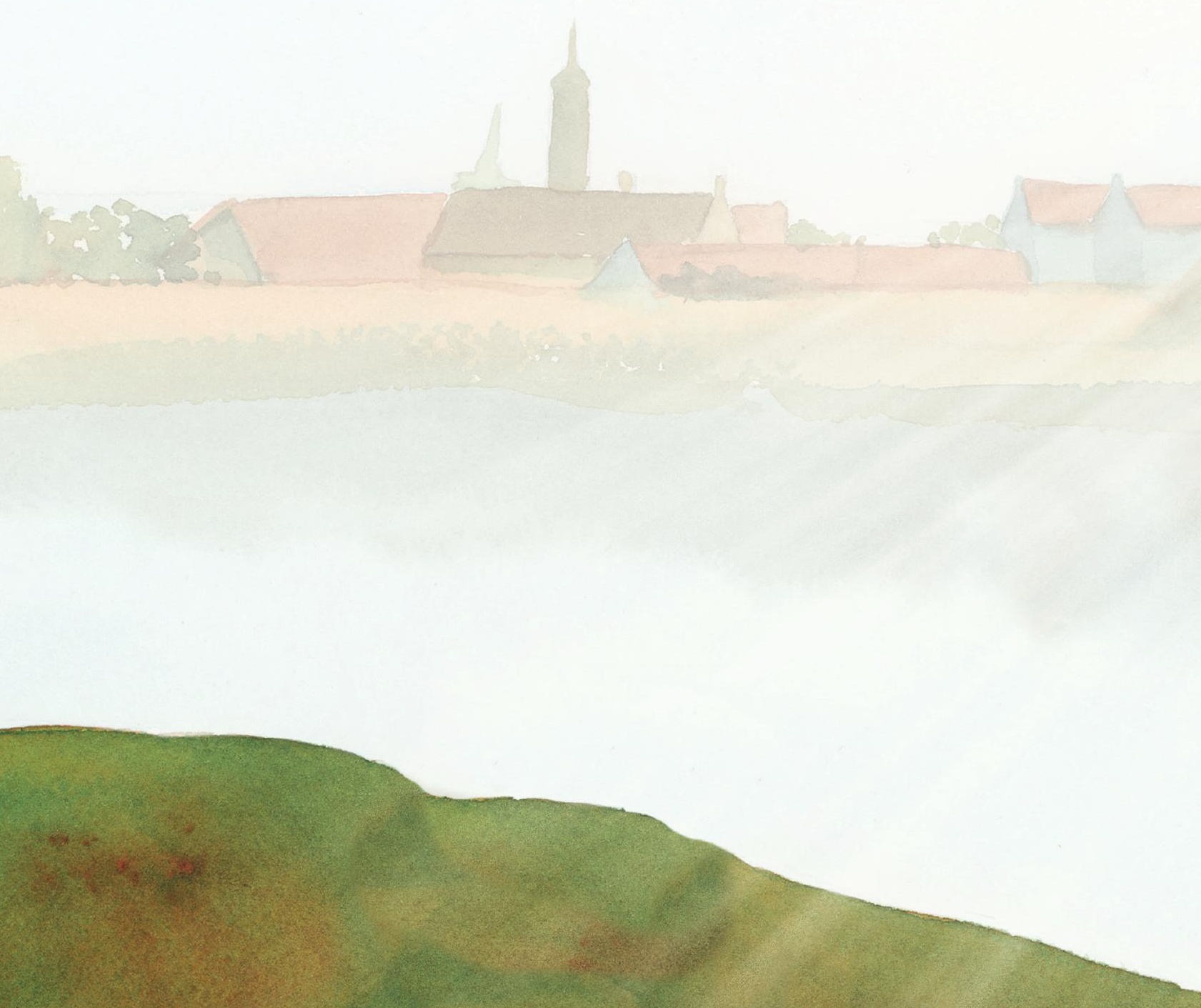




\section{CHAPTER 11}

Impact Paragraph 



\section{IMPACT PARAGRAPH}

In performing clinical studies in the field of medicine, it is only logical that its results have an impact on society at multiple levels. Clear communication to health care providers, policy makers, insurance companies and patients can help them to better understand the impact and value of the research on their situation. This thesis presents research in two different fields of refractive surgery. As described in chapter 1, spectacle independence can be used with implanted intraocular lenses (1) placed additionally in an eye that still has its natural (crystalline) lens (phakic intraocular lens implantation) or (2) removing the crystalline lens and placing a multifocal or extended depth of focus (EDOF) intraocular lens. Both procedures can only exist with a high level of efficacy while providing a safe procedure.

Chapters 1, 2, 5, and $\mathbf{6}$ show the highly effective correction of refractive errors in short and long term studies in patients with phakic intraocular lenses. The resulting good uncorrected and corrected visual acuity has been shown to result in high levels of patient satisfaction, achieving the main surgical goal. ${ }^{1}$ In a similar fashion, chapters $\mathbf{1 , 8}$, and $\mathbf{9}$ show excellent correction after implantation with a multifocal or EDOF intraocular lens. Distance and near visual acuity are especially good in patients with multifocal intraocular lenses, with intermediate coming third in the priority ranking. EDOF intraocular lenses on the other hand provide good distance and intermediate visual acuity, and need (mini)monovision in order to generate a better visual acuity at near. ${ }^{2}$

However, even though they provide good refractive correction and visual acuity, both phakic and the multifocal intraocular lenses described in this thesis can sometimes have lens-specific side-effects.

Anterior chamber phakic lenses are positioned close to the corneal endothelium while using anglesupport (chapter 2) or iris-fixation (chapters 3, 4, 5, 6, and 7) to stay in position. The results of this thesis show that angle-supported phakic lenses have higher rates of endothelial cell loss in the first six months after implantation compared to iris-fixated phakic lenses. In spite of showing similar rates of chronic endothelial cell loss (from 6 months until the end of follow-up), the manufacturer marketing angle-supported lenses decided to take them of the market (chapter 2). ${ }^{3,4}$ We presented an extensive report on long-term safety in eyes with iris-fixated intraocular lenses and the risk factors that influence them and describe why (bi)annual check-ups and modified implantation criteria should be enforced, statements that have found wide support within the ophthalmological community (chapters 3, 4, and 5)., 6 These lenses should be marketed as a long-term but nonpermanent solution for refractive correction, and come with an obligation for registration of implantation, complications, and regular follow-up. In the field of ophthalmology safety issues resulted in a discontinuation or modification of multiple phakic lenses that had all initially received 
their access to the market. ${ }^{4,7-9}$ But the most significant recent case of defective medical implants occurred in the field of plastic surgery, when Poly Implant Prothèse (PIP) breast implants were associated with high rates of complications. ${ }^{10}$ Follow-up studies in the Netherlands showed unreported or unknown deviations from the original specifications in all breast implants used at that time. Furthermore, it proved to be difficult to identify which woman was implanted with which type of implant, especially if a clinic had gone bankrupt since implantation and the medical records were lost. ${ }^{11}$ The Dutch Society for Plastic Surgery took the lead to construct an opt-out database, together with the industry, that obligated surgeons to supply a minimal amount of internationally reviewed safety outcomes, as well as patient and product identification. Similar to the field of ophthalmology, they previously had opt-in databases where it was recommended to report their safety data. However, these types of databases have low participation rates and did not result in timely signaling of the PIP related complications. The current opt-out system obligates both surgeon and industry to cooperate, and excludes data only if the patient refuses to be registered. ${ }^{11}$ A similar symbiotic database between patient, surgeon and industry would be the best solution for registration and timely detection of complications in patients implanted with phakic intraocular lenses. Patient specific data should only be accessible to the individual patient, and to the clinic that performed the surgery. That way the clinic can self-signal and check the safety outcomes, and the database safety monitoring board will signal complications with specific implants or clinics that are not meeting safety standards. In order to prevent bias, a safety monitoring board or independent research body should investigate clinics blinded and only notify clinics when their outcomes show severe discrepancies. Safety outcomes should be focused on major complications that can arise after phakic intraocular lens implantation and report intraocular pressure, endothelial cell density, presence of cataract, and all additional ophthalmological treatments (i.e., glaucoma laser or drops, laser refractive correction, lens exchange, lens explanation, cataract surgery, corneal surgery).

Obligatory safety databases will apply some standardization of outcomes, but there is still a large role to play by focus groups and ophthalmological journals to develop standardized reporting of these outcomes in the literature. In the most prominent ophthalmological journals, efficacy outcomes have to adhere to specific reporting guidelines already. ${ }^{12,13}$ However, not all papers adhere to this and the lack of standardization of (corneal) health reports, as well as explantation rates makes it even harder to compare different types of phakic intraocular lenses (chapters 1, and 10). ${ }^{14}$ Further standardization will help health care providers and patients to verify statements promised by manufacturers, whereas obligatory safety databases will help the industry to signal unexpected and unwanted results.

In order to increase comparability and create a clearer overview of the efficacy of different multifocal lens designs, similar discussions on testing and reporting in a standardized manner are ongoing in the field of multifocal intraocular lenses. ${ }^{15-17}$ And while manufacturers must adhere to a set of testing criteria when they want to publish a report on a new lens design when hits 
the market, individual reports do not have to meet these criteria to be eligible for publication. Further modifications in standardization are absolutely required, both for initial reports on a new lens as well as separate studies published after a lens has first entered the market.

In addition to standardization, technical development in the field of multifocal IOLs is an ongoing process. Research shows that most multifocal and EDOF lenses are succeeding in fulfilling their promises at providing improved spectacle independence, and have excellent visual acuity at multiple distances (chapter 1).2,18 However, since traditional multifocal and EDOF lenses function by dividing incoming light in multiple foci, they may create a variety of unwanted visual side effects such as glare, halo's and loss of contrast (chapters 1, 8, and 9).2, 18 A recent survey published by the European Society for Cataract and Refractive Surgery (ESCRS) does not show a significant increase in the - self-reported - number of multifocal or EDOF lenses that are implanted by their members, but rather a consistently 7-8\% ratio of multifocal and EDOF lens implantation in their practices since $2016 .{ }^{19}$ So in spite of continued improvements in quality of vision at near and intermediate, patients are not selecting these lenses for implantation. Expert panels believe this is not due to the additional costs, but the risk of having to cope with multifocal- and EDOF specific side effects such as glare, halo's, loss of contrast, which prevents patients from choosing these lenses for implantation. It seems that safety issues or the risk of side-effects, and possibility of lens exchange if they cannot cope with the side-effects, are essential in their decision. ${ }^{19}$ Recently, the industry has responded by developing a new type of lenses, that focus more on the absence of side-effects, rather than on the presence of true multifocality. ${ }^{2}, 20$ As these new types of lenses are each using different techniques to achieve their goal, there is a variety of names that manufacturers use to define their mechanisms. The definition that was recently suggested in a 2020 Ophthalmology publication is enhanced monofocal lenses. ${ }^{2}$ Rather than dividing light to create multiple foci, these lenses are extending their one focal point to extend the depth of vision slightly. Further improvement of depth of focus can be achieved by implanting the non-dominant eye with a lens that leaves a patient with a -0.25 diopter (D) to - $0.50 \mathrm{D}$ residual refractive error postoperatively to create micro-monovision. Preliminary results show promising results with patients reporting no visual side-effects, while reporting functional visual acuity at the intermediate distance, as well as increased spectacle independence. ${ }^{20-22}$ Even though newer lenses show less side-effects and expected rates of lens exchanges, it is important that obligatory safety databases are constructed for these lenses as well. Similar to phakic lenses, it should be an opt-out database where a minimal amount of safety data, as well as patient and product identification are stored. Safety data in these lenses could initially be limited to registration of lens exchanges due to side-effects, as no standardized assessment of optical side-effects exists. Information should be blinded to all but the individual patient accessing their own data, or clinics assessing the results of their own patients. Future research on specific and validated tests for visual side-effects of these lenses could later be added if necessary. 
Multiple experts at the most recent meeting of the ESCRS firmly are convinced that the enhanced monofocal lenses will become increasingly popular and could become the lenses to beat in the near future, possibly replacing the traditional monofocal lenses altogether, as some of the experts are using these lenses in most of their monofocal patients already. ${ }^{20,23}$ It means that the added depth of focus from the enhanced monofocal lens could become a part of the natural technical evolution of standard cataract surgery and replace the monofocal lenses currently in use. A lot of that depends on how these enhanced monofocal lenses will be processed by the Dutch health care system, because multifocal or EDOF intraocular lenses are not funded by any health insurance policy and require patients to contribute an additional fee. If enhanced monofocals are registered as monofocal lenses, fast replacement of regular monofocal lenses by enhanced monofocal lenses seems likely. However, if a lens is registered as multifocal or EDOF, additional costs are likely and clinics will have to choose if they will ask patients for an additional fee for these lenses, or if they will cover the costs of these lenses themselves. This decision is likely to take up more time, since a large variety of lenses, a large variety of test methods, different reported outcome measures and individually named technologies make it very hard to compare and select lenses.

Standardization of tests and reported outcomes in the field of cataract and refractive surgery is essential to answer this question. This thesis has shown how standardized reports on (longterm) results and complications can convey a clear message to the field of ophthalmology, helping to improve policies and provide clear communications between the industry, policymakers, doctors and patients alike. It highlights the importance of (inter)national safety databases based on a system where collaborations between the industry and ophthalmologists will design an obligatory blinded registration with an opt-out system, in order to guarantee sufficient participation and prevent bias. 


\section{REFERENCES}

1. Tahzib NG, BootsmaSJ, Eggink FA, Nuijts RM. Functional outcome and patient satisfaction after Artisan phakic intraocular lens implantation for the correction of myopia. Am J Ophthalmol 2006;142(1):31-9.

2. Rampat R, Gatinel D. Multifocal and Extended Depth-of-Focus Intraocular Lenses in 2020. Ophthalmology 2020.

3. Kohnen T, Knorz MC, Cochener B, et al. AcrySof phakic angle-supported intraocular lens for the correction of moderate-to-high myopia: one-year results of a multicenter European study. Ophthalmology 2009;116(7):1314-21, 21.e1-3.

4. Kohnen T, Maxwell WA, Holland S. Correction of Moderate to High Myopia with a Foldable, Angle-Supported Phakic Intraocular Lens: Results from a 5-Year Open-Label Trial. Ophthalmology 2016;123(5):1027-35.

5. Kohnen T. Phakic intraocular lenses: Where are we now? J Cataract Refract Surg 2018;44(2):121-3.

6. Guell JL. Phakic IOLs: overview, indications and results. ESCRS Winter Meeting 2021. Virtual2021.

7. Bernard P, Fournier M. Definitive stop of marketing, product recall and follow-up of implanted patients. Presbyopic intraocular lenses NEWLIFE/VIVARTE PRESBYOPIC. Agence Française de Sécurité Sanitaire des Produits de Santé (AFSSAPS), 2007; v. 2016.

8. Donoso R, Castillo P. Correction of high myopia with the PRL phakic intraocular lens. J Cataract Refract Surg 2006;32(8):1296-300.

9. Guber I, Mouvet V, Bergin C, et al. Clinical Outcomes and Cataract Formation Rates in Eyes 10 Years After Posterior Phakic Lens Implantation for Myopia. JAMA Ophthalmol 2016.

10. Grall J-Y, Maraninchi D. Situation update on checking procedures performed by the heatlh authorities on Poly Implant Prothèse Company. Agence Française de Sécurité Sanitaire des Produits de Santé (AFSSAPS), 2011.

11. Rakhorst HA, Mureau MAM, Cooter RD, et al. The new opt-out Dutch National Breast Implant Registry - Lessons learnt from the road to implementation. J Plast Reconstr Aesthet Surg 2017;70(10):1354-60.

12. Dupps WJ, Jr., Kohnen T, Mamalis N, et al. Standardized graphs and terms for refractive surgery results. J Cataract Refract Surg 2011;37(1):1-3.

13. Reinstein DZ, Archer TJ, Randleman JB. JRS standard for reporting astigmatism outcomes of refractive surgery. J Refract Surg 2014;30(10):654-9.

14. MacRae S, Holladay JT, Hilmantel G, et al. Special Report: American Academy of Ophthalmology Task Force Recommendations for Specular Microscopy for Phakic Intraocular Lenses. Ophthalmology 2017;124(1):141-2.

15. Lum F, Holladay JT, Glasser A, et al. Special Report: The American Academy of Ophthalmology Task Force for Developing Novel End Points for Premium Intraocular Lenses Introduction. Ophthalmology 2017;124(1):133-4.

16. MacRae S, Holladay JT, Glasser A, et al. Special Report: American Academy of Ophthalmology Task Force Consensus Statement for Extended Depth of Focus Intraocular Lenses. Ophthalmology 2017;124(1):139-41.

17. Glasser A, Hilmantel G, Calogero D, et al. Special Report: American Academy of Ophthalmology Task Force Recommendations for Test Methods to Assess Accommodation Produced by Intraocular Lenses. Ophthalmology 2017;124(1):134-9.

18. de Vries NE, Nuijts RM. Multifocal intraocular lenses in cataract surgery: literature review of benefits and side effects. J Cataract Refract Surg 2013;39(2):268-78. 
19. Find O. Review of ESCRS presbyopia clinical survey data. ESCRS Winter Meeting 2021. Virtual 2021.

20. Auffarth GU. Enhanced Monofocals: Minimizing dysphotopsia and maximizing visual quality. ESCRS Winter Meeting 2021. Virtual2021.

21. Auffarth GU, Gerl M, Tsai L, et al. Clinical evaluation of a new monofocal intraocular lens with enhanced intermediate function in cataract patients. J Cataract Refract Surg 2020.

22. Schallhorn JM. Multifocal and Extended Depth of Focus Intraocular Lenses: A Comparison of Data from the United States Food and Drug Administration Premarket Approval Trials. J Refract Surg 2021;37(2):98-104.

23. Nuijts RMMA, Findl $O$, Ribeiro F, et al. Panel discussion: pearls on best practices with today's presbyopia and toric lens technologies. ESCRS Winter Meeting 2021. Virtual2021. 







\section{Addendum}

Summary

Samenvatting 



\section{SUMMARY}

Implantation with a phakic- or multifocal intraocular lens (IOL) aims at improving patients' spectacle independence and, as a result, improving quality of life. Both are elective surgeries and are regularly performed in the Netherlands on otherwise healthy patients. It is therefore important to ensure that these procedures are both safe and effective. The chapters included in this thesis discuss the safety and efficacy of multiple types of anterior chamber phakic IOLs, as well as bifocal and trifocal multifocal IOLs.

Chapter 1 starts by outlining the cause and treatment of different refractive errors, introduces phakic- and multifocal IOLs, and provides a comprehensive overview of previous results and relevant safety issues after phakic- and multifocal IOL implantation.

Chapter 2 reports the six months to two year safety and efficacy results of the anterior chamber angle-supported phakic $\mathrm{OL}$ included in this thesis. Implantation of this lens results in an effective correction of moderate to high myopia during the entire two year study period. However, shortterm endothelial cell (EC) loss significantly exceeds that of iris-fixated phakic IOLs, whereas chronic EC loss resembles that of iris-fixated lenses.

Chronic EC loss after iris-fixated phakic IOL implantation is the main focus of chapters 3 and 4 . Both chapters describe a linear increase in EC loss, indicating the need for altered implantation criteria to safeguard long-term corneal health. Smaller anterior chamber depth and close proximity of the lens to the endothelium are identified as risk factors for increased EC loss in eyes with rigid iris-fixated phakic IOLs in chapter 3. However, this complication is not observed in foldable iris-fixated phakic IOLs in chapter 4. It is hypothesized that different material characteristics are responsible for differences in chronic (subclinical) inflammation and subsequent differences in EC loss.

In chapters $\mathbf{5}$ and $\mathbf{6}$ we report visual, refractive and biometric changes over a 10 year period in eyes with rigid iris-fixated phakic IOLs, and over a 5 year period in eyes with foldable iris-fixated phakic IOLs, respectively. Generally, excellent visual and refractive outcomes are reported as well as a slight, but significant, myopisation over time. Cataract formation and increase of the axial length are proposed as possible causes for this myopisation. Subgroup analyses using biometry showed a significant annual increase in axial length in highly myopic adults. However, due to the small number of eyes suited for longitudinal analysis, population-based studies are required to confirm these results. 
Chapter $\mathbf{7}$ describes the rate of iris-fixated phakic IOL explantation, reasons for explantation and the estimated time until explantation. Survival analyses showed that after an estimated 11 and 15 years $25 \%$ and $50 \%$ of lenses are explanted, respectively. We found higher preoperative age, longer axial length, smaller anterior chamber depth, and smaller preoperative endothelial cell density to be risk factors for a shorter time until explantation.

In chapter $\mathbf{8}$ we report the results of a randomized clinical trial, comparing outcomes after implantation of either the same bifocal multifocal IOL in both eyes or a combination of two different bifocal multifocal IOLs. Distance corrected visual acuity at far and intermediate distances were similar between groups. The group combining two different bifocal multifocal IOLs showed superior visual acuity at near distance.

A second randomized clinical trial is presented in chapter $\mathbf{9}$, comparing patients after bilateral implantation with either a bifocal or trifocal multifocal IOL. Visual acuity at far, intermediate and near distance did not differ between groups, but the defocus curve in the trifocal group showed superior results at intermediate distance. We found higher numbers of complete spectacle independence in the trifocal group.

Chapter 10 discusses the main findings of this thesis, current and future research, and addresses the need for further standardization of safety criteria (i.e., corneal health, side effects of multifocal IOLs) and (patient-reported) outcome measures in cataract- and refractive surgery.

Chapter 11 sheds light on how the results of this thesis could impact society. It suggests an obligatory symbiotic database between patient, surgeon and industry for registration and timely detection of complications in patients implanted with phakic, multifocal, EDOF, or enhanced monofocal intraocular lenses. 


\section{SAMENVATTING}

Het doel van implantatie met een fake- of multifocale intraoculaire lens (IOL) is het vergroten van de brilonafhankelijkheid en dientengevolge het verbeteren van de kwaliteit van leven. Beide electieve ingrepen worden regelmatig uitgevoerd bij gezonde patiënten. Het is daarom belangrijk om de patiënt een bewezen veilige en effectieve behandeling te bieden. Dit proefschrift bespreekt de veiligheid en effectiviteit van verschillende soorten fake intraoculaire lenzen geplaatst in de voorste oogkamer, alsmede van bifocale- en trifocale multifocale intraoculaire lenzen.

In hoofdstuk 1 worden de oorzaak en behandeling uitgelegd van verschillende refractieve afwijkingen, fake- en multifocale intraoculaire lenzen geïntroduceerd en een overzicht gegeven van eerdere resultaten en veiligheidsoverwegingen na implantatie met een fake- of multifocale lens.

Hoofdstuk 2 beschrijft de veiligheid en effectiviteit van een kamerhoekgesteunde fake lens in de voorste oogkamer gedurende zes maanden tot twee jaar na implantatie. We vonden een effectieve correctie beschreven van matige tot hoge myopie gedurende de gehele follow-up periode van twee jaar. Het endotheelcelverlies in de eerste zes maanden na implantatie was echter significant meer ten opzichte van patiënten die geïmplanteerd waren met iris-gefixeerde fake intraoculaire lenzen in de voorste oogkamer. Het endotheelcelverlies in de postoperatieve periode van zes maanden tot twee jaar was vergelijkbaar in beide groepen.

Hoofdstuk $\mathbf{3}$ en $\mathbf{4}$ richten zich beide op het chronische (vanaf zes maanden postoperatief) endotheelcelverlies na implantatie met een iris-gefixeerde fake lens in de voorste oogkamer. In beide hoofdstukken werd een lineair versnelde afname gezien in het aantal endotheelcellen, wat een aanpassing van de preoperatieve criteria noodzakelijk maakt om op de lange termijn de gezondheid van het cornea endotheel te beschermen. In hoofdstuk 3 werden een kleinere voorste oogkamerdiepte en kortere afstand van de lens tot het endotheel geïdentificeerd als risicofactoren voor een versnelde afname van de endotheelcellen, specifiek bij patiënten met een rigide iris-gefixeerde fake lens. Deze risicofactoren werden niet bevestigd in hoofdstuk 4, dat zich richt op flexibele iris-gefixeerde fake lenzen. Mogelijkerwijs veroorzaken de diverse lensmaterialen een verschillende chronische (subklinische) inflammatie en het daaruit voortvloeiend verschil in endotheelcelverlies.

Veranderingen in visus, refractie en biometrie in de periode tien jaar na implantatie met rigide iris-gefixeerde lenzen, en vijf jaar na implantatie met flexibele iris-gefixeerde lenzen worden respectievelijk beschreven in hoofdstuk $\mathbf{5}$ en $\mathbf{6}$. Met de jaren bleven visus en refractie zeer goed, en werd er een kleine significantie myopisatie beschreven die mogelijk wordt veroorzaakt 
door vorming van cataract of groei van het oog (toename van de aslengte). Subgroep analyses toonden een significante jaarlijkse toename van de aslengte in deze hoog myope populatie. Door de kleine grootte van de subgroep bleek het echter niet mogelijk om een longitudinale analyse te verrichten. Aanvullend epidemiologisch onderzoek is derhalve nodig om deze hypothese te bevestigen.

Hoofdstuk 7 beschrijft resultaten rondom explantatie van iris-gefixeerde fake lenzen door middel van survival analyses. Het rapporteert het percentage explantaties, de redenen voor explantatie en de verwachte tijd tot explantatie (survival). De analyses schatten dat het respectievelijk 11 en 15 jaar zal duren tot in 25\% en 50\% van de gevallen een explantatie van de lens is verricht. Risicofactoren voor een kortere survival waren een hogere preoperatieve leeftijd, langere aslengte, kleinere voorste oogkamer en lagere endotheelceldichtheid.

In hoofdstuk $\mathbf{8}$ zijn in een gerandomiseerde klinische studie twee groepen met multifocale intraoculaire lenzen met elkaar vergeleken: één groep met hetzelfde type bifocale lens in beide ogen en één groep met een combinatie van twee verschillende typen bifocale lenzen. Intermediaire en verte visus, gemeten met optimale correctie voor veraf, waren vergelijkbaar in beide groepen. Visuele uitkomsten nabij waren significant beter in de groep met twee verschillende bifocale lenzen.

Hoofdstuk 9 vergelijkt patiënten met bilaterale implantatie met bifocale en trifocale lenzen met elkaar in een tweede gerandomiseerde klinische studie. Visuele uitkomsten veraf, intermediair en nabij waren vergelijkbaar tussen de groepen, echter de defocus curve in de trifocale groep liet intermediair een significant beter resultaat zien. Het hoogste percentage volledig brilonafhankelijke patiënten werd bereikt in de trifocale groep.

In hoofdstuk 10 vindt een discussie plaats over de voornaamste bevindingen van dit proefschrift, evenals suggesties voor huidig en toekomstig onderzoek. Daarnaast bespreekt het de noodzaak voor standaardisering van veiligheidsnormen (corneale gezondheid, bijwerkingen van multifocale intraoculaire lenzen) en (patiënt gerapporteerde) uitkomstmaten in cataract-en refractiechirurgie.

Hoofdstuk 11 bespreekt de impact van deze thesis op de maatschappij. Het stelt een verplichte registratie voor van veiligheidsgegevens waaraan patiënt, oogarts en industrie hun medewerking verlenen. Het doel van de database is een vroege detectie van complicaties in patiënten geïmplanteerd met fake, multifocale, EDOF of 'enhanced' monofocale intraoculaire lenzen. 



\section{Addendum}

\section{Dankwoord}





\section{DANKWOORD}

Dit proefschrift zou niet tot stand zijn gekomen zonder hulp van velen. Collega's, vrienden en familie wil ik graag bedanken voor hun inzet, interesse, steun en begrip als mijn promotieplanningswoede er weer eens voor zorgde dat ook de tijd voor ontspanning gepland moest worden.

Een aantal mensen wil ik hier graag in het bijzonder bedanken:

Prof. dr. R.M.M.A. Nuijts. Beste Rudy, bedankt voor je vertrouwen, het creëren van dit promotietraject en het feit dat je me de afgelopen jaren bent blijven pushen. Hoewel ik het je zeker niet altijd in dank heb afgenomen heb je me geleerd dat niets onmogelijk is als je hard werkt en blijft verbeteren. Ik kijk met be- en verwondering naar je werkethos en ben erg blij dat 'artikelen reviseren' voor jou ook een vorm van ontspanning is. Zonder jou zou dit proefschrift er nooit zijn gekomen, ontzettend bedankt!

Dr. T.T.J.M. Berendschot. Beste Tos, bedankt dat je de afgelopen jaren mijn statistische sparringpartner bent geweest. Bedankt ook voor je relativeringsvermogen en de manier waarop je laat zien een balans aan te brengen tussen werk en privé.

Dr. N.J.C. Bauer, Beste Noël, bedankt voor je feedback bij het schrijven van artikelen, abstracts en subsidieaanvragen. Vooral in de afronding van mijn onderzoek heb ik veel gehad aan onze brainstorms, het bediscussiëren van onze bevindingen en het stroomlijnen van de resultaten.

Dr. I.E.Y. Saelens. Beste Isabelle, bedankt voor je supersnelle reacties op mails, artikelen en andere vragen. Jouw klinische input, supervisie van (studie)patiënten, enthousiasme en interesse in mijn onderzoek hebben me onwijs geholpen, dank hiervoor.

De gehele afdeling oogheelkunde, van niveau 0 tot 6, van AIOS tot TOA, in de kliniek en tijdens research, bedankt voor jullie medewerking en begrip. In het bijzonder Aïssa, Lenny, Mark en alle andere optometristen, bedankt voor jullie hulp op het refractiechirurgiespreekuur, aanvullen van de database en bijspringen met het zien van studiepatiënten. Ellen en Veronique, bedankt voor het alle logistieke ondersteuning, tips en tricks tijdens de uitvoering van mijn onderzoek en nu opnieuw tijdens de afrondende fase van dit promotietraject.

Gerard, voor het opzetten van de database en het omzetten van alle oude gegevens. Annelies, Annick, Andreas en Gerard, voor jullie co-auteurschap en onmisbare inzet in het aanvullen van alle data. Bjorn, voor het meedenken over en nalopen van onze statistische analyses. Zonder jullie medewerking had dit proefschrift niet tot stand kunnen komen. 
Mijn collega-onderzoekers: Anja, Claudette, Eline, Hellen, Ilona, Laura, Lindsay, Natalia, Palwasha, Christian, Jurriaan, Rob, en Suryan voor de samenwerking als 'lotgenoten' in de kantoortuin op niveau 6 en daarbuiten. Zonder jullie humor, adviezen en inzichten was 'onderzoek doen' maar een eenzame bedoeling geweest.

Natalia, bedankt voor je positiviteit, gezelligheid en 'Russische nuchterheid'. Sinds we in 2013 zijn gestart in de oogtoren hebben we samen artikelen geschreven, congressen bezocht en georganiseerd, presentaties gegeven en naast elkaar gewerkt. Ik heb bewondering voor je schijnbaar oneindige energie, en ben blij dat je vandaag mijn paranimf wil zijn.

Lief groot klein zusje, lieve Raquel, wat ben ik trots op hoe jij de afgelopen jaren hebt gebikkeld om je doelen te bereiken. Ik vind het heel bijzonder dat je mijn paranimf wil zijn, en dat we deze dag samen kunnen vieren. Heel erg bedankt voor je steun en verpleegkundige blik op de patiëntenzorg. Jij maakt mij een betere arts.

Papa en mama, voor jullie hulp en eindeloze steun de afgelopen jaren. Bedankt dat jullie me altijd de ruimte en het vertrouwen hebben gegeven om mijn eigen keuzes te maken, zonder druk of voor opgelegd plan en met een rotsvast geloof in mijn kunnen.

Lieve opa, bedankt voor je aanmoedigingen en enthousiasme. Hoewel het soms lastig bleek om te begrijpen waar ik nu precies de hele dag mee bezig was, ben je mijn grootste fan en houd je iedereen die het wil horen - en velen die het misschien niet willen horen - op de hoogte van mijn pres(en)taties. Deze is voor jou. 
DANKWOORD 


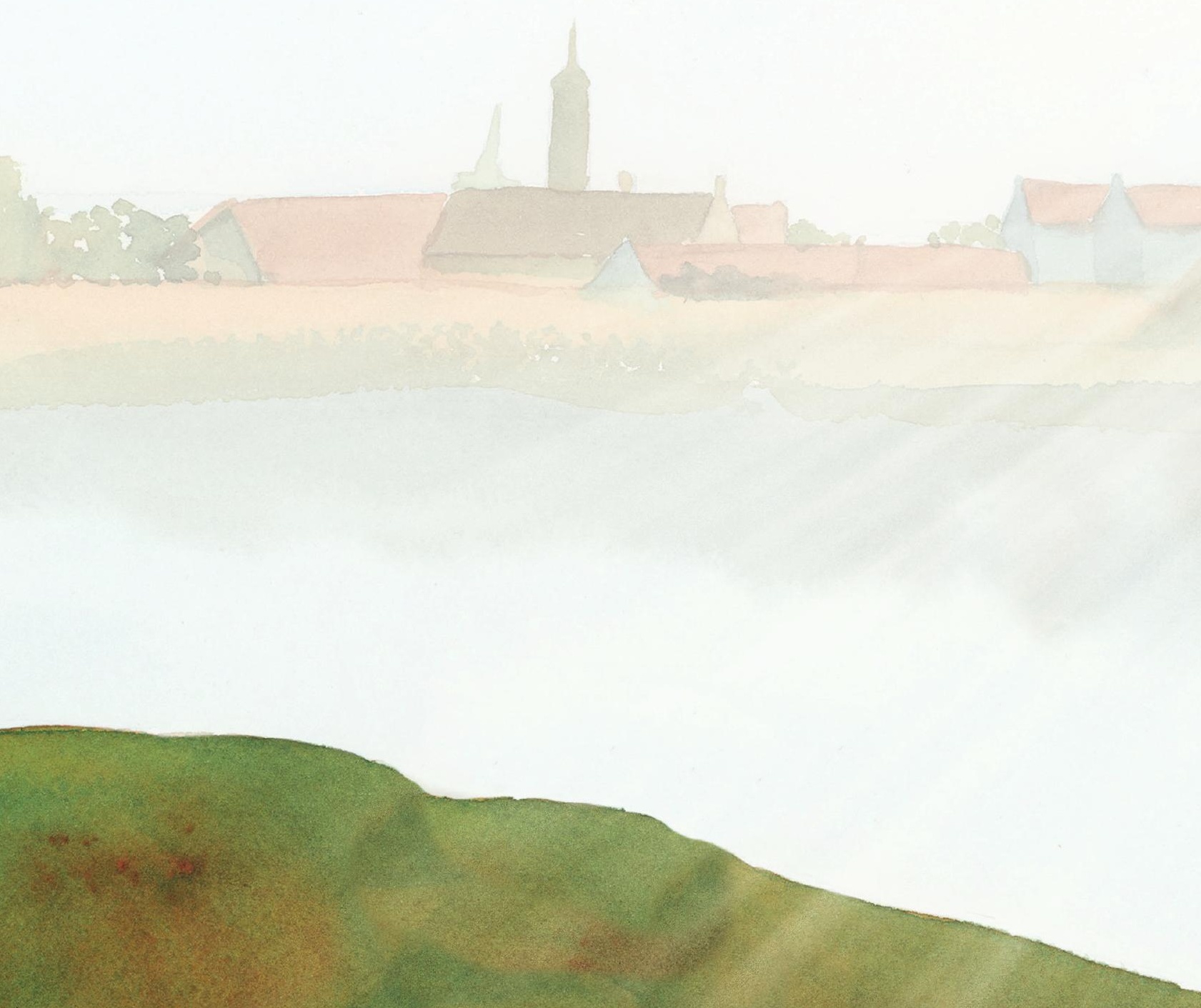




\section{Addendum}

Curriculum Vitae 



\section{CURRICULUM VITAE}

Soraya Maria Regina Jonker was born on June $25^{\text {th }} 1990$, in 's-Hertogenbosch, the Netherlands. She graduated from Gymnasium Beekvliet in Sint-Michielsgestel in 2008. That same year she started medical school at Maastricht University. During medical school she performed her internship in ophthalmology in Aarhus, Denmark, sparking her interest in ophthalmology. In her final year of medical school she combined a research and clinical internship at the University Eye Clinic Maastricht, supervised by prof. dr. R.M.M.A. Nuijts and dr. N.J.C. Bauer. In 2014 she obtained her medical degree and started her PhD research under the supervision of prof. $d r$. R.M.M.A. Nuijts, dr. N.J.C. Bauer and dr. T.T.J.M. Berendschot. She presented at numerous (inter)national conferences and was part of the organizing committee of the fifth annual Dutch ophthalmology PhD students (DOPS) conference in 2016. She has received travel grants from the European Society of Cataract and Refractive Surgeons (ESCRS) and the Association for Research in Vision and Ophthalmology (ARVO). She has also co-authored several book chapters on refractive surgery during her research. From January 2018, Soraya has been working as a resident in ophthalmology at the University Eye Clinic Maastricht. 


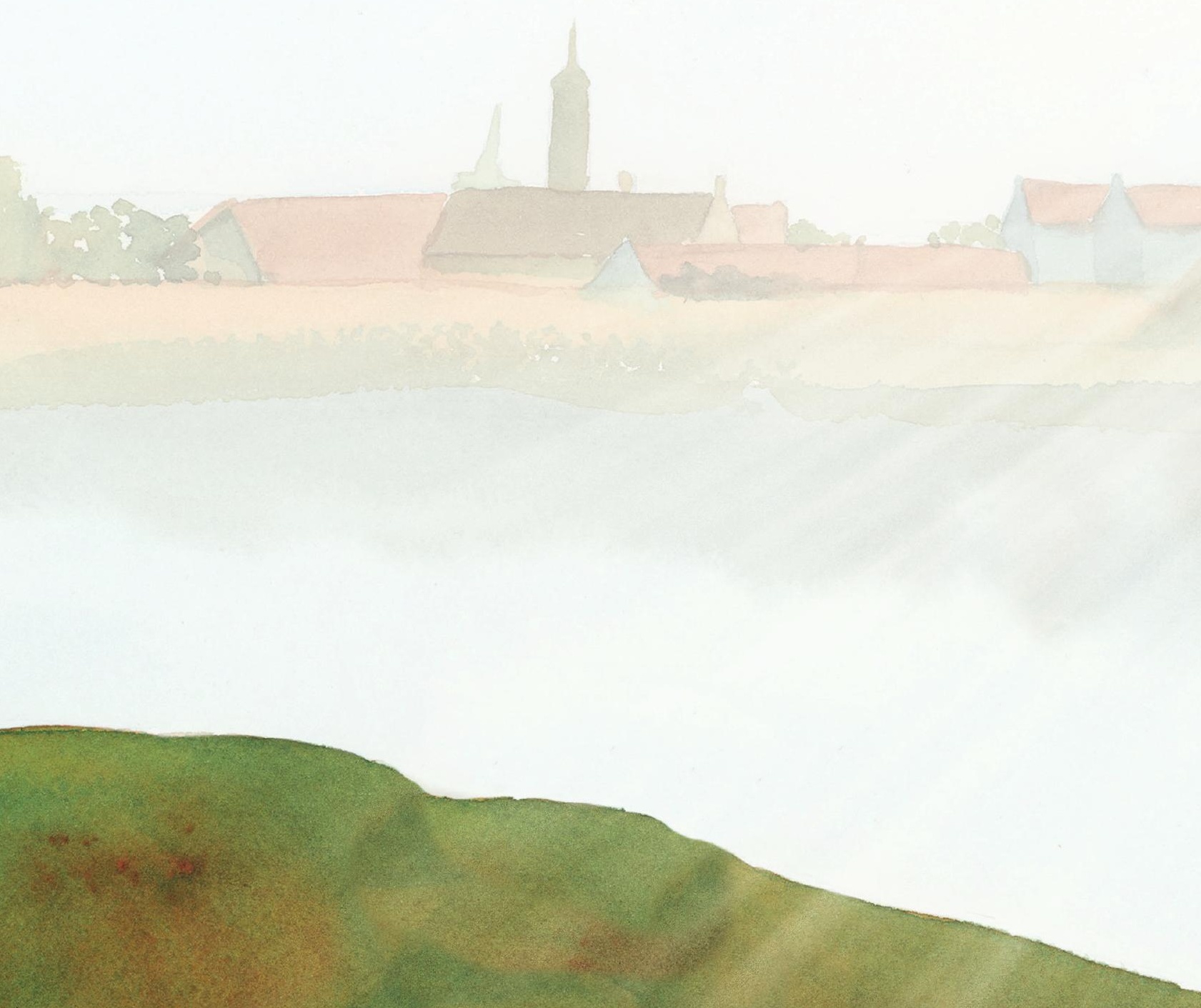




\section{Addendum}

List of Publications 



\section{LIST OF PUBLICATIONS}

Thesis

Jonker, S.M.R., Berendschot, T.T.J.M., Ronden, A.E., Saelens, I.E.Y., Bauer, N.J.C., Nuijts, R.M.M.A.: Changes in visual outcomes and ocular morphometrics after foldable myopic and toric intraocular lens implantation: 5 year results. Submitted for peer review

Jonker, S.M.R., Berendschot, T.T.J.M., Saelens, I.E.Y., Bauer, N.J.C., Nuijts, R.M.M.A.: Phakic intraocular lenses: An overview. Indian J Ophthalmol. 2020 Dec;68(12):2779-2796.

Jonker,S.M.R., Berendschot, T.T.J.M., Ronden, A.E., Saelens, I.E.Y., Bauer, N.J.C., Nuijts, R.M.M.A.: Longterm changes in visual outcomes and ocular morphometrics after myopic and toric phakic intraocular lens implantation: Five- and 10-year results. J Cataract Refract Surg. 2019 Oct;45(10):1470-79

Jonker, S.M.R., Van Averbeke, A.A.C., Berendschot, T.T.J.M., Saelens, N.J.C., Nuijts, R.M.M.A.: Risk factors for explantation of iris-fixated phakic intraocular lenses. J Cataract Refract Surg. 2019 Aug;45(8):1092-98

Jonker, S.M.R., Berendschot, T.T.J.M., Ronden, A.E., Saelens, I.E.Y., Bauer, N.J.C., Nuijts, R.M.M.A.: Five-Year Endothelial Cell Loss After Implantation With Artiflex Myopia and Artiflex Toric Phakic Intraocular Lenses. Am J Ophthalmol. 2018 Oct;194(10):110-19

Jonker, S.M.R., Berendschot, T.T.J.M., Ronden, A.E., Saelens, I.E.Y., Bauer, N.J.C., Nuijts, R.M.M.A.: Long-Term Endothelial Cell Loss in Patients with Artisan Myopia and Artisan Toric Phakic Intraocular Lenses: 5 and 10 year results. Ophthalmology. 2018 Apr;125(4):486-94

Nuijts, R.M.M.A., Jonker, S.M.R., Kaufer, R.A., Lapid-Gortzak, R., Mendicute, J., Peris Martines, C., Schmickler, S., Kohnen, T.: Bilateral implantation of +2.5 D multifocal intraocular lens and contralateral implantation of +2.5 D and +3.0 D multifocal intraocular lenses: Clinical outcomes. J Cataract Refract Surg. 2016 Feb;42(2):194-202.

Aerts, A.A.S., Jonker, S.M.R., Wielders, L.H.P., Berendschot, T.T.J.M., Doors, M., de Brabander. J., Nuijts, R.M.M.A.: Acrysof Cachet phakic intraocular lens: 2 year results and comparison of endothelial cell loss to iris-fixated lens implantation. J Cataract Refract Surg. 2015 Oct;41(10):2258-65.

Jonker, S.M., Bauer, N.J., Makhotkina, N.Y., Berendschot, T.T., van den Biggelaar, F.J., Nuijts, R.M.:Comparison of a trifocal intraocular lens with a +3.0 D bifocal IOL: Results of a prospective randomized clinical trial. J Cataract Refract Surg. 2015 Aug;41(8):1631-40. 


\section{Other}

Jonker, S.M.R., Tahzib, N.G., Nuijts, R.M.M.A.: Predicting the Unhappy Patient and Patient Expectations. In Management of Complications in Refractive Surgery. Editor: Alió, J.L. Pp 41318,2018

Jonker, S.M.R., and Nuijts, R.M.M.A.: Bilateral, contralateral multifocal IOLs yield similar distance, intermediate visual acuity. Ocular Surgery News U.S. Edition, June 25: 26, 2016.

Nuijts, R.M.M.A., and Jonker, S.M.R.: The Multifocal IOL Evolution. Ophthalmology Times 40(9): 1-15, 2015.

Nuijts, R.M.M.A., Jonker, S.M.R., Saelens, I.E.Y.: Surgical management of postkeratoplasty astigmatism. In Cornea, ESASO course series, Vol. 6. Editor: Güell J.L. Pp 26-38, 2015.

Jonker, S.M.R., Saelens, I.E.Y., Nuijts, R.M.M.A.: Keratoconus. Eurotimes 20 (5): 9, 2015 